\title{
AGENTE TOPOLÓGICO DE APRENDIZADO POR REFORÇO
}

\author{
Arthur Plínio de Souza Braga
}

Tese apresentada à Escola de Engenharia de São Carlos da Universidade de São Paulo, como parte dos requisitos para a obtenção do título de Doutor em Engenharia Elétrica.

Orientador: Prof. Dr. Aluízio Fausto Ribeiro Araújo

São Carlos 
Ficha catalográfica preparada pela Seção de Tratamento da Informação do Serviço de Biblioteca - EESC/USP

B813a Braga, Arthur Plínio de Souza

Agente topológico de aprendizado por reforço / Arthur Plínio de Souza Braga. -- São Carlos, 2004.

Tese (Doutorado) -- Escola de Engenharia de São Carlos-Universidade de São Paulo, 2004.

Área: Engenharia Elétrica.

orientador: Prof. Dr. Aluízio Fausto Ribeiro Araújo.

1. Aprendizagem por reforço. 2. Mapas autoorganizáveis. 3. Aprendizagem latente. 4. Navegação de robô móvel. I. Título. 
FOLHA DE JULGAMENTO

Candidato: Engenheiro ARTHUR PLIINIO DE SOUZA BRAGA

Tese defendida e julgada em 07-04-2004 perante a Comissão Julgadora:

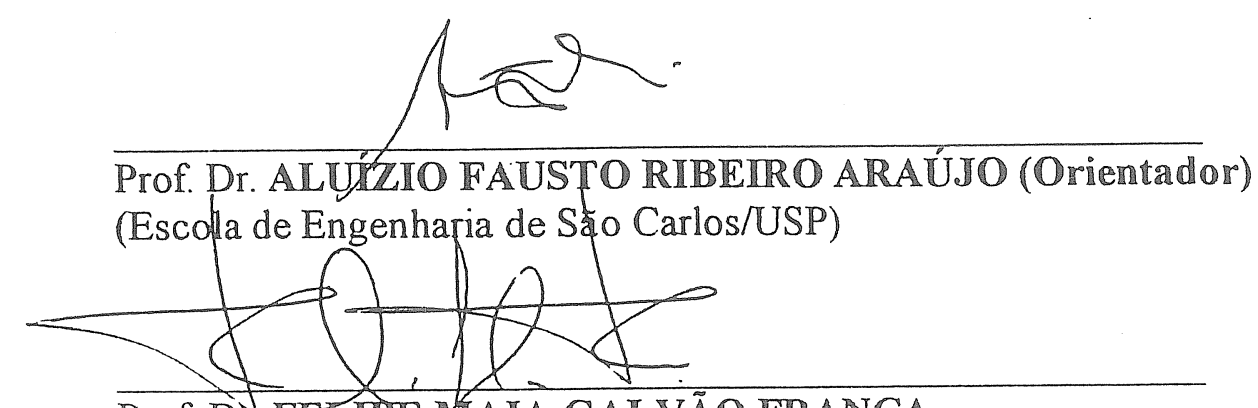

HPinitado

Prof. Dr. FELIPE MAIA GALVAO IRANCA

Aprovado

(Universidade Federal do Rio de Janeiro/UFRJ)

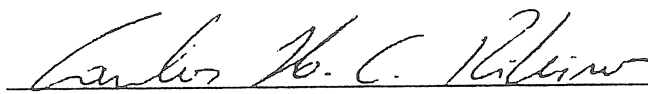

APROYADO

Prof. Assoc. CARLOS HIENRIQUE COSTA RIBEIRO

(Instituto Tecnológico de Aeronáutica/ITA)

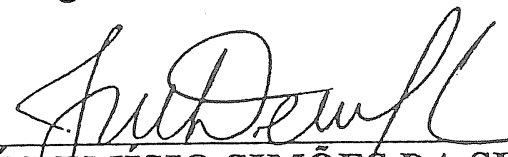

Prof. Dr. JOSÉ ITMISIO SIMÕES DA SILVA

(Instituto Nacional de Pesquisas Espaciais/INPE)

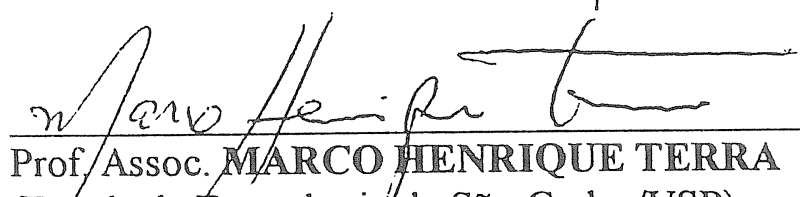

(Escola de/Engenharig//de São Carlos/USP)

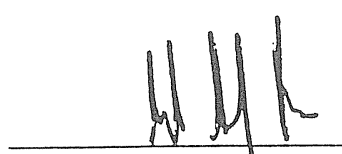

Prof. Assoc. MURULO ARAUJO ROMERO

Coordenador do Programa de Pós-Graduação em Engenharia Elétrica

APMUAOO
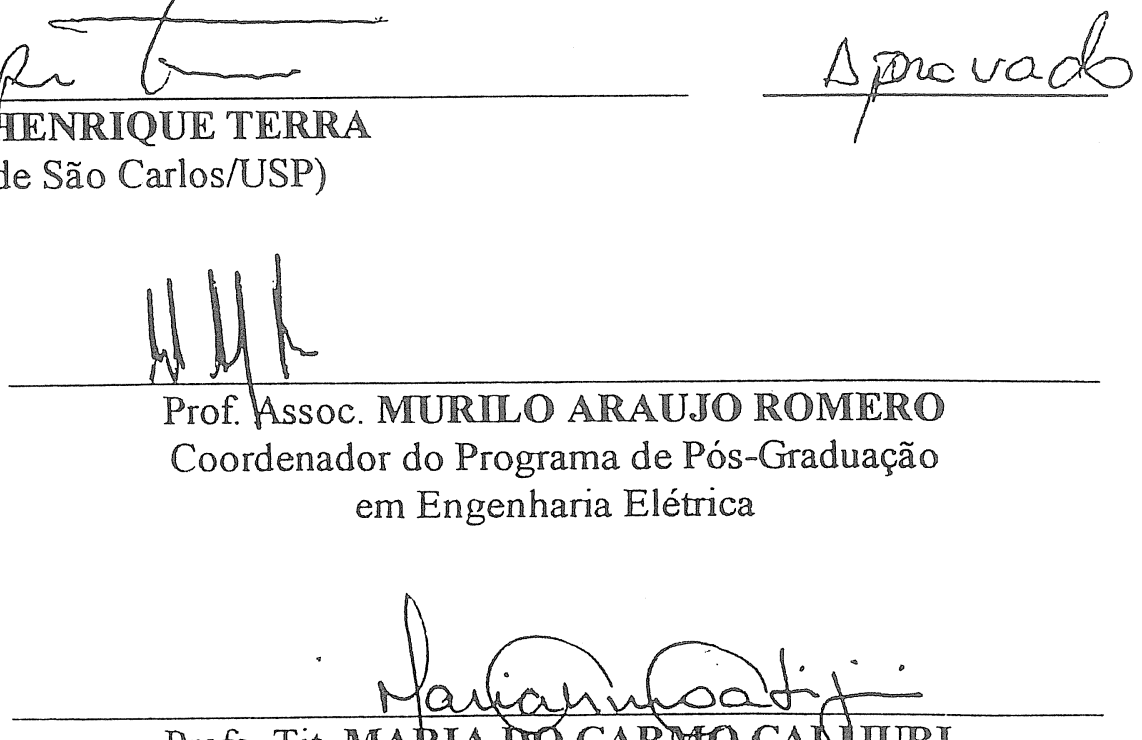

Profa. Tit. MARIA DO CARMO CANUURI

Presidente da Comissão de Pós-Graduação 
Dedico este trabalho aos meus pais, Elizete e José Newton, pelo contínuo apoio e incentivo. 
Aos meus pais, Elizete e José Newton, por tudo.

Ao Prof. Dr. Aluízio Fausto Ribeiro Araújo, pelas oportunidades propiciadas a partir de seu convite para o programa de doutoramento do Departamento de Engenharia Elétrica da EESC/USP.

A Nilza Mendes que, pelo apoio, carinho e compreensão, contribuiu em muito para a conclusão deste trabalho.

Aos amigos de longa convivência, Marcelo Rosa, Guilherme Barreto, José Carlos, Renato Tinós, João Bosco, Patrícia Leite, Mário Oleskowski, Karla, Terra; e aos mais recentes, Aline, Antônio Carlos, Cléber, Gilson, Everaldo, Márcio, agradeço a paciência, o incentivo e a amizade.

A Daniel, Flávio e Humberto, pelo companheirismo em nossa antiga república.

Ao Dr. Jeremy Wyatt, Yoshiyuki, Fred, sua esposa Alcione, e todo o grupo de brasileiros em Birmingham, pelo auxílio e agradável convivência durante meu curto estágio na Inglaterra.

A todos os amigos e amigas que por falha minha não estão mencionados, pelas boas lembranças.

Ao Departamento de Engenharia Elétrica, pela utilização e fácil acesso aos seus laboratórios, bem como aos professores e funcionários, em especial, Roseli, Gérson, Marisa, Denise, Cida, José Carlos e Aura, que direta ou indiretamente ajudaram no desenvolvimente deste trabalho.

À Fundação de Amparo à Pesquisa do Estado de São Paulo (FAPESP), pelo suporte financeiro fornecido durante o período da realização deste trabalho. 


\section{SUMÁRIO}

LISTA DE FIGURAS ............................................................................................................................... III

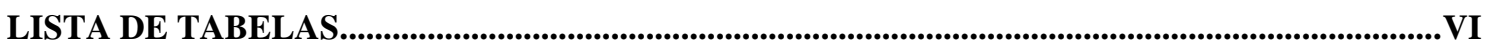

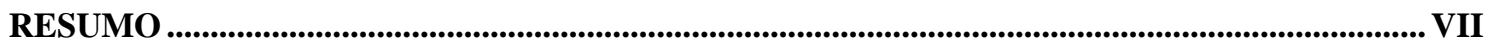

ABSTRACT

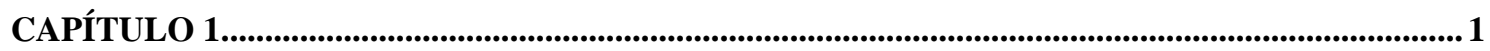

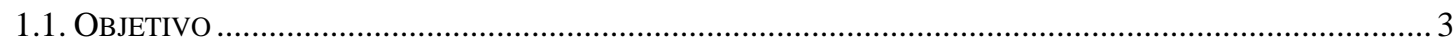

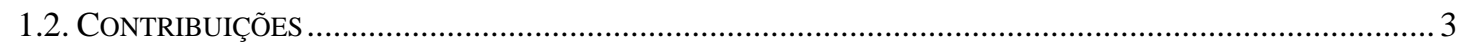

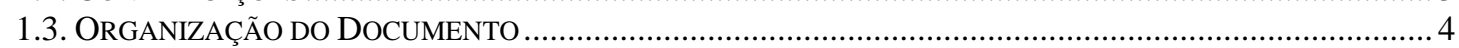

CAPÍTULO 2

2.1. PROBLEMA GERAL: ACELERAR A SOLUÇÃO DO PARDM ……………………………………….... 6

2.2. PROBLEMA ESPECÍ́FICO: A NAVEGAÇÃO AUTÔNOMA DE UM ROBÔ MÓVEL ...................................

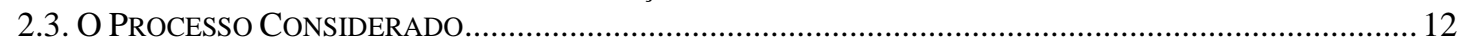

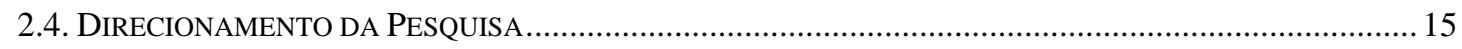

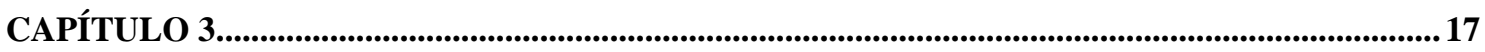

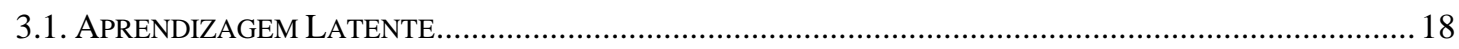

3.1.1. Neurofisiologia dos Mapas Cognitivos - Células Posicionais..................................................2 20

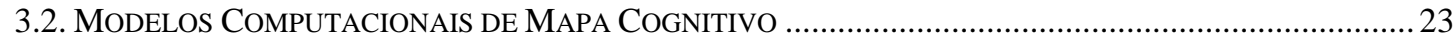

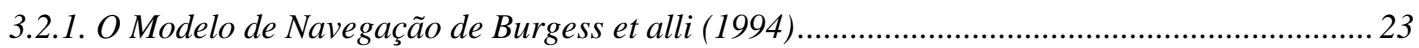

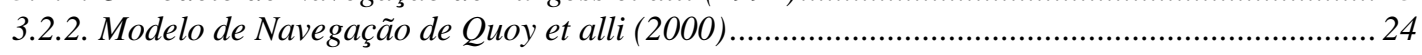

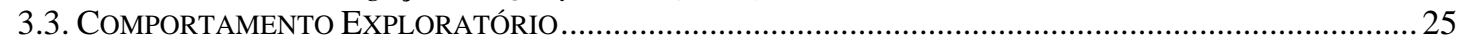

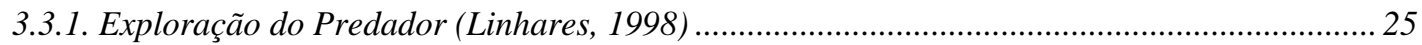

3.3.2. Comportamento Exploratório de Tchernichovski et alli (1998)................................................. 26

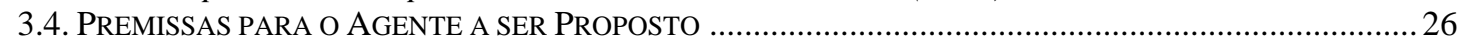

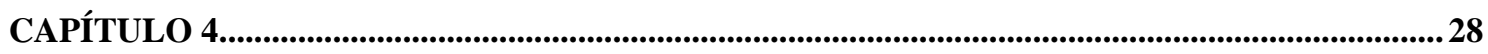

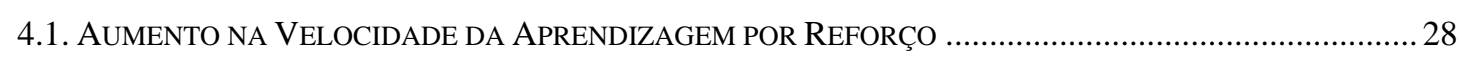

4.1.1. Simplificação do Processo de Assinalação Temporal de Crédito ................................................2 29

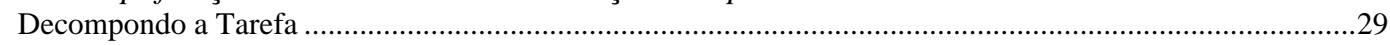

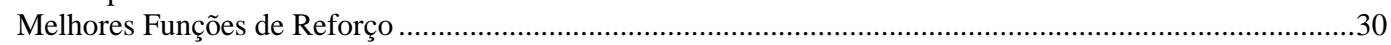

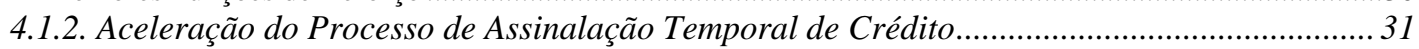

Traços de Elegibilidade ………………………………………………………………………………………....31

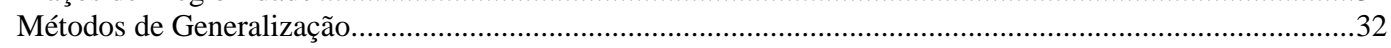

4.1.3. Comentários sobre a Opção Adotada para a Assinalação de Crédito..........................................33

4.2. MAPAS AUTO-ORGANIZÁVEIS EM APRENDIZAGEM POR REFORÇO...................................................... 34

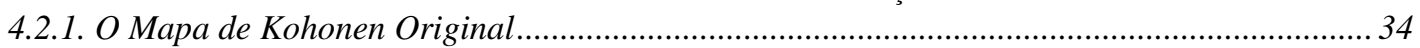

ESTUDO DE CASO: Q-Kohon (Touzet, 1997) .........................................................................................35

ESTUDO DE CASO: Smith (2001) ..................................................................................................

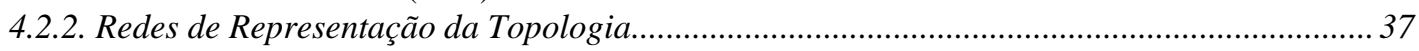

ESTUDO DE CASO: Großmann (2001) ...............................................................................................38

ESTUDO DE CASO: Aprendizagem-Q de Ação Contínua (Millán; Posenato e Dedieu, 2002).......................39

4.2.3. Discussão sobre os Algoritmos Apresentados........................................................................ 42

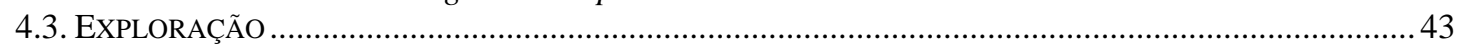

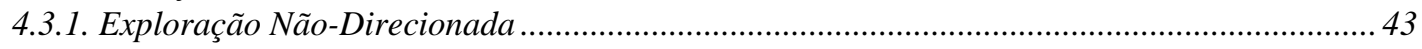

4.3.2. Exploração Direcionada, com medidas locais........................................................................... 44

4.3.3. Exploração Direcionada, com medidas globais....................................................................... 45

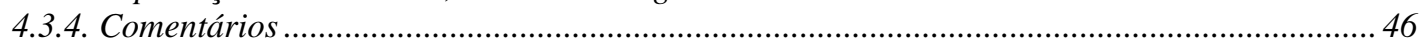

4.4. CoMENTÁRIOS FinAIS E CAMINHOS PARA A PESQUISA ………………………………………….... 47 


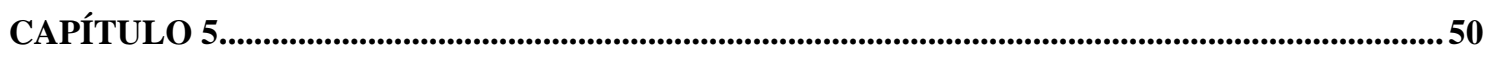

5.1. APRENDIZAGEM LATENTE - ESPALHAMENTO DA INFORMAÇÃO ........................................................ 51

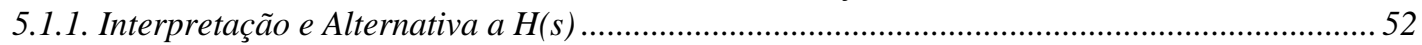

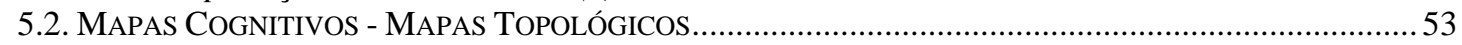

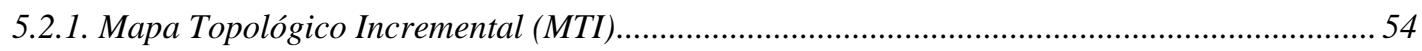

5.2.2. Mapa Topológico Incremental Classificador (MTIC)...........................................................56

5.3. O AGENTE TOPOLÓGICO DE APRENDIZAGEM POR REFORÇO (ATAR) ...............................................5 59

5.3.1. Versão 1 do Agente Topológico de Aprendizagem por Reforço (ATAR 1).............................. 63

5.3.2. Versão 2 do Agente Topológico de Aprendizagem por Reforço (ATAR 2).............................. 63

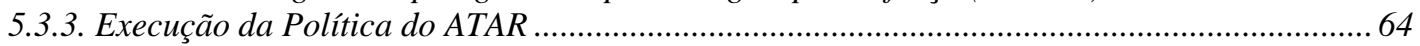

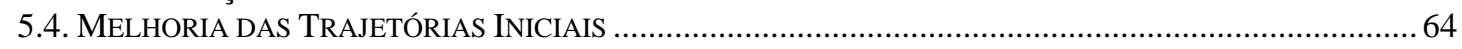

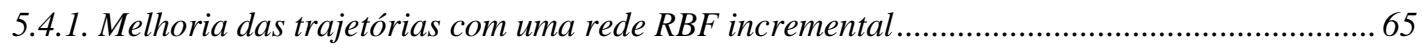

5.4.2. Melhoria das trajetórias por detecção de ponto interior ........................................................... 68

5.4.3. Comparação entre as duas alternativas de melhoria das trajetórias........................................6 69

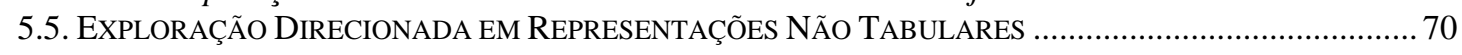

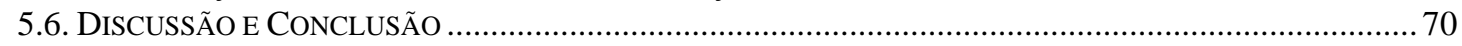

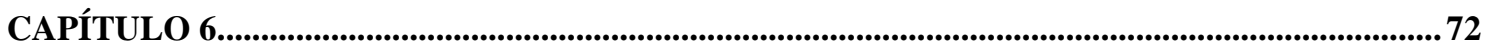

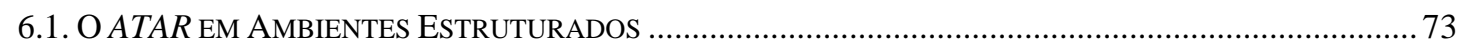

6.1.1. Resultados com Relação ao Critério 1 .................................................................................. 73

6.1.2. Resultados com Relação ao Critério 2 ..................................................................................... 75

6.1.3. Consolidação dos Resultados Através de Testes de Hipóteses................................................ 77

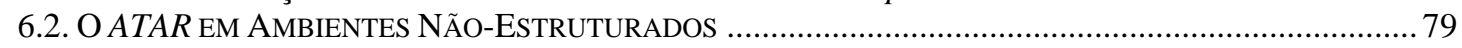

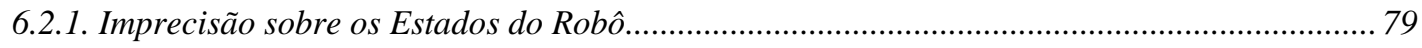

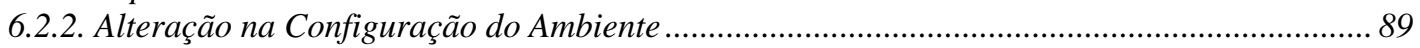

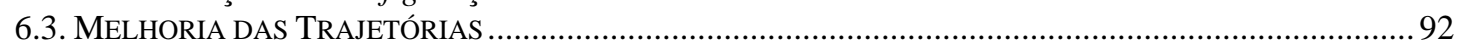

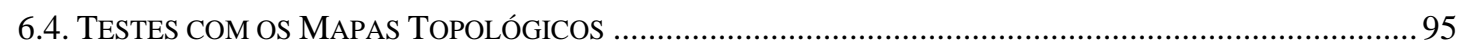

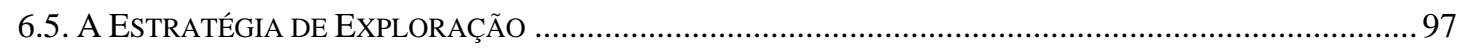

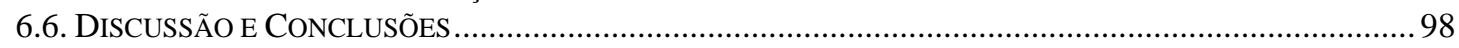

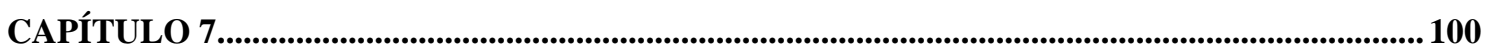

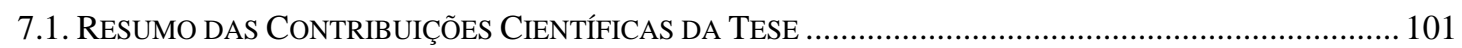

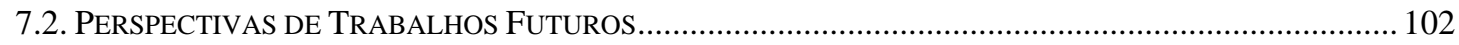

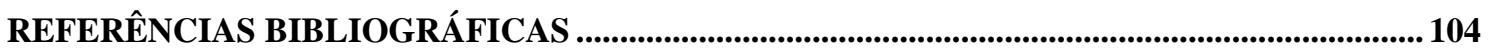

APÊNDICE A - ALGORITMOS DE APRENDIZAGEM POR REFORÇO SIMULADOS ......... 116

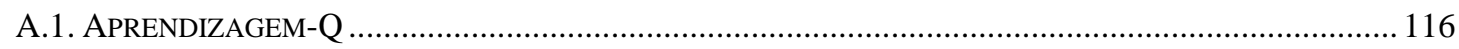

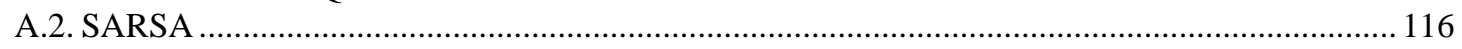

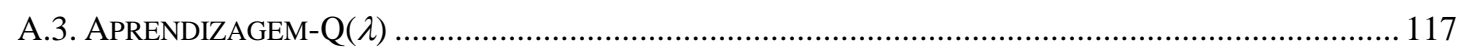

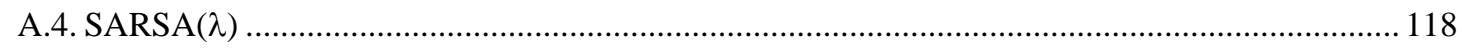

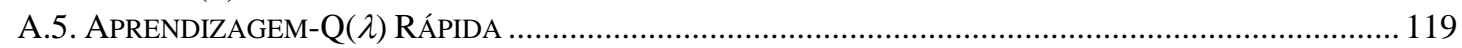

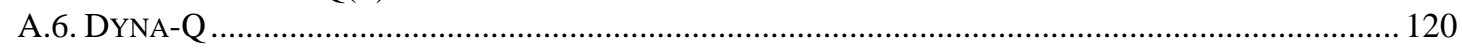

APÊNDICE B - PARÂMETROS UTILIZADOS NOS ALGORITMOS SIMULADOS..................121 


\section{Lista de Figuras}

FIGURA 2.1 - Estrutura genérica do aprendizado por reforço (Sutton e Barto, 1998)............................ 7

FIGURA 2.2 - Diagrama considerado para o funcionamento do agente. ........................................... 12

FIGURA 2.3 - Figura reproduzida de Zalama et alli (1995): Durante um intervalo de tempo $\Delta t$, o robô move-se ao longo de uma trajetória circular com centro em $\mathrm{X}_{\mathrm{C}}$ através de uma distância $\Delta \mathrm{S}$ e ângulo

$\Delta \theta$ conforme as velocidades aplicadas às rodas.

FIGURA 2.4 - (a) Representação dos oito movimentos considerados do robô. Cada estado possui espaço suficiente para este ser capaz de realizar uma rotação em torno de seu eixo central. (b) Representação vetorial dos oito possíveis movimentos. As distâncias percorridas pelo robô, em cada transição de estado, dependem do movimento ser realizado nas diagonais ou nos sentidos dos eixos vertical ou horizontal.

FIGURA 2.5 - Diferentes configurações usadas para testar o ATAR: (E1) Sala simples com uma barreira, (E2) Sala simples com obstáculo em U, (E3) Ambiente complexo, e (E4) Labirinto.......... 14

FIGURA 2.6 - Ambiente de quatro quartos utilizado para testar o ATAR em ambiente dinâmico: (a) Configuração com porta aberta entre o ponto inicial e a meta. (b) Configuração com porta fechada entre o ponto inicial e a meta.

FIGURA 3.1 - Exemplo de experimento que indica a existência de orientação espacial (inspirado em Tolman, 1948): (a) Labirinto em que os ratos foram originalmente treinados. (b) Labirinto modificado em que foram feitos os experimentos......

FIGURA 3.2 - Localização do hipocampo no cérebro de um roedor - áreas CA1 e CA3 em destaque (Redish, 1997).

FIGURA 3.3 - (a) Arena circular. (b) Padrão de ativação de uma única célula do hipocampo em cada posição da arena circular (Redish, 1997). ....

FIGURA 3.4 - (a) Representação topológica de seis campos posicionais em um ambiente. (b) Exemplo da conectividade das seis células posicionais relacionadas aos campos indicados: sinapses conectando pares de células posicionais com campos próximos são fortalecidas (linhas grossas), e sinapses conectando células posicionais com campos posicionais distantes são enfraquecidas (linhas finas).

FIGURA 3.5 - Modelo proposto por Burgess et alli (1994) para escolha de ações motoras em uma tarefa de navegação.

FIGURA 5.1 - Transições de estado, e respectivos sinais de reforço recebidos, do agente ao realizar uma política $\pi$

FIGURA 5.2 - O subconjunto $T\left(s_{t}\right)$ do espaço de estados $S$ representa a região de influência do estado $s_{t}$.

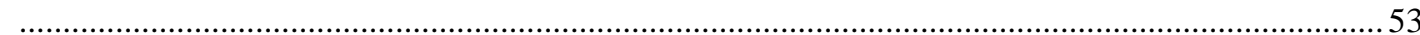

FIGURA 5.3 - Posição relativa do vértice $s$ (representado pelo seu vetor referência $w_{s}$ ) com relação ao círculo com diâmetro nos vértices $n$ e $m\left(w_{n}\right.$ e $w_{m}$, respectivamente): (a) interno ao círculo; (b) na fronteira do círculo e (c) externo ao círculo.

FIGURA 5.4 - Exemplos de geração dos vértices do mapa (segunda linha) a partir da classificação dos estados sensoriados durante a exploração dos ambientes (primeira linha) pelo robô. Regiões classificadas como livres estão em branco. Regiões classificadas como obstáculos estão em verde. 57

FIGURA 5.5 - Possíveis configurações para os três pontos: (a) Em seqüência horária, (b) Colineares ou (c) Em seqüência anti-horária...

FIGURA 5.6 - Possíveis configurações para círculo que circunscreve o triângulo $T_{n}$ formado pelos pontos $\left(n_{1}, n_{2}, n_{3}\right)$ e o estímulo $\xi$ : (a) Estímulo externo ao círculo, (b) Estímulo pertencente ao círculo ou (c) Estímulo interno ao círculo. 
FIGURA 5.7 - Exemplo de triangularização local incremental: (a) Mapa topológico inicial, (b) Ocorrência do estímulo $\xi$, e exibição do polígono $P$ formado pelos triângulos cujos círculos contêm o novo estímulo e (c) Novo mapa topológico.

FIGURA 5.8 - (a) Uma região de um mapa topológico aprendido - com destaque no vértice G. (b) Vizinhanças (0-3) da célula de Voronoi que contém o vértice $\mathrm{G}$ - as cores indicam as vizinhanças consideradas: células de mesma cor estão a um mesmo número de arestas do vértice $\mathrm{G}$.

FIGURA 5.9 - Atributos dos vértices do ATAR.

FIGURA 5.10 - (a) Sala simples com uma barreira na qual um único estado meta é especificado. (b) Exemplo de um mapa topológico gerado para representar o ambiente de (a).

FIGURA 5.11 - Vértices representando as $k=0, \ldots, 11$ vizinhanças topológicas do estado meta para o ambiente da Figura 5.10.

FIGURA 5.12 - (a) Estimativa da função de avaliação gerada pelo ATAR para a tarefa de navegação do ambiente da Figura 5.10.a; (b) Superfície obtida a partir da regressão da estimativa da função de avaliação gerada pelo ATAR; (c) Curvas de nível da estimativa da função de avaliação gerada pelo ATAR; (d) Curvas de nível da superfície gerada a partir da regressão da estimativa da função de avaliação gerada pelo ATAR.

FIGURA 5.13 - (a) e (b) Trajetórias geradas antes e depois, respectivamente, da regressão da estimativa da função de avaliação obtida com o ATAR 1 (100 treinamentos) para o agente partindo do estado $(5,5)$. (c) e (d) Trajetórias geradas antes e depois, respectivamente, da regressão da estimativa da função de avaliação obtida com o ATAR 1 (100 treinamentos) para o agente partindo do estado $(20,10)$.

FIGURA 5.14 - (a) e (b) Trajetórias geradas antes e depois, respectivamente, da regressão da estimativa da função de avaliação obtida com o ATAR 1 (100 treinamentos com o ambiente simples com barreira foram ainda mais sentidos em ambientes mais complexos como) para o agente partindo do estado $(35,5)$.

FIGURA 5.15 - (a) Trajetória original obtida a partir do mapa topológico. (b)-(c) Estágios intermediários da manipulação do mapa. (d) Trajetória final.

FIGURA 5.16 - Exemplos de melhoria da trajetória por detecção de ponto interior: (a) e (c) Trajetórias originais gerada a partir do mapa topológico entre um ponto inicial $(5,5)$ e a meta $(29,29)$, (b) e (d) sub-grafos resultantes da aplicação depois do processo de mudanças nas arestas originais entre ponto inicial e meta.

FIGURA 6.1 - Número de passos conectando as posições inicial e final para os sete algoritmos AR simulados, após cada treinamento, considerando os quatro ambientes da Figura 2.2: E1 - Ambiente simples com barreira, E2 - Ambiente simples com obstáculo em U, E3 - Ambiente complexo, e E4 Labirinto.

FIGURA 6.2 - Número de atualizações da função de avaliação para os sete algoritmos AR simulados, a cada treinamento, para os quatro ambientes da Figura 2.2: E1 - Ambiente simples com barreira, E2 Ambiente simples com obstáculo em U, E3 - Ambiente complexo, e E4 - Labirinto. ...................... 76

FIGURA 6.3 - Diagrama do ensaio inicial proposto para análise do agente em um ambiente nãoestruturado.

FIGURA 6.4 - Curvas dos tamanhos das trajetórias geradas pela Aprendizagem-Q, com a evolução dos treinamentos, para cinco diferentes fatores de ruídos nos ambientes: (a) E1, (b) E2, (c) E3 e (d) E4.

FIGURA 6.5 - Curvas dos tamanhos das trajetórias geradas pelo SARSA, com a evolução dos treinamentos, para cinco diferentes fatores de ruídos nos ambientes: (a) E1, (b) E2, (c) E3 e (d) E4.

IGURA 6.6 - Curvas dos tamanhos das trajetórias geradas pela Aprendizagem- $Q(\lambda)$, com a evolução dos treinamentos, para cinco diferentes fatores de ruídos nos ambientes: (a) E1, (b) E2, (c) E3 e (d) E4.

FIGURA 6.7 - Curvas dos tamanhos das trajetórias geradas pelo $S A R S A(\lambda)$, com a evolução dos treinamentos, para cinco diferentes fatores de ruídos nos ambientes: (a) E1, (b) E2, (c) E3 e (d) E4.

FIGURA 6.8 - Curvas dos tamanhos das trajetórias geradas pela Aprendizagem-Q( $\lambda$ ) Rápida, com a evolução dos treinamentos, para cinco diferentes fatores de ruídos nos ambientes: (a) E1, (b) E2, (c) E3 e (d) E4.

FIGURA 6.9 - Curvas dos tamanhos das trajetórias geradas pelo Dyna-Q, com a evolução dos treinamentos, para cinco diferentes fatores de ruídos nos ambientes: (a) E1, (b) E2, (c) E3 e (d) E4. 
FIGURA 6.10 - Curvas dos tamanhos das trajetórias geradas pelo ATAR, com a evolução dos treinamentos, para cinco diferentes fatores de ruídos nos ambientes: (a) E1, (b) E2, (c) E3 e (d) E4.

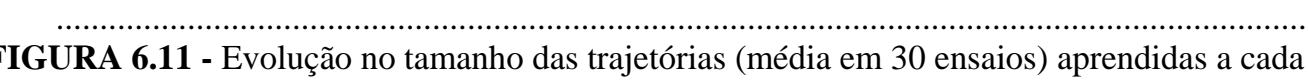

treinamento para as configurações da Figura 2.6. ............................................................... 90

FIGURA 6.12 - Exemplos de trajetórias geradas pelo ATAR para o ambiente da Figura 2.6 na condição de: (a) porta aberta e (b) porta fechada.

FIGURA 6.13 - Número das atualizações da função de avaliação (média para 30 ensaios) para as configurações da Figura 2.6.

FIGURA 6.14 - Gráficos comparativos entre as trajetórias originalmente geradas pelo ATAR e as trajetórias equivalentes geradas ao aplicar o método de melhoria por detecção do ponto interno, segundo as classes de trajetórias definidas na Tabela 6.1 para os quatro ambiente: E1, E2, E3 e E4.93

FIGURA 6.15 - Exemplos das trajetórias originalmente geradas pelo ATAR e as trajetórias equivalentes geradas ao aplicar o método de melhoria por detecção do ponto interno para os quatro ambiente: E1, E2, E3 e E4.

FIGURA 6.16 - Gráficos comparativos entre os mapas topológicos MTI e MTIC sob os aspecto da geração de vértices - (a),(c),(e) e (g) - e a geração de bordas - (b),(d), (f) e (h)

FIGURA 6.17 - Exemplo de mapas topológicos gerados para um mesmo ambiente pelo: (a) MTI - 505 vértices. (b) MTIC - 131 vértices.

FIGURA 6.18 - Comparação das curvas de aprendizagem do ATAR usando o MTI ou o MTIC para os ambientes da Figura 2.2: (a) E1 - Ambiente simples com barreira, (b) E2 - Ambiente simples com obstáculo em U, (c) E3 - Ambiente complexo, e (d) E4 - Labirinto.

FIGURA 6.19 - Curvas de aprendizagem do ATAR para diferentes técnicas de exploração (nãodirecionada, direcionada local, direcionada global) nos ambientes da Figura 2.5. 98 


\section{Lista de Tabelas}

TABELA 6.1 - Média e desvio padrão do número de passos calculados sobre os 50 últimos treinamentos.

TABELA 6.2 - Média e desvio padrão do número de atualizações calculadas para os 50 últimos treinamentos.

TABELA 6.3 - Primeiro treinamento em que há rejeição da hipótese $\mathrm{H}_{0}$ : a média do número de passos das trajetórias geradas pelo ATAR é menor que a média dos demais agentes AR com nível de significância de 0.01 .

TABELA 6.4 - Primeiro treinamento em que há rejeição da hipótese $\mathrm{H}_{0}$ : a média do número de atualizações do ATAR é menor que a média dos demais agentes AR com nível de significância de 0.01 .

TABELA 6.5 - Acumulado do número de atualizações da função de avaliação para a Aprendizagem-Q ao longo de 100 treinamentos.

TABELA 6.6 - Acumulado do número de atualizações da função de avaliação para o SARSA ao longo de 100 treinamentos.

TABELA 6.7 - Acumulado do número de atualizações da função de avaliação para a Aprendizagem-Q( $\lambda)$ ao longo de 100 treinamentos.....

TABELA 6.8 - Acumulado do número de atualizações da função de avaliação para o $S A R S A(\lambda)$ ao longo de 100 treinamentos.

TABELA 6.9 - Acumulado do número de atualizações da função de avaliação para a Aprendizagem-Q( $\lambda)$ Rápida ao longo de 100 treinamentos.

TABELA 6.10 - Acumulado do número de atualizações da função de avaliação para o Dyna-Q ao longo de 100 treinamentos.

TABELA 6.11 - Acumulado do número de atualizações da função de avaliação para o ATAR ao longo de 100 treinamentos.

TABELA 6.12 - Medidas $D$ das curvas de aprendizagem para a Aprendizagem-Q................................ 88

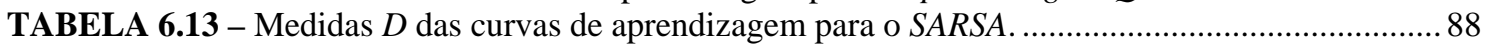

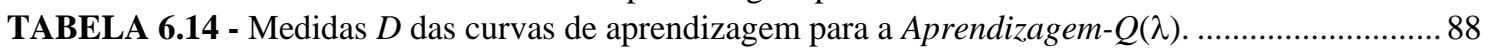

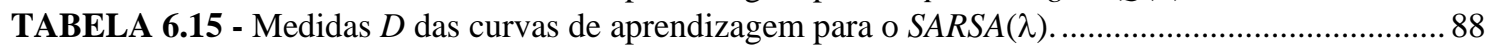

TABELA 6.16- Medidas $D$ das curvas de aprendizagem para a Aprendizagem-Q( $\lambda$ ) Rápida.................88

TABELA 6.17 - Medidas $D$ das curvas de aprendizagem para o Dyna-Q. ........................................... 88

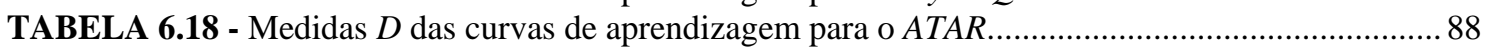

TABELA 6.19 - Classes de trajetórias consideradas para analisar as melhorias nas trajetórias - as trajetórias de cada ambiente foram dividas em 10 classes conforme o seu tamanho. ........................92

TABELA 6.20 - Medidas obtidas a partir da variação da estratégia de exploração. ................................97 


\section{Resumo}

BRAGA, A. P. S. (2004). AGENTE TOPOLÓgICO DE APRENDIZADO POR REFORÇO. São Carlos, 2004. 121 p. Tese (doutorado) - Escola de Engenharia de São Carlos, Universidade de São Paulo.

Os métodos de Aprendizagem por Reforço (AR) se mostram adequados para problemas de tomadas de decisões em diversos domínios por sua estrutura flexível e adaptável. Apesar de promissores, os métodos AR frequentemente tem seu campo de atuação prático restrito a problemas com espaço de estados de pequeno ou médio porte devido em muito à forma com que realizam a estimativa da função de avaliação.

Nesta tese, uma nova abordagem de AR, denominada de Agente Topológico de Aprendizagem por Reforço $(A T A R)$, inspirada em aprendizagem latente, é proposta para acelerar a aprendizagem por reforço através de um mecanismo alternativo de seleção dos pares estado-ação para atualização da estimativa da função de avaliação. A aprendizagem latente refere-se à aprendizagem animal que ocorre na ausência de reforço e que não é aparente até que um sinal de reforço seja percebido pelo agente. Este aprendizado faz com que um agente aprenda parcialmente uma tarefa mesmo antes que este receba qualquer sinal de reforço. Mapas Cognitivos são usualmente empregados para codificar a informação do ambiente em que o agente está imerso. Desta forma, o ATAR usa um mapa topológico, baseado em Mapas Auto-Organizáveis, para realizar as funções do mapa cognitivo e permitir um mecanismo simples de propagação das atualizações.

$\mathrm{O} A T A \mathrm{R}$ foi testado, em simulação, para planejamento de navegação de um robô móvel em ambientes inicialmente desconhecidos e não-estruturados. Comparações com outros seis algoritmos AR avaliaram comparativamente o desempenho do agente proposto na navegação. Os resultados obtidos são promissores e comparáveis com os algoritmos AR mais rápidos testados, alcançando em alguns ensaios desempenho superior aos dos demais algoritmos - principalmente nas simulações que consideram situações observadas em ambientes não-estruturados.

Três características do $A T A R$ original foram alteradas para tornar ainda mais viável sua aplicação prática: (i) mudanças no mapa topológico para reduzir o número de vértices, (ii) mudança na heurística usada na seleção das ações do agente e (iii) variações na estratégia de exploração do ATAR. Do ponto (i), foi proposto e implementado um novo mapa topológico, o Mapa Topológico 
Incremental Classificador - MTIC, que a partir da classificação dos estados do ambiente gera os vértices de uma triangularização de Watson. O ponto (ii) criou um método aplicável a outros problemas de planejamento de trajetória em grafos denominado de Melhoria das trajetórias por deteç̧ão de ponto interior. O terceiro estudou estratégias direcionadas de exploração como uma opção para acelerar o aprendizado do $A T A R$.

Palavras-chave - Aprendizagem por Reforço; mapas auto-organizáveis; aprendizagem latente; navegação de robô móvel. 


\section{Abstract}

BRAGA, A. P. S. (2004). TOPOLOGICAL REINFORCEMENT LEARNING AGENT. São Carlos, 2004. 121 p. Thesis (PhD) - Escola de Engenharia de São Carlos, Universidade de São Paulo.

Reinforcement Learning (RL) methods have shown to be a good choice for decision-making problems due to their flexible and adaptive characteristics. Despite such promising features, RL methods often have their practical application restricted to small or medium size (at state, or state-action, space) problems mainly because of their standard strategies for value function estimation.

In this thesis, a new RL approach, called "Topological Reinforcement Learning Agent"- TRLA, is proposed to accelerate learning through an alternative mechanism to update the state-action value function. TRLA is inspired in latent learning, which refers to animal learning that occurs in the absence of reinforcements and that is not visible until an environmental reinforcement is perceived. This concept considers that part of a task can be learned even before the agent receives any indication of how to perform such a task. Cognitive Maps are usually used to encode information about the environment where the agent is immersed. Thus, the TRL $A$ uses a topological map, based on Self-Organized Maps, to implement cognitive map functions and permit a new simple mechanism to execute the propagation of state-action updates.

The chosen problem to test TRLA is the simulation of a mobile robot navigation in some initially unknown and unstructured environments. Performance comparisons of the TRLA with six other RL algorithms were carried out to the execution of the navigation task. The obtained results are very promising and comparable with some of faster RL algorithms simulated. In some experiments, the TRLA's performance overcomes the others - especially in simulations with unstructured environments. Three characteristics of the original TRLA were modified to make it more suitable for real implementations: (i) changes in the topological map construction to reduce the vertices number, (ii) changes in the agent's heuristic for action selection, and (iii) variations on the TRLA's strategy for exploration of the state-action space. In (i), a new procedure to construct topological maps was proposed and implemented, the "Incremental Classifier Topological Map - ICTM", which generates the vertices for a Watson's triangulation from the classification of the input states. In (ii), it was proposed a method to optimize trajectory planning problems based on graphs, denoted "trajectory improvement from inner point detection". The third point considers directed exploration strategies as an option for TRLA's learning acceleration.

Keywords - Reinforcement learning; self-organizing maps; latent learning; mobile robot navigation. 


\section{Capítulo 1}

\section{Introdução}

Técnicas baseadas em Aprendizagem por Reforço (AR) (Kaelbling et alli, 1996; Bertsekas e Tsitsiklis, 1996; Sutton e Barto, 1998) vêm sendo utilizadas na construção de sistemas que aprendem a realizar tarefas não triviais de tomada de decisões tais como o controle de navegação de robôs móveis (Milán, 1996; Mataric, 1997; Samejima e Omori, 1999; Touzet, 2000; Pipe, 2000; Millán et alli, 2002), o planejamento do tráfego de linhas telefônicas (Littman e Boyan, 1993; Carlstrom e Norstrom, 1997; Nie e Haykin, 1999; Tong e Brown, 2002) ou a determinação de estratégias em jogos (Littman, 1994; Thrun, 1995; Tesauro, 1995). Essa metodologia vem despertando o interesse de pesquisadores de diversas áreas (controle, inteligência artificial, psicologia cognitiva) por unir características como aprendizagem por interação autônoma entre agente $^{1}$ e ambiente de trabalho ${ }^{2}$, possibilidade de atuar em um ambiente sem o conhecimento prévio de seu modelo, capacidade de anexação incremental de conhecimento sobre um processo e um formalismo matemático bem definido (os Processos de Decisão Markovianos - PDMs) (Puterman, 1994).

Promissora para a aplicação em problemas de tomadas de decisões em diversos domínios por sua estrutura flexível e facilmente adaptável, a aprendizagem por reforço tem seu campo de atuação prático restrito a problemas com espaço de estados de pequeno ou médio porte (Dean et. alli, 1995; Haykin, 1999). Isto ocorre porque muitos algoritmos AR realizam a estimativa da função de avaliação sobre cada par estado-ação. Com o crescimento do conjunto dos pares estado-ação, esta estimativa passa a ser lenta por exigir muitas iterações com o ambiente, tornando os agentes AR de difícil aplicação em problemas do mundo real. Entre as principais abordagens para acelerar os algoritmos de aprendizagem por reforço, tem-se os traços de elegibilidade (Rummery, 1995; Peng e Williams, 1996; Wiering e Schimidhuber, 1998a), estratégias de generalização (Tesauro, 1995; Touzet, 1997), opções baseadas em modelo (Sutton, 1991; Moore e Atkeson, 1993; Peng e Williams, 1993) e estruturas hierárquicas (Mahadevan e Connell, 1992; Lin, 1993). A aceleração no

\footnotetext{
${ }^{1}$ Agente (Russel e Norvig, 1995) pode ser entendido, de maneira geral, como qualquer entidade que possui as capacidade de perceber e agir sobre o seu ambiente. Na terminologia aqui usada, um agente AR é o sistema que utiliza técnicas de AR para planejar suas ações sobre o ambiente de trabalho.

${ }^{2}$ Ambiente é o sistema externo ao agente e que deve ser controlado.
} 
aprendizado obtida com estas abordagens é, em geral, computacionalmente dispendiosa. Muitas atualizações da função de avaliação precisam ser realizadas para que a aceleração da convergência da aprendizagem seja conseguida. Ou seja, a redução no número de iterações com o ambiente é conseguida com um maior processamento das informações já obtidas.

Nesta tese, uma nova abordagem de AR, denominada de Agente Topológico de Aprendizagem por Reforço ( $A T A R)$, inspirada no fenômeno da aprendizagem latente (Tolman, 1948) é proposta para acelerar a aprendizagem por reforço ao simplificar a estimativa da função de avaliação. A aprendizagem latente refere-se à aprendizagem animal que ocorre na ausência de reforço e que não é aparente até que um sinal de reforço seja percebido pelo agente. Este conceito permite que parte do aprendizado de uma dada tarefa seja realizado mesmo antes que o agente receba qualquer indicação de como tal tarefa deva ser realizada. $\mathrm{Na}$ aprendizagem latente, um mapa cognitivo é freqüentemente usado para explicar como é codificada a informação sobre o ambiente em que a tarefa será executada. Durante os anos de 1970, alguns experimentos (O'Keefe e Dostrovsky, 1971; O’Keefe e Nadel, 1978) indicaram o hipocampo como a estrutura cerebral envolvida com as funções do mapa cognitivo. O ATAR utiliza mapas topológicos, baseados em Mapas Auto-Organizáveis (Fritzke, 1994; Kohonen, 1984; Martinetz e Schulten, 1994), para realizar as funções do mapa cognitivo e permitir um mecanismo simples de propagação para executar aprendizagem do tipo latente.

O problema escolhido para testar o ATAR é a navegação de um robô móvel em um ambiente inicialmente desconhecido e não-estruturado. Pacher e Chandler (1998) associam ambiente nãoestruturado a incerteza, a qual pode englobar: (i) incerteza paramétrica (desconhecimento dos parâmetros do modelo); (ii) dinâmica não-modelada; (iii) distúrbios estocásticos; (iv) ruído (aleatório) nas medidas dos sensores; (v) múltiplos agentes de controle e um padrão complexo de informação (controle descentralizado); (vi) um sinal de controle (determinístico) adicional manipulado por um agente não-cooperativo; (vii) medida de ruído cuja intensidade é controlada por um agente cooperativo ou não-cooperativo, ou (viii) medidas determinísticas do erro que são inseridas e controladas por um agente não-cooperativo.

Tal tarefa representa um desafio utilizado por muitos pesquisadores de inteligência artificial para testar agentes autônomos (Kortenkamp et alli, 1998; Rylatt et alli, 1998; Arkin, 1998). Além disto, os métodos AR são particularmente interessantes para aplicações em robótica por permitirem que o robô aprenda autonomamente uma tarefa em um ambiente desconhecido, adaptando-se às mudanças ambientais (Johannet e Sarda, 1999; Althoefer et alli, 2001), e a existência de um conjunto grande de estados ou pares estado-ação é uma característica comum em robótica que é pertinente com respeito ao problema que se pretende tratar nesta tese. 


\subsection{Objetivo}

O objetivo desta tese é a proposição e implementação de uma alternativa para a aceleração da estimativa da função de avaliação de um agente AR, a um custo computacional comparativamente menor (redução do número de atualizações da função de avaliação) que o de outras abordagens, que permita a este agente ser capaz de realizar tarefas de tomadas de decisão direcionadas a atingir um estado meta em um ambiente com características comumente encontradas em sistemas reais: (i) espaço de estados grande, e (ii) ausência inicial de informação sobre o ambiente.

\subsection{Contribuições}

As principais contribuições deste trabalho de doutorado estão relacionadas abaixo:

(i) Proposição de um mecanismo que combina aprendizagem por reforço e não supervisionada;

(ii) Proposição de um algoritmo adaptável a diversos ambientes para tarefas em robótica móvel;

(iii) Proposição de uma representação compacta para a topologia de um ambiente para navegação robótica;

(iv) Estudo do uso de representações distintas para o uso de uma função de avaliação dos estados e uma função de avaliação da exploração na determinação da política do agente.

(v) Solução (mesmo que parcial e/ou limitada) de problemas em ambientes dinâmicos e não estruturados;

(vi) Contribuição nos algoritmos derivados do SOM com estrutura variável;

(vii) Inclusão de mecanismo para considerar apendizagem latente;

(viii) Inclusão de estratégia heurística de melhoria de soluções iniciais.

Parte destes tópicos geraram os seguintes artigos:

- $\quad$ BRAGA e ARAÚJO (2002). Aplicando mapas topológicos para acelerar aprendizagem por reforço na tarefa de navegação de robôs móveis. Anais do XIV CONGRESSO BRASILEIRO DE AUTOMÁTICA - CBA 2002. p.1595 - 1600. Natal - RN.

- $\quad$ BRAGA e ARAÚJO (2002). Applying topological maps to accelerate reinforcement learning in mobile robot navigation. Anais do 2002 IEEE International Conference on Systems, Man and Cybernetics. Hammamet - Tunísia.

- $\quad$ BRAGA e ARAÚJO (2003). A topological reinforcement learning agent for navigation.

Neural Computing \& Applications. 12 (3-4): 220-236. 


\subsection{Organização do Documento}

Os demais capítulos desta tese estão organizados na seguinte forma:

- CAPÍTULO 2: Comenta o Problema de Aprendizagem por Reforço Direcionado à Meta (PARDM), listando suas dificuldades práticas e teóricas. O problema real considerado é descrito, apresentando as principais abordagens para solucioná-lo, e o contexto da Aprendizagem por Reforço nestas soluções. As características desejadas para a solução do PARDM são relacionadas.

- CAPÍTUlO 3: A Aprendizagem por Reforço, desde a origem de seu termo até seus princípios de funcionamento, assim como a robótica, principalmente na linha de pesquisa conhecida como comportamental (Kortenkamp et alli, 1998; Arkin, 1998), têm utilizado estudos em comportamento animal como referência para a proposição de novos algoritmos. Neste Capítulo, os princípios biológicos que inspiram o algoritmo $A T A R$ são apresentados. Aprendizagem latente, mapas cognitivos e comportamento exploratório são os principais tópicos tratados que serão utilizados na proposição do agente.

- CAPÍTULO 4: Um breve levantamento das abordagens para acelerar os algoritmos de aprendizagem por reforço são discutidos. Um ramo destas abordagens de particular interesse é a que une aprendizagem por reforço e não-supervisionada, e para demonstrar a relevância e atualidade desta linha de pesquisa são comentados como casos de estudo quatro algoritmos. Um levantamento das estratégias de exploração empregadas em AR aponta a direção que será adotada neste tópico para a melhoria do $A T A R$.

- CAPÍTULO 5: Os princípios de funcionamento da proposta de algoritmo AR desta tese são descritos. Os passos do algoritmo do Agente Topológico de Aprendizagem por Reforço são comentados, bem como variações testadas para melhorar o desempenho do agente: (i) proposta de um mapa topológico mais simples, (ii) redução das trajetórias do agente a partir da manipulação do mapa topológico aprendido, (iii) adoção de uma estratégia de exploração direcionada.

- CAPÍTULO 6: Apresenta um estudo comparativo do desempenho do $A T A R$ relativo a outros algoritmos AR. Este estudo considera situações de ambientes estruturados e nãoestruturados como forma de analisar a viabilidade do ATAR em problema simples e problemas próximos do mundo real. As melhorias do $A T A R$ discutidas no Capítulo 5 são gradativamente avaliadas, permitindo observar os ganhos e limitações de cada uma e o tipo de ambiente para o qual cada variação é mais adequada.

- CAPÍTULO 7: Este capítulo traz um resumo do que foi exposto ao longo deste documento, comenta as contribuições obtidas com a pesquisa e discute possíveis caminhos para a continuação deste trabalho como: a aplicação do $A T A R$ em outras áreas, um maior desenvolvimento matemático formal do modelo, alternativas para a redução das limitações 
observadas nos ensaios realizados e experimentos para maior consolidação das características do agente.

Dois Apêndices acompanham este documento. O Apêndice A contém os algoritmos AR utilizados no Capítulo 6 para comparação com o ATAR. O Apêndice $\mathrm{B}$ traz os parâmetros utilizados nas simulações. 


\section{Capítulo 2}

\section{Descrição do Problema}

Diversos fatores afetam, em maior ou menor grau, a velocidade no processo de aprendizagem ${ }^{3} \mathrm{de}$ tarefas reais utilizando-se algoritmos AR. Tais fatores são tanto de ordem teórica, quando observase os princípios aplicados no funcionamento dos algoritmos AR para solucionar Processos de Decisão Markovianos (Puterman, 1994), quanto prática, quando observa-se que sistemas reais não se comportam exatamente como PDMs. Com a exposição de algumas destas dificuldades para melhorar o desempenho dos algoritmos AR, este capítulo pretende atingir três objetivos: (i) apresentar ao leitor uma descrição mais detalhada do problema que se está tratando nesta tese, (ii) descrever o cenário em que o algoritmo proposto será testado e (iii) apontar as escolhas tomadas na direção da solução do problema colocado.

A Seção 2.1 coloca o Problema de Aprendizagem por Reforço Direcionada à Meta (PARDM). A ênfase do PARDM nesta tese está na redução do número de iterações necessárias para a sua solução, mesmo diante de um ambiente dinâmico, não-estruturado e inicialmente desconhecido como normalmente ocorre em sistemas reais. O cenário-teste considerado, a navegação de um robô móvel, traz todas estas características que se deseja enfatizar e é comentado na Seção 2.2. Para situar como o agente AR atuará na navegação de um robô móvel, a Seção 2.3 traz uma visão geral do processo considerado. O capítulo é encerrado na Seção 2.4 com um resumo das características pretendidas para o agente proposto - estas serão desenvolvidas a partir dos Capítulos 3 e 4, culminando com a proposta do $A T A R$ no Capítulo 5.

\subsection{PROBLEMA GERAL: Acelerar a Solução do PARDM}

O problema tratado nesta tese busca formas mais rápidas, e que consequentemente permitam a aplicação em sistemas reais, de obter a solução do Problema de Aprendizagem por Reforço Direcionado à Meta (PARDM) (Koenig e Simmons, 1996). O PARDM considera duas etapas:

- A Solução do Problema de Exploração Direcionada à Meta (PEDM): Este estágio envolve a exploração do espaço de estados para determinar ao menos um caminho viável,

${ }^{3}$ Certas implementações de algoritmos AR chegam mesmo a não ter assegurada a convergência de sua aprendizagem. 
não necessariamente o mais curto, que ligue o estado inicial ao estado meta.

- A Melhoria da Solução encontrada: Esta etapa aproveita o conhecimento adquirido do ambiente durante a exploração do espaço de estados para melhorar as avaliações dos estados, buscando alcançar uma política ótima para o agente.

O que é chamado de aprendizagem no PARDM ocorre no mapeamento, a política $\pi$, entre as entradas $s \in S$ (conjunto dos estados do ambiente) do agente e suas saídas $a \in A(s)$ (conjunto das possíveis ações a partir do estado $s$ ). Para associar a cada estado a melhor ação que deve ser tomada, tal mapeamento é baseado nas realimentações do ambiente através de sinais de reforço, $r \in \mathfrak{R}$ (conjunto dos números reais), que indicam a contribuição das ações tomadas em cada estado para alcançar a meta desejada. A interação entre $s$, $a$ e $r$, que em AR é geralmente tratada como um Processo de Decisão Markoviano 4 (PDM) (Puterman, 1994), ocorre conforme o esquema da Figura 2.1, sendo que neste processo são utilizados quatro componentes principais (Kaelbling et alli, 1996; Sutton e Barto, 1998):

- Uma política $(\pi)$ : Função que mapeia estados do ambiente em ações $(\pi: S \rightarrow A)$.

- Uma função de retorno (r): Função que mapeia estados do ambiente em um valor real, o reforço $(r: S \rightarrow \mathfrak{R})$.

- Uma função de avaliação ( $\boldsymbol{V}$ ou $\boldsymbol{Q}$ ): Valor que estima um valor acumulado dos retornos entre um dado estado $s$ e o estado final desejado. Esta função mapeia estados em valores reais $(V: S \rightarrow \mathfrak{R})$ ou pares estado-ação em valores reais $(Q: S, A \rightarrow \mathfrak{R})$.

- Um modelo do mundo ${ }^{5}$ : Este componente modela o comportamento do ambiente. Ele mapeia estados do ambiente em sinais de reforço.

A maioria dos algoritmos AR têm suas políticas baseadas na estimativa da função de avaliação ${ }^{6}$ que busca maximizar um acumulado dos reforços recebidos do ambiente pelo agente.

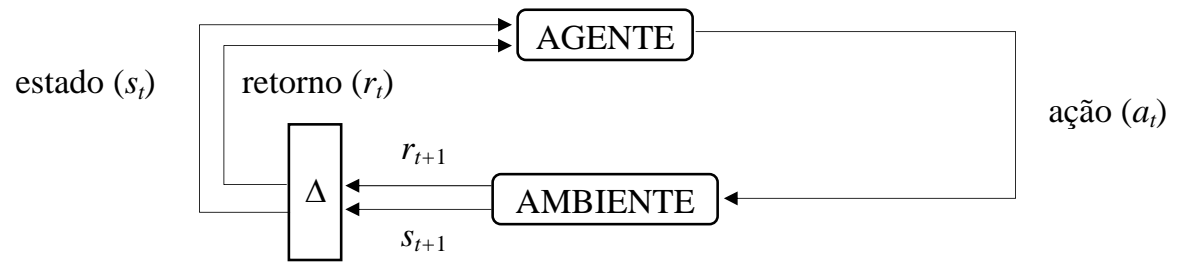

FIGURA 2.1 - Estrutura genérica do aprendizado por reforço (Sutton e Barto, 1998).

Um formato comum para as funções de avaliação, que permite que o somatório dos reforços convirja para um valor finito quando $t \rightarrow \infty$, é o acumulado descontado dos reforços que utiliza

\footnotetext{
${ }^{4}$ Um problema de tomada de decisão em um ambiente com propriedades markovianas define um Processo de Decisão Markoviano.

${ }^{5} \mathrm{O}$ modelo de mundo não está presente em todo agente AR (Kaelbling et alli, 1996).

${ }^{6}$ Alguns métodos de busca como algoritmos genéticos, simulated annealing ou otimização podem ser utilizados para solucionar problemas AR inferindo diretamente a política do agente sem o intermédio da função de avaliação (Sutton e Barto, 1998).
} 
uma taxa de desconto, $0 \leq \gamma<1$, para valorizar os sinais de reforço imediatos no tempo, e reduz a importância dos sinais futuros como nas expressões a seguir:

$$
\begin{gathered}
V(s)=E\left\{\sum_{k=0}^{\infty} \gamma^{k} r_{t+k+1} \mid s_{t}=s\right\} \\
Q(s, a)=E\left\{\sum_{k=0}^{\infty} \gamma^{k} r_{t+k+1} \mid s_{t}=s, a_{t}=a\right\}
\end{gathered}
$$

sendo que $E\{$.$\} indica que se trata de uma estimativa. A partir da função de avaliação, a seleção das$ ações do agente AR a cada instante $t$ deve ocorrer conforme uma política $\pi$ que maximize os retornos a longo prazo:

$$
\pi(s)=\underset{a \in A(s)}{\arg \max }\{Q(s, a)\}
$$

sendo $A(s)$ o conjunto das possíveis ações a partir do estado $s$.

O objetivo principal desta tese é obter a estimativa da função de avaliação com o menor número possível de interações do agente com o ambiente.

Entretanto, algumas dificuldades teóricas podem ser apontadas na busca por este objetivo:

1. A maldição da dimensionalidade (curse of dimensionality): Termo cunhado por Bellman (1957) para designar o crescimento exponencial da complexidade do problema com o número de estados e ações. Haykin (1999) exemplifica que em um problema de programação dinâmica, um dos métodos para obter a função de avaliação (Sutton e Barto, 1998), que envolva N estados possíveis e M ações admissíveis para cada estado seriam necessárias aproximadamente $\mathrm{N}^{2} \cdot \mathrm{M}$ operações para uma política estacionária. Isto freqüentemente torna inviável completar uma única iteração do algoritmo quando $\mathrm{N}$ é muito grande.

2. A maldição da modelagem (curse of modeling) (Bertsekas e Tsitsiklis, 1996): Ao buscar solucionar o PDM diretamente por programação dinâmica seria necessário obter o modelo completo do sistema que consistiria das matrizes de probabilidade das transições dos estados $P_{s s^{\prime}}^{a}=\operatorname{Pr}\left\{s_{t+1}=s^{\prime} \mid s_{t}=s, a_{t}=a\right\}$ e do retorno imediato $R_{s s^{\prime}}^{a}=E\left\{r_{t+1} \mid s_{t}=s, a_{t}=a, s_{t+1}=s^{\prime}\right\}$ pois os algoritmos de iteração da política e da avaliação requerem conhecimento prévio do PDM em curso. Apesar deste conhecimento nem sempre estar disponível, é necessária a explícita construção das matrizes, gerando o problema denominado de maldição da modelagem, que em alguns casos pode ser tão computacionalmente dispendioso quanto a maldição da dimensionalidade. 
3. Problemas com aproximações da avaliação: Para contornar o problema da modelagem, os métodos de diferença temporal (Temporal Difference - TD) (Sutton, 1988) utilizados em AR não fazem, necessariamente, uso de um modelo do sistema, aproximando as funções de avaliação e a política diretamente a partir dos retornos obtidos do ambiente. A forma com que estas aproximações são armazenadas, entretanto, em alguns casos afetam a convergência do algoritmo: o uso de aproximadores de função como as redes MLP podem levar à divergência do aprendizado (Tsitsiklis e Van Roy, 1996; Gordon, 1995; Baird, 1995; Boyan e Moore, 1995).

\subsection{PROBLEMA ESPECÍFICO: A Navegação Autônoma de um Robô Móvel}

O problema da navegação autônoma de um robô móvel em um mundo dinâmico e inicialmente desconhecido é uma tarefa não trivial (Thrun et alli, 1991) e consiste na atuação do agente, que deve selecionar ações em intervalos de tempo determinados, em um ambiente que possui obstáculos estáticos e dinâmicos, decorrentes de mudanças no ambiente ou presença de outros agentes, objetivando alcançar por um caminho de custo mínimo uma posição alvo pré-estabelecida. O PARDM a ser tratado é uma variação do problema básico de planejamento do movimento descrito por Latombe (1996):

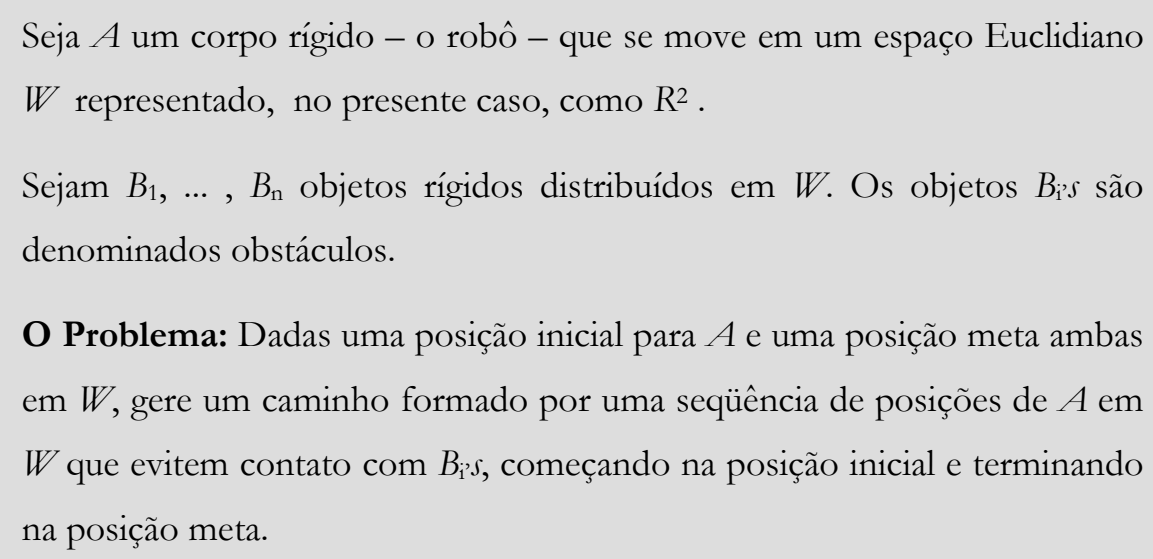

O problema da navegação de um robô móvel é tratado em diversos trabalhos de robótica (Gray e Caldwell, 1996; Latombe, 1996; Kortenkamp et alli, 1998; Rylatt et alli, 1998; Arkin, 1998; Nehmzow, 2000; Franz e Mallot, 2000). Uma solução definitiva ainda não foi encontrada, porém muitos avanços têm sido obtidos na área. Basicamente, há duas grandes classes de soluções para a navegação autônoma de robôs móveis ${ }^{7}$ (Gray e Caldwell, 1996; Arkin, 1998; Ribeiro et alli, 2001):

\footnotetext{
${ }^{7}$ As soluções com trajetórias pré-estabelecidas não são citadas por fugirem do escopo desta pesquisa ao não proporcionarem as características desejadas do agente.
} 
- Os sistemas deliberativos: De maneira geral, estes decompõem o planejamento em três etapas (Kortenkamp et alli, 1998; Brooks, 1986): (i) sensoriamento (traduz os dados sensoriais para um modelo do mundo), (ii) planejamento (a partir do modelo do mundo, gera-se uma seqüência de ações que levam o agente a atingir a meta estabelecida.) e (iii) execução (transformação das ações em sinais para os atuadores). Entretanto, uma limitação operacional do planejamento deliberativo é que estes sistemas costumam operar em malha aberta, baseando-se em um modelo determinístico do mundo (Arkin, 1998) falhas podem não ser detectadas, comprometendo esta abordagem em ambientes dinâmicos (Salichs e Moreno, 2000). Outro ponto a contar contra os sistemas puramente deliberativos é o tempo necessário para a escolha de suas ações (Kortenkamp et alli, 1998; Salichs e Moreno, 2000): somente após ter sido gerado todo o plano é que uma ação é executada e, como a geração de um plano é essencialmente um problema de busca (Hendler et alli, 1990), esta busca pelo espaço de estados pode chegar a um crescimento exponencial das interações entre os estados (Chapman, 1987).

- Os sistemas reativos: Surgiram a partir da insatisfação com os métodos puramente deliberativos e uma conscientização crescente da importância de observar sistemas biológicos como a base para a construção de comportamentos inteligentes (Brooks, 1986; Beer et alli, 1990; Nolfi, 2002). Robôs reativos foram concebidos para reagir a estímulos do ambiente utilizando uma coleção de comportamentos primitivos de baixo nível de abstração (Arkin, 1998). Comportamentos físicos complexos emergem através da interação de um conjunto de comportamentos simples e da complexidade inerente ao ambiente em que o robô se encontra (Brooks, 1990; Salichs e Moreno, 2000). Porém, sistemas puramente reativos apresentam duas limitações principais para a navegação autônoma em ambientes inicialmente desconhecidos (Millán, 1996): (i) as trajetórias costumam ser ineficientes por selecionarem a próxima ação simplesmente como uma função das leituras instantâneas dos sensores (Franz e Mallot, 2000) e (ii) a dificuldade em selecionar o conjunto de comportamentos básicos para a solução de uma tarefa (Nolfi, 2002).

Cada abordagem tem seus pontos fortes nas deficiências da outra. Assim, a tendência atual dos projetistas é a adoção de uma terceira classe de soluções, os sistemas deliberativos-reativos ou híbridos (Gray e Caldwell, 1996; Arkin, 1998; Rylatt et alli, 1998) que possuem em um mecanismo único características das outras duas abordagens:

- As arquiteturas deliberativas-reativas: Permitem a reconfiguração de sistemas reativos com base no conhecimento que o agente adquire do ambiente, combinando o processamento em tempo real dos sistemas reativos, com a capacidade de avaliar as conseqüências das ações executadas dos sistemas deliberativos (Payton et alli, 1990; Arkin, 
1998; Ribeiro et alli, 2001).

Segundo Whitehead e Ballard (1991), o imediatismo na tomada de decisões aproxima os sistemas que utilizam métodos AR dos sistemas reativos (Brooks, 1986; Agre e Chapman, 1987; Georgeff e Lansky, 1987). Entretanto, diferentemente da vasta maioria dos sistemas reativos, os métodos AR possuem a capacidade de se adaptar - tornando a Aprendizagem por Reforço uma abordagem apropriada para a implementação das arquiteturas deliberativas-reativas. Em sistemas reativos, o conhecimento para a tomada de decisões é codificado pelos projetistas de forma explícita (Brooks, 1986; Agre, 1988) ou através da especificação de modelos de mundo que eventualmente são compilados em um conjunto de regras reativas (Fikes et alli, 1972; Laird et alli, 1986). Os sistemas AR não precisam ter conhecimento pré-definido para a tomada de decisões (Sutton e Barto, 1998). Eles aprendem estratégias de controle por tentativa-e-erro ao interagir com o mundo, recebendo realimentações na forma de sinais de reforço. Esta adaptabilidade atenua o trabalho de ter que fornecer um completo conhecimento do domínio de trabalho ao agente, uma vez que este é adquirido com a experiência (Milán, 1996; Bhanu et alli, 2001).

O objetivo secundário desta tese é que o agente AR proposto apresente evidências de poder atuar em um problema real.

Como a aplicação pretendida para o agente AR desta tese é uma tarefa no mundo real, a navegação em um ambiente não-estruturado, dinâmico e inicialmente desconhecido, surge um grupo de dificuldades de ordem prática:

1. A interação do ambiente ser tratada como um PDM: Conforme Mataric (1994) comenta, para que a interação agente/ambiente (AG/AM) possa ser modelada como um PDM certas considerações fundamentais são assumidas:

1. AG e AM são autômatos de estado finito sincronizados entre si.

2. AG e AM interagem em intervalos de tempo discretos.

3. AG pode sempre distinguir um estado de AM e usar esta informação para selecionar uma ação.

4. Após AG executar uma ação, AM realiza uma transição para um novo estado.

5. AG recebe um sinal de reforço após realizar uma ação.

Entretanto, ambientes reais não costumam satisfazer a todas estas considerações (Wyatt, 1997), e desta "desobediência" surgem as principais causas da diferença de desempenho entre agentes AR simulados e agentes AR situados (situated agents - agentes que atuam em situações do mundo real) (Mataric, 1994).

2. Incerteza sobre os estados do ambiente: A teoria de PDM considera que há certeza quanto ao estado observado do ambiente (Kaelbling et alli, 1996; Ribeiro, 2002). Entretanto, as leituras reais de sensores que servem para a determinação do estado do ambiente são ruidosas, 
implicando em incertezas (Pendrith, 1994; Pacher e Chandler, 1998; Wyatt et alli, 1998; Fox et alli, 1999; Olson, 2000). Alguns pesquisadores buscam tratar esta incerteza, em problemas de planejamento, modelando a interação agente-ambiente como um Processo de Decisão Markoviano Parcialmente Observável (PDMPO) (Kaelbling et alli, 1996; Shatkay e Kaelbling, 2002), no entanto a solução destes processos são ainda mais complexas que as do PDM implicando em um maior comprometimento na velocidade de aprendizagem do agente AR (Zhang e Zhang, 2001).

3. Tabula rasa: Em sistemas complexos, não-estruturados (Capítulo 1), a informação sobre suas dinâmicas é de difícil modelagem. Assim, seria de interesse, e talvez até necessário, que o agente fosse capaz de aprender a operar nestes ambientes independente de qualquer informação a priori sobre eles. Entretanto, a ausência de informação inicial, aqui considerada como situação inicial do robô móvel, pode levar o agente a comportamentos indesejáveis como a caminhada aleatória ou mesmo a ficar preso em ótimos locais.

\subsection{O Processo Considerado}

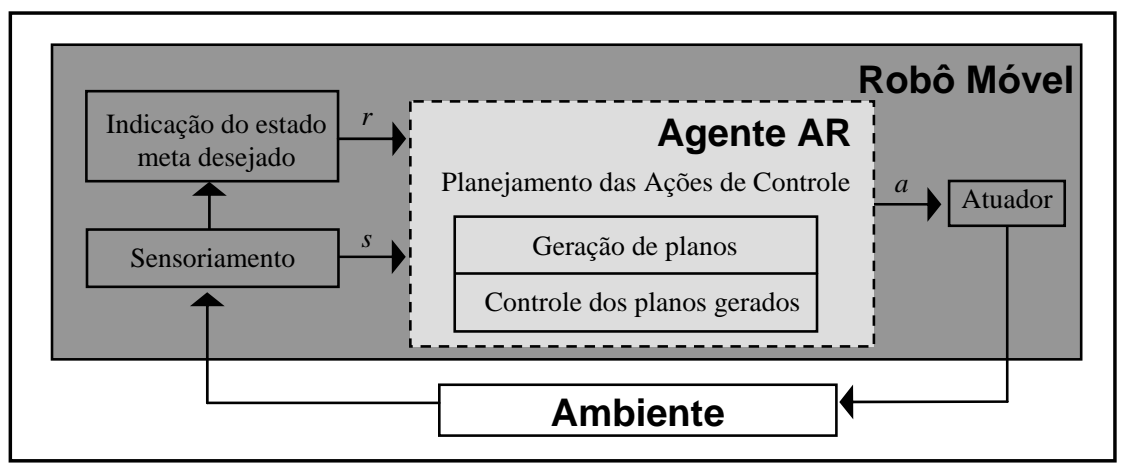

FIGURA 2.2 - Diagrama considerado para o funcionamento do agente.

Além do Agente AR, foco desta pesquisa, a Figura 2.2 apresenta o robô móvel como formado por mais três blocos funcionais:

(i) Indicação do estado meta desejado: No problema tratado nesta tese, esta indicação é dada pela função de retorno (Sutton e Barto, 1998). Por exemplo, as leituras dos sensores do robô para um dado estado permite classificá-lo em uma das três categorias: estado livre, obstáculo e meta. Neste caso, pode-se estabelecer uma função de retorno do tipo:

$$
r_{t+1}\left(s_{t}, a_{t}, s_{t+1}\right)=\left\{\begin{array}{c}
+1, \forall s_{t} \in F, a \in A, e s_{t+1} \in G ; \\
-1, \forall s_{t} \in F, a \in A, e s_{t+1} \in O ; \\
0, \forall s_{t} \in F, a \in A, e s_{t+1} \in F
\end{array}\right.
$$

sendo $G$ o conjunto finito dos estados meta, $O$ o conjunto finito dos estados com obstáculos, $F$ o conjunto finito dos estados livres e $s_{t} \in S, \varnothing \neq G \subseteq S, \varnothing \neq O \subset S, G \neq O$, e $F=S-(G \cup O)$. 
(ii) Sensoriamento: Em robôs móveis, a percepção do estado do ambiente costuma ser realizada por um sistema de localização para a determinação de sua posição: $s=(x, y)$. Os métodos de localização probabilística vêm sendo muito utilizados e são normalmente baseados em uma matriz P que representa a probabilidade da localização do robô em cada estado: os elementos da matriz armazenam uma probabilidade $p(L)$ de que o robô esteja na posição $L$. A atualização destas probabilidades segue uma regra de Bayes - supondo $P(L)$ como sendo a probabilidade $a$ priori de $L$ ser a posição atual do robô móvel, a probabilidade a posteriori de $L$, a partir do vetor $\left(s_{1} \cdots s_{n}\right)$ das leituras dos $n$ sensores do robô, é calculada por (Großmann, 2001; Fox, Burgard e Thrun, 1999):

$$
p\left(L \mid s_{1} \cdots s_{n}\right)=\frac{p\left(s_{1} \mid L\right) \cdots p\left(s_{n} \mid L\right) p(L)}{\sum_{L^{\prime} \in P} p\left(s_{1} \mid L^{\prime}\right) \cdots p\left(s_{n} \mid L^{\prime}\right) p\left(L^{\prime}\right)}
$$

sendo $p\left(s_{i} \mid L\right)$ um modelo do sensor que indica a probabilidade de se obter a leitura $s_{i}$ quando o robô está na posição $L$ (Fox, 1998). Geralmente considera-se o estado com maior probabilidade $p\left(L \mid s_{1} \cdots s_{n}\right)$ como o que representa a posição atual do robô ${ }^{8}$. Caso diversos estados apresentem a mesma probabilidade, movimentos são realizados pelo robô para capturar novos dados sensoriais $\left(s_{1} \cdots s_{n}\right)$ que permitam aplicar a Eq. 2.5. A atualização das probabilidades de localização com a movimentação do robô se repete até que haja apenas um estado com máxima probabilidade. A presença de incerteza nesta estimativa da localização do robô será considerada em algumas das simulações realizadas com o ATAR (Capítulo 6).

(iii) Atuador: Transforma a saída a, Figura 2.2, do agente AR nas velocidades das rodas do robô móvel real (Figura 2.3).

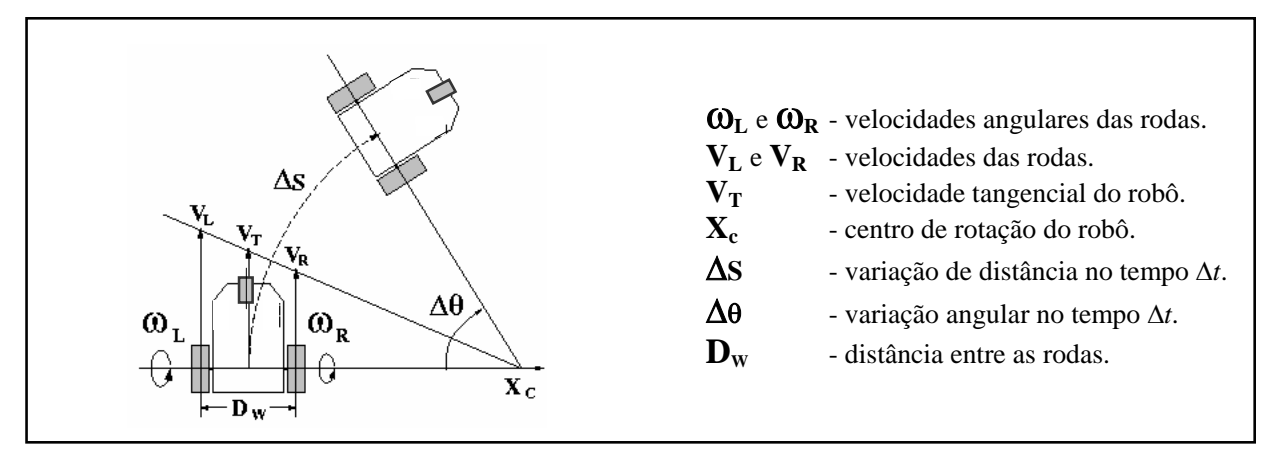

FIGURA 2.3 - Figura reproduzida de Zalama et alli (1995): Durante um intervalo de tempo $\Delta t$, o robô move-se ao longo de uma trajetória circular com centro em $\mathrm{X}_{\mathrm{C}}$ através de uma distância $\Delta \mathrm{S}$ e ângulo $\Delta \theta$ conforme as velocidades aplicadas às rodas.

\footnotetext{
${ }^{8}$ Outros critérios podem ser tomados, como realizar uma média ponderada entre os estados com maior probabilidade $p\left(L \mid s_{1} \cdots s_{n}\right)$.
} 
As possíveis ações do robô foram limitadas às oito mostradas na Figura 2.4, compostas por procedimentos de rotação e translação. Considerações sobre as características nãoholonômicas ${ }^{9}$ do robô, e o projeto dos controladores fogem ao escopo deste trabalho

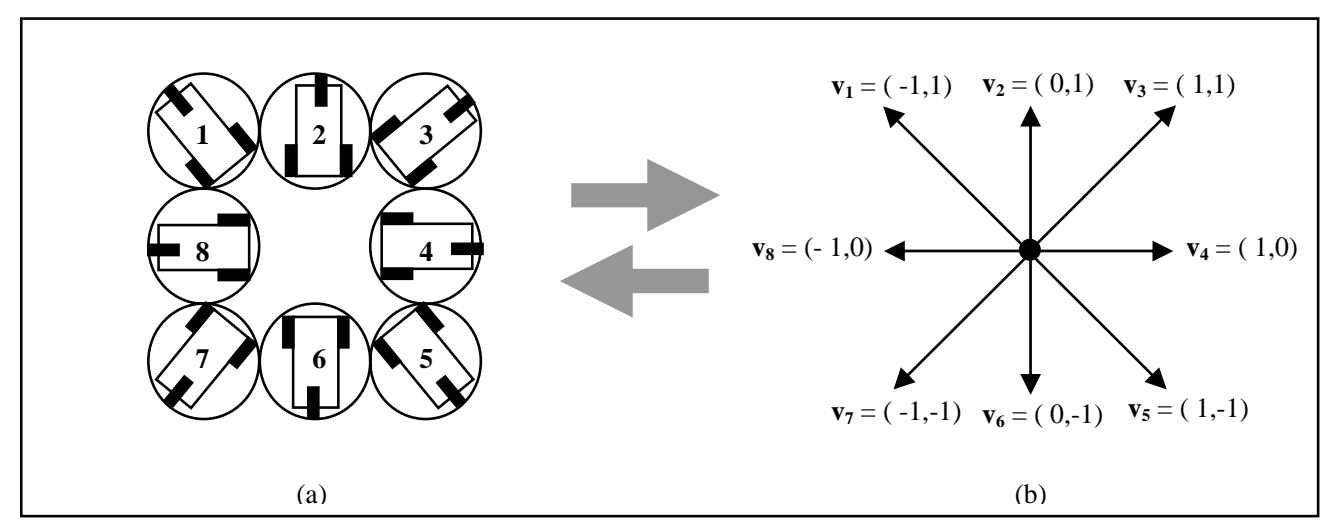

FIGURA 2.4 - (a) Representação dos oito movimentos considerados do robô. Cada estado possui espaço suficiente para este ser capaz de realizar uma rotação em torno de seu eixo central. (b) Representação vetorial dos oito possíveis movimentos. As distâncias percorridas pelo robô, em cada transição de estado, dependem do movimento ser realizado nas diagonais ou nos sentidos dos eixos vertical ou horizontal.

A partir das considerações apresentadas sobre os blocos funcionais que interagem com o agente AR, adotou-se uma representação dos estados em que o robô móvel pode ser tratado como sendo pontual ${ }^{10}$ (Figura 2.4) - cada estado corresponde a uma região suficiente para permitir ao robô um giro em torno de seu eixo central. A flexibilidade do agente será testada em ambientes de diferentes configurações que seguem um nível crescente de complexidade (Figura 2.5).

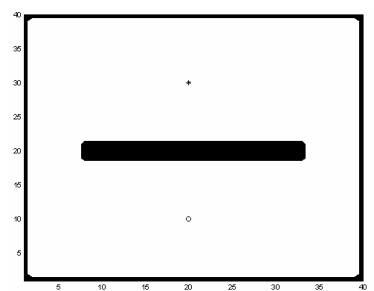

(E1)

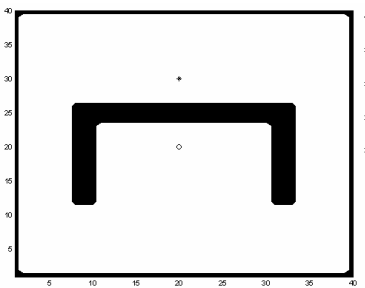

(E2)

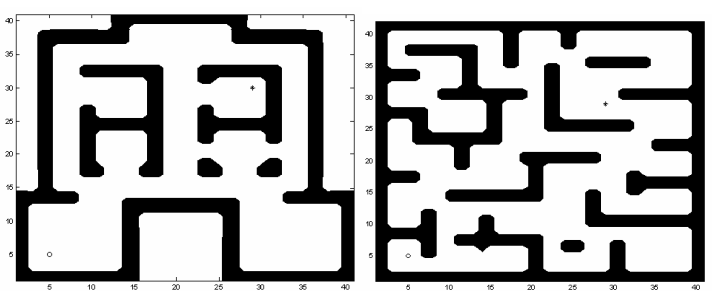

(E3)
(E4)

FIGURA 2.5 - Diferentes configurações usadas para testar o ATAR: (E1) Sala simples com uma barreira, (E2) Sala simples com obstáculo em U, (E3) Ambiente complexo, e (E4) Labirinto.

Incertezas sobre o estado do robô serão simuladas em alguns testes com o $A T A R$ (Capítulo 6) adicionando ruído aleatório.

\footnotetext{
${ }^{9}$ Um robô é dito não-holonômico quando existem restrições de movimento impostas por limitações físicas, tais como máximo ângulo de giro das rodas (Schmitt, 1996; Ribeiro et alli, 2001).

${ }^{10}$ Alguns problemas que utilizam AR com robôs móveis preferem representar os estados no espaço de características (as leituras dos sensores). Optou-se pela discretização espacial do ambiente por parecer mais adequada ao problema que se pretende (grande quantidade de estados).
} 


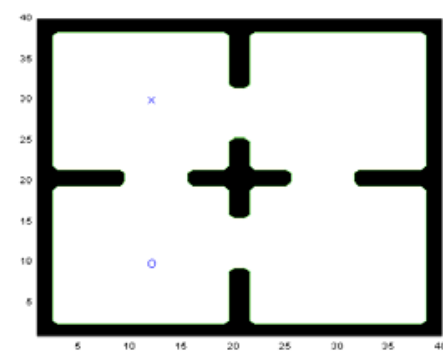

(a)

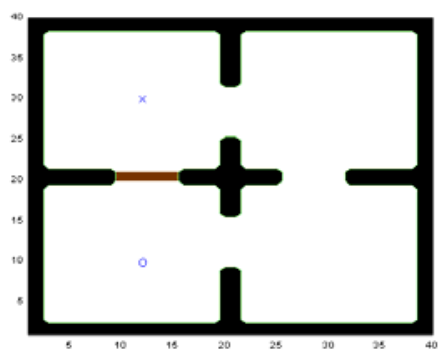

(b)

FIGURA 2.6 - Ambiente de quatro quartos utilizado para testar o ATAR em ambiente dinâmico: (a) Configuração com porta aberta entre o ponto inicial e a meta. (b) Configuração com porta fechada entre o ponto inicial e a meta.

Testes também serão realizados para avaliar o $A T A R$ em um ambiente que pode ter sua configuração modificada ao longo do tempo como a abertura e fechamentos de portas da Figura 2.6.

\subsection{Direcionamento da Pesquisa}

A aprendizagem por reforço permite que um agente escolha otimamente uma ação com base em suas experiências atual e passadas de tal forma a maximizar uma função de avaliação ao longo do tempo (Braga e Araújo, 2002b). Esta função de avaliação (i) estima o desempenho do agente na execução de uma dada tarefa, (ii) é aprendida por interações entre o ambiente e o agente, e (iii) não necessita de um conhecimento completo do ambiente a ser explorado. Em particular, os métodos AR são interessantes para aplicações em robótica por permitirem que o robô aprenda autonomamente uma tarefa em um ambiente desconhecido, adaptando-se às mudanças ambientais (Althoefer et alli, 2001; Johannet e Sarda, 1999). Entretanto, os métodos AR são freqüentemente lentos para convergir em ambientes que possuem um conjunto grande de estados ou pares estadoação (Dean et alli, 1995; Haykin, 1999), uma característica comum em robótica.

Para contornar esta limitação na solução do PARDM, levantou-se algumas das dificuldades para melhorar o aprendizado da função de avaliação como forma de definir uma estratégia para a pesquisa (Mataric, 1994; Kaelbling et alli, 1996; Wyatt, 1997; Sutton, 1999; Haykin, 1999):

- Dificuldades teóricas: a maldição da dimensionalidade, a maldição da modelagem e problemas com aproximações da função avaliação.

- Dificuldades práticas: a interação do ambiente ser tratada como um PDM, incerteza sobre os estados do ambiente e tabula rasa.

Destes pontos apresentados, depreende-se algumas características que devem estar presentes na forma de: (i) Representação da função de avaliação: compacta, representativa das transições realizadas pelo robô, capaz de trabalhar na presença de ruídos e de armazenar incrementalmente informação durante a exploração do ambiente; (ii) Atualização da função de avaliação: não 
dependente de conhecimento prévio da matriz de transições de estados do processo; e (iii) Exploração do ambiente: deve alcançar a meta e vasculhar o ambiente no menor número de iterações possível.

A estratégia para alcançar estas características utilizou duas fontes de inspiração: estudos em navegação animal e a revisão das propostas correntes para acelerar o PARDM como os traços de elegibilidade (Peng e Williams, 1996; Rummery, 1995; Wiering e Schimidhuber, 1998), estratégias de generalização (Tesauro, 1995; Touzet, 1997), opções baseadas em modelo (Moore e Atkeson, 1993; Peng e Williams, 1993; Sutton, 1991) e estruturas hierárquicas (Lin, 1993; Mahadevan e Connell, 1992). Os dois capítulos que se seguem resumem as premissas extraídas de cada uma destas fontes que convergiram para a proposição do $A T A R$ (Capítulo 5). 


\section{Capítulo 3}

\section{Navegação Animal: Etologia e Neuroetologia de um Comportamento Direcionada à Meta}

Animais ao planejarem suas ações objetivando alcançar uma posição meta, como um roedor que vai ao encontro do seu alimento em um labirinto (Schultz et alli, 1997), realizam (decorrente do processo de evolução) a assinalação de créditos (Minsky, 1961; Haykin, 1999) de forma rápida e eficiente ao distinguirem caminhos promissores daqueles que não os são. A proposta deste Capítulo é estudar como animais conseguem este desempenho, objetivando extrair conceitos e premissas que serão utilizados no $A T A R$, através do levantamento de alguns tópicos do que é atualmente conhecido sobre navegação animal (Waterman, 1989; Gallistel, 1990; Trullier et alli, 1997).

Para compreender como animais aprendem a realizar uma tarefa direcionada à meta como a navegação, há uma questão precedente: como as informações relacionadas à tarefa são codificadas de forma a viabilizar o aprendizado? Esta não é uma discussão nova, e possui duas linhas predominantes de raciocínio (Tolman, 1948): (i) O comportamento animal utiliza associações do tipo estímulo-resposta e (ii) $\mathrm{O}$ comportamento animal utiliza uma representação interna do ambiente. Evidências, como encontradas para aprendizagem latente (Seção 3.1), fornecem argumentos à segunda escola ${ }^{11}$ e apontam para melhor desempenho no aprendizado graças a esta representação interna.

À primeira escola de representação do comportamento, comportamental ou behaviorista, podese fazer uma analogia com a representação par estado-ação muito empregada em AR (Kaelbling et alli, 1996). O uso de modelos do ambiente em AR para acelerar o aprendizado não é uma novidade (ver Capítulo 9 de Sutton e Barto, 1998), entretanto a eficiência na assinalação de créditos por animais motiva o estudo das características dos mapas cognitivos (Seção 3.2), tipo de modelo discutido pela segunda escola, para buscar um análogo a ser empregado em um agente AR.

Premissas sobre o comportamento exploratório são extraídas das discussões apresentadas na Seção 3.3. A Seção 3.4 encerra este Capítulo resumindo as idéias extraídas do material levantado, e as traduz em premissas que serão incorporadas ao $A T A R$ (Capítulo 5).

\footnotetext{
${ }^{11}$ Trullier e colegas (1997) apresentam uma visão aceita atualmente por muitos pesquisadores de que estas duas escolas não são excludentes, mas representam diferentes níveis de aprendizagem da navegação animal.
} 


\subsection{Aprendizagem Latente}

A aprendizagem latente ocorre na ausência de reforço e é interessante por permitir que parte do aprendizado de uma tarefa seja realizado mesmo antes que o agente receba qualquer indicação de como tal tarefa deva ser realizada. Muitos organismos aprendem na ausência de reforços, entretanto eles não demonstram uma resposta a este aprendizado até que um sinal de reforço seja percebido. Hugh Blodgett conduziu um dos primeiros experimentos que usava o paradigma da aprendizagem sem recompensa em 1929. Tolman e Honzik (1930) repetiram o experimento, em que ratos percorriam um labirinto com doze escolhas de caminho e uma posição meta, utilizando três grupos de cobaias:

- Grupo 1: Sempre que um rato alcançasse a posição meta, este era retirado do labirinto e colocado de volta a sua gaiola.

- Grupo 2: Sempre que um rato alcançasse a posição meta este era premiado com comida.

- Grupo 3: O rato era removido do labirinto e colocado em sua gaiola quando alcançasse a posição meta nas dez primeiras tentativas. A partir da décima primeira tentativa, comida era deixada na posição meta como premiação.

Os erros cometidos por cada rato para alcançar a posição meta foram contados e, como esperado, durante as primeiras dez tentativas o Grupo 2 mostrou um decréscimo significativo no número de erros ao buscar uma rota para a meta. Os dois grupos que não receberam reforço também diminuíram o número de erros realizados, em um grau muito menor. Contudo, após a décima primeira tentativa, ocorre uma dramática redução no número de erros do Grupo 3. Os ratos do terceiro grupo, que estavam tendo um desempenho similar aos do Grupo 1, ao começar a ter reforço pela introdução da comida, apresentam enorme decréscimo no número de erros em uma tentativa, de tal forma que alcançaram o mesmo nível de desempenho dos ratos do Grupo 2. Aprendizagem latente ${ }^{12}$ foi o termo cunhado por Tolman para esta rápida melhoria como indicação de que os ratos não premiados tinham aparentemente aprendido sobre o labirinto tanto quanto aqueles que estavam sendo premiados, entretanto este aprendizado não estava sendo expresso até que o reforço fosse introduzido. O tipo de informação aprendida durante a aprendizagem latente pode ser parcialmente inferida a partir características observadas em outros experimentos descritos por Tolman:

1) Seleção ativa das associações entre estímulo e aşão: Contrariando os psicólogos que prevêem respostas reativas $^{13}$ aos estímulos do ambiente na tomada de decisões do animal, há evidências de mecanismos mais sofisticados para estabelecer a associação entre estímulos e ações:

\footnotetext{
${ }^{12}$ Por essa razão, Lorenz (1995) propõe que é latente, até que uma situação de necessidade ocorra, o conhecimento já adquirido por meio da exploração e, por essa razão, o termo conhecimento latente talvez seja mais adequado para o fenômeno.

${ }^{13}$ Entenda-se por respostas reativas a teoria de que o comportamento é guiado por associações simples do tipo estímulo-ação.
} 
- Em situações críticas em um ambiente, o animal apresenta-se hesitante na tomada de suas decisões mesmo após ter passado por uma série de treinamentos. Estas indecisões fornecem subsídios à argumentação de que o animal seleciona e compara os estímulos. Tolman (1948), por exemplo, cita que ratos ao receberem choques fazem associações da causa deste estímulo apenas com observações realizadas após a ocorrência do mesmo. A partir desse experimento, fica reforçado o argumento de que animais não recebem e agem reativamente a todo estímulo apresentado, mas sim selecionam entre os estímulos recebidos aqueles que devem ser considerados para a construção de seu mapa cognitivo.

- Diante de um labirinto formado por uma seqüência de quatro bifurcações, que apresenta em cada bifurcação duas portas (cada uma pintada com uma cor ou padrão diferente), o rato segue uma sistemática para descobrir a seqüência de portas que levam à saída do labirinto: começa escolhendo praticamente todas as portas à direita, depois praticamente todas à esquerda, e então aquelas com tons mais escuros, e assim por diante. Com isso, temos uma evidência da forma como vai se processando a escolha dos estímulos que devem ser considerados: inicialmente todas as bifurcações são consideradas iguais (o estímulo para selecionar a ação é a visão de duas portas e apenas a relação esquerda ou direita é observada), depois começa-se a realizar distinções entre cada uma das bifurcações (considera-se agora os padrões pintados nas portas das bifurcações também como estímulos relevantes) e, com a evolução do aprendizado, a seqüência de ações é aprendida.

2) Orientação espacial: Treinados inicialmente para realizar uma seqüência de movimentos que deve terminar em uma determinada posição de um labirinto (Figura 3.1.a), ratos colocados em uma variação do mesmo labirinto (Figura 3.1.b), na qual o caminho da seqüência de movimentos treinados é bloqueado, têm suas decisões observadas diante desta modificação no ambiente.

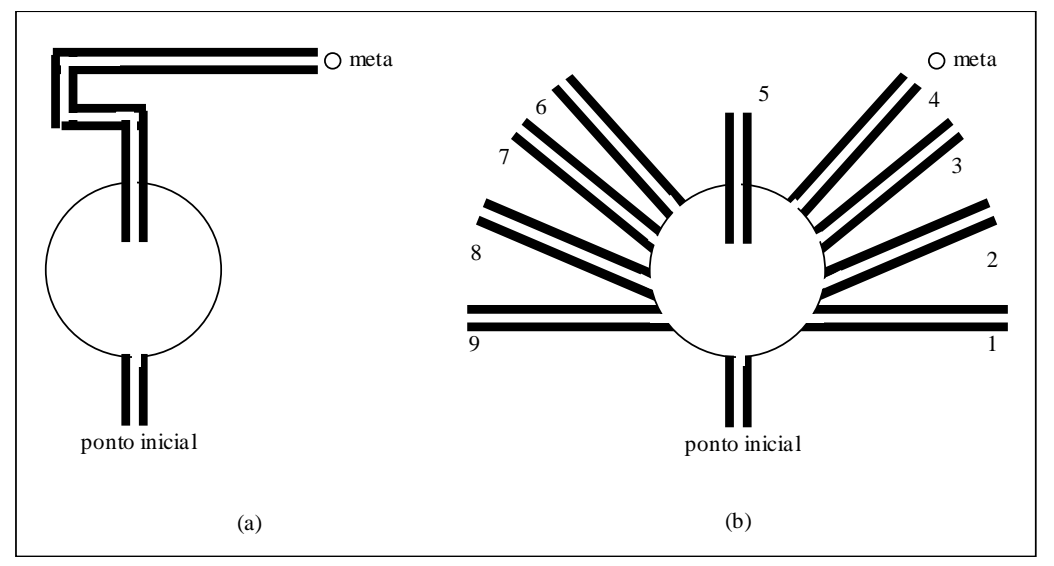

FIGURA 3.1 - Exemplo de experimento que indica a existência de orientação espacial (inspirado em Tolman, 1948): (a) Labirinto em que os ratos foram originalmente treinados. (b) Labirinto modificado em que foram feitos os experimentos. 
Os dados levantados sugerem que os ratos têm preferência por caminhos do labirinto que levam diretamente à posição final anteriormente aprendida ou a caminhos que estão perpendiculares a esta posição. No caso da Figura 3.1.b, os caminhos que os ratos escolheriam com maior freqüência seriam, em primeiro lugar, o caminho 4, e logo em seguida o caminho 1. Estes resultados parecem indicar que os ratos do experimento aprenderam as relações espaciais para a posição final treinada.

Até o final da década de 1960, o conteúdo acima justificava os mapas cognitivos (cognitive maps) (Tolman, 1948) como o mecanismo envolvido para codificar informação sobre o ambiente durante aprendizagem latente. Estes seriam a estrutura em que as informações sobre o ambiente estariam guardadas e o percursor de conceitos como memória espacial (Muller et alli, 1996). Com os avanços no estudo da neurofisiologia e neuroetologia novas evidências contribuíram para uma melhor compreensão dos mapas cognitivos, permitindo até a proposição de modelos matemáticos.

\subsubsection{Neurofisiologia dos Mapas Cognitivos - Células Posicionais}

Com o trabalho de O'Keefe e Dostrovsky (1971), passou-se a cogitar que o hipocampo abrigaria as funções dos mapas cognitivos (O’Keefe e Nadel, 1978). O hipocampo, também denominado de chifre de Ammon ${ }^{14}$ (Cornu Ammonis - CA) devido à sua forma, possui quatro regiões denominadas CA1 - CA4 (Lorente de Nó, 1934). A região CA4 atualmente não é considerada como uma região separada, e as fronteiras da região CA2 não são muito claras, o que faz com que geralmente só se faça referência às regiões CA1 e CA3 do hipocampo (Figura 3.2) - justamente a característica das células presentes nestas regiões, as células piramidais ou posicionais (place cells) (O'Keefe e Dostrovsky, 1971), é que fornecem subsídios à hipótese do mapa cognitivo.

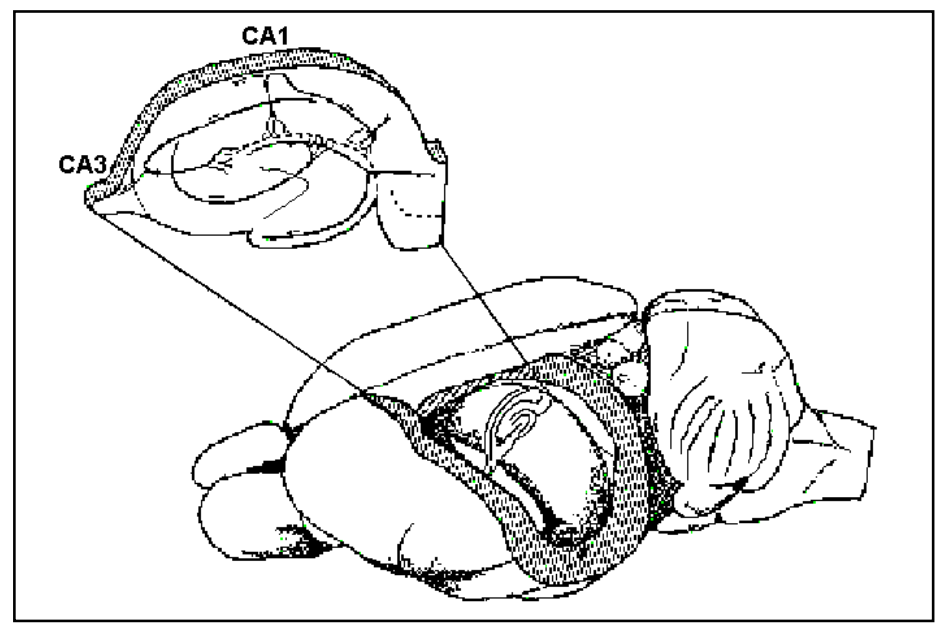

FIGURA 3.2 - Localização do hipocampo no cérebro de um roedor - áreas CA1 e CA3 em destaque (Redish, 1997).

\footnotetext{
${ }^{14}$ Rei dos deuses da cidade de Tebas, e depois de todo o Egito. Os primeiros anatomistas julgaram a forma do hipocampo semelhante a um chifre presente em algumas representações de Ammon (Lent, 2001).
} 
Esta característica é apresentada nas seguintes definições dadas por O’Keefe (1979) para as células posicionais:

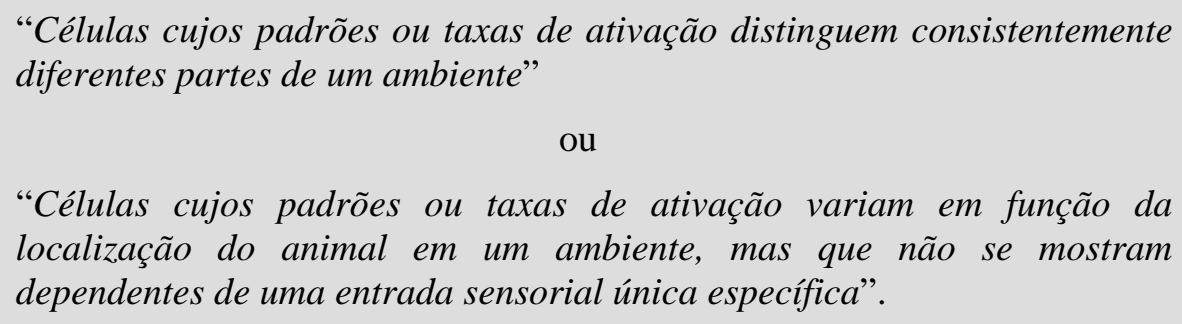

O disparo das células posicionais quando o rato se move para posições diferentes no ambiente sugere que tais células podem representar regiões limitadas de um ambiente. Quando o animal está na região do ambiente associada a uma determinada célula posicional, denominada de campo posicional (place field) da célula, há uma probabilidade acima de $70 \%$ desta célula disparar. Um exemplo de campo posicional pode ser observado na Figura 3.3: após deixar um rato explorar a arena circular da Figura 3.3.a, verifica-se o histograma de disparo de uma única célula CA1 para diversas posições no interior da arena (Figura 3.3.b - os tons escuros indicam disparo mais intenso, e os tons claros indicam disparos mais brandos).

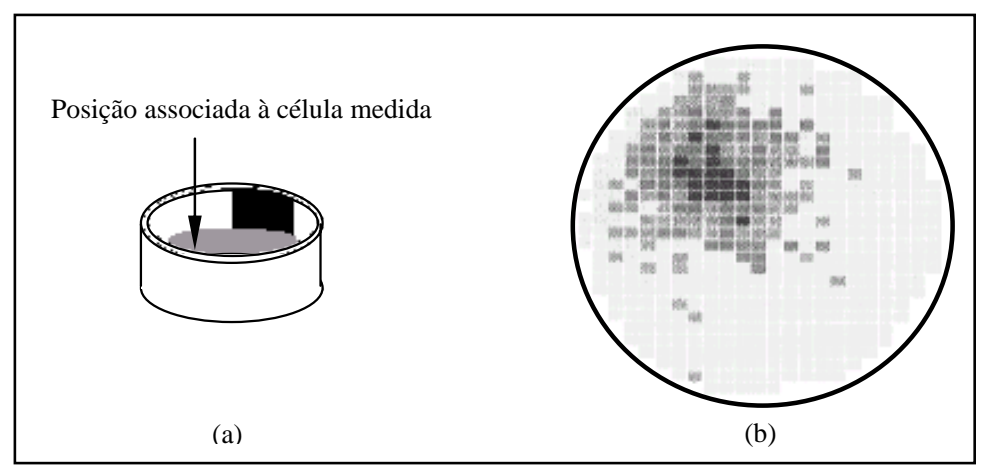

FIGURA 3.3 - (a) Arena circular. (b) Padrão de ativação de uma única célula do hipocampo em cada posição da arena circular (Redish, 1997).

A partir dos dados levantados sobre o comportamento dos disparos das células posicionais, O’Keefe e Burgess (1996) trazem evidências de que a formação dos campos posicionais se baseia em características geométricas do ambiente. As relações espaciais entre células posicionais mudam de ambiente para ambiente (O'Keefe e Conway, 1978; Kubie e Ranck, 1983; Thompson e Best, 1989; Muller e Kubie, 1987) e são estáveis em cada ambiente (Muller et alli, 1987). Thompson e Best (1990) reportam registros de campos posicionais que se mantiveram por meses. Outras características observadas nos campos posicionais:

- Quando o animal atravessa um caminho repetidas vezes, o que geralmente ocorre em ambientes fechados (limitados por paredes), os campos posicionais passam a ser dependentes da direção, isto é, a taxa de disparo da célula posicional correspondente passa a ter dependência com a direção da cabeça do animal (Gothard et alli, 1996). 
Entretanto, em ambientes abertos, as células posicionais não são dependentes da direção (Muller et alli, 1994).

- $\mathrm{O}$ movimento de referências espaciais ${ }^{15}$ produz um movimento correspondente dos campos posicionais (Muller e Kubie, 1987).

- Os padrões de disparo das células posicionais podem ser controlados por referências não visuais (como o tato, por exemplo) (Hill e Best, 1981; Save et alli, 1996): em ratos cegos as células posicionais continuam a fazer associações com os campos posicionais.

- Campos posicionais são modificados se os marcos são movidos, contudo, nestas circunstanciais, as células posicionais continuam a apresentar o mesmo padrão de disparo (Muller e Kubie, 1987; O’Keefe e Speakman, 1987; Pico et alli, 1985; O’Keefe e Conway, 1978).

- Alterações na estrutura do ambiente produzem mudanças nos campos posicionais associados à região do ambiente que sofreu alterações (Muller e Kubie, 1987). Quando uma barreira é adicionada à arena circular (Figura 3.3.a), as taxas de disparo de 9 entre 10 células cujos campos intersectam a barreira diminuem e as demais células vizinhas à barreira aumentam sua taxa de disparo. Ao substituir por uma barreira transparente a barreira original não houve mudanças nos resultados. O efeito apenas ocorreu quando a barreira interferiu com o movimento do rato.

As células piramidais da região CA3 possuem extensivas terminações colaterais recorrentes que fazem sinapses com outras células piramidais, e com neurônios CA3 inibidores (Gulyás et alli., 1993; Arbib et alli, 1998). A partir destas terminações, Muller e colegas (Muller et alli, 1996) argumentam que uma representação do tipo mapa topológico poderia ser construída considerando a potenciação de longo prazo (long-term potentiation - LTP).

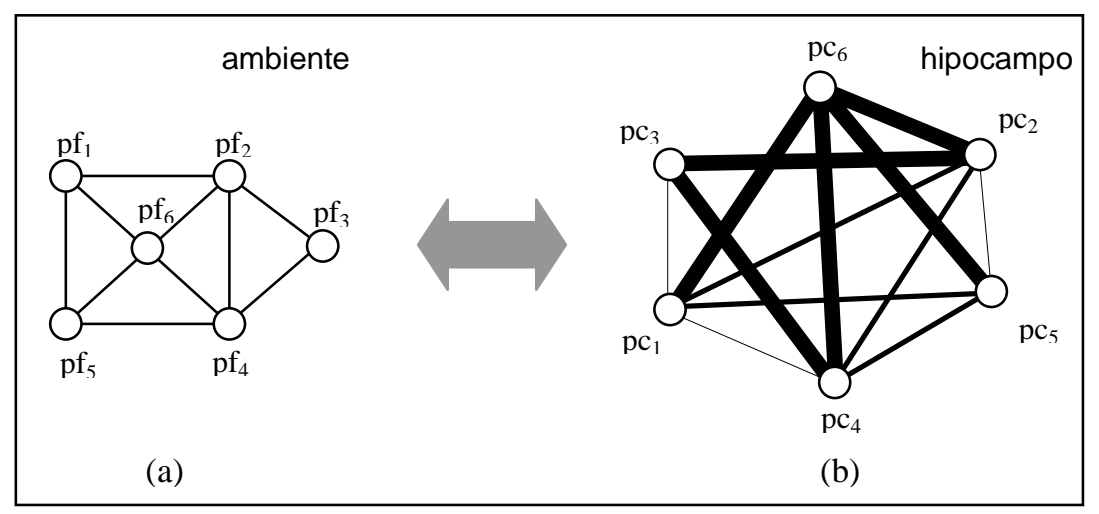

FIGURA 3.4 - (a) Representação topológica de seis campos posicionais em um ambiente. (b) Exemplo da conectividade das seis células posicionais relacionadas aos campos indicados: sinapses conectando pares de células posicionais com campos próximos são fortalecidas (linhas grossas), e sinapses conectando células posicionais com campos posicionais distantes são enfraquecidas (linhas finas).

\footnotetext{
${ }^{15}$ Para se localizar no ambiente, há evidências de que o animal seleciona referências espaciais, como árvores em um ambiente aberto.
} 
Neste sentido, um mapa do ambiente poderia ser armazenado a partir do fortalecimento das sinapses CA3 $\rightarrow$ CA3 que conectam pares de células piramidais/posicionais. Duas razões são usadas em (Muller et alli, 1996) para supor este fortalecimento sináptico:

(1) Duas células representando posições próximas dispararão freqüentemente em um intervalo curto de tempo. Caso estas células estejam conectadas por uma sinapse Hebbiana, os curtos intervalos de tempo entre seus picos de disparo deverão aumentar a força da sinapse.

(2) Duas células representando posições distantes raramente dispararão juntas. Assim, a sinapse Hebbiana que as conecta deve permanecer fraca.

A Figura 3.4 exemplifica como a topologia de um ambiente poderia ser codificada no hipocampo: campos posicionais (pf - place field) espacialmente próximos no ambiente (Figura 3.4.a) não correspondem necessariamente a células posicionais ( $\mathrm{pc}$ - place cell) próximas nos hipocampo, entretanto a intensidade das sinapses (Figura 3.4.b) indicará a distância entre os campos posicionais. Modelos que implementam o mapa cognitivo a partir dos princípios levantados por Muller e colegas (1996) são mostrados na próxima seção.

\subsection{Modelos Computacionais de Mapa Cognitivo}

A implementação computacional das hipóteses sobre mapa cognitivo discutidas na seção anterior deve passar por considerações de ordem prática que permitam garantir que os algoritmos gerados contornem as limitação presentes em AR descritas nas Seções 2.1 e 2.2. Para tal, dois modelos computacionais de mapa cognitivo são comentados nesta seção como forma de levantar caminhos para o algoritmo do agente proposto. Os modelos foram escolhidos por resumirem o que é normalmente encontrado na literatura correlata. O primeiro, proposto por Burgess e colegas (1994), é um dos mais comentados na literatura, possui forte plausibilidade biológica, inspirou outros modelos de navegação como os de Brown e Sharp (1995) e Foster et alli (2000), para citar alguns, e serve para visualizar as vantagens em se usar alguns dos mecanismos do comportamento animal em agentes autônomos. O segundo, Quoy e colegas (2000), está mais próximo da visão de Muller e colegas (1996) do mapa cognitivo como um grafo - mesma abordagem de trabalhos como Trullier e Meyer (2000) e Voicu e Schmajuk (2002).

\subsubsection{O Modelo de Navegação de Burgess et alli (1994)}

Este modelo é uma rede neural de alimentação direta (feedforward) de 5 camadas (Figura 3.5) no qual a estrutura do ambiente é aprendida nas sinapses que ligam as camadas de células EC, PC e SC (Burgess e seus colaboradores criaram estas camadas de células para serem fiéis a camadas presentes no hipocampo). As células GC (goal cells) representam as ações que podem ser tomadas (aqui codificadas como direções norte, sul, leste e oeste). $\mathrm{O}$ aprendizado de qual ação tomar para alcançar a meta a cada posição é feito quando o agente atinge a meta: ao alcançar a meta o agente visualiza 
esta por todas as direções possíveis (ativando as células de direção da cabeça) e as sinapses entre as camadas de células SC e GC são modificadas por uma regra de aprendizagem por reforço. Uma vez atingida a meta e a tarefa de navegar naquele ambiente tenha sido aprendida, quando agente for novamente colocado no ambiente apresentará a cada posição do espaço ativações nas células GC.

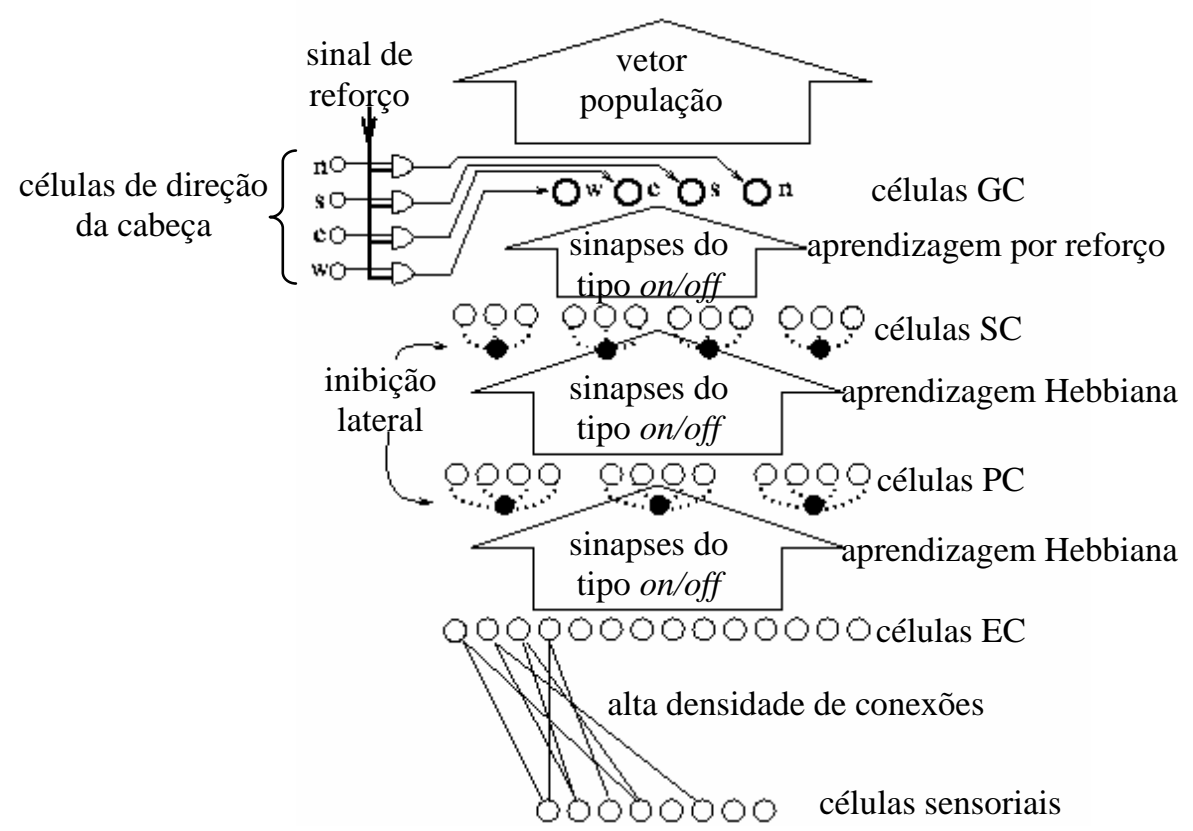

FIGURA 3.5 - Modelo proposto por Burgess et alli (1994) para escolha de ações motoras em uma tarefa de navegação.

A ação a ser tomada será o vetor população que é obtido pela soma, ponderada pelas ativações de GC, das possíveis direções (no caso da Figura 3.5: norte, sul, leste e oeste). Neste modelo, ao se mudar o estado meta basta alterar as sinapses entre as camadas SC e GD, mantendo os pesos das sinapses entre as demais camadas, para aprender como alcançar a nova posição meta - o que corresponde a dizer que é realizado aprendizado latente.

\subsubsection{Modelo de Navegação de Quoy et alli (2000)}

O trabalho de Quoy e colegas (2000) gera trajetórias, em ambientes que podem se modificar ao longo do tempo, visando alcançar diversas posições meta. Para tal, é realizada continuamente a aprendizagem do mapa cognitivo. As arestas entre os neurônios deste mapa são reforçadas (aprendizagem hebbiana associativa) por neurônios associados com posições sucessivas reconhecidas. A regra de aprendizagem é a seguinte:

$$
\frac{d W_{i, j}}{d t}=-\lambda W_{i, j}+\left(1+\frac{d \mathrm{R}}{d t}\right) \cdot\left(1-W_{i, j}\right) \cdot \bar{G}_{i} \cdot G_{j}
$$

sendo: $0<W_{i j}<1$ o peso associado com o fato de que é possível alcançar diretamente a posição $j$ a partir da posição $i, G_{i}$ é a avaliação do neurônio $i ; d \mathrm{R} / d t$ é a variação do sinal de reforço oriundo 
do ambiente; $\bar{G}_{i}$ é um valor que decai com o tempo e serve como uma medida da distância entre $i$ e $j$.

A avaliação $G_{i}$ do neurônio $i$ é dada por um mecanismo de difusão em que a avaliação do neurônio meta $i_{0}$, é inicicializada com 1 e a avaliação dos demais neurônios é inicialmente nula:

$$
G_{i_{0}} \leftarrow 1 \text { e } G_{i} \leftarrow 0, \forall i \neq i_{0}
$$

A difusão destas avaliações iniciais ocorre de forma que, enquanto a atividade da rede não se estabilizar a seguinte atualização é realizada:

$$
G_{j} \leftarrow \max _{i}\left(W_{i, j} \cdot G_{i}\right), \forall j
$$

A seleção das ações é realizada de tal forma que o agente segue o gradiente da atividade do neurônio no mapa cognitivo. Quoy e colegas mostram que esta forma de aprendizagem permite o planejamento de trajetórias tanto em ambientes estacionários quanto em ambientes que mudem com o tempo. Problemas gerados por obstáculos temporários como portas que se abrem e se fecham ao longo do tempo seriam tratados nesta arquitetura pela expressão (3.1): ao se ver impedido de atravessar entre duas posições espaciais barradas por uma porta, o peso $W$ associado à ligação entre estes pontos decairia fazendo com que este trecho passasse a ser evitado pelo agente. Com a adoção de uma regra de atualização da ponderação das arestas (Eq. 3.1), o mapa cognitivo é de fato um mapa auto-organizável mais flexível cuja topologia consegue reproduzir melhor as características topológicas do ambiente.

\subsection{Comportamento Exploratório}

A velocidade alcançada por alguns animais para cobrir largas áreas justifica interesse particular em seus comportamentos exploratórios. Aparentemente aleatório, há heurísticas que podem ser extraídas do estudo do comportamento exploratório.

\subsubsection{Exploração do Predador (Linhares, 1998)}

Um predador inicialmente explora o ambiente de maneira a cobrir a maior área possível. Entretanto, quando confrontado com uma presa, o predador imediatamente muda seus padrões de movimento, reduzindo seu passo, movimentando-se em torno da vizinhança do ponto de captura da presa. Este comportamento é aparentemente motivado pelo conhecimento instintivo de que suas presas andam em bando. Assim, o surgimento de uma primeira presa induz o predador a restringir sua área de exploração como forma de selecionar um animal do grupo que possa ser capturado com o menor esforço e/ou abater o maior número possível de animais. A partir deste comportamento, Linhares (1998) estabeleceu duas premissas para descrever a exploração do predador: 
- Premissa 1: O predador move-se extensivamente sobre o espaço de busca usando a informação que esteja disponível para estabelecer as direções de busca. Caso observe uma presa, o predador segue a Premissa 2.

- Premissa 2: Em seguida à detecção da presa, o predador intensifica a busca na vizinhança. Esta área de busca é gradualmente aumentada, caso nenhuma outra presa seja observada, o predador retorna à Premissa 1.

Linhares (1998) faz referência a Smith (1974) para justificar a eficiência e adaptabilidade da estratégia de restrição de área - para diversos habitats e distribuição de presas, o tempo dispensado com esta estratégia de exploração é proporcional ao número de presas na área de exploração. A forma com que o predador realiza a busca é interessante para cobrir vastas áreas com o objetivo de capturar presas. Entretanto, quando a meta da exploração é aprendizagem espacial, outra fonte de motivação deve existir.

\subsubsection{Comportamento Exploratório de Tchernichovski et alli (1998)}

Tchernichovski e colegas (Tchernichovski et alli, 1998), (Tchernichovski e Benjamini, 1998) sugerem que o comportamento exploratório seja governado por parâmetros associados com os conceitos de motivação e não-familiarização. O comportamento exploratório é descrito como excursões regulares que partem de posições espaciais preferenciais, denominadas bases domésticas (bome bases) (Tchernichovski et alli, 1998), no ambiente - posições no espaço em que os animais despendem grandes intervalos de tempo quando exploram um ambiente (Chance e Mead, 1955; Golani et alli, 1993). O processo de crescimento da excursão seria um reflexo da diminuição do parâmetro não-familiarização do animal com o ambiente.

A base doméstica neste modelo seria um ponto de mínimo de não-familiaridade, e as demais posições do espaço possuiriam um nível de não-familiaridade proporcionalmente crescente com a distância para a base. $\mathrm{O}$ animal se mantém motivado quando está na base doméstica, e quando começa uma excursão. Assim, conforme o animal passa por outras posições do espaço o parâmetro motivação decai proporcionalmente ao nível de não-familiaridade associado àquela posição. Uma vez que toda a motivação tenha desaparecido, o animal retorna à base onde a não-familiaridade é mínima, e a motivação é máxima, antes de começar uma nova excursão (Tchernichovski e Benjamini, 1998). Quanto à velocidade do animal, esta muda em conformidade com o aumento do tamanho da excursão e do nível de não-familiaridade do rato com as posições do ambiente: o padrão primitivo da velocidade consiste de lenta progressão enquanto o animal se afasta da base doméstica, e rápida progressão quando retorna a ela.

\subsection{Premissas para o Agente a ser Proposto}

Os temas discutidos neste Capítulo não devem ser tomados como fenômenos a serem simulados de 
maneira fiel à sua versão biológica, mas sim como uma referência que ajude a: (i) esclarecer quais informações devem ser aprendidas pelo agente, (ii) como estas informações podem ser codificadas e (iii) heurísticas para coletar de forma rápida estas informações.

Uma primeira observação interessante que o estudo do comportamento animal trouxe é a de que a solução de um problema de aprendizagem direcionada à meta (como o PARDM) começar a ser traçada antes mesmo do agente conhecer o estado meta - o aprendizado latente (Tolman, 1948) é a evidência disto. O funcionamento das células do hipocampo traz certa luz sobre o tema: este aprendizado aparentemente é local, tendo em vista a extensão da influência causada pela inclusão de uma barreira nos campos espaciais descrita por Muller e Kubie (1987) e estaria baseado em campos posicionais (Subseção 3.1.1) envolvidos na representação da informação necessária à navegação. Há indícios de que haja informação vetorial na representação do ambiente (a informação das células posicionais associada à informação das células de direção de cabeça poderiam ser utilizadas de forma semelhante a vetores aplicados a posições do espaço) e o gasto computacional envolvido no aprendizado espacial é aparentemente baixo. As indicações apontam que os campos posicionais sejam estabelecidos a partir de características geométricas do ambiente - este formato justifica considerar estas células para representação topológica do ambiente (Muller et alli, 1996).

Dos modelos estudados de mapa cognitivo, Burgess et alli (1994) e Quoy et alli (2000), percebese que o uso de aprendizagem hebbiana para a intensidade das sinapses tende a tornar o aprendizado do modelo de Burguess mais lento que o de Quoy que utiliza um mecanismo de difusão. O dimensionamento destes modelos, a quantidade de neurônios a serem utilizados, não é muito claro e na operação de um ambiente inicialmente desconhecido pode tornar-se um problema - assim, torna-se desejável que o mapa tenha um crescimento incremental. Para tal, a ocorrência de associação ativa entre estímulo e ação no agente permite selecionar estímulos considerados para construção de mapas cognitivos. Esta estratégia pode levar a se cogitar que o agente aprenda apenas quando necessário, por exemplo, apenas quando encontrar obstáculos no caminho.

$\mathrm{Na}$ exploração do ambiente, uma contribuição interessante do estudo de comportamento animal foi o estabelecimento de princípios da interação do rato com o ambiente que obedecem uma dinâmica governada por parâmetros associados com os conceitos de motivação e familiarização para a determinação das ações (Tchernichovski et alli, 1998; Tchernichovski e Benjamini, 1998).

As maneiras para fazer uso das premissas levantadas neste capítulo são apresentadas no Capítulo 5 visando contornar limitações comumente observadas nos atuais algoritmos AR. O próximo capítulo comenta sobre alguns destes algoritmos fazendo uma revisão geral daqueles que mais se adequam ao problema desta pesquisa. 


\section{Capítulo 4}

\section{Abordagens para Acelerar a Solução do PARDM}

A partir do levantamento em comportamento animal do Capítulo 3, colocou-se o fenômeno da aprendizagem latente como uma importante fonte de inspiração para a aceleração do PARDM: mapas cognitivos estariam envolvidos na representação do ambiente e teriam papel de destaque na rápida aprendizagem observada em ratos. $\mathrm{Na}$ literatura de $\mathrm{AR}$, representações do tipo mapa também vêm sendo utilizadas - abordagens que combinam AR e mapas auto-organizáveis têm despertado o interesse de muitos pesquisadores (Großmann, 2001; Smith, 2001; Prescott, 1994; Touzet, 1997; Quoy et alli, 2000; Milán et alli, 2002; Smith, 2002; Murao e Kitamura, 1998) e gerado implementações em problemas do mundo real, principalmente em robótica, que permitiram ao agente AR aprender autonomamente uma tarefa em um ambiente desconhecido, adaptando-se às mudanças ambientais (Althoefer et alli, 2001; Johannet e Sarda, 1999). Os objetivos deste Capítulo são (i) fornecer uma visão geral das abordagens para a aceleração do PARDM, (ii) situar o leitor da relevância e atualidade dos caminhos adotados na proposta do $A T A R$ e (iii) elencar novas premissas para o $A T A R$ a partir das capacitações e limitações de estudos de casos.

A Seção 4.1 apresenta dois grandes grupos de abordagens para o aumento da velocidade da aprendizagem em agentes AR (Peng e Williams, 1996; Rummery, 1995; Wiering e Schimidhuber, 1998a; Tesauro, 1995; Touzet, 1997; Moore e Atkeson, 1993; Peng e Williams, 1993; Sutton, 1991; Lin, 1993; Mahadevan e Connell, 1992; Mataric, 1994, entre outras). Destas abordagens, a linha de pesquisa que relaciona AR com mapas auto-organizáveis é tratada na Seção 4.2 sob a forma de estudos de casos. Um breve levantamento sobre estratégias de exploração adotadas em AR é apresentado na Seção 4.3, e a Seção 4.4 encerra este Capítulo resumindo os principais pontos tratados e relacionando quais destes pontos são desejados no agente proposto desta pesquisa.

\subsection{Aumento na Velocidade da Aprendizagem por Reforço}

De forma geral, Wyatt (1997) argumenta que há basicamente duas opções para melhorar a velocidade do aprendizado: 
- Simplificar o processo de assinalação temporal de crédito. Esta opção inclui: (i) métodos que decomponham a tarefa (Singh, 1992) e (ii) a construção de funções de reforço melhores (Mataric, 1994).

- Acelerar o processo de assinalação temporal de crédito do agente. Esta opção tem se concretizado em duas linhas: (i) trabalhar com mecanismos de traço mais efetivos (Cichosz, 1995) e (ii) trabalhar no uso de métodos de generalização (Tesauro, 1995).

As duas próximas subseções tratam destas opções, descrevendo abordagens para a implementação de cada uma delas. A Subseção 4.1.3 encerra com comentários sobre a opção selecionada para o $A T A R$.

\subsubsection{Simplificação do Processo de Assinalação Temporal de Crédito}

A assinalação mais simples de crédito decorre de maior conhecimento sobre a tarefa a ser realizada e/ou o ambiente de trabalho.

\section{Decompondo a Tarefa}

Decompor uma tarefa em subtarefas menores pode levar à redução da complexidade do problema (Newell e Simon, 1972 e Korf, 1985). Trabalhos como os de Mahadevan e Connell (1992); Lin (1992, 1993); Humphrys (1995); Kalmár et alli (1998) seguiram esta estratégia para a proposição de soluções em AR. Tais algoritmos guardam semelhanças com a arquitetura de especialistas locais proposta por Jacobs et alli (1991) - o espaço de trabalho é dividido em regiões, e um mecanismo de seleção aprende a indicar qual "especialista" é mais adequado para operar em cada região. Humphrys (1996) lista maneiras de implementar algoritmos AR em que os especialistas e o mecanismo de seleção são agentes de Aprendizagem- $Q$ :

- Aprendizagem-Q hierárquica: Lin (1993) sugeriu a utilização de uma coleção de agentes de Aprendizagem- $Q, A_{1}, A_{2}, \ldots A_{n}$ para aprender subtarefas em conjunto com um outro agente de Aprendizagem- $Q$ que aprende qual agente $i$ deve ser chamado para cada estado $s$ (este aprendizado é armazenado na função de avaliação $Q(s, a)$ ). Há sinais de reforço "personalizados" que são utilizados no aprendizado de cada um dos agentes AR especialistas, e uma função de reforço global que serve para aprender $Q(s, a)$.

- Aprendizagem- W (minimização da pior penalização): Humphrys (1995) propõe que os agentes AR se auto-organizarem na ausência de um sinal de recompensa global por acordo mútuo: dado um estado $s$, cada agente indica uma ação a ser tomada e estas são ponderadas por pesos $W_{i}(s)$. Um vencedor $k$ é escolhido tal que:

$$
W_{k}(s)=\max _{i \in 1, \ldots, n} W_{i}(s)
$$

e a ação $a$ associada ao agente $k$ é executada e os pesos $W_{i}(s)$ são modificados conforme as repercussões da execução desta ação. Uma variação seria considerar a ponderação $W$ como 
sendo a própria função de avaliação $(W=Q)$. Humphrys (1995) comenta que a principal diferença na escolha da ponderação vem de que ao se tomar uma função $W$ busca-se maximizar o retorno global enquanto ao utilizar a própria função de avaliação $Q$ maximizase apenas o retorno esperado do agente que toma a ação.

- Maximização da premiação coletiva: Este método é apenas citado por Humphrys (1995) que explica não possuir nenhum resultado empírico que justifique esta abordagem. Caso se considere, de forma generalizada, que a soma das recompensas dos agentes é o critério a ser maximizado e os agentes possuam o mesmo conjunto de ações, então a escolha da ação para um estado $s$ deve tomada de forma a satisfazer:

$$
\max _{a \in A}\left[\sum_{i=1}^{n} Q_{i}(s, a)\right]
$$

Para um grande número de agentes, essa abordagem coletiva é provavelmente inadequada (nas palavras de Humphrys, 1995): "O agente final combinado estará sempre realizando ações seguras (já conbecidas), evitando a exploração do ambiente (que poderia ser apontada por uma minoria de agentes que tenderiam a ser cada vez menos considerados)".

Em problemas com um espaço $S \mathrm{x} A$ grande, o princípio de "dividir-para-conquistar" pode ser muito interessante para acelerar a aprendizagem de agentes AR. Entretanto, sinais de reforço mais informativos seriam necessários para: (i) determinar como a seleção dos especialistas deve ocorrer e (ii) treinar os especialistas AR nas particularidades de sua região de atuação.

\section{Melhores Funções de Reforço}

Nos métodos AR, a função de reforço é a única fonte de informação do agente para aprender sua tarefa. Assim, Mataric (1994) argumenta que, para melhorar a velocidade de aprendizagem em AR, considerações devem ser feitas para tornar as funções de reforço mais informativas. Tais considerações podem ser resumidas na adoção das seguintes providências:

- Evitar reforços únicos e adotar reforços múltiplos: Agentes que atuam em ambientes reais geralmente possuem diversas metas a serem satisfeitas. Associar a cada uma destas metas sinais de reforço permitiria uma maior densidade de sinais de reforço não nulos. Este esquema é chamado de função de reforço heterogênea.

- Usar estimadores de progresso: Caso sejam necessárias seqüências complexas de ações para o cumprimento de cada uma das metas do agente, os sinais de reforço podem sofrer muitos atrasos (delays) e as funções de reforço heterogêneas perdem sua eficácia pois voltam a ser informação esparsa para o agente. Nestes casos, a adoção de uma medida do progresso do agente é interessante para evitar esta esparsidade. Tais medidas seriam fornecidas pelo que Mataric (1994) denomina de estimadores de progresso: associados a 
metas específicas, estimadores indicariam uma medida da melhoria relativa do agente para o cumprimento destas metas.

Trabalhos como os de Koenig e Simmons (1996) e Santos e Touzet (1999) vêm contribuindo para trazer maior rigor teórico para o uso de funções de retorno heterogêneas e estimadores de progresso. Entretanto, os critérios para a melhoria das funções de reforço ainda são muito empíricos e dependentes da tarefa a ser executada pelo agente AR.

\subsubsection{Aceleração do Processo de Assinalação Temporal de Crédito}

A assinalação mais rápida de crédito utiliza mecanismos que permitam atualizar em uma única iteração do agente AR a avaliação de diversos estados, ou pares estado-ação.

\section{Traços de Elegibilidade}

Maior rapidez na assinalação temporal de crédito pode ser obtida caso, a cada instante de tempo $t$, sejam atualizadas as avaliações de diversos estados e não apenas a avaliação do estado atual. Entretanto, uma única medida de erro é obtida a cada instante $t$ :

$$
\text { Erro_TD }(t)=r_{t+1}+\gamma V_{t}\left(s_{t+1}\right)-V_{t}\left(s_{t}\right)
$$

Para se obter uma indicação de como este erro pode ser considerado para a atualização dos demais estados utilizam-se os traços de eligibilidade, $e_{t}(s)$, (Barto et alli, 1983; Sutton e Barto, 1998):

$$
e_{t}(s)=\sum_{k=1}^{t}(\lambda \gamma)^{t-k} \delta_{s, s_{k}}, \text { sendo } \delta_{s, s_{k}}=\left\{\begin{array}{l}
1, \text { caso } s=s_{k} \\
0, \text { caso contrário }
\end{array}\right.
$$

A elegibilidade de um estado $s$ é uma medida de quanto este foi visitado em seu passado recente (Kaelbling et alli, 1996). Os estados que tenham sido visitados mais recentemente terão maior influência do Erro_TD(t) na atualização de suas avaliações. A Equação (4.4) é normalmente implementada incrementalmente de maneira que:

$$
e_{t}(s)= \begin{cases}\gamma \lambda e_{t-1}(s), & \text { se } s \neq s_{t} \\ \gamma \lambda e_{t-1}(s)+1, & \text { se } s=s_{t}\end{cases}
$$

e a atualização das avaliações dos estados passa a ser calculada por:

$$
\Delta V_{t}(s)=\alpha * E_{1} r{ }_{-} T D(t) * e_{t}(s), \text { para todo } s \in S
$$

Os traços de elegibilidade podem também ser utilizados com pares estado/ação, Equação (4.7), gerando algoritmos como o $S A R S A(\lambda)$ (Rummery, 1995) e a Aprendizagem-Q( $(\lambda)$ (Watkins, 1989).

$$
\Delta Q_{t}(s, a)=\alpha * E r o_{-} T D(t) * e_{t}(s) \text {, para todo } s \in S, a \in A
$$

O ganho de velocidade obtido com as Equações (4.6) e (4.7), entretanto, tem alto custo computacional (Kaelbling et alli, 1996; Cichosz, 1995; 1997). Este custo torna inviável a aplicação direta desta técnica a problemas reais, e um caminho para reduzi-lo é restringir o conjunto de 
estados (ou pares estado-ação) que terão suas avaliações atualizadas. A Aprendizagem- $Q(\lambda)$ de Peng e Williams (1996) e a Aprendizagem-Q( $\lambda$ ) rápida de Wiering e Schimidhuber (1998a) são exemplos de algoritmos que reduzem o esforço computacional ao aplicar a Equação (4.7) não mais sobre o conjunto $S \times A$, mas sobre uma lista $H$ em que não são incluídos os pares estado-ação cujos traços de eligibilidade sejam muito baixos e levariam a atualizações desprezíveis de suas avaliações. Os resultados obtidos com a Aprendizagem-Q( $(\lambda)$ rápida em aplicações on-line são muito promissores, conforme pode ser visto no estudo realizado por Bhanu et alli (2001) em um robô móvel. O modelo de Wiering e Schimidhuber posterga a atualização das avaliações-Q, até que elas sejam necessárias, com base em que as avaliações- $Q$ necessárias a cada instante são apenas aquelas relativas às possíveis ações partindo do estado atual. Tal adiamento causa significativa redução no esforço computacional aliada ao aprendizado mais rápido.

Apesar dos relevantes avanços, as implementações do mecanismo de traços de elegibilidade ainda são muito dependentes do uso de tabelas para o armazenamento dos traços. Logo, em problemas nos quais o espaço $S \mathrm{x} A$ seja muito grande, como em robótica, esta dependência dificulta sua aplicação prática.

\section{Métodos de Generalização}

Em geral, os processos reais possuem um conjunto grande de estados, e as implementações discretas de algoritmos AR costumam ter convergência do aprendizado extremamente lenta devido ao grande número de parâmetros a serem ajustados: os elementos da tabela que armazena a função de avaliação. Muitos autores (Tesauro, 1995; Crites e Barto, 1996; Tsitsiklis e Van Roy, 1997; Samejima e Omori, 1999; Milán et alli, 2002; Smith, 2002, entre outros) vêm utilizando aproximadores de funções, em especial redes neurais, para reduzir o número de parâmetros necessários para codificar o conhecimento armazenado por um agente AR e obter, em conseqüência, a aceleração do aprendizado desses algoritmos. A forma mais comum de utilizar redes neurais em AR é na aproximação da função de avaliação ${ }^{16}$, aproveitando diretamente o erro TD no cálculo da atualização dos pesos $w$ da rede:

$$
\Delta w=-\alpha\left(r+\gamma V\left(s_{t+1}\right)-V\left(s_{t}\right)\right)\left(-\frac{\partial}{\partial w} V\left(s_{t}\right)\right)
$$

ou, seguindo a proposta de Baird (1999), considera-se o "resíduo médio quadrático de Bellman" para a atualização dos pesos da rede que leva à expressão:

$$
\Delta w=-\alpha\left(r+\gamma V\left(s_{t+1}\right)-V\left(s_{t}\right)\right) \cdot\left(\frac{\partial}{\partial w} \gamma V\left(s_{t+1}\right)-\frac{\partial}{\partial w} V\left(s_{t}\right)\right)
$$

\footnotetext{
${ }^{16}$ Há abordagens que tentam solucionar o problema de Aprendizagem por Reforço aproximando diretamente a política ótima (Baxter e Barlett, 1999), sem passar pela aproximação da função de avaliação.
} 
Para redes com unidades de saída lineares ${ }^{17}$ como as RBFs (Haykin, 1999), há provas de convergência do aprendizado da função de avaliação (Tsitsiklis e Van Roy, 1997): o Teorema da Contração (Khalil, 1996) pode ser aplicado sobre a atualização dos pesos deste tipo de rede demonstrando que estas convergem para um ponto fixo. Para o caso geral, em que há uma nãolinearidade na camada de saída, resultados práticos (Tsitsiklis e Van Roy, 1996; Gordon, 1995; Baird, 1995; Boyan e Moore, 1995) mostram que a utilização de redes neurais, mesmo em tarefas muito simples, podem levar à divergência do aprendizado ou à oscilação da política aprendida.

\subsubsection{Comentários sobre a Opção Adotada para a Assinalação de Crédito}

As abordagens com assinalação temporal de crédito mais simples costumam exigir maior interferência do projetista - a simplificação ocorre em grande parte graças ao conhecimento que este possui do problema específico a ser tratado. $\mathrm{Na}$ decomposição do problema $\mathrm{AR}$, o projetista é usualmente quem define, antes do aprendizado, a arquitetura dos "especialistas", se o mecanismo de seleção será fixo e se cada "especialista" compreende um comportamento pré-definido. $\mathrm{Na}$ estratégia de melhoria da função de reforço, o estabelecimento de um sinal de reforço mais informativo também fica normalmente a cargo do projetista. As abordagens com assinalação temporal de crédito mais rápida utilizam mecanismos que possibilitam a atualização das avaliações (Eqs. 2.1 e 2.2) do maior conjunto possível de estados, ou pares estado-ação, a cada interação agente-ambiente. Os traços de elegibilidade permitem uma ponderação para a correção da avaliação de todos os pares estado-ação, a partir de um único erro TD (Eq. 4.3). A generalização permite agrupar pares estado-ação e realizar avaliações sobre estes grupos, e não mais sobre cada par, reduzindo assim o espaço de trabalho.

Tendo em vista a natureza do problema descrito no Capítulo 2, o desconhecimento inicial do ambiente dificulta o trabalho do projetista de uma abordagem por assinalação temporal de crédito mais simples, tornando abordagens com rápida assinalação temporal de crédito mais adequadas para o levantamento de premissas a serem usadas no agente proposto. Assim, acrescenta-se às premissas desejadas para o agente proposto uma combinação das características dos traços de elegibilidade e dos métodos de generalização: (i) mecanismo de atualização da avaliação de múltiplos pares estado-ação a partir de uma única medida de erro e (ii) redução do espaço de trabalho a partir do agrupamento de estados ou pares estado-ação.

A visão voltada para trás (backward view), comentada em (Sutton e Barto, 1998) para descrever os traços de elegibilidade, será incorporada ao ATAR - no Capítulo 5 se detalhará como foi realizada a implementação. Da generalização, há diferentes arquiteturas de redes neurais que já foram utilizadas em AR, perceptron de múltiplas camadas, redes RBF, redes CMAC, redes recorrentes, mapas auto-organizáveis (SOM - Self-Organizing Map), e a questão é qual adotar para o agente proposto. Dada a premissa levantada no Capítulo 3 de incorporar aprendizagem latente ao

${ }^{17}$ Estas redes são caracterizadas pela camada de saída ser uma combinação linear de funções de base. 
agente proposto como forma de acelerar seu aprendizado, adotou-se os mapas auto-organizáveis para o armazenamento da função de avaliação do agente por terem certos paralelos com a concepção de mapas cognitivos proposta por Muller et alli, 1996 (ver Subseção 3.1.1) e por também permitirem aprendizagem incremental e rápida. A próxima seção realiza um resumo de alguns dos trabalhos que já utilizaram SOM em AR, comentando os ganhos conseguidos e as limitações que devem ser contornadas pelo $A T A R$.

\subsection{Mapas Auto-Organizáveis em Aprendizagem por Reforço}

Muitos trabalhos recentes vêm utilizando SOM para implementar agentes AR, a grande maioria com aplicações em robótica móvel (Prescott, 1994; Touzet, 1997; Murao e Kitamura, 1998; Quoy et alli, 2000; Großmann, 2001; Smith, 2001; Milán et alli, 2002; Smith, 2002). Uma das características marcantes desta arquitetura de rede neural é sua capacidade de preservar a topologia do espaço de entrada. Em AR, esta característica permite realizar o aprendizado sobre uma representação compacta do espaço de entrada em que as transições entre regiões deste espaço podem ser preservadas; ou seja, a solução de um PDM pode ser aproximada a partir de um PDM menor que, em princípio, está menos susceptível às maldições da dimensionalidade (Bellman, 1957) e da modelagem (Bertsekas e Tsitsiklis, 1996).

Diferentes aspectos podem ser analisados nas implementações existentes de SOM com AR para extrair pontos a serem perseguidos e evitados no agente proposto. Destaque será dado à forma de construção do mapa - a Subseção 4.2.1 trata de trabalhos que utilizam o modelo originalmente proposto por Kohonen e a Subseção 4.2.2 de trabalhos que utilizam modelos derivados do SOM original que podem variar a estrutura do mapa. Os exemplos expostos nestas subseções representam um resumo da literatura correlata, e servem para o levantamento das premissas do agente discutidas na Subseção 4.2.3.

\subsubsection{O Mapa de Kohonen Original}

No modelo original do mapa auto-organizável de Kohonen (1984) utiliza-se uma grade $M$ discreta de neurônios/vértices, de dimensão $m$ (freqüentemente, $m=2$ ) cujo número de vértices ${ }^{18}$ e as $\operatorname{arestas}^{19}$ que conectam estes vértices são definidos pelo projetista. Cada vértice desta grade recebe um índice $n$ e possui um vetor de pesos, $\boldsymbol{w}_{n}$ a ele associado que pertence ao espaço de entrada $S$. A resposta de um SOM a um vetor de entrada $\boldsymbol{s}$ é o vértice $n^{*}$ vencedor cujo vetor de referência $\boldsymbol{W}_{n}{ }^{*}$ esteja mais próximo da entrada $\boldsymbol{s}$, conforme o seguinte critério:

$$
n^{*}=\underset{\forall n \in M}{\arg \min }\left\|\mathbf{w}_{n}-\mathbf{s}\right\|
$$

\footnotetext{
${ }^{18}$ No contexto desta tese, os termos vértices, nós e neurônios são tratados como sinônimos.

${ }^{19}$ No contexto desta tese, os termos arestas e conexões são tratados como sinônimos.
} 
A distribuição dos vetores referência, ou "pesos" $\boldsymbol{w}_{h}$, é realizada iterativamente por uma seqüência de treinamento sobre vetores $\boldsymbol{s}$ do espaço de entrada. Este treinamento se processa de tal forma que a cada vez que é encontrado o vértice $n^{*}$ para uma determinada entrada $\boldsymbol{s}$ todos os vetores de referência são atualizados por uma regra de atualização do tipo:

$$
\Delta \mathbf{w}_{n}=\alpha \Lambda\left(n, n^{*}\right)\left(s-\mathbf{w}_{n}\right), \quad \forall n \in M
$$

sendo $\alpha$ a taxa de aprendizagem que decai no decorrer do treinamento e $\Lambda\left(n, n^{*}\right)$ uma função de vizinhança que é igual a 1 quando $n=n^{*}$ e decai com a distância para o nó $n^{*}$ (Hertz et alli, 1991). Além da redução da dimensão do problema, ao realizar o mapeamento topográfico do espaço de entrada, autores tiram vantagem da utilização do SOM em AR ao aproveitar a função de vizinhança na atualização da função de avaliação como nos casos de estudo que são abaixo descritos: Touzet (1997) e Smith (2001).

\section{ESTUDO DE CASO: Q-Kohon (Touzet, 1997)}

Em seu trabalho de 1997, Touzet utiliza o mapa auto-organizável clássico de Kohonen (número de neurônios e arestas entre estes pré-estabelecidos) para auxiliar um robô Khepera a aprender por aprendizagem por reforço a tarefa de desvio de obstáculos, e reporta ganho na velocidade de aprendizagem de 40 vezes em comparação com os piores resultados das demais versões de Aprendizagem- $Q$ por ele implementadas. O modelo, denominado de Q-KOHON, é bastante simples: durante a fase de aprendizagem, os neurônios do mapa auto-organizável aproximam a função densidade de probabilidade do espaço de estados (as entradas da rede) e servem como uma memória associativa para armazenar o trio estado, ação e avaliação Q. O aprendizado é realizado incrementalmente: a cada ação a do robô, a partir de um estado s, há a seleção de uma unidade $n$ do mapa auto-organizável $M$ pela distância:

$$
d(n)=\left|\mathbf{s}-\mathbf{w}_{s, n}\right|+\left|\mathbf{a}-\mathbf{w}_{a, n}\right|
$$

os vetores referência associados ao estado, $\mathbf{w}_{s, n}$, e à ação, $\mathbf{w}_{a, n}$, da unidade $n$ são atualizados pelas Eqs. (4.13) e (4.14), e a avaliação Q associada a este par estado-ação é atualizada pela Eq. (4.15):

$$
\begin{gathered}
\mathbf{w}_{s, n}(t+1)=\mathbf{w}_{s, n}(t)+\lambda \cdot\left(\mathbf{s}_{t}-\mathbf{w}_{s, n}(t)\right) \\
\mathbf{w}_{a, n}(t+1)=\mathbf{w}_{a, n}(t)+\lambda \cdot\left(a_{t}-\mathbf{w}_{a, n}(t)\right) \\
Q_{t+1}(s, a)=Q_{t}(s, a)+\beta \cdot\left(r+\gamma \cdot \max _{a^{\prime}}\left(Q_{t}\left(s^{\prime}, a^{\prime}\right)\right)-Q_{t}(s, a)\right)
\end{gathered}
$$

As unidades vizinhas a $n$ também são atualizadas, seguindo a idéia de agrupamentos de estados por "similaridades sintáticas" e localidade do trabalho de McCallum (1992), utilizando um coeficiente de aprendizagem, $\lambda$, menor que o utilizado para atualizar os vetores de $n$. 
A seleção da melhor ação $a$ é realizada identificando-se a unidade $n$ que apresente a menor distância do vetor referência $\mathbf{w}_{s, n}$ para o estado $\mathbf{s}$ observado e do vetor referência associado à avaliação do par estado-ação, $\mathbf{w}_{Q, n}$, para o valor +1 :

$$
d(n)=\left|\mathbf{s}-w_{s, n}\right|+\left|1-w_{Q, n}\right|
$$

a ação $a$ associada a este neurônio $n$ é considerada a melhor ação e executada pelo robô.

O Q-KOHON é talvez a forma mais simples e direta de combinar SOM e AR e, por isso, uma das melhores formas de observar a principal vantagem desta combinação: o ganho na velocidade de aprendizagem pela generalização sobre pares estado-ação similares dados pelas vizinhanças presentes no mapa. Duas limitações podem ser destacadas deste modelo: (i) a função vizinhança adotada considera apenas os quatro neurônios vizinhos, o que restringe a quantidade de unidades cujas avaliações são atualizadas a cada iteração do algoritmo e (ii) a estrutura fixa de conexões entre os vértices do mapa faz com que o SOM não possa preservar a topologias mais complexas, como os labirintos muito presentes em aplicações de robótica móvel.

\section{ESTUDO DE CASO: Smith (2001)}

O modelo de Smith (2001) trata, entre outros problemas, do desvio de obstáculos de um robô móvel utilizando duas redes SOM: a primeira, chamada de mapa de entrada (the input map) está relacionada com o espaço de estados e se adapta na maneira usual do SOM em resposta a cada vetor de estado. Assim, o espaço de estados estará representado com maior resolução nas regiões mais ativas do espaço. A segunda rede SOM, chamada de mapa de ações (the action map), está relacionada com o espaço de ações e tem sua representação deste espaço construída através de exploração que, por tentativa e erro, busca descobrir quais ações contribuem com maior sinal de reforço para o conjunto das entradas observadas. Para realizar esta exploração, o seguinte algoritmo é usado:

1. Para cada vetor de estado, a unidade do mapa de entrada com menor distância Euclidiana para este vetor de estado é identificada como a vencedora.

2. Uma das unidades do mapa de ação é selecionada de acordo com o critério usual da Aprendizagem-Q (política $\varepsilon$-greedy). $\mathrm{O}$ vetor de peso associado com esta unidade de ação ganhadora é então usado como base para a ação avaliada a ser tomada, isto é, o vetor de pesos desta ação codifica a ação proposta (proposed action). Tal ação sofre interferência de um ruído aleatório formando a ação perturbada (perturbed action), a qual será a saída para o agente AR.

3. Caso o sinal de reforço recebido ao realizar a ação perturbada seja maior que o reforço esperado associado com o par estado-ação ganhador, então a exploração no mapa parece ter sido bem sucedida e o mapa de ação é atualizado na direção da ação perturbada. Caso contrário, nenhum aprendizado ocorre no mapa de ação. Nos dois casos, a avaliação $Q$ do par estado-ação vencedor é atualizada pela regra normal da Aprendizagem-Q. Entretanto, Smith 
busca usar a característica de preservação da topologia do SOM para que as unidades da vizinhança de entrada tendam a manter estimativas similares da função de avaliação para as unidades da vizinhança de ação. Com isto, uma simples correção não afeta a atualização apenas da avaliação $\mathcal{Q}$ do par estado-ação vencedor, mas implicará na atualização de todos os pares estado-ação proporcionalmente ao produto das duas funções de vizinhança (dos mapas de entrada e de ação). Smith chama esta vizinhança de viz̧inhança da Aprendizagem- $Q$ (neighboubood Q-learning).

$\mathrm{O}$ algoritmo de Smith pode ser interpretado como uma Aprendizagem- $Q$ padrão com estados discretos sendo representados por unidades dinâmicas do mapa de entrada (residindo no espaço de estados), e as ações discretas sendo representadas pelas unidades dinâmicas do mapa de ações (residindo no espaço de ação). Entretanto, algumas características interessantes surgem desta nova implementação da Aprendizagem-Q: (i) redução do espaço de estados devido à quantização realizada pelo mapa de entrada; (ii) não se faz uso de um conjunto fixo de ações, o mapa de ação aleatoriamente explora o espaço de ações com atualizações que favorecem a descoberta das ações que melhoram o desempenho do agente e (iii) a atualização das avaliações de todos os pares estadoação pode ocorrer a cada instante com o auxílio das funções vizinhanças das unidades vencedores dos mapas de entrada e de ação. Diferente de Touzet (1997), Smith utiliza uma função de vizinhança para a atualização da função de avaliação que cobre todas as unidades do mapa (passo 3 do algoritmo) - o que permite que todas as avaliações das unidades sejam atualizadas a cada iteração do algoritmo, ganhando maior velocidade no aprendizado. Entretanto, ainda permanece neste modelo a limitação decorrente da adoção de uma estrutura fixa de conexões entre os vértices do mapa: o algoritmo pode não operar adequadamente em ambientes com topologias mais complexas.

\subsubsection{Redes de Representação da Topologia}

Para obter mapeamentos que preservassem mais precisamente a topologia do espaço de entrada, Martinetz e Schulten (1994) propuseram a aprendizagem hebbiana competitiva. Nela as arestas que conectam os vértices de $M$ passam a ser aprendidas a partir de uma regra "o vencedor leva tudo" (winner-take-all) fazendo com que os vértices mais próximos do estímulo $\xi \in S$ sejam interligados por uma aresta. Fritzke (1994) também contribuiu para a melhoria das redes de representação da topologia, com sua rede GCS (Growing Cell Structure), ao propor que os vértices da grade $M$ possam ser criados ou podados buscando satisfazer um critério de desempenho estabelecido. A rede GNG (Growing Neural Gas) (Fritzke, 1995) combinou estas duas formas de modificar a estrutura do mapa topológico: novos vértices são adicionados à estrutura a cada $l$ iterações do algoritmo para compensar o vértice que apresente maior erro acumulado, e arestas são criadas entre os dois neurônios que apresentem maior atividade para uma dada entrada. Variações da rede GNG têm sido utilizadas em aplicações práticas de AR como nos trabalhos que são abaixo comentados: Großmann (2001) e Millán et alli, 2002. 


\section{ESTUDO DE CASO: Großmann (2001)}

O modelo de Großmann (2001) utiliza uma rede neural auto-organizável construtiva derivada do Growing Neural Gas (GNG) de Fritzke $(1993,1995)$ denominada de Estruturas Construtivas de Células (Constructive Cell Structures - CCS) para armazenar a função de avaliação que guia a coleta de latas, por um robô móvel, em ambiente inicialmente desconhecido. O CCS se diferencia do GNG basicamente pelo critério utilizado para a inserção de novas unidades no mapa - os estados são considerados distintos quando estes possuem diferentes políticas de ação ou diferentes avaliações, e são unidos quando apresentam a mesma política de ação e a mesma avaliação. Este critério é inspirado no trabalho de McCallum (1995) que sugere a utilização de testes estatísticos para analisar se a criação de uma nova unidade melhora as estimativas da função de avaliação.

O algoritmo começa buscando uma segmentação aceitável do espaço de entrada: na fase de pré-aprendizagem o agente coleta experiência inicial ao executar ações aleatórias ou ações selecionadas por um demonstrador. A aprendizagem da experiência é armazenada como uma cadeia de exemplos de transição, no formato de $T_{t}=\left\{T_{t-1}, a_{t-1}, \mathbf{s}_{t}, r_{t}\right\}$, na qual as observações encontradas são então usadas como exemplos de treinamento pelo algoritmo para encontrar a estrutura inicial de vértices e arestas do mapa topológico:

1. Escolha a observação $\mathbf{s}_{t}$ do conjunto de todos os exemplos de transição e o apresente para a rede.

2. Determine a unidade $n_{b}$ que possui o vetor de referência $\boldsymbol{w}_{\boldsymbol{b}}$ mais próximo da observação st: $\left\|\mathbf{w}_{b}-\mathbf{s}_{t}\right\| \leq\left\|\mathbf{w}_{i}-\mathbf{s}_{t}\right\|$, para todo vértice $n_{i}$ do mapa topológico $M$.

3. Ajuste os vetores referência de $n_{b}$ e de seus vizinhos topológicos na direção de $\mathbf{s}_{t}$.

A ação $a_{t-1}$ em $T_{t}$ é selecionada com base na observação $\mathbf{s}_{t-1}$, a qual faz parte de $T_{t-1}$. A fase de aprendizagem consiste dos seguintes passos:

1. O agente realiza um passo no ambiente. As transições realizadas são armazenadas como exemplos e colocadas no final da cadeia de exemplos. O algoritmo armazena o exemplo $T_{t}$ com o vértice de melhor casamento com a observação $\mathbf{s}_{t-1}$ do predecessor $T_{t-1 .}$.

2. Para cada passo no ambiente, o agente atualiza a avaliação das unidades da rede, que passam a ser considerados como estados:

$$
Q\left(s_{t}, a_{t}\right) \leftarrow R\left(s_{t}, a_{t}\right)+\sum_{s^{\prime}} T\left(s_{t}, a_{t}, s_{t+1}\right) V\left(s_{t+1}\right)
$$

com $V\left(s_{t}\right)=\max _{a_{t} \in A} Q\left(s_{t}, a_{t}\right) . R\left(s_{t}, a_{t}\right)$ e $T\left(s_{t}, a_{t}, s_{t+1}\right)$ podem ser calculados diretamente a partir dos exemplos gravados.

3. A cada número de iterações do algoritmo múltiplo de um valor $l$ pré-estabelecido, o agente testa se uma nova informação adicionada, ou a atualização da função de avaliação, gerou uma mudança considerável do desvio padrão da estimativa da função 
de avaliação. Caso isto ocorra, analisa-se a necessidade da criação de uma nova unidade na rede: (i) cria-se uma nova unidade $n_{n}$ conectada à unidade $n_{\text {desvio }}$ que apresentou maior desvio da avaliação; (ii) realiza-se o teste de Komogorov-Smirnov (McCallum, 1995) para verificar se o desvio da estimativa da função de avaliação é reduzido com a inclusão de $n_{n}$ na rede e (iii) caso o teste indique que houve uma mudança significativa, o novo vértice permanece na rede; caso contrário, a arquitetura anterior da rede é retomada.

4. Retorne ao passo (1).

Em resumo, o modelo CCS de Großmann (2001) gera uma quantização adaptativa do espaço de estados. Um critério estatístico, o teste de Komogorov-Smirnov, é utilizado para definir o crescimento da rede conforme este crescimento melhore a estimativa da função de avaliação. A atualização da avaliação, conforme observa-se na Eq. (4.17), não difere da regra utilizada em soluções tabulares. Os ganhos deste modelo são principalmente dois: (i) redução do espaço de estados e (ii) adaptabilidade do agente AR a mudanças no ambiente, dado que estas sejam percebidas pelo teste estatístico adotado. Duas limitações podem ser comentadas no modelo de Großmann: (i) o modelo não faz uso de funções de vizinhança na atualização da função de avaliação que possibilitaram uma aceleração do aprendizado nos modelos já comentados de Touzet (1997) e Smith (2001) e (ii) o fato do crescimento do crescimento do mapa ocorrer conforme um agendamento prévio de $l$ iterações.

\section{ESTUDO DE CASO: Aprendizagem-Q de Ação Contínua (Millán; Posenato e Dedieu, 2002)}

O modelo de Millán et alli (2002) controla um robô móvel na tarefa de desvio de obstáculos através de uma versão do algoritmo Aprendizagem- $Q$ que trabalha no espaço contínuo das ações, o que permite a aproximação de ações ótimas por parte do robô. Esta solução combina duas idéias principais: (i) a geração de uma representação apropriada para o espaço de entrada, a qual é obtida com o Mapa Incremental Preservador da Topologia (Incremental Topology Preserving Map - ITPM) (Millán, 1997) e (ii) a utilização de conhecimento prévio do domínio, através do uso de $\operatorname{reflexos}^{20}$, para melhorar a velocidade do aprendizado e evitar ações que coloquem o robô em risco.

O ITPM é baseado no Growing Neural Gas (GNG) proposto por Fritzke (1993, 1995), mas difere basicamente nos seguintes pontos com sua versão original: O ITPM foi pensado para operar on-line, ao contrário do GNG, pois insere novas unidades sempre que ache necessário uma melhor cobertura do espaço de entrada, enquanto o GNG adiciona novas unidades a intervalos fixos de tempo. Além disto, a remoção de uma unidade $n$ no GNG ocorre quando não há arestas

\footnotetext{
${ }^{20}$ Reflexos correspondem a comportamentos reativos simples codificados a partir de conhecimento prévio sobre a tarefa a ser realizada (Brooks, 1986; Milán, 1996).
} 
conectadas a $n$, Millán et alli (2002) não realizam este tipo de remoção no ITPM sob o argumento de que tal estratégia pode ser perigosa no controle de um robô autônomo.

A seleção das ações do robô móvel é realizada por dois meios: por um controlador, que é o agente AR, e por reflexos pré-programados. Sempre que ocorre uma falha do controlador (a posição atual do robô está fora do campo receptivo ${ }^{21}$ de todas as unidades do ITPM ou há a ocorrência de uma colisão), os reflexos assumem a seleção das ações do robô e uma nova unidade $n$, cuja ação a é direcionada para a ação tomada pelo reflexo acionado, é acrescentada ao ITPM com a finalidade de incorporar o conhecimento de como contornar tal falha. As regras de autoorganização do ITPM seguem abaixo, sendo $\mathbf{s}_{\mathrm{t}}$ o estado atual do robô e $n_{p}$ e $n_{s}$ as unidades mais próximas:

1. SE uma nova unidade $n$ for criada, ENTÃO (i) crie uma aresta de $n$ para $n_{\mathrm{p}}$ e $n_{\mathrm{s}}$, (ii) remova a aresta entre $n_{\mathrm{p}}$ e $n_{\mathrm{s}}$ caso esta exista, (iii) considere o novo vértice $n$ como sendo a unidade mais próxima, $n_{p} \leftarrow n$. SENÃO crie uma aresta entre $n_{\mathrm{p}}$ e $n_{\mathrm{s}}$ caso estas unidades já não estejam conectadas.

2. Ajuste os vetores referência de $n_{\mathrm{p}}$ e de todas as unidades $r$ vizinhas

$$
\begin{gathered}
\Delta \mathbf{w}_{n_{p}} \leftarrow \delta\left(\mathbf{s}_{t}-\mathbf{w}_{n_{p}}\right) \\
\Delta \mathbf{w}_{r} \leftarrow \delta_{r}\left(\mathbf{s}_{t}-\mathbf{w}_{r}\right)
\end{gathered}
$$

sendo $\delta$ e $\delta_{\mathrm{r}}$ as taxas de aprendizagem da unidade mais próxima e de suas vizinhas.

As vantagens proporcionadas com estas regras são a obtenção de um mapa auto-organizável que aloca automaticamente suas unidades nas partes visitadas do espaço de entrada, ajustando dinamicamente a resolução para diferentes regiões. O algoritmo geral do agente AR segue os seguintes passos:

1. Inicialização: determinar o estado inicial s e selecionar a ação a através dos reflexos ou da unidade $n_{p}$ mais próxima do ITPM.

2. Laço: Realize $a$, perceba o novo estado s e o reforço $r$

3. Encontre a unidade $n_{p}$ de ITPM mais próxima de $\mathbf{s}$, se houver.

4. Caso $\mathbf{s}_{t+1}$ esteja fora do campo receptivo de $n_{p}$ ou ocorra uma falha, então

(A) use os reflexos para selecionar a próxima ação $a$.

(B) Adicione uma nova unidade $n$ ao ITPM centrada em s e com uma avaliação $Q$ tal que uma política elitista (greedy) selecionaria $a$, e

(C) Siga para o passo 6.

5. Use as avaliações $Q$ da unidade vizinha mais próxima $n_{p}$ para selecionar a próxima ação $a$.

6. Aprendizagem por Reforço: ajuste as avaliações $Q$ da unidade $n$ que era anteriormente a mais próxima.

\footnotetext{
${ }^{21}$ Campo receptivo é a região de influência no espaço de estados associada a uma unidade da rede.
} 
7. Auto-organização: atualize a conectividade da vizinhança de $n_{p}$ ou $n$, e ajuste os vetores referência destas unidades.

8. $\mathbf{s} \leftarrow \mathbf{s}_{t} ; n \leftarrow n_{p} ; a \leftarrow a_{t}$; siga para o passo 2 caso a tarefa ainda não tenha sido finalizada.

Os melhores resultados obtidos no trabalho de Millán e colegas foram com o cálculo da função de avaliação pelo acumulado descontado dos sinais de reforço (em comparação com o cálculo pela premiação média). Na implementação destes autores buscou-se um espaço contínuo das ações ao selecioná-las da seguinte maneira: considerando que a unidade $i$ seja a mais próxima do estado s e que $a_{l}$ é a ação com maior avaliação $Q(i, l)$, as ações vizinhas à esquerda, $a_{l-1}$, e à direita, $a_{l+1}$, de $a_{l}$ são consideradas na seleção da ação $a$ a ser tomada pelo robô da maneira que se segue:

$$
a=a_{l}+\text { direita } *\left(a_{l+1}-a_{l}\right)+\text { esquerda } *\left(a_{l-1}-a_{l}\right)
$$

sendo direita e esquerda termos que ponderam a influência das ações vizinhas dados por:

$$
\text { direita }=\frac{1}{2+(Q(i, l)-Q(i, l+1))^{2}} \quad \text { e } \quad \text { esquerda }=\frac{1}{2+(Q(i, l)-Q(i, l-1))^{2}}
$$

com esta estratégia, o robô está constantemente explorando em torno da ação ótima atual, o que permite a geração de trajetórias mais suaves. A avaliação $Q(i, a)$ da ação selecionada é dada por:

$$
Q(i, a)=\frac{Q(i, l)+\text { direita }^{*} Q(i, l+1)+\text { esquerda } * Q(i, l-1)}{1+\text { direita }+ \text { esquerda }}
$$

A atualização das avaliações é realizada utilizando traços de elegibilidade calculados por:

$$
e_{\iota \varsigma} \leftarrow \begin{cases}\frac{1}{1+\text { direita }+ \text { esquerda }}, \text { caso } \iota=i \text { e } \varsigma=l \\ \frac{\text { direita }}{1+\text { direita }+ \text { esquerda }}, \text { caso } \iota=i \text { e } \varsigma=l+1 \\ \frac{\text { esquerda }}{1+\text { direita }+ \text { esquerda }}, \text { caso } \iota=i \text { e } \varsigma=l-1 \\ \lambda \gamma e_{\iota \varsigma}, \text { caso contrário }\end{cases}
$$

e dada pela expressão abaixo sobre todo o espaço $S_{\mathrm{x}} A$ :

$$
\Delta Q(l, \varsigma) \leftarrow \alpha\left(r+\gamma Q\left(i_{t+1}, a_{t+1}\right)-Q\left(i_{t}, a_{t}\right)\right) \cdot e_{\iota \varsigma}
$$

Observa-se que o agente AR de Millán e colegas exemplifica uma forma de combinar traços de elegibilidade com generalização (Seção 4.1), mas também traz outras contribuições interessantes como: (i) a mudança na quantização do espaço de estados ocorrer de forma on-line; (ii) a topologia ajustável do Mapa Incremental de Preservação da Topologia permitir ao agente AR se adaptar a ambientes com topologias complexas e (iii) o conjunto das ações do agente ser variável, permitindo trajetórias mais suaves. Diferente do modelo de Großmann (2001), Millán e colegas adotam um mapa topológico que é construído mais rapidamente - a exemplo da rede GWR (Grow When 
Required) de Marsland et alli (2002), o ITPM não tem a atualização de sua estrutura dependente de um número $l$ pré-definido de iterações.

\subsubsection{Discussão sobre os Algoritmos Apresentados}

$\mathrm{O}$ uso de tabelas, tão difundido nas primeiras implementações em AR por herança da Programação Dinâmica, vêm sendo cada vez mais substituído pelo uso de estruturas mais flexíveis, e que ocupem menor espaço de memória, como os mapas auto-organizáveis. A vantagem talvez mais evidente no uso de mapas auto-organizáveis em um problema AR é o ganho de velocidade no algoritmo ao reduzir o espaço de trabalho pela segmentação do mesmo, surgindo com isso questões sobre qual a forma mais adequada de realizar esta segmentação. Trabalhos como os de Touzet (1997) e Smith (2001), em que a estrutura do mapa é pré-definida (quantidade de neurônios e conectividade), fornecem bons resultados na aceleração do PARDM desde que uma escolha adequada da estrutura do mapa para o problema em particular seja feita pelo projetista na etapa anterior à aprendizagem. Entretanto, para problemas reais, suposições a priori sobre o ambiente devem ser ao máximo evitadas, buscando dotar o algoritmo de mecanismos que permitam escolher a melhor formar de distribuir as unidades do mapa como ocorre nos trabalhos de Großmann (2001) e Millán et alli (2002).

Outra vantagem dos mapas auto-organizáveis em AR é a possibilidade de utilizar a função de vizinhança entre as unidades para gerar novas regras de atualização da função de avaliação como é feito, principalmente, em Touzet (1997) que aproveita as relações de vizinhança na atualização das avaliações das unidades do mapa que estão mais próximas do neurônio vencedor a cada iteração, e Smith (2001) que emprega a função de vizinhança gerada por seu algoritmo para atualizar a cada iteração todos os pares estado-ação representados nos dois SOMs que este modelo utiliza.

Do apresentado, retira-se premissas para o agente proposto: (i) mapas com estrutura variável têm uma maior capacidade de representar as transições do espaço de estados de entrada, (ii) as relações de vizinhança entre os vértices do mapa topológico são informações que podem facilitar em muito a atualização da avaliação de um grande número de estados, pares estado-ação, a cada iteração e (iii) o critério de crescimento do mapa pode comprometer a velocidade de aprendizagem do agente AR, principalmente se este adotar que a verificação de uma medida, como o erro máximo global, seja realizada a números fixos e pré-definidos de iterações.

A despeito dos bons resultados relatados na literatura, o tempo de treinamento necessário para os algoritmos AR com SOM ainda pode não ser adequado. Apesar de estratégias como os reflexos de Millán et alli (2002) e a generalização pelas unidades vizinhas de Touzet (1997) para o melhor aproveitamento da informação disponível no treinamento do agente AR, a quantidade de interações com o ambiente para a convergência da função de avaliação ainda pode ser significativa (Sutton, 1999). Para conseguir uma forma eficiente de reduzir este número de interações, um particular interesse deve ser dado à estratégia de exploração adotada - tema da próxima seção. 


\subsection{Exploração}

Das duas etapas do PARDM (Seção 2.1), a primeira, o PEDM, é a que costuma consumir mais tempo. Desta forma, agentes que devam trabalhar com restrições de tempo, como é o caso aqui tratado, devem ser capazes de realizar eficientemente a exploração de seu espaço de estados. Para compreender como alcançar uma estratégia eficiente de exploração, convém conhecer que esta pode possuir quatro componentes (Wyatt, 2001):

(i) Uma medida local de avaliação da exploração que pode ser usada para influenciar a escolha das ações do agente AR. Esta medida pode se basear: na premiação que o agente receba do ambiente, em contadores das visitas a estados (ou pares estado-ação) do ambiente, nos erros da estimativa da avaliação, no tempo de visitação a estados (ou pares estado-ação) ou na variância da estimativa da função de avaliação.

(ii) A possível transformação da medida local em uma medida remota (distal) da avaliação da exploração usando uma equação de Bellman.

(iii) Um possível modelo do mundo para auxiliar na inferência da função de avaliação da exploração caso a estratégia seja baseada em modelo.

(iv) Uma regra de decisão baseada nas funções de avaliação aprendidas pelo agente de aprendizagem por reforço (como uma regra determinística, $\varepsilon$-greedy ou Boltzmann).

Tradicionalmente, estas quatro componentes não são totalmente consideradas na classificação das estratégias de exploração, sendo em geral adotada a divisão proposta por (Thrun, 1992) de dois grandes grupos separados pela informação utilizada na seleção das ações: (i) as explorações nãodirecionadas, que são estratégias dependentes da aleatoriedade para a seleção das ações, e (ii) as explorações direcionadas, que usam algum conhecimento específico para guiar a escolha das ações, e que vêm demonstrado consideráveis melhorias no desempenho da aprendizado por reforço (Barto e Singh, 1990; Kaelbling, 1993; Moore, 1990). Mais recentemente, aspectos como o uso de modelos do mundo (Wiering e Schmidhuber, 1998b; Dearden et alli, 1999; Wyatt, 2001) e a utilização de medidas globais da incerteza (Sutton, 1990; Meleau e Bourgine, 1999; Wyatt, 2001) vêm ganhando mais destaque. Para apresentar uma visão geral das técnicas de exploração que vêm sendo empregadas em agentes AR aplicados à robótica móvel, as próximas subseções tratarão de rever: as técnicas não-direcionadas (Subseção 4.3.1), as técnicas direcionadas que fazem uso de medidas locais (Subseção 4.3.2) e as técnicas direcionadas que fazem uso de medidas globais (Subseção 4.3.3). A Subseção 4.3.4 encerra esta seção comentando sobre os aspectos de interesse das técnicas apresentadas, buscando delimitar características a serem utilizadas no agente proposto no Capítulo 5.

\subsubsection{Exploração Não-Direcionada}

As técnicas de exploração não-direcionadas são caracterizadas por utilizar aleatoriedade na exploração. A técnica de exploração não-direcionada mais simples é a exploração aleatória que 
seleciona as ações segundo uma distribuição uniforme, sem utilizar nenhuma informação do ambiente e sem considerar os custos da exploração. Um robô que realize uma exploração aleatória do ambiente colidirá repetidas vezes com os obstáculos, independente de já ter observado os mesmos obstáculos anteriormente. Outras técnicas de exploração não-direcionada consideram os custos da exploração modificando a distribuição de probabilidade que governa a seleção das ações, conforme estas são selecionadas, de maneira a reduzir a probabilidade das escolhas mais onerosas. Como exemplos de custos que costumam ser utilizados para modificar as distribuições usadas na seleção das ações tem-se: (i) o número de vezes que uma ação e/ou estado já foi selecionado, (ii) o número de colisões geradas pela escolha de uma ação e/ou estado e (iii) os sinais de reforço negativo gerados a partir da seleção de uma ação e/ou estado. Estas técnicas costumam ser ineficientes no tempo de aprendizagem de um agente AR, podendo levar o tempo de aprendizagem a uma escala de tempo exponencial com o tamanho do espaço de estados do ambiente (Whitehead, 1991).

\subsubsection{Exploração Direcionada, com medidas locais}

Técnicas de exploração direcionadas (Poncela et alli, 2002; Schmidhuber, 1991) utilizam algum conhecimento exploratório específico para guiar a exploração. No lugar de selecionar aleatoriamente as ações, as regras de exploração destas técnicas determinam diretamente qual a ação a ser selecionada a cada instante para obter a melhor exploração do ambiente. O objetivo da exploração direcionada é selecionar ações que maximizem o desempenho da aprendizagem do agente ao longo do tempo. Entretanto, esta é uma meta impossível de se atingir precisamente uma vez que não se pode saber com antecedência como uma ação melhorará a aprendizagem de um agente em um ambiente desconhecido ou parcialmente desconhecido. Por isto, as técnicas de exploração direcionadas são normalmente heurísticas baseadas em medidas locais da incerteza. Thrun (1992) relaciona três classes de explorações direcionadas que empregam medidas locais:

- Exploração baseada em contadores (counter-based): Utiliza contadores $c($ ) para armazenar o número de visitas a cada estado e opta por explorar na busca pelos estados menos visitados. Um exemplo simples desta estratégia (Thrun, 1992) é selecionar sempre a ação que maximiza a seguinte expressão:

$$
E_{\text {contador }}(a)=\frac{c\left(s_{t}\right)}{E\left[c\left(s_{t+1}\right) \mid s_{t}, a\right]}=\frac{c\left(s_{t}\right)}{c\left(\hat{s}_{t+1}\left(s_{t}, a\right)\right)}
$$

sendo: $s_{t}$ o estado atual, $E[. \mid$.$] a estimativa e \hat{s}_{t+1}$ o próximo estado previsto ao ser executada a ação $a$.

- Exploração baseada no erro (error-based): Emprega estimativas dos erros para guiar o agente partindo da consideração de que estados ou regiões do espaço de estados com grandes erros são pouco exploradas e merecem melhor "varredura". Isto é obtido ao se maximizar a expressão: 


$$
E_{\text {erro }}(a)=E\left[\Delta \hat{V}\left(s_{t+1}\right) \mid s_{t}, a\right]
$$

sendo: $\Delta \hat{V}(s)$ a estimativa de erro da função de avaliação para o estado $s$ (medida que é armazenada a cada atualização da função de avaliação).

- Exploração baseada no tempo de visitação (recency-based): Esta técnica de exploração é mais adequada para problemas não-estacionários, e seu princípio é preferir os estados adjacentes que tenham sido visitados com menor recência. Para tal, a cada estado $s$ é associado um valor $\rho(s)$ que armazena o último instante de tempo que $s$ foi visitado - a escolha do próximo estado é feita buscando-se maximizar a diferença entre o instante de tempo atual e os valores $\rho$ dos estados adjacentes.

A combinação destas heurísticas, ao buscar maximizar a soma das medidas locais listadas, também é uma estratégia para tornar ainda mais eficiente a exploração - normalmente, os resultados obtidos com o uso de medidas locais simples ou combinadas superam significativamente qualquer técnica de exploração não-direcionada em termos de tempo de aprendizagem de um agente AR (Thrun, 1992; Wyatt, 1997; Meleau e Bourgine, 1999).

\subsubsection{Exploração Direcionada, com medidas globais}

Meleau e Bourgine (1999) (pg. 134) comentam que o uso de medidas locais da incerteza, apesar de proporcionarem uma melhoria da exploração, podem levar, em certos ambientes, o agente AR a reduzir a exploração prematuramente e, assim, passar a realizar uma política sub-ótima. Tal situação pode ser observada nos resultados em simulação obtidos por Thrun (1992) com a exploração baseada em contagem - o agente AR, em uma tarefa de navegação de um robô em um labirinto, acaba convergindo para trajetórias sub-ótimas. Para evitar tal problema, medidas globais da incerteza seriam necessárias para guiar a exploração. Trabalhos como os de Martin (1967) (abordagem Bayesiana) e Feldbaum (1965) (Programação Dinâmica) propõem políticas globais de exploração, entretanto ao custo de uma quantidade de memória e tempo de processamento impraticáveis para maioria dos problemas do mundo real. Meuleau e Bourdine (1999) e Großmann (2001) argumentam que uma alternativa mais viável para gerar estimativas globais da incerteza que possam ser usadas em estratégias de exploração é a retropropagação das medidas locais de incerteza. Duas estratégias, muito semelhantes, nesta direção podem ser citadas:

- Dyna-Q+ de Sutton (1990): a arquitetura Dyna- $Q+$ possui uma técnica de exploração proposta para operar em ambientes que se modificam ao longo do tempo. Para cada par estado-ação $(s, a)$ é mantido um contador $\Delta(s, a)$ que registra a quantidade de intervalos de tempo decorridos desde que a ação a foi executada pela última vez no estado s. Para estimular a exploração, este contador é utilizado no cálculo do bônus de exploração $\delta(s, a)$ definido por: 


$$
\delta(s, a)=\varepsilon \sqrt{\Delta(s, a)}
$$

sendo $\varepsilon$ um parâmetro positivo. O efeito da medida local de exploração é tornado global ao incorporá-lo na regra de atualização da função de avaliação:

$$
Q\left(s_{t}, a_{t}\right) \leftarrow Q\left(s_{t}, a_{t}\right)+\alpha\left(r\left(s_{t}, a_{t}\right)+\delta\left(s_{t}, a_{t}\right)+\gamma \cdot \max _{a_{t+1} \in A} Q\left(s_{t+1}, a_{t+1}\right)-Q\left(s_{t}, a_{t}\right)\right)
$$

a seleção das ações é realizada de forma a sempre maximizar a Expressão (4.28).

- Meuleau e Bourgine (1999): com uma atualização da função de avaliação semelhante à adotada pelo Dyna- $Q^{+}$(4.29), a diferenciação da implementação da exploração com retropropagação de Meuleau e Bourgine está em que o agente AR não usa um modelo de mundo (como é o caso no Dyna- $Q^{+}$), e um bônus de exploração diferente é utilizado:

$$
\delta(s, a)=\sigma_{\max } \frac{z_{\alpha / 2}}{\sqrt{n(s, a)}}
$$

sendo $n(s, a)$ o número de vezes que a ação $a$ foi executada no estado $s$, $\{\alpha / 2$ o tamanho do intervalo de confiança (Kaelbling, 1993) e $\sigma_{\max }$ a variância máxima do sinal de reforço definido por:

$$
\sigma_{\max } \stackrel{\Delta}{=} \frac{r_{M}-r_{m}}{2(1-\gamma)}
$$

sendo:

$$
r_{M} \stackrel{\Delta}{=} \max _{s \in S, a \in A} r(s, a) \quad \text { e } \quad r_{m} \stackrel{\Delta}{=} \min _{s \in S, a \in A} r(s, a)
$$

a seleção das ações é realizada de forma a maximizar a avaliação $Q(s, a)$ ou pela ação em que o contador $n(s, a)$ ainda tenha valor nulo.

Resultados apresentados por Meuleau e Bourdine (1999) demonstram experimentalmente a superioridade das técnicas de exploração global sobre as locais.

\subsubsection{Comentários}

Muito do estudo de exploração em AR vêm de trabalhos que tratavam de problemas com um único estado e diversas ações possíveis (bandit arms problems) (Kaelbling, 1993; Wyatt, 1997; Meuleau e Bourdine, 1999). A extensão para problemas com múltiplos estados, como é normalmente o caso em robótica, nem sempre é direta - o alto custo computacional envolvido dificulta, ou mesmo impossibilita, soluções elegantes e bem definidas como modelos Bayesianos (Martin, 1967; Wiering e Schmidhuber, 1998b; Dearden et alli, 1999; Wyatt, 2001). Assim, a necessidade prática reduz o leque de estratégias de exploração a serem consideradas para uso em robótica àquelas que tenham uma implementação computacionalmente mais "barata". Neste sentido, foram listadas três classes de estratégias: as técnicas não-direcionadas (Subseção 4.3.1), as técnicas direcionadas que fazem uso 
de medidas locais (Subseção 4.3.2) e as técnicas direcionadas que fazem uso de medidas globais (Subseção 4.3.3). Fica evidente a superioridade das duas últimas, mas convém salientar que estas também apresentam limitações práticas: (i) costumam associar contadores a cada par estado-ação do ambiente, o que exigiria grande quantidade de memória para ambientes grandes e dificultaria a implementação em ambientes contínuos; (ii) podem se tornar computacionalmente dispendiosas devido aos cálculos realizados com os contadores e (iii) a maioria destas técnicas foram projetadas para ambientes determinísticos e em ambientes dinâmicos (sujeitos a mudanças ao longo do tempo) tais técnicas podem ter seu bom desempenho comprometido. Assim, cabe buscar um compromisso entre reduzir as limitações de implementação das técnicas direcionadas e tirar o máximo proveito de suas vantagens.

Um trabalho particularmente interessante no levantamento de como tratar o compromisso limitações/vantagens em exploração é o de Meuleau e Bourgine (1999), que aponta três possibilidades para alcançar bons resultados:

(i) Adicionar bônus de exploração à premiação do agente AR. O bônus de exploração, $\delta_{0}$, representa o valor máximo de recompensa que se está disposto a pagar para se realizar uma observação. Este mede a importância de realizar uma exploração para obter informação no lugar de simplesmente explotar para obter a premiação esperada. Esta medida deve ser tal que $\lim _{n \rightarrow \infty} \delta_{0}(n)=0$. Isto reflete o fato de que, quando um estado é visitado um número infinito de vezes, suas características são conhecidas com certeza e não há nenhuma outra informação a ser aprendida ao amostrá-lo. E ao adicionar esta medida à premiação do agente, passa a propagar para os demais estados quais regiões já foram mais ou menos visitadas.

(ii) Escalonar a magnitude do bônus de exploração para torná-lo compatível com os demais sinais de reforço que o agente possa receber.

(iii) Buscar uma inicialização adequada das variáveis principais para incentivar a exploração de regiões pouco ou não-visitadas. Ao adotar a inicialização de estados não visitados com altos valores, associado com a incerteza, passa-se a adotar a estratégia conhecida na literatura como “Otimismo Diante de Incerteza” (Wyatt, 2001; Großmann, 2001).

\subsection{Comentários Finais e Caminhos para a Pesquisa}

A revisão realizada neste Capítulo visou delimitar aspectos de interesse para resolução do PARDM presentes em implementações anteriores. Para tal, foram observados trabalhos sobre formas de melhorar a aprendizagem do agente AR e mecanismos de exploração do ambiente. Alguns destes trabalhos foram revisados segundo estas duas etapas do PARDM:

- Melhoria do Aprendizado: Nas pesquisas em AR de forma geral, a velocidade de aprendizagem é um dos principais temas de interesse. Na Seção 4.1 foram revisados alguns dos métodos utilizados para melhorar o desempenho de AR em robôs móveis 
seguindo a divisão proposta por Wyatt (1997) ${ }^{22}$ : (i) O uso de traços de eligibilidade permite que ao ocorrer um sinal de reforço não-nulo esta informação possa ser propagada para outros estados, além do atual, de forma a produzir atualizações mais precisas; (ii) A generalização da função de avaliação permitiria que as avaliações de estados ainda não visitados possam ser estimados a partir das avaliações aprendidas nos estados visitados; (iii) A decomposição da tarefa de navegação em sub-tarefas seria uma forma de reduzir a complexidade do problema maior ao atacá-lo como sendo formado por diversos problemas menores e mais fáceis de serem solucionados; (iv) A proposição de novas funções de reforço seria uma forma de melhorar a qualidade da informação que é utilizada pelo agente. A combinação destes métodos deve ser o caminho para a proposição de melhores agentes $\mathrm{AR}$, e uma estrutura que vem ganhando recentemente muito espaço na literatura em AR aplicada à robótica móvel, por sua capacidade de se expandir conforme a complexidade do ambiente, mostra grande potencial para ser uma forma adequada de realizar esta combinação (Großmann, 2001; Smith, 2001; Prescott, 1994; Touzet, 1997; Quoy et alli, 2000; Milán et alli, 2002; Smith, 2002; Murao e Kitamura, 1998): os mapas auto-organizáveis.

- Exploração do Espaço de Estados: Como é inevitável que problemas reais possuam grandes espaços de estado, as estratégias de exploração destes espaços devem ser escolhidas de tal forma que se consiga o máximo de informação com o mínimo de exploração (para um survey sobre o assunto, consulte Thrun, 1992). Neste sentido, muitas implementações ainda pecam por adotar estratégias aleatórias - nestes casos apenas para um intervalo de tempo grande, proporcional ao tamanho do espaço que está sendo explorado, todo o espaço será percorrido. Estratégias mais recentes buscam uma forma mais racional de explorar o espaço de estados utilizando medidas que refletem a incerteza sobre certas regiões do espaço de estado como o erro do aprendizado ou o número de visitas. A retropropagação destas medidas, que são realizadas localmente, como uma forma de gerar estimativas globais da incerteza tem levado a estratégias ainda mais eficientes de exploração como a de Meuleau e Bourgine (1999).

\section{Caminhos para Novos Agentes AR}

A partir dos casos de SOM aplicada a AR selecionados para estudo, optou-se por três premissas básicas que deveriam estar presentes no ATAR: (i) mapas com estrutura variável têm uma maior capacidade de representar as transições do espaço de estados de entrada, (ii) as relações de vizinhança podem facilitar a atualização da avaliação de um grande número de estados, pares

\footnotetext{
${ }^{22}$ Variações e/ou melhorias destes métodos também podem ser vistos na literatura como a utilização de modelos da dinâmica do ambiente, a adoção de outras formas de cálculo das avaliações como o uso do valor médio do reforço, a aproximação direta da política ou a atualização priorizada das estimativas.
} 
estado-ação, a cada iteração e (iii) o critério de crescimento do mapa deve evitar agendamentos com um números fixos e pré-definidos de iterações. Nenhum dos casos de estudo reunia as três premissas levantadas, entretanto o $A T A R$ apresentará todas.

A exploração direcionada com medidas globais aponta como sendo a estratégia mais eficaz para o agente AR cobrir todo o espaço de estado com o menor número de iterações, entretanto a implementação desta forma de exploração com mapas auto-organizáveis não é direta. No formato de tabela, a implementação desta estratégia de exploração é facilitada por estados ainda não visitados já possuírem uma posição na tabela apontando, através da avaliação alta de sua incerteza, que estes devem ser visitados. Em mapas auto-organizáveis construtivos, não existe, à princípio, uma representação para as regiões não visitadas do espaço de trabalho, dificultando uma abordagem similar a que ocorre na tabela entre uma posição desconhecida e uma indicação de sua incerteza. Assim, mecanismos para contornar este problema devem ser estabelecidos. Uma representação híbrida, SOM para a função de avaliação e tabular para a exploração, é o caminho mais direto para a combinação das aparentemente melhores soluções para as duas etapas do PARDM. 


\section{Capítulo 5}

\section{O Agente Topológico de Aprendizagem por Reforço - ATAR}

A aceleração na assinalação de crédito (Subseção 4.1.2) utiliza mecanismos que permitem atualizar em uma única iteração do agente AR a avaliação de diversos estados, ou pares estado-ação (Wyatt, 1997). Neste capítulo é proposta uma nova abordagem, denominada de Agente Topológico de Aprendizagem por Reforço (ATAR) (Braga e Araújo, 2002a-b; 2003), para assinalação rápida de crédito em AR inspirada no fenômeno da aprendizagem latente (Tolman, 1948) discutido no Capítulo 3. A forma com que a aprendizagem latente é implementada no ATAR possibilita a atualização das avaliações dos estados do espaço de trabalho através do conceito de regiões de influência. Um mapa topológico, que preserva relações de vizinhança no espaço de entrada, é utilizado para definir estas regiões que são usadas para restringir o conjunto de estados que terão suas avaliações atualizadas.

Outros trabalhos em AR (Barto et alli, 1983; Watkins, 1989; McCallum, 1992; Rummery, 1995; Peng e Williams, 1996; Touzet, 1997; Ribeiro, 1998 e Pegoraro, 2001) utilizam o espalhamento do erro TD para acelerar a solução do PARDM. Porém, a simplicidade do mecanismo adotado no ATAR permite, comparativamente (resultados no Capítulo 6), resultados semelhantes a um custo computacional menor ao reduzir, em comparação a algoritmos como a Aprendizagem-Q e o $S A R S A$, o número de atualizações necessárias para estimar a função de avaliação.

A Seção 5.1 coloca como a aprendizagem latente é considerada no equacionamento da atualização das estimativas das avaliações dos estados. Os mapas topológicos empregados no $A T A R$ e a descrição de seu algoritmo são os temas, respectivamente, das Seções 5.2 e 5.3. Duas formas de melhorar o desempenho do $A T A R$ são propostas: (i) a melhoria das trajetórias iniciais ao manipular a informação aprendida no mapa topológico (Seção 5.4) e (ii) a adoção de estratégias de exploração direcionadas adaptadas para trabalharem em conjunto com os mapas topológicos (Seção 5.5). A seção 5.6 encerra o Capítulo discutindo os temas apresentados e como estes serão tratados no Capítulo 6 de resultados. 


\subsection{Aprendizagem Latente - Espalhamento da Informação}

Conforme apresentado no Capítulo 3, a aprendizagem em muitos animais pode ocorrer mesmo na ausência de reforços provenientes do ambiente e só emergir quando um sinal de reforço é percebido. O interesse por aprendizagem latente (Tolman, 1948) nesta pesquisa remonta às observações realizadas por Blodgett (1929) e Tolman e Honzik (1930) de que este tipo de aprendizagem pode acelerar o aprendizado de uma tarefa guiada por reforços, como a navegação de roedores em um labirinto na busca por alimento. Modelos de comportamento animal como os apresentados na Seção 3.2 reproduzem a aprendizagem latente com o auxílio de representações do ambiente que facilitam a assinalação de créditos. Técnicas tradicionais para acelerar a solução do PARDM (Capítulo 4) também se valem de informações sobre o ambiente para melhorar o desempenho: os traços de elegibilidade (Peng e Williams, 1996; Cichosz, 1997; Wiering e Schimidhuber, 1998a) e a generalização (Crabbe e Dyer, 2000; Pipe, 2000; Samejima e Omori, 1999; Santamaría et alli, 1997), por exemplo, são estratégias que permitem atualizar em uma única iteração do algoritmo AR a avaliação de diversos estados, ou pares estado-ação, ao propagar através de transições aprendidas durante os treinamentos anteriores o erro TD calculado no instante atual - a atualização da avaliação dos estados, ou pares estado-ação, próximos ao estado atual sofrem uma maior influência deste erro TD, e menores atualizações ocorrem na avaliação dos demais estados, ou pares estado-ação.

Como caminho para a aplicação das premissas de comportamento animal (Seção 3.4) a algoritmos AR, parte-se da seguinte regra de atualização das avaliações dos estados:

$$
V(s):=V(s)+\alpha \cdot H(s) \cdot\left[r_{t+1}+\gamma \cdot V\left(s_{t+1}\right)-V\left(s_{t}\right)\right], \forall s \in S
$$

a Equação 5.1 permite que as estimativas das avaliações de todos os estados $S \in S$ sejam atualizadas a partir do erro TD, $r_{t+1}+\gamma \cdot V\left(s_{t+1}\right)-V\left(s_{t}\right)$, calculado na transição do estado $s_{t}$ para o estado $s_{t+1}$ graças à função $H(s)$ que realiza o espalhamento deste erro para todos os estados $s$ do espaço de trabalho S. Diversos trabalhos em AR utilizam uma regra de atualização como a Equação 5.1, diferenciando-se quanto à forma de obter $H(s)$. Conforme se observa na Subseção 4.1.2 (Equação 4.6), $H(s)$ pode ser calculada como o traço de elegibilidade da Equação 4.5. Em McCallum (1992), a função $H(s)$ é denominada proximidade transicional sendo calculada com o auxílio de uma tabela que armazena todas as transições aprendidas pelo agente. Touzet (1997), em que o conjunto $S$ são os vértices de uma rede SOM, aproxima a função $H(s)$ pelos vértices vizinhos ao vértice atual - a cada iteração são atualizadas as avaliações do vértice atual e dos vértices a ele conectados. Ribeiro (1998), ao propor a Aprendizagem-QS, e Pegoraro (2001), ao estudar variações da Aprendizagem-QS, chamam $H(s)$ de função de espalhamento e a calculam, respectivamente, como dependente da distância Euclidiana entre o estado $s_{t}$ e os demais estados do espaço $S$ (ver Capítulo 4 de Ribeiro, 1998) ou dependente de outras similaridades entre os pares estado-ação como, por exemplo, a conectividade entre os estados e a simetria espacial (ver Seção 5.3 de Pegoraro, 2001). 
Dos comentários apresentados, observa-se que as implementações de $H(s)$ relacionam, de alguma forma, esta função à distância entre o estado atual e os demais estados. Porém, duas restrições podem ser observadas nos métodos citados para estimar $H(s)$ : (i) os cálculos envolvidos demandam um razoável esforço computacional (como ocorre com os traços de elegibilidade usados em Barto et alli, 1983; Watkins, 1989 e Rummery, 1995, e a proximidade transicional de McCallum, 1992) ou (ii) a estimativa de $H(s)$ é realizada em uma vizinhança imediata a s, abrangendo em geral apenas um subconjunto muito restrito de $S$ a cada instante $t$ (como ocorre em Touzet, 1997; Ribeiro, 1998 e Pegoraro, 2001) - o que reduz o esforço computacional, mas com um desempenho na estimativa da função de avaliação abaixo do conseguido com os traços de elegibilidade.

\subsubsection{Interpretação e Alternativa a $H(s)$}

Um agente AR se comporta esquematicamente conforme a Figura 5.1.

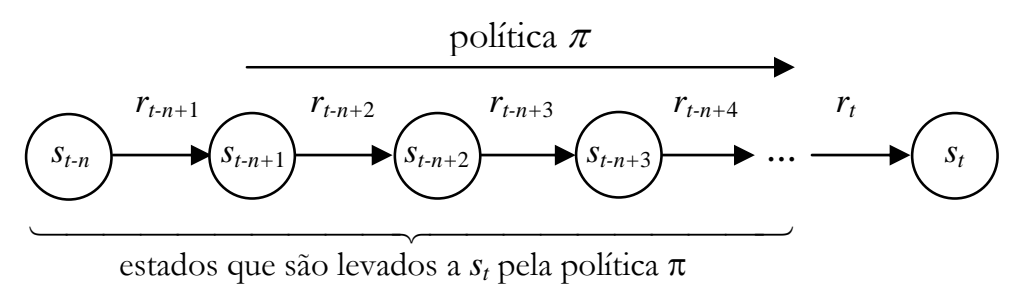

FIGURA 5.1 - Transições de estado, e respectivos sinais de reforço recebidos, do agente ao realizar uma política $\pi$.

As transições de estado são guiadas por uma política $\pi$, sinais de reforço são gerados ao longo deste processo, e a dependência das avaliações dos estados (Equação 2.1) anteriores com a avaliação do estado atual, $s_{t}$, é dada por:

$$
V^{\pi}\left(s_{t-n}\right)=r_{t-n+1}+\gamma \cdot r_{t-n+2}+\gamma^{2} \cdot r_{t-n+3}+\cdots+\gamma^{n-1} \cdot r_{t}+\gamma^{n} \cdot V^{\pi}\left(s_{t}\right)
$$

sendo $V^{\pi}(s)$ a avaliação do estado $s$ ao seguir a política $\pi$. A Equação 5.2 e a Figura 5.1 explicitam que, com uma dada política $\pi$, a cada estado $s_{t}$ está associado um conjunto de outros estados cujas avaliações são influenciadas por $V^{\pi}\left(s_{t}\right)$. Os traços de elegibilidade (Subseção 4.1.2) e a Equação 5.1 podem ser interpretados como formas, respectivamente, de: (i) definir este conjunto de estados influenciados pelo estado atual e (ii) como atualizar a estimativa das avaliações destes estados com base nesta influência. As propostas levantadas nesta subseção, e que serão as bases para o $A T A R$, são: (i) com o auxílio de uma representação topológica do espaço $S$, buscar nas vizinhanças do estado atual, $s_{t}$, os estados cujas avaliações são dadas na forma da Equação 5.2 e (ii) restringir, a cada instante $t$, a este conjunto de estados a atualização da função de avaliação que, não necessariamente será por propagação do erro TD. Com estas propostas espera-se conseguir um desempenho na estimativa da função de avaliação semelhante ao dos traços de elegibilidade (Peng e Williams, 1996; Wiering e Schimidhuber, 1998a), mas a um custo computacional menor ao realizar as atualizações em um conjunto mais restrito de $S$ (como em Touzet, 1997; Ribeiro, 1998 e Pegoraro, 2001). 
Como forma didática de apresentar como são selecionados os estados que serão atualizados a cada instante $t$, cria-se o conceito de região de influência de $s_{t}$, denotado $T\left(s_{t}\right)$ (Figura 5.2) - esta região contém os estados que, por uma política elitista (greedy), são levados a $s_{t}$.

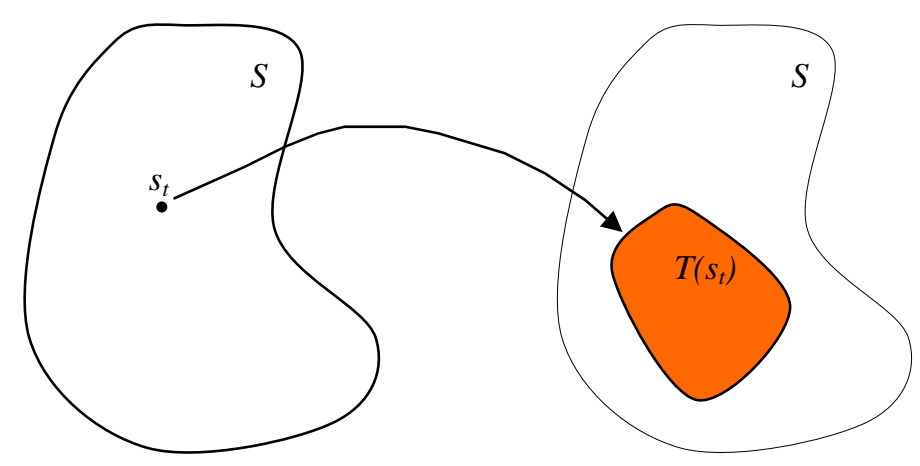

FIGURA 5.2 - O subconjunto $T\left(s_{t}\right)$ do espaço de estados $S$ representa a região de influência do estado $s_{t}$.

Para encontrar $T\left(s_{t}\right)$ parte-se do argumento de McCallum (1992) de que um algoritmo AR aprende fundamentalmente um mapeamento $(V: S \rightarrow \mathfrak{R}$ ou $Q: S, A \rightarrow \mathfrak{R})$ que preserva uma topologia, dois estados espacialmente adjacentes tendem a estar próximos no espaço de avaliações, e de que, como os estados da região de influência são levados a $s_{t}, \forall s \in T\left(s_{t}\right), V(s)<V\left(s_{t}\right)$. Assim, a premissa animal levantada no Capítulo 3 do uso de uma representação que preserve a topologia do espaço de entrada ${ }^{23}$ pode ser usada para, ao buscar nas vizinhanças topológicas regiões em que as avaliações são menores que a do estado atual, aproximar $T\left(\mathrm{~s}_{\mathrm{t}}\right)$.

A implementação e uso das regiões de influência para o cálculo da função de avaliação são tratados na Seção 5.3 ao apresentar as versões do $A T A R$. Antes, a próxima seção comenta sobre as representações topológicas adotadas.

\subsection{Mapas Cognitivos - Mapas Topológicos}

A teoria de mapa cognitivo proposta em Muller et alli (1996) relaciona a mudança das sinapses entre células posicionais às relações de conectividade entre regiões de um ambiente (ver Subseção 3.1.1). Variações do modelo de mapa auto-organizável de Kohonen (1984), como Martinetz e Schulten, 1994; Fritzke, 1994 e 1995, têm um comportamento semelhante ao utilizarem uma regra hebiana para aprender a conectividade entre os vértices do mapa. Entretanto, distintamente da proposta de Muller e colegas, os pesos das sinapses das variações do SOM são binários (conectado ou nãoconectado) - o que reduz o números iterações necessárias para a geração do mapa.

Os mapas discutidos nas subseções seguintes devem ser entendidos como uma representação do ambiente que mantém a característica de conectividade entre regiões próximas apresentada na

\footnotetext{
${ }^{23}$ A topologia do espaço de estados, ou dos pares estado-ação, é baseada nas transições que conectam os estados, pares estado-ação, para estados resultantes de acordo com a política que escolhe as ações.
} 
teoria de mapa cognitivo de Muller e colegas: os vértices são associados a regiões restritas, da mesma forma que os campos posicionais, e as arestas são criadas de forma semelhante às transições esperadas entre campos posicionais. A habilidade de acrescentar vértices extras é uma característica potencialmente útil para uma rede neural auto-organizada (Marsland et alli, 2002). Uma rede capaz de adicionar vértices pode aproximar o espaço de entrada de forma mais apurada, e freqüentemente de maneira mais "parcimoniosa", que uma rede com estrutura e tamanho pré-definidos, como o SOM. Além disso, uma rede crescente pode tratar com distribuições de entradas dinâmicas. A maioria das redes construtivas propostas na literatura (Fritzke, 1994, 1995; ver o levantamento em Marsland et alli, 2002) adicionam novos vértices para reduzir discrepâncias no vértice que tenha acumulado o maior erro durante as iterações anteriores ou para dar suporte a estruturas topológicas. Isso geralmente significa que novos vértices são acrescentados apenas quando o número de iterações é um múltiplo inteiro de alguma constante pré-definida $\tau$, e nas outras iterações faz-se necessário o acúmulo do erro em cada vértice. Uma vez que um vértice tenha sido adicionado, diversas outras iterações de aprendizagem são realizadas antes que outro vértice seja introduzido. Assim, a rede cresce a uma razão fixa independente de como a distribuição da entrada esteja mudando.

O Mapa Topológico Incremental (MTI), proposto por Jockusch (2000), e seu derivado proposto nesta tese, o Mapa Topológico Incremental Classificador (MTIC), são exemplos de redes neurais auto-organizáveis que crescem em conformidade com a apresentação dos estados do espaço de entrada.

\subsubsection{Mapa Topológico Incremental (MTI)}

Critérios geométricos, de modo distinto dos critérios estatísticos não dependem do levantamento de uma grande quantidade de informação, são uma alternativa interessante para a geração de mapas auto-organizáveis. Neste sentido, a rede MTI (em inglês, ITM - Instantaneous Topological Map) proposta por Jockusch (2000), e Jockusch e Ritter (1999), é particularmente interessante. Esta rede é inicializada com dois vértices ${ }^{24}$ interconectados $^{25}$ e seu crescimento segue passos pré-determinados de funcionamento para aprender a distribuição de densidade de um dado espaço de entrada (o ambiente) do qual são amostrados estímulos $\xi$ :

1. Encontre o vértice $n$ mais próximo e o segundo mais próximo $s$ do estímulo $\xi$ pela distância Euclidiana.

$$
n=\underset{i}{\arg \min }\left\|\xi-w_{i}\right\|, s=\underset{j, j \neq n}{\arg \min }\left\|\xi-w_{j}\right\|
$$

\footnotetext{
${ }^{24}$ Neste texto há equivalência entre vértice (de um grafo) e nó (de uma rede neural).

${ }^{25}$ No caso da aplicação em navegação, adotou-se que um destes primeiros vértices é associado com a posição inicial do robô, e o segundo vértice corresponde a esta posição inicial acrescida de um pequeno ruído.
} 
sendo $i, j, n$ e $s \in M$, em que $M$ é o mapa topológico

2. Mova o vetor de referência do vértice $n$ na direção do estímulo $\xi$ por um fator $\in$ :

$$
\Delta w_{n}=\in\left(\xi-w_{n}\right)
$$

3. Crie uma aresta $\overline{n s}$ conectando $n$ e $s$ caso esta não exista. Ao criar uma nova aresta, teste para cada vértice $m \in N(n)$, em que $N(n)$ é o conjunto dos vértices conectados a $n$, se alguma das arestas $\overline{n m}$ já existentes se tornou uma aresta que não obedece a triangulação de Delaunay pelo critério estabelecido em (5.5). Se for o caso, elimine tal aresta.

$$
\forall m \in N(n): \text { Se }\left(w_{n}-w_{s}\right) \cdot\left(w_{m}-w_{s}\right)<0 \text {, remova } \overline{n m}
$$

sendo $w_{s}, w_{n}$ e $w_{m}$ os vetores referência dos vértices $s, n$ e $m$, respectivamente. Quando eliminar uma aresta, caso o vértice $m$ desconectado passe a ficar sem nenhum vizinho, remova este vértice.

4. Caso o estímulo $\xi$ satisfaça ambos critérios a seguir:

$$
\left(w_{n}-\xi\right) \cdot\left(w_{s}-\xi\right)>0 \quad \text { e } \quad\left\|w_{n}-\xi\right\|>e_{\max }
$$

crie um novo vértice $y, \operatorname{com} w_{y}=\xi$, conecte os vértices $y$ e $n$ por uma aresta $\overline{n y}$ e, caso:

$$
\left\|w_{n}-w_{s}\right\|<0.5 * e_{\max }
$$

remova o vértice $s$.

As relações geométricas (5.5)-(5.7) utilizadas pelo MTI permitem o aprendizado rápido do mapa topológico do espaço de entrada por utilizarem apenas informação local. Para compreender estas relações, deve-se destacar que o MTI busca realizar uma triangularização de Delaunay (George, 1991; Martinetz e Schulten, 1994). Uma característica de tal processo é que a cada triângulo de Delaunay pode se associar um círculo que o circunscreve, e dentro destes círculos não podem estar quaisquer dos vetores usados como vértices para a triangularização26 (George, 1991). Para garantir que o MTI satisfaça esta característica, a Equação (5.5) verifica se o vértice $s$ está dentro do círculo que tem seu diâmetro entre os vértices $n$ e $m$ (Figura 5.3). Em caso afirmativo, a triangulação não está sendo satisfeita (Figura 5.3.a) e retira-se a aresta mais antiga $\overline{n m}$, mantendo-se a aresta recém criada $\overline{n s}$ por trazer nova informação sobre o ambiente; caso contrário, o MTI continua a satisfazer a triangularização de Delaunay mesmo com a nova aresta $\overline{n s}$.

As Equações (5.5)-(5.6) também buscam garantir a permanência da citada característica da triangulação de Delaunay quando um novo vértice é criado no MTI: caso um novo estímulo $\xi$ esteja fora do círculo que tem seu diâmetro entre os vértices $n$ e $s$, e a uma distância $e_{\max }{ }^{27}$ do vértice

\footnotetext{
${ }^{26}$ Esta característica é chamada de “critério da esfera vazia” (George, 1991).

${ }^{27} \mathrm{O}$ parâmetro $e_{\max }$ é usado para estabelecer o tamanho dos triângulos.
} 
n, então um novo vértice pode ser criado satisfazendo o "critério da esfera vazia".

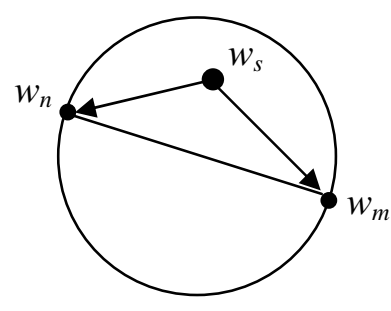

$\left(w_{n}-w_{s}\right) \cdot\left(w_{m}-w_{s}\right)<0$

(a)

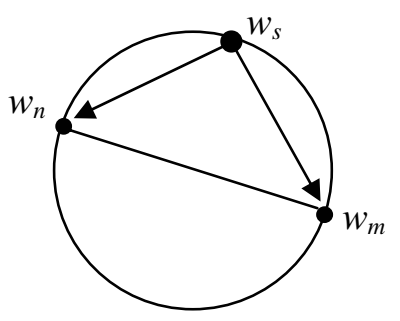

$\left(w_{n}-w_{s}\right) \cdot\left(w_{m}-w_{s}\right)=0$

(b)

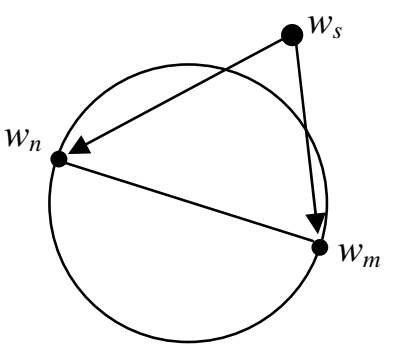

$\left(w_{n}-w_{s}\right) \cdot\left(w_{m}-w_{s}\right)>0$

(c)

FIGURA 5.3 - Posição relativa do vértice $s$ (representado pelo seu vetor referência $w_{s}$ ) com relação ao círculo com diâmetro nos vértices $n$ e $m$ ( $w_{n}$ e $w_{m}$, respectivamente): (a) interno ao círculo; (b) na fronteira do círculo e (c) externo ao círculo.

Uma limitação do MTI é sua dependência do parâmetro $e_{\max }$. Este parâmetro representa a resolução da discretização do espaço de entrada realizado pelo mapa $M$, e uma escolha inadequada de $e_{\max }$ pode levar o mapa a não preservar algumas das relações de vizinhança (informação utilizada no $A T A R)$ presentes neste espaço. Assim, um estudo para a escolha de $e_{\max }$ deve ser realizado para a escolha de um valor adequado a um dado espaço de entrada. Para não precisar do ajuste de um parâmetro tão crucial na geração de $M$ e que demanda prévio conhecimento do ambiente, um novo mapa topológico inspirado no MTI, e que não mantém dependência com parâmetros pré-definidos, é proposto na próxima subseção.

\subsubsection{Mapa Topológico Incremental Classificador (MTIC)}

No lugar de se pré-estabelecer uma resolução para a discretização do ambiente, o MTI realiza isto através do $e_{\max }$, propõem-se um mapa topológico, o Mapa Topológico Incremental Classificador (MTIC), que não realiza uma discretização uniforme do espaço de entrada gera, de forma mais autônoma, uma representação mais compacta deste espaço ao criar seus vértices e arestas em consonância com a complexidade do ambiente. Para tal, adotou-se como critério de crescimento da rede uma informação que o agente pode obter localmente durante sua movimentação: a classificação dos estados à sua volta (ver Seção 2.3). O mapa $M$ é inicializado de forma a classificar todo o ambiente como formado por estados livres e, conforme a classificação dada a uma região seja incompatível com as leituras dos sensores, novos vértices são acrescidos a $M$ para corrigir erros de classificação. A cada vértice $n$ do mapa topológico $M$ associou-se uma classe $C_{n}$ que indica se o vértice corresponde a uma região livre ou obstáculo (Figura 5.4). 


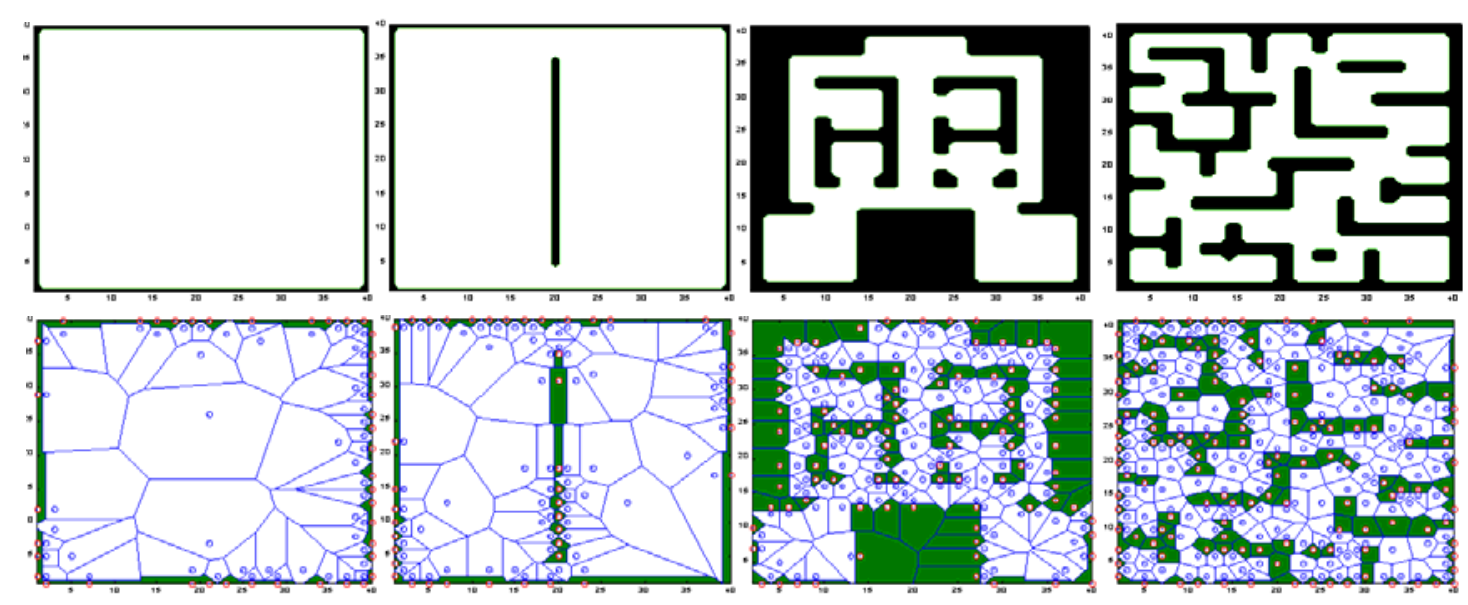

FIGURA 5.4 - Exemplos de geração dos vértices do mapa (segunda linha) a partir da classificação dos estados sensoriados durante a exploração dos ambientes (primeira linha) pelo robô. Regiões classificadas como livres estão em branco. Regiões classificadas como obstáculos estão em verde.

A exemplo do MTI, o critério para a geração das arestas é geométrico e baseia-se em uma triangulação incremental de Delaunay (Watson, 1981). O mapa $M$ é inicializado conforme a Figura 5.4 , e as posições dos vértices são estabelecidas de forma que cubram todo o ambiente ${ }^{28}$. O critério para a geração de vértices depende da classe do vértice $n$ mais próximo ao estímulo $\xi$ corresponder à informação sensorial observada. Os três passos descritos abaixo constituem o Mapa Topológico Incremental Classificador (MTIC).

1. Casamento: Encontre o vértice $n$ mais próximo do estímulo $\xi$ pela distância Euclidiana.

$$
n=\underset{i}{\arg \min }\left\|\xi-w_{i}\right\|
$$

sendo $i$ e $n \in M$. Em que $M$ é o mapa topológico formado por vértices associados a estados livres e a obstáculos (ver Seção 2.3).

2. Adaptação dos vértices: Seguindo o princípio adotado por Milán e colegas (2002) de atualizar o mapa topológico apenas quando necessário, e não uma medida de erro verificada a intervalos fixos de tempo (Fritzke, 1994 e 1995) ou seguindo uma resolução pré-estabelecida (Jockusch e Ritter, 1999 e Jockusch, 2000), no MTIC um novo vértice é acrescido à $M$ apenas caso $C_{n}$ (a classificação associada ao vértice $n$ definido na Eq. 5.8) não corresponda à classe de $\xi$. Este novo vértice terá como vetor referência a posição do estímulo, e será da mesma classe que $\xi$.

3. Adaptação das arestas: Sendo o mapa topológico $M$ uma triangulação de Delaunay, considerase $T=\left\{T_{1}, T_{2}, \ldots, T_{k}\right\}$ como o conjunto dos triângulos formados pelo vértices do mapa $M$. Ao acrescentar um novo vértice a $M$, as arestas do mapa topológico são refeitas de forma a manter o critério de esfera vazia (George, 1991) de uma triangularização de Delaunay: dentro de cada círculo que circunscreve um triângulo de Delaunay não pode estar nenhum dos vértices empregados na triangularização. Assim, deve-se cumprir duas etapas: (i) descobrir quais 
triângulos são afetados pela inclusão do novo vértice e (ii) realizar uma triangularização local incremental dentro do polígono $P$ formado pelos triângulos com a inclusão do novo vértice. A implementação destas etapas é descrita abaixo, utilizando primitivas geométricas (Fortune, 1987).

3.1. Determinação dos triângulos afetados: Duas primitivas geométricas (Fortune, 1987) são utilizadas para determinar quais os triângulos do conjunto $T$ são afetados pelo estímulo $\xi$ : (i) o teste de orientação e (ii) o teste de ponto interior à circunferência. $O$ teste de orientação verifica a orientação de uma seqüência de pontos. Dados os vértices $n_{1}=\left(x_{1}, y_{1}\right)$, $n_{2}=\left(x_{2}, y_{2}\right), n_{3}=\left(x_{3}, y_{3}\right)$ que formam o triângulo $T_{n} \in T$, a orientação é dada por:

$$
\operatorname{Orient}\left(n_{1}, n_{2}, n_{3}\right)=\operatorname{sign}\left(\operatorname{det}\left[\begin{array}{lll}
x_{1} & y_{1} & 1 \\
x_{2} & y_{2} & 1 \\
x_{3} & y_{3} & 1
\end{array}\right]\right)
$$

Caso a orientação tenha valor nulo, os três pontos são colineares (Figura 5.5.b), a orientação +1 indica que os vértices estão na seqüência horária (Figura 5.5.a) e a orientação -1 indica que os vértices estão na seqüência anti-horária (Figura 5.5.c).

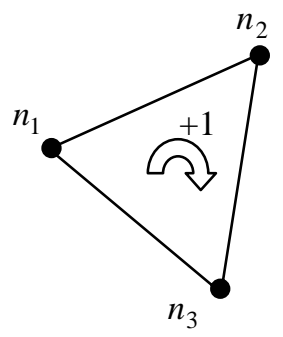

(a)

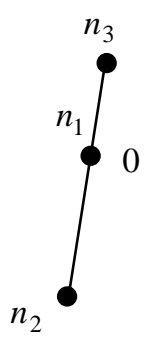

(b)

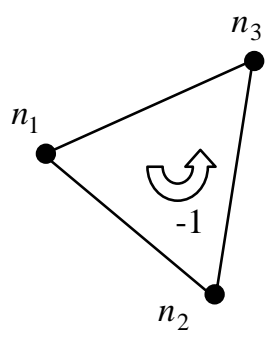

(c)

FIGURA 5.5 - Possíveis configurações para os três pontos: (a) Em seqüência horária, (b) Colineares ou (c) Em seqüência anti-horária.

O círculo que circunscreve um triângulo é o único círculo que passa por cada um de seus três vértices. Dados os vértices $n_{1}=\left(x_{1}, y_{1}\right), n_{2}=\left(x_{2}, y_{2}\right), n_{3}=\left(x_{3}, y_{3}\right)$ que formam o triângulo $T_{n}$, sabendo-se a orientação destes três vértices, e o estímulo $\xi=(\mathrm{x}, \mathrm{y})$, o teste para saber se $\xi$ é ponto interior à circunferência associada a $T_{n}$ é realizado a partir do valor de:

$$
\operatorname{Interior}\left(\xi, T_{n}\right)=\operatorname{orient}\left(n_{1}, n_{1}, n_{1}\right) \cdot \operatorname{sign}\left(\operatorname{det}\left[\begin{array}{cccc}
x^{2}+y^{2} & x & y & 1 \\
x_{1}^{2}+y_{1}^{2} & x_{1} & y_{1} & 1 \\
x_{2}^{2}+y_{2}^{2} & x_{2} & y_{2} & 1 \\
x_{3}^{2}+y_{3}^{2} & x_{3} & y_{3} & 1
\end{array}\right]\right)
$$

caso o valor seja +1 o estímulo $\xi$ é externo ao círculo (Figura 5.6.a), caso seja nulo o estímulo pertence ao círculo (Figura 5.6.b) e caso seja -1 o estímulo é interior ao círculo (Figura 5.6.c).

${ }^{28} \mathrm{Na}$ ausência de informação sobre o ambiente, basta iniciar os quatro primeiros vértices de $M$ com valores elevados. 


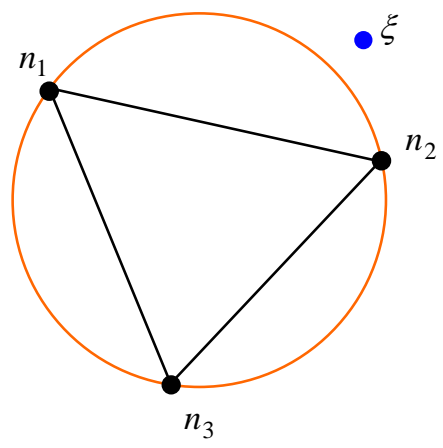

(a)

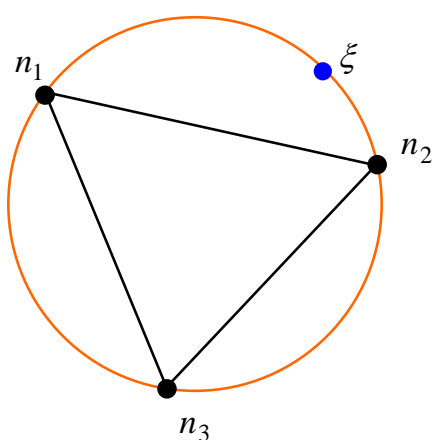

(b)

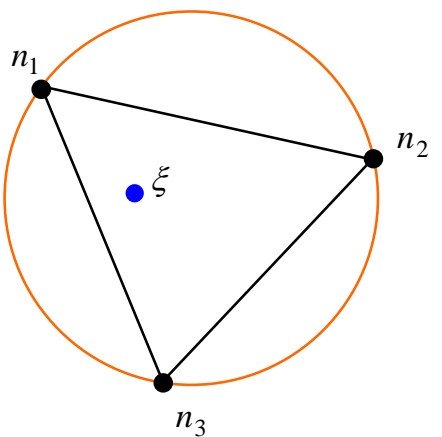

(c)

FIGURA 5.6 - Possíveis configurações para círculo que circunscreve o triângulo $T_{n}$ formado pelos pontos $\left(n_{1}, n_{2}, n_{3}\right)$ e o estímulo $\xi$ : (a) Estímulo externo ao círculo, (b) Estímulo pertencente ao círculo ou (c) Estímulo interno ao círculo.

3.2. Triangularização local incremental: $O$ conjunto dos triângulos que fazem com que a Eq. 5.10 tenha valor -1 formam um polígono $P$ (Figura 5.7.b). As arestas internas a $P$ são eliminadas e novas arestas são criadas conectando o novo vértice com os vértices do polígono (Figura 5.7.c).

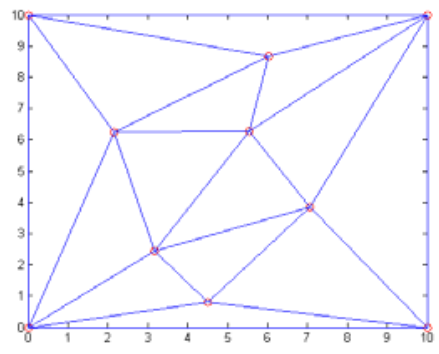

(a)

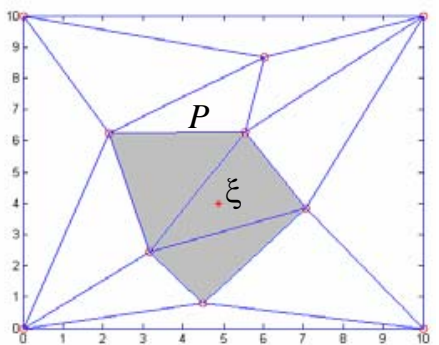

(b)

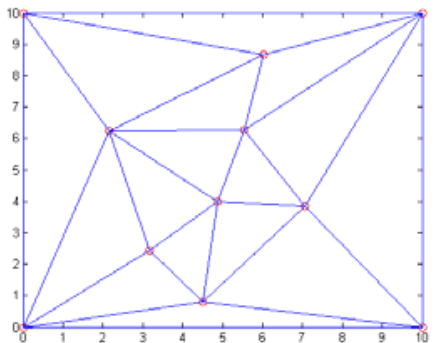

(c)

FIGURA 5.7 - Exemplo de triangularização local incremental: (a) Mapa topológico inicial, (b) Ocorrência do estímulo $\xi$, e exibição do polígono $P$ formado pelos triângulos cujos círculos contêm o novo estímulo e (c) Novo mapa topológico.

Conforme Watson (1981), a triangularização local da Figura 5.7 mantém o critério de esfera vazia da triangularização de todo o mapa $M$.

O MTI e o MTIC serão utilizados nos resultados do Capítulo 6. A próxima seção descreve o ATAR independente do mapa topológico utilizado.

\subsection{O Agente Topológico de Aprendizagem por Reforço (ATAR)}

De acordo com a visão para trás (backward view) comentada em (Sutton e Barto, 1998), sempre que um agente AR alcançar o estado meta, esta informação é propagada para trás no espaço de estados/estados-ações. Conforme já apresentado, a principal idéia do presente trabalho é executar tal propagação em menos passos ao efetuar menos atualizações da função de avaliação que outros algoritmos AR, usando as vizinhanças topológicas aprendidas pelo mapa auto-organizável. A 
função de avaliação é estimada por vizinhanças topológicas, permitindo a atualização das avaliações de todos os estados pertencentes a uma dada vizinhança topológica.

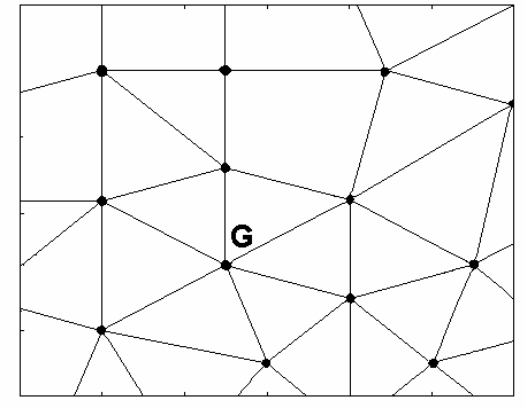

(a)

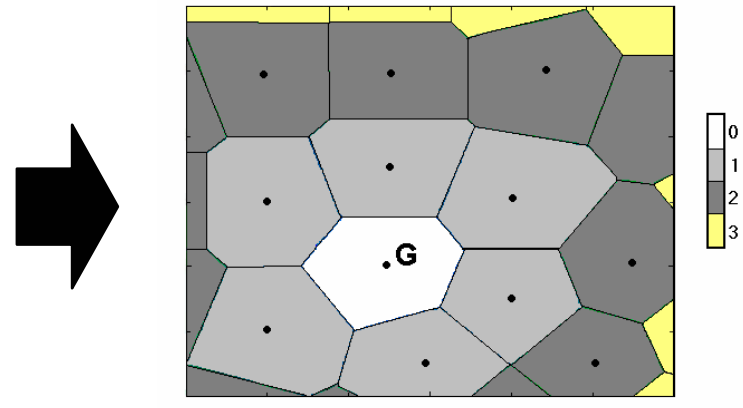

(b)

FIGURA 5.8 - (a) Uma região de um mapa topológico aprendido - com destaque no vértice G. (b) Vizinhanças (0-3) da célula de Voronoi que contém o vértice $\mathrm{G}$ - as cores indicam as vizinhanças consideradas: células de mesma cor estão a um mesmo número de arestas do vértice $G$.

A Figura 5.8 mostra como um mapa auto-organizável pode discretizar o ambiente, dividindo-o em regiões. Na Figura 5.8.a um mapa é formado por vértices, representados por seus vetores referência, e conectados por arestas. Conforme já mencionado na Subseção 5.2, diz-se que este mapa é gerado a partir de uma triangularização de Delaunay (Martinetz e Schulten, 1994). Associada a cada vértice $n$ deste mapa há uma região, chamada de célula de Voronoi (George, 1991; Kohonen, 2001), formada pelos pontos que estão mais próximos de $n$ que de qualquer outro vértice do mapa auto-organizável. A discretização do ambiente vista na Figura 5.8.b é o conjunto das células de Voronoi dos vértices do mapa topológico e é denominada de diagrama de Voronoi (George, 1991; Kohonen, 2001). Como na aprendizagem latente biológica, a questão é como utilizar este mapa. Para o problema de navegação tratado (Capítulo 2), os vértices do mapa representam estados livres no ambiente (a célula de Voronoi associada a cada vértice é um conjunto de estados que mantêm uma proximidade espacial e que se assume terem valores muito próximos em sua função de avaliação) e as arestas representam transições permitidas (que não devem levar o agente a colidir com obstáculos do ambiente) entre estes estados livres. Como um exemplo da forma adotada para propagar o erro TD com o auxílio do mapa auto-organizável, tome-se um dado vértice $G$ representando o estado meta (Figura 5.8.a) - a função de avaliação objetiva atribuir a mesma avaliação aos estados pertencentes a cada vizinhança aprendida. Na Figura 5.8.b, as células de Voronoi da mesma cor representam as vizinhanças topológicas consideradas - os números 0-3 indicam o número de arestas dos estados de uma dada vizinhança para a meta. Assim, a Figura 5.8.b mostra 4 vizinhanças da célula de Voronoi do vértice G: vizinhanças 0, 1, 2 e 3.

A abordagem anteriormente descrita possui similaridades com os métodos de campo potencial (Khatib, 1986), isto é, as curvas de nível exercem um papel análogo ao das vizinhanças topológicas. Assim, todos os estados de uma vizinhança topológica particular possuem a mesma avaliação. Para estabelecer as vizinhanças topológicas e calcular suas avaliações, o Agente Topológico de 
Aprendizagem por Reforço utiliza cinco atributos ${ }^{29}$ em cada vértice: $w$, arestas, $V, Q$, r e $e$ (Figura $5.9)$.

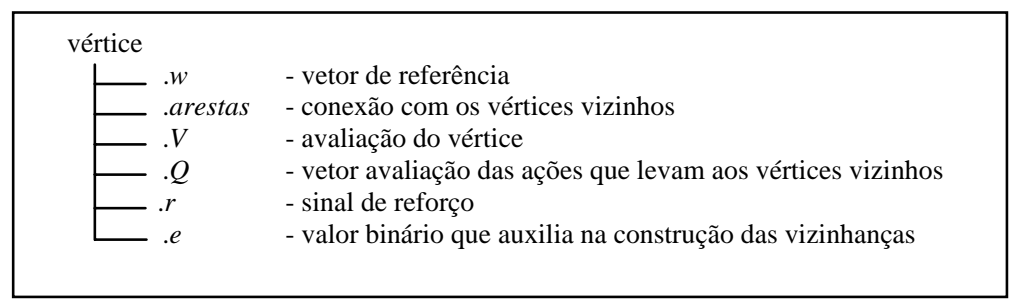

FIGURA 5.9 - Atributos dos vértices do ATAR.

Cada atributo $w$ guarda um vetor de referência associado ao vértice, no caso da tarefa de navegação estes vetores indicam as posições de cada vértice no espaço bidimensional. $\mathrm{O}$ atributo arestas armazena as conexões entre um vértice $n$ e seus vértices vizinhos. A avaliação associada ao vértice é guardada no atributo $V$. Um vetor $Q$ guarda a avaliação das ações que levam aos vértices vizinhos. $\mathrm{O}$ sinal de reforço observado nos estados associados ao vértice é representado em $r$. O atributo $e$ é usado para construir vizinhanças como as mostradas na Figura 5.8.b.

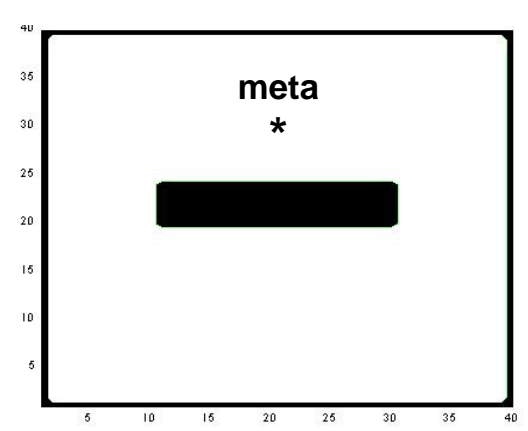

(a)

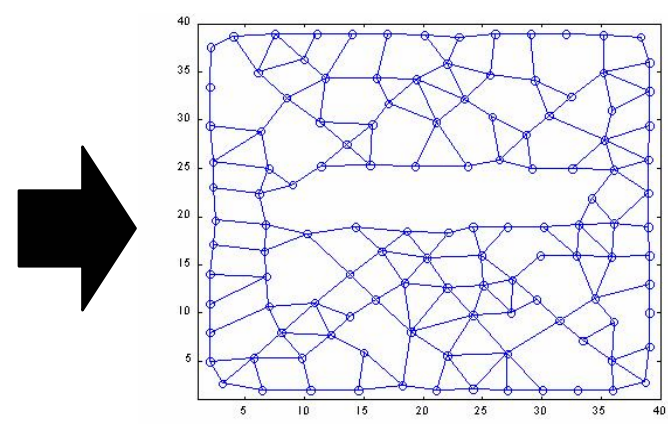

(b)

FIGURA 5.10 - (a) Sala simples com uma barreira na qual um único estado meta é especificado. (b) Exemplo de um mapa topológico gerado para representar o ambiente de (a).

Inicialmente, todos os vértices têm seus atributos $e$ iguais a zero. As atualizações na função de avaliação e o reconhecimento das vizinhanças topológicas ocorrem interativamente. Quando uma vizinhança $k$ é definida, os atributos $V$ de todos os vértices nesta vizinhança assumem um mesmo valor $V_{k}$ atualizado com base no retorno real observado do ambiente e o valor de avaliação da vizinhança predecessora, $V_{k-1}$.

Para melhor entendimento do processo, a construção das vizinhanças topológicas para o ambiente mostrado na Figura 5.10.a e seu correspondente mapa topológico (Figura 5.10.b) é ilustrada na Figura 5.11. A construção das vizinhanças topológicas começa com a Vizinhança 0 $(\mathrm{k}=0)$. Esta é formada simplesmente pelo vértice meta, isto é, o vértice espacialmente mais próximo do estado meta. Seu atributo $e$ é modificado para $1(e=1)$. No passo seguinte, a Vizinhança $1(\mathrm{k}=1$ na Figura 5.11) é definida pelo conjunto de vértices dados pelo atributo arestas do vértice meta cujos

\footnotetext{
${ }^{29}$ Quando a implementação do mapa topológico é feita com o MTIC, o atributo $r$ também serve como classificador do vértice.
} 
atributos $e$ sejam nulos. Em seguida à construção da Vizinhança 1, os atributos $e$ de seus vértices são mudados para 1 e novamente a vizinhança seguinte, a Vizinhança 2 ( $k=2$ na Figura 5.11), é formada pelos vértices nos atributos arestas da atual vizinhança cujos os atributos $e$ sejam nulos. Todo vez que uma nova vizinhança é determinada seus vértices têm seus atributos $e$ assinalados para 1. Este processo é finalizado quando a última vizinhança é construída. O mapa topológico do ambiente da Figura 5.10.b possui doze vizinhanças topológicas exibidas na Figura 5.11.

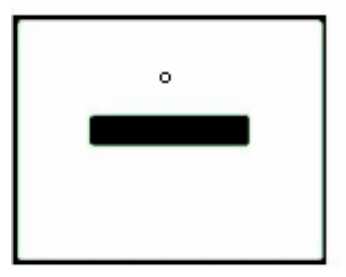

$\mathbf{k}=\mathbf{0}$

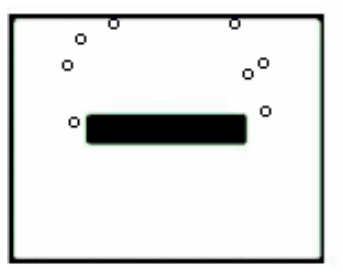

$\mathbf{k}=\mathbf{4}$

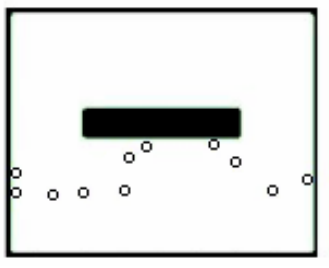

$\mathbf{k}=\mathbf{8}$

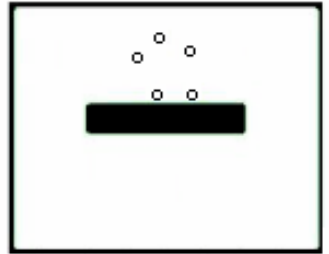

$\mathbf{k}=\mathbf{1}$

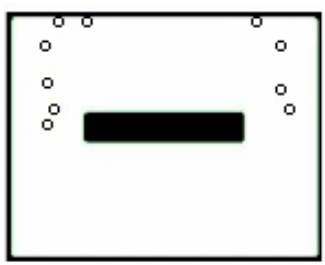

$\mathbf{k}=\mathbf{5}$

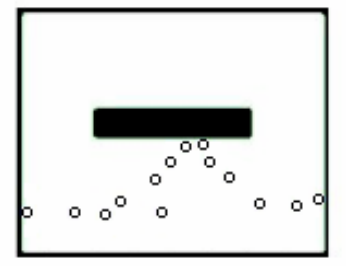

$\mathbf{k}=\mathbf{9}$

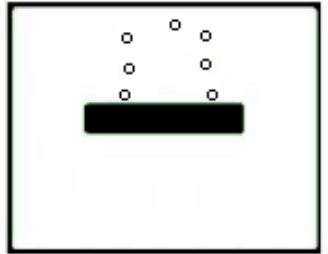

$\mathbf{k}=\mathbf{2}$

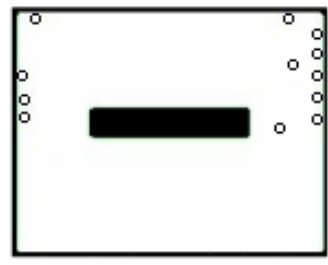

$\mathbf{k}=\mathbf{6}$

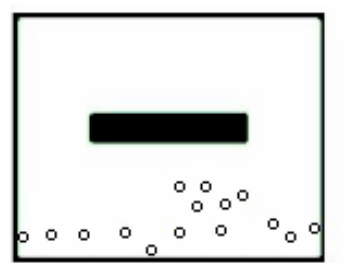

$\mathbf{k}=\mathbf{1 0}$

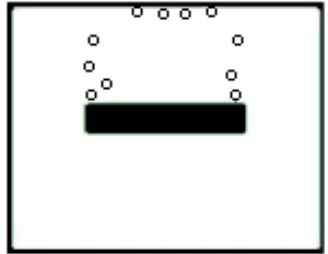

$\mathbf{k}=\mathbf{3}$

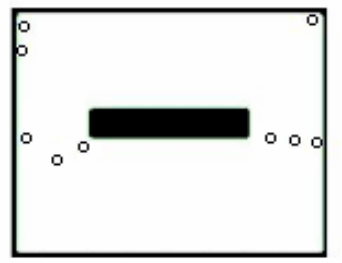

$\mathbf{k}=7$

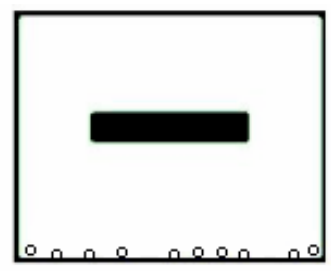

$\mathbf{k}=\mathbf{1 1}$

FIGURA 5.11 - Vértices representando as $k=0, \ldots, 11$ vizinhanças topológicas do estado meta para o ambiente da Figura 5.10.

Duas versões de mecanismo de propagação das atualizações da função de avaliação foram criadas para o $A T A R$ : (i) o $A T A R$ 1, um algoritmo que trata do caso em que há um único estado com sinal de reforço não-nulo, o estado meta com $r=1$ e a área de influência (Subseção 5.1.1) da meta é todo o espaço de entrada, criado como caso de estudo da viabilidade da estratégia de atualizar a estimativa da função de avaliação por vizinhanças topológicas e (ii) o $A T A R$ 2, uma versão incremental do $A T A R 1$ que trabalha com funções de retorno mais complexas do que um único estado com reforço não-nulo e que trata com regiões de influência diferentes para cada estado visitado. As subseções seguintes discutem como cada versão realiza a assinalação de créditos. Nos dois casos a geração do mapa $M$ pode ser realizada em fase pré-assinalação de créditos ou interativamente com as atualizações da função de avaliação - sendo mais adequada a primeira opção para as situações que tratem de ambientes não-estruturados. 


\subsubsection{Versão 1 do Agente Topológico de Aprendizagem por Reforço (ATAR 1)}

Esta primeira versão possui um funcionamento semelhante ao da regra de atualização descrita na Eq. 5.1 quando o espalhamento é dado por $H(s)=\gamma^{k}$. Uma vez que $s_{t+1}$ seja a meta, todos os estados pertencentes a uma mesma vizinhança topológica da meta recebem a mesma avaliação conforme o algoritmo (Braga e Araújo, 2003):

1. Para $\forall s \in N^{k}\left(s_{t+1}\right), k=1,2,3, \ldots, N_{v i z}$, 1.1. $V_{k}=r_{k-1}+\gamma V_{k-1}$

sendo $k$ o número da vizinhança topológica, $N(s)$ o conjunto dos estados em uma mesma vizinhança de $s, V_{k}$ a avaliação dos vértices da vizinhança $k, N_{\text {viz }}$ o número total de vizinhança e $r_{k} \mathrm{O}$ retorno observado nos vértices da vizinhança $k$. Conforme os resultados em Braga e Araújo (2003), este algoritmo possui um desempenho similar, ou superior em alguns casos, ao de algoritmos baseados em traços de elegibilidade e ao Dyna- $Q$ nos ambientes estruturados simulados.

\subsubsection{Versão 2 do Agente Topológico de Aprendizagem por Reforço (ATAR 2)}

O ATAR 1 possui uma regra determinística aplicável a um tipo específico de problema, ambiente estruturado com um único estado de reforço não nulo, servindo mais como uma forma básica de demostrar o funcionamento e o desempenho da idéia geral do $A T A R$, mas não é aplicável a uma gama maior de problemas de AR. A segunda versão do ATAR é uma proposta incremental para o $A T A R 1$ capaz de tratar uma gama maior de problemas. $\mathrm{O}$ algoritmo é resumido no dois passos abaixo:

1. Para $\forall s \in N^{1}\left(s_{t+1}\right)$,

1.1. Erro_tD $=r\left(s_{t+1}\right)+\gamma V\left(s_{t+1}\right)-Q\left(s, a_{s s_{t+1}}\right)$

1.2. Caso $\mid$ Erro_TD $\mid>\phi$,

$$
1 \cdot 2 \cdot 1 \cdot Q\left(s, a_{s s_{t+1}}\right)=Q\left(s, a_{s s_{t+1}}\right)+\alpha \cdot E_{1} o_{-} T D
$$

1.2.2. $V(s)=\max _{a} Q(s, a)$

1.2.3. $\theta=\theta+\mid$ Erro_TD $\mid$

2. Caso $\theta>\theta_{0}$,

2.1. $\theta_{0}=0$

2.2. Para $\forall s \in N^{k}\left(s_{t+1}\right), \quad k=2,3,4, \ldots, N_{\text {viz }}, V(s)<V\left(s_{t+1}\right)$ e $r(s)=0$,

2.2.1. $s_{b}=\arg \max _{b \in N^{1}(s)} V(b)$

2.2.2. Erro_TD' $=r\left(s_{b}\right)+\gamma N\left(s_{b}\right)-Q\left(s, a_{s s_{b}}\right)$

$2.2 .3 . Q\left(s, a_{s s_{b}}\right)=Q\left(s, a_{s s_{b}}\right)+\alpha \cdot$ Erro_$_{-} T D^{\prime \prime}$

$2.2 .4 . V(s)=\max _{a} Q(s, a)$ 
sendo $\phi$ um limite inferior para erro na estimativa das avaliações, $\theta$ um acumulador dos erros TD, $\theta_{o}$ um valor máximo para o acumulado dos erros $\mathrm{TD}, N^{k}(s)$ a vizinhança topológica $k$ do estado $s$.

O Passo 1 do ATAR 2 garante que a cada transição de estados sejam realizadas atualizações das avaliações dos estados na Vizinhança 1 de $s_{t+1}$ caso o erro seja maior que um patamar. O Passo 2 realiza a atualização da avaliação dos estados pertencentes à região de influência de $s_{t+1}$ caso o acumulado dos erros seja elevado. Outra diferença desta versão do $A T A R$ é que as atualizações das avaliações no passo 2 são feitas de forma a aproximar diretamente a função de avaliação ótima como na Aprendizagem-Q, e não pelo espalhamento de um único erro-TD como na Equação 5.1.

\subsubsection{Execução da Política do $A T A R$}

Para cada estado de uma célula de Voronoi, a seleção das ações busca alcançar o vértice vizinho com maior avaliação. A seleção da ação do agente é definida pelo vetor referência do vértice vizinho que tenha maior avaliação, assim a política segue a seguinte expressão $0^{30}$ :

$$
\pi(s)=\underset{i \in A(s)}{\arg \max }\left\{\mathbf{v}_{d} \cdot \mathbf{v}_{i}\right\}
$$

sendo $A(s)$ o conjunto das possíveis ações a partir do estado $s$, os vetores $\mathbf{v}_{\boldsymbol{i}}$ estão associados a cada ação $\boldsymbol{i}$ de $A(s)$ representando as transições de estado esperadas (Figura 2.2.b) na forma:

$$
\mathbf{v}_{1}=(-1,1) ; \mathbf{v}_{2}=(0,1) ; \mathbf{v}_{3}=(1,1) ; \mathbf{v}_{4}=(1,0) ; \mathbf{v}_{5}=(1,-1) ; \mathbf{v}_{6}=(0,-1) ; \mathbf{v}_{7}=(-1,-1) ; \mathbf{v}_{\mathbf{8}}=(-1,0)
$$

e o vetor $\mathbf{v}_{\boldsymbol{d}}$ é definido como:

$$
\mathbf{v}_{d}=\mathbf{w}_{\text {vence }}-\mathbf{s}
$$

sendo $\mathbf{w}_{\text {vence }} \mathrm{O}$ vetor referência associado ao vértice vizinho de maior avaliação e $\mathbf{s}$ o estado atual. Caso múltiplos vértices vizinhos apresentem a mesma avaliação superior aos demais, um dentre estes vértices com maior avaliação é escolhido aleatoriamente.

\subsection{Melhoria das Trajetórias Iniciais}

Conforme comenta Thrun (1998), trajetórias geradas a partir de mapas topológicos tendem a ser sub-ótimas. Isto ocorre basicamente devido aos diferentes tamanhos das regiões cobertas pelas células de Voronoi associadas aos vértices do mapa. Para buscar melhorar estas trajetórias, tornando-as com um menor número de transições de estados ao suavizá-las, duas alternativas são estudadas:

\footnotetext{
${ }^{30}$ A política adotada foi uma $\varepsilon$-greedy (Sutton e Barto, 1998) em que a ação é selecionada com probabilidade 1- $\varepsilon$ pela Equação 5.11, e com probabilidade $\varepsilon$ por uma estratégia de exploração.
} 
1) A regressão sobre os valores da função de avaliação aprendida pelo $A T A R$. A regressão busca, dado um conjunto de pontos, ajustar uma curva que, pelo critério dos mínimos quadráticos, esteja à menor distância de todos os pontos dados.

2) Manipular o mapa topológico para reduzir o número de transições de estados ao buscar ligações diretas entre os vértices início e meta.

As subseções seguintes apresentam a implementação destas alternativas e os resultados conseguidos.

\subsubsection{Melhoria das trajetórias com uma rede RBF incremental}

Tomando-se como saídas desejadas os valores estimados da função de avaliação nos vértices do mapa topológico do $A T A R, \hat{\boldsymbol{y}}=\left[n_{1} . V, n_{2} . V, \ldots, n_{p} . V,\right]^{\mathrm{T}}$, sendo $n_{i \cdot} V$ o valor do atributo $V$ (Figura 5.7) do vértice $n_{i}$ do mapa topológico do $A T A R$ e $p$ o número de vértices do mapa, a rede RBF usada seleciona suas funções de base conforme Fritzke (1994b): a cada vértice $n_{i}$ é associada uma gaussiana cujo raio $r_{i}$ (desvio padrão da gaussiana) é calculado como o valor médio do tamanho de todas as arestas que partem de $n_{i}$ e o centro é o vetor de referência associado ao vértice, $\boldsymbol{c}_{i}=n_{i} \boldsymbol{w}$ (atributo vetor de referência do vértice $n_{i}$ ). A idéia é que a gaussiana de $n_{i}$ se sobreponha de forma limitada às gaussianas dos vértices vizinhos. O vetor de pesos da RBF é calculado por (Orr, 1996):

$$
\boldsymbol{w}_{\mathrm{RBF}}=\boldsymbol{A}^{-1} \boldsymbol{H}^{\mathrm{T}} \hat{\boldsymbol{y}}
$$

sendo:

$$
\begin{aligned}
& \boldsymbol{A}^{-1}=\left(\boldsymbol{H}^{\mathrm{T}} \boldsymbol{H}+\boldsymbol{\Lambda}\right) \quad \text { - a matriz de variância. } \\
& \boldsymbol{H}=\left[\begin{array}{cccc}
h_{1}\left(\boldsymbol{x}_{1}\right) & h_{2}\left(\boldsymbol{x}_{1}\right) & \cdots & h_{m}\left(\boldsymbol{x}_{1}\right) \\
h_{1}\left(\boldsymbol{x}_{2}\right) & h_{2}\left(\boldsymbol{x}_{2}\right) & \cdots & h_{m}\left(\boldsymbol{x}_{2}\right) \\
\vdots & \vdots & \ddots & \vdots \\
h_{1}\left(\boldsymbol{x}_{p}\right) & h_{2}\left(\boldsymbol{x}_{p}\right) & \cdots & h_{m}\left(\boldsymbol{x}_{p}\right)
\end{array}\right] \quad \text { - a matriz de projeto (design matrix). } \\
& h_{i}(\boldsymbol{x})=\exp \left(-\frac{\left\|\boldsymbol{x}-\boldsymbol{c}_{i}\right\|^{2}}{r_{i}{ }^{2}}\right) \quad \text { - a função de base associada ao vértice } n_{i} \text {. } \\
& \boldsymbol{\Lambda}=\left[\begin{array}{cccc}
\lambda_{1} & 0 & \cdots & 0 \\
0 & \lambda_{2} & \cdots & 0 \\
\vdots & \vdots & \ddots & \vdots \\
0 & 0 & \cdots & \lambda m
\end{array}\right] \quad \begin{array}{l}
\text { - é uma matriz diagonal cujos elementos não- } \\
\text { (Orr, 1996). }
\end{array}
\end{aligned}
$$


Os pontos $\boldsymbol{x}_{j}{ }^{\prime}$ s dados para a construção da matriz $\boldsymbol{H}$ de projeto são os vetores de referência dos vértices do mapa topológico de $A T A R$, e os parâmetros de regularização foram ajustados todos iguais. Ao aplicar a rede RBF descrita para as avaliações esboçadas na Figura 5.12.a (função de avaliação obtida pelo $A T A R$ no ambiente E1), obtém-se conseguida uma versão mais suave da estimativa da função de avaliação (Figura 5.12.b). Como o ATAR gera sua trajetória buscando sempre estados com uma avaliação maior, comparando-se as curvas de nível das superfícies antes (Figura 5.12.c) e após a regressão (Figura 5.12.d) percebe-se que as mudanças de direção do agente deverão ser menos bruscas ao usar as avaliações da Figura 5.12.b.

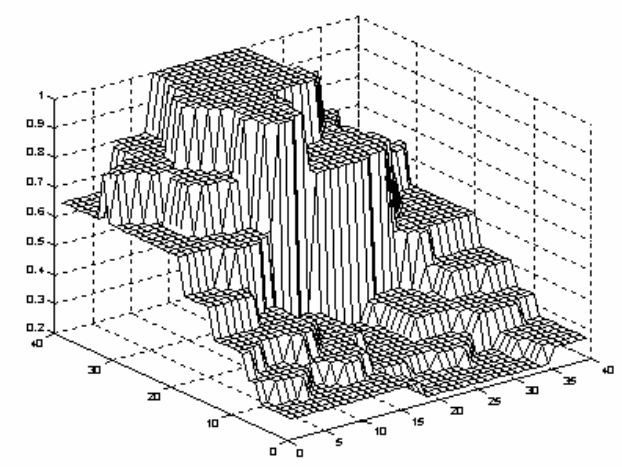

(a)

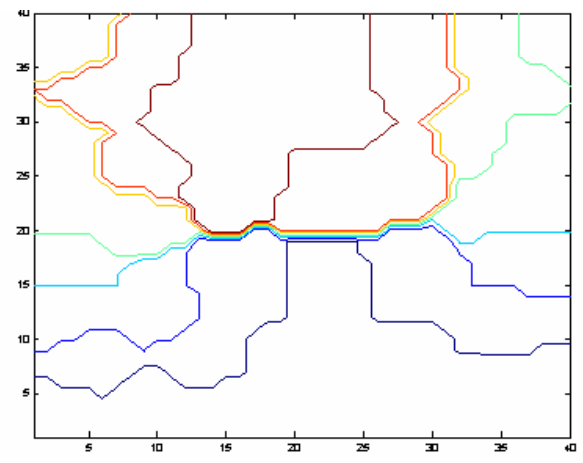

(c)

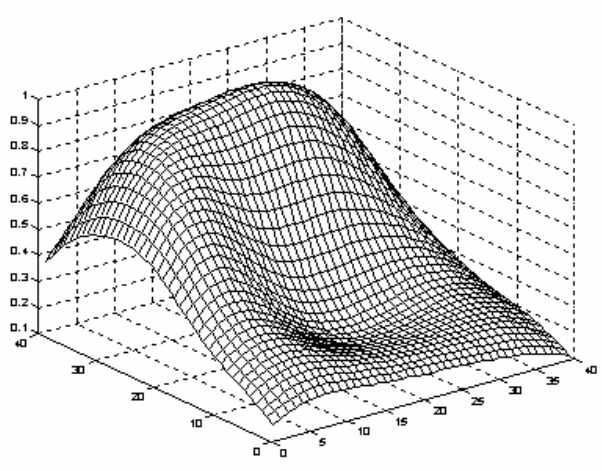

(b)

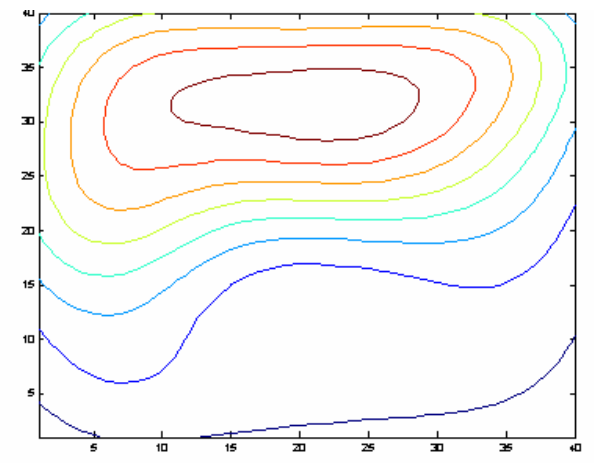

(d)

FIGURA 5.12 - (a) Estimativa da função de avaliação gerada pelo ATAR para a tarefa de navegação do ambiente da Figura 5.10.a; (b) Superfície obtida a partir da regressão da estimativa da função de avaliação gerada pelo ATAR; (c) Curvas de nível da estimativa da função de avaliação gerada pelo ATAR; (d) Curvas de nível da superfície gerada a partir da regressão da estimativa da função de avaliação gerada pelo ATAR.

Dois exemplos das mudanças observadas nas trajetórias são apresentadas na Figura 5.13. Percebe-se que com o uso da rede RBF estas passam a realizar menos mudanças de direção, tornando-se mais suave, e estando aparentemente mais próximas do critério de otimalidadade considerado: menor número possível de transições de estados. 


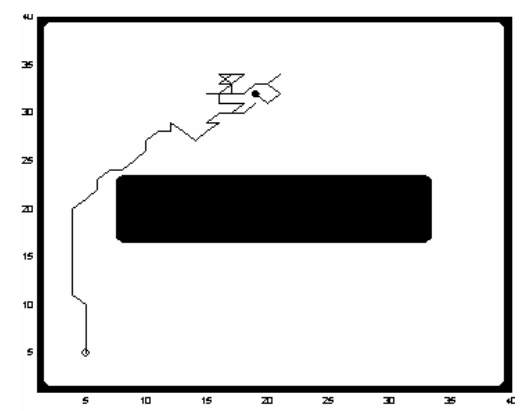

(a)

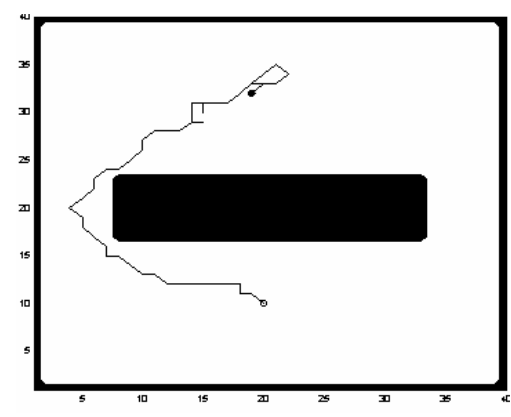

(c)

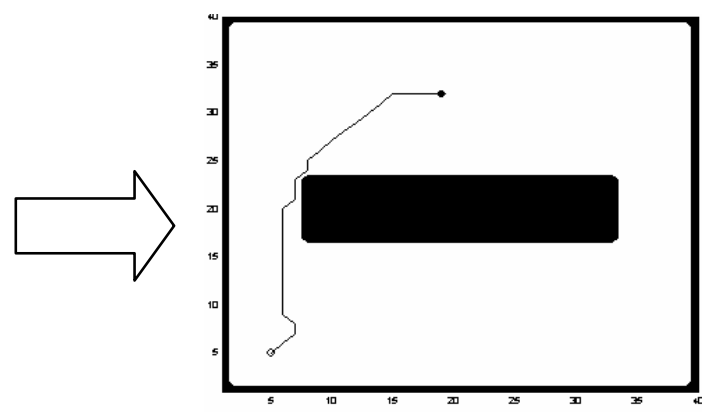

(b)

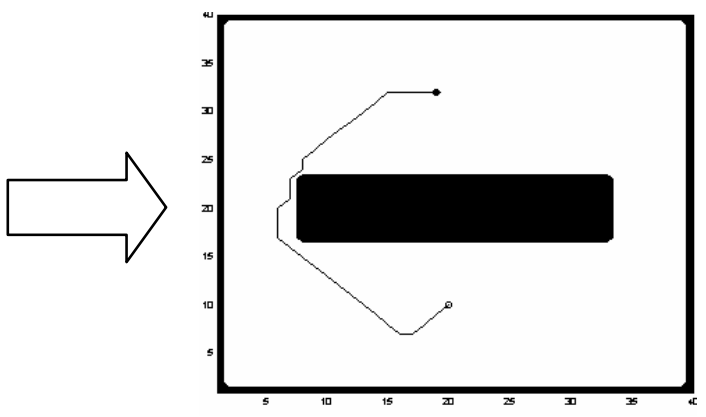

(d)

FIGURA 5.13 - (a) e (b) Trajetórias geradas antes e depois, respectivamente, da regressão da estimativa da função de avaliação obtida com o ATAR 1 (100 treinamentos) para o agente partindo do estado (5,5). (c) e (d) Trajetórias geradas antes e depois, respectivamente, da regressão da estimativa da função de avaliação obtida com o ATAR 1 (100 treinamentos) para o agente partindo do estado $(20,10)$.

No entanto, a aproximação da função de avaliação pela RBF pode gerar pontos críticos que prendam o agente, ou levá-lo a colidir com obstáculos (Figura 5.14).

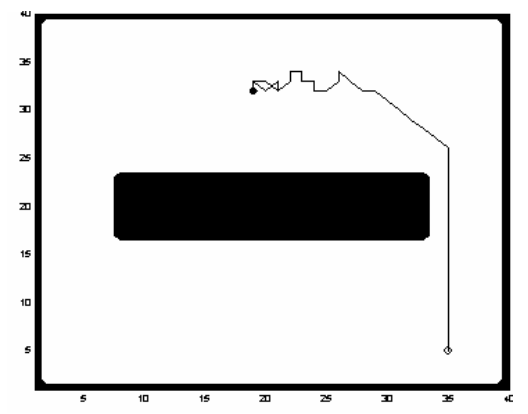

(a)

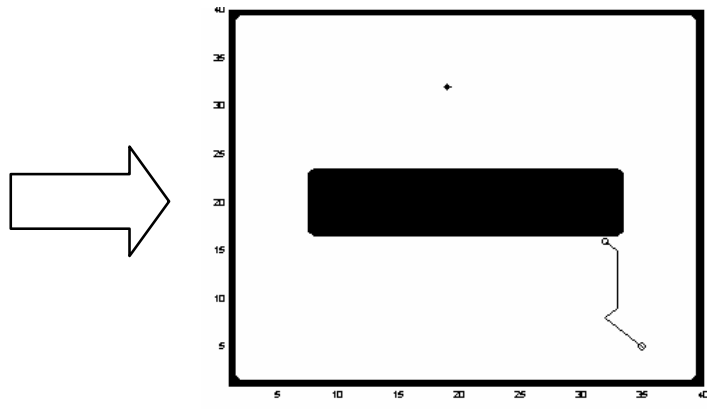

(b)

FIGURA 5.14 - (a) e (b) Trajetórias geradas antes e depois, respectivamente, da regressão da estimativa da função de avaliação obtida com o ATAR 1 (100 treinamentos com o ambiente simples com barreira foram ainda mais sentidos em ambientes mais complexos como) para o agente partindo do estado $(35,5)$.

Estes problemas derivam principalmente de: (i) a aproximação da função de avaliação pela RBF também "suaviza" a função nas arestas dos obstáculos, o que faz com que o agente (que usa a informação da função de avaliação para selecionar as ações) perca a definição de onde começa o obstáculo (a região a ser evitada) e (ii) uma escolha inadequada dos parâmetros de regularização (elementos da diagonal da matriz $\Lambda$ ), o que pode levar ao surgimento de pontos críticos locais na 
função aproximada pela RBF.

\subsubsection{Melhoria das trajetórias por deteç̧ão de ponto interior}

Estabelecida uma trajetória no mapa $\mathrm{M}$, a manipulação é realizada considerando-se apenas os vértices desta trajetória conforme o exemplo da Figura 5.15.

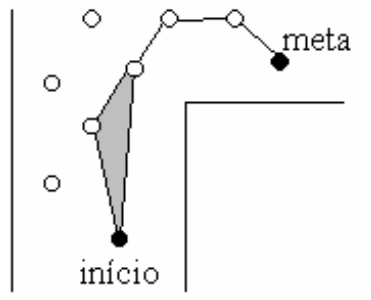

(a)

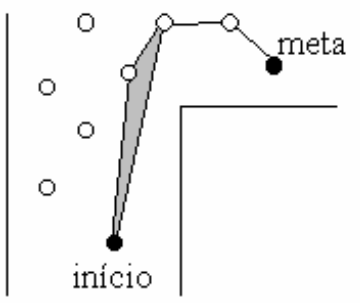

(b)

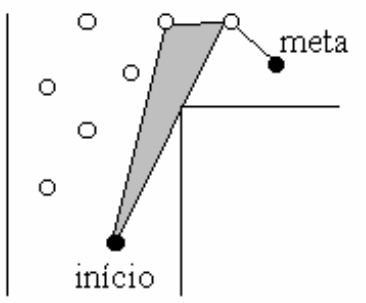

(c)

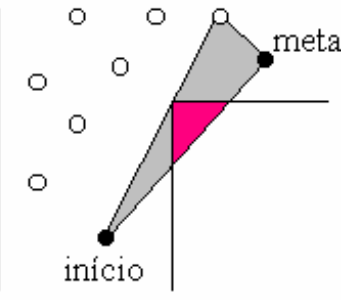

(d)

FIGURA 5.15 - (a) Trajetória original obtida a partir do mapa topológico. (b)-(c) Estágios intermediários da manipulação do mapa. (d) Trajetória final.

Gerada a trajetória original (Figura 5.15.a), testa-se novas conexões (Figuras 5.15.b e c) até que se alcance a melhor conexão direta entre dois vértices da trajetória que não atravesse obstáculos do ambiente. O teste implementado baseia-se em um problema comum na área de geometria computacional: o teste do ponto em um polígono (point in polygon test) (Foley et alli, $1990 \mathrm{e}$ O’Rourke, 1998) - "Dado um ponto $R$ e um polígono fechado $P$ qualquer representado como um conjunto de $m$ pontos $P_{0}, P_{1}, \ldots, P_{m}$, determine se $\mathrm{R}$ é interno ou externo ao polígono $P$ '. Os polígonos $P$ testados são os triângulos $(m=3)$ em destaque na Figura 5.15 formados a partir dos vértices $n_{\text {inicio, }} n_{1}, n_{2}, n_{3}, \ldots, n_{\text {meta }}$ da trajetória gerada no mapa topológico. Os pontos $R$ são os estados classificados como obstáculos no ambiente (ver Seção 2.2). Caso não haja obstáculos internos a esses polígonos (Figura 5.15.a-c), estabelece-se temporariamente uma trajetória direta entre o primeiro e o último dos pontos usados para formar o polígono.

A abordagem adotada para realizar o teste do ponto no polígono é conhecida como número de circulação (winding number), $\omega(\mathrm{R}, P)$, de $R$ com relação a $P$, o qual indica o número de vezes que se contorna $R$ ao caminhar ao longo de $P$ :

$$
\omega(R, P)=\frac{1}{2 \pi} \sum_{i=0}^{m-1} \arccos \left(\frac{\left\langle\overline{R P_{i}}, \overline{R P_{i+1}}\right\rangle}{|\overline{R P}||| \overline{R P_{i+1}} \mid}\right) \cdot \operatorname{sign}\left(\operatorname{det}\left[\begin{array}{ll}
R P_{i}^{x} & R P_{i+1}{ }^{x} \\
R P_{i}^{y} & R P_{i+1}^{y}
\end{array}\right]\right) \text {. }
$$

sendo $P_{i}=w_{i}$ o vetor referência associado ao vértice $n_{i}, \overline{R P_{i}}$ o vetor de $\mathrm{R}$ a $P_{i}, R P_{i}^{x}$ e $R P_{i}{ }^{y}$ as componentes $x$ e $y$ do vetor $\overline{\mathrm{RP}}$.

Por definição, $R$ é interno ao polígono caso o número de circulação (Eq. 5.18) seja diferente de zero. Dois exemplos dos resultados da aplicação deste processo podem ser vistos na Figura 5.16. 


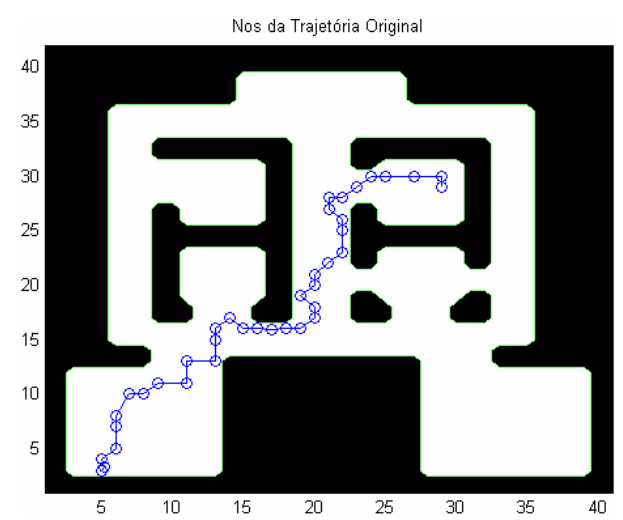

(a)

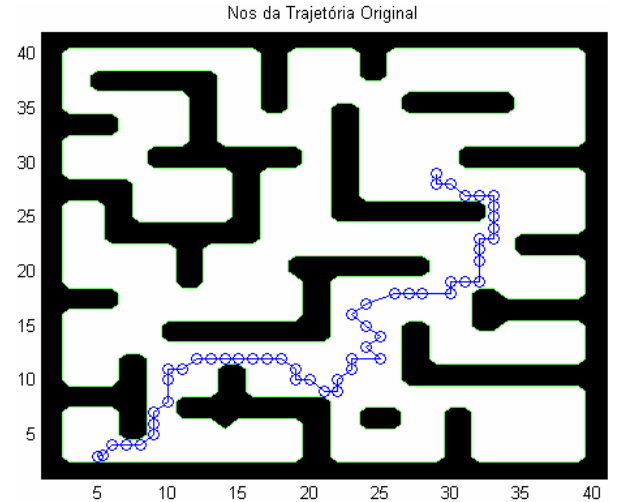

(c)

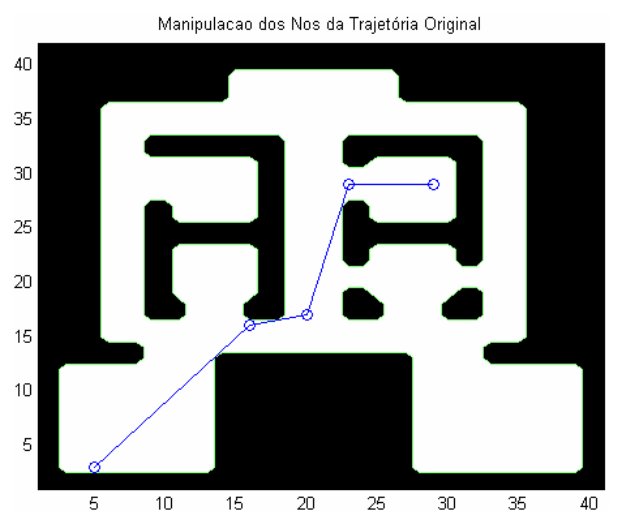

(b)

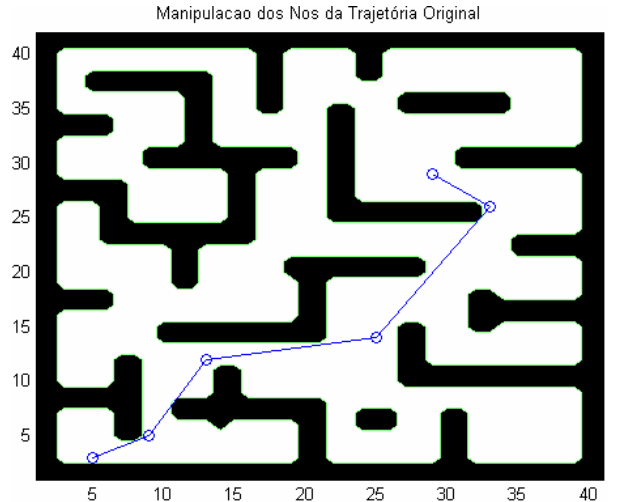

(d)

FIGURA 5.16 - Exemplos de melhoria da trajetória por detecção de ponto interior: (a) e (c) Trajetórias originais gerada a partir do mapa topológico entre um ponto inicial $(5,5)$ e a meta $(29,29)$, (b) e (d) sub-grafos resultantes da aplicação depois do processo de mudanças nas arestas originais entre ponto inicial e meta.

Ao utilizar os grafos das Figuras 5.16.b e d, no lugar dos grafos das Figuras 5.16.a e c, buscase que o agente AR gere trajetórias com um número menor de transições de estados - caminhos mais curtos que poderiam ser estabelecidos entre dois pontos mesmo que passando por regiões não visitadas.

\subsubsection{Comparação entre as duas alternativas de melhoria das trajetórias}

Ambas as alternativas colocadas forneceram trajetórias menores que as originalmente geradas pelo ATAR. Entretanto, além da possibilidade de ocorrência de pontos críticos na regressão da função de avaliação, o esforço computacional envolvido no uso de uma rede RBF para a melhoria das trajetórias torna esta alternativa pouco viável para o processo real considerado de navegação de um robô móvel (Seção 2.3) - a inversão de matriz realizada no cálculo dos pesos da rede (Equação 5.13) consumiria demasiado tempo de processamento conforme se aumentasse o número de vértices do mapa topológico.

A alternativa da detecção de pontos interiores, aplica-se apenas aos vértices da trajetória originalmente gerada pelo $A T A R$, é de aplicação mais simples. 


\subsection{Exploração Direcionada em Representações Não Tabulares}

São dois os motivos principais para não ser direta a passagem das técnicas de exploração direcionada usadas nas representações tabulares para as representações variáveis, como os mapas topológicos utilizados no $A T A R$ :

(i) As representações tabulares costumam conter representações explícitas tanto de estados visitados quanto de estados não-visitados, o que permite inicializar com valores relativamente elevados as medidas de incerteza dos estados não visitados e usar estes valores para guiar a seleção das ações. Em representações variáveis, que vão sendo construídas com a exploração do ambiente, os estados não visitados não possuem uma representação explícita a qual se possa associar uma medida da incerteza o que dificulta a aplicação de uma regra determinística de exploração que sempre siga para o estado menos visitado.

(ii) As representações tabulares costumam considerar que todos os estados possuem o mesmo tamanho e correspondem a uma posição na tabela, o que permite considerar que uma visita a um estado capture toda a informação contida neste estado. Nos mapa auto-organizáveis, os vértices representam grupos de estados. Assim, diversas visitas podem ser necessárias para verificar as informações dos estados contidos nestes grupos. Como estes aglomerados de estados podem ser de tamanhos diferentes, o número de visitas necessárias para cada um deles deve ser diferente.

Diante destes motivos, adotou-se separar a estrutura que representará a função de avaliação, no caso aqui tratado um mapa topológico, da estrutura usada para tratar da incerteza, que será mantida como sendo tabular. Assim, a avaliação total de cada estado será dada por:

$$
V_{\text {total }}(s)=V(s)+V_{\text {incerteza }}(s)
$$

sendo: $V(s)$ a estimativa da avaliação calculada pelo $A T A R$ e $V_{\text {incertea }}(s)$ uma avaliação da incerteza sobre o estado $s$ calculada como os bônus de exploração das técnicas de exploração direcionada tratadas na Seção 4.3. A avaliação da incerteza pode conter informação local (Subseção 4.3.2) ou global (4.3.3).

Para as simulações do Capítulo 6, contadores serão utilizados na implentação da exploração direcionada local. Para a exploração direcionada global, um algoritmo Aprendizagem-Q, uma "função

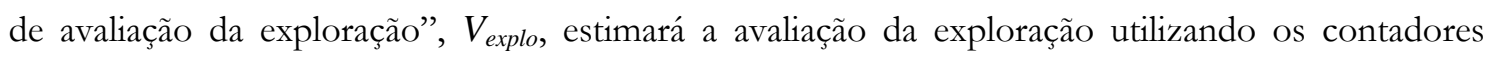
associados a cada estado como sinal de reforço.

\subsection{Discussão e Conclusão}

O propósito da maioria dos algoritmos de aprendizagem por reforço é a política ótima gerada a partir da função de avaliação ótima. Diversas estratégias foram propostas para acelerar a convergência do aprendizado da função de avaliação ótima (veja Kaelbling et alli, 1996 e Sutton e 
Barto, 1998, para uma revisão), entretanto elas usualmente são computacionalmente custosas e/ou muito lentas para aplicações reais por exigir um número elevado de atualizações da estimativa da função de avaliação. No $A T A R$, o aprendizado da função de avaliação também é realizado de forma a aproximar diretamente o seu valor ótimo. Conforme mencionado anteriormente, isto é realizado ao considerar que estados pertencentes a uma mesma vizinhança topológica têm uma mesma avaliação. Esta consideração é consistente com a designação temporal de crédito realizada pelos algoritmos AR padrões uma vez que estados em uma mesma vizinhança topológica, com relação ao estado meta, devem necessitar de um número similar de transições de estado para alcançar este estado meta. Da mesma forma que a Aprendizagem-Q, o ATAR é um algoritmo independente da política uma vez que este não depende diretamente da política adotada, mas sim das vizinhanças topológicas consideradas (veja Seção 5.3).

Para comprovar o desempenho do $A T A R$ com outros algoritmos AR, o próximo Capítulo traz testes para: (i) a confirmação da redução no número de atualizações da função de avaliação, (ii) verificar o comportamento do algoritmo na presença de ruídos, simulando erros de posicionamento em um robô móvel durante o aprendizado da tarefa de navegação, (iii) verificar o comportamento quando da ocorrência de mudanças na estrutura do ambiente, (iv) comparação entre o uso dos mapas MTI e MTIC na implementação do ATAR, (v) os ganhos obtidos com a melhoria das trajetórias por detecção de ponto interno (Subseção 5.4.2) e (vi) os ganhos com mudanças na estratégia de exploração.

Conforme comentado na Subseção 5.3.2, o ATAR 2 é a versão incremental do $A T A R 1$ e de aplicação mais genérica. Assim, os ensaios do Capítulo 6 são realizados apenas sobre o ATAR 2, que desde ponto em diante da tese passa a ser referido apenas como $A T A R$. 


\section{Capítulo 6}

\section{Resultados Finais}

Da revisão apresentada no Capítulo 2 sobre as soluções para o problema da navegação de um robô móvel, vê-se que as pesquisas em robótica móvel evoluíram de uma visão de ambiente estático em que o único componente que se altera é o próprio robô (ambiente estruturado) para uma mais realista em que diversos fatores se modificam no ambiente (ambiente não-estruturado) - desde a forma com que este é percebido pelo robô, até características de sua estrutura. Para avaliar o desempenho do $A T A R$, estes dois tipos de ambiente são considerados e comparações são realizadas com outros algoritmos AR (Apêndice A): considera-se que o ambiente inicialmente desconhecido não se altera com o tempo; e em seguida, toma-se considerações mais próximas do que se observaria em uma implementação real, com um ambiente que além de permanecer inicialmente desconhecido é percebido com erros na estimativa de seus estados e que também apresenta variações ao longo do tempo.

Uma idéia central no $A T A R$ é a de reduzir o número de atualizações da função de avaliação ao realizá-las sobre conjuntos de estados que formam vizinhanças topológicas (Seção 5.3). A aplicação desta idéia em ambientes estruturados é apresentada na Seção 6.1, ficando a Seção 6.2 a tratar de ambientes não-estruturados. Mapas topológicos são utilizados no $A T A R$ como uma representação do ambiente com que o agente está interagindo. Entretanto, muitos autores comentam que o uso de tal representação em problemas de navegação, devido a sua forma de discretizar o ambiente, podem implicar em trajetórias sub-ótimas. Como forma de contornar tal limitação no ATAR, a Seção 6.3 apresenta uma proposta de manipulação do mapa topológico que busca melhorar as trajetórias geradas.

Para melhorar o aprendizado do $A T A R$, um novo mapa topológico mais compacto e menos dependente de parâmetros pré-estabelecidos foi visto na Subseção 5.2.2. A Seção 6.4 apresenta os resultados conseguidos com esta segunda versão do $A T A R$ e as mudanças de desempenho verificadas. Outro ponto também testado para melhorar o $A T A R$ foi a adoção de uma estratégia direcionada de exploração (Seção 4.3). As contribuições conseguidas com a nova estratégia são tratadas na Seção 6.5. A Seção 6.6 encerra este Capítulo resumindo os resultados conseguidos, enfatizando as contribuições do $A T A R$ na solução do problema proposto e suas limitações, sempre tomando por comparação outros algoritmos AR referenciados na literatura. 


\subsection{O ATAR em Ambientes Estruturados}

Considera-se um ambiente inicialmente desconhecido, imutável e perfeitamente observável pelo robô, o desempenho do ATAR no problema de navegação descrito no Capítulo 2 é testado e os resultados são comparados com os obtidos com seis algoritmos AR (veja parâmetros usados para testes no Apêndice B): (i) Aprendizagem-Q(0) (Watkins, 1989); (ii) $S A R S A(0)$ (Rummery, 1995); (iii)

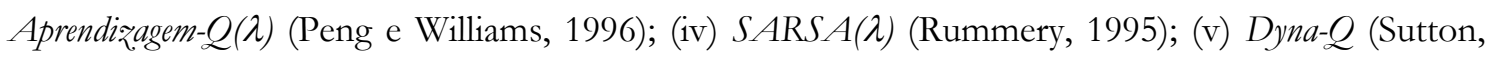
1991) e (vi) Aprendizagem-Q( $\lambda$ ) rápida (Wiering e Schimidhuber, 1998a). Tal tarefa de navegação considera um agente que se move em seu ambiente, evitando obstáculos, de forma a alcançar uma posição meta pré-estabelecida que é reconhecida pelo agente, logo o agente descobre sua posição meta apenas quando a alcança. As quatro configurações da Figura 2.5 foram usadas para testar o desempenho dos agentes AR. A função de retorno (Sutton e Barto, 1998) é dada por:

$$
r_{t+1}=\left\{\begin{array}{l}
1, \text { caso seja } s_{t+1} \text { o estado meta } \\
0, \text { caso contrário }
\end{array}\right.
$$

Dois critérios de desempenho foram considerados para comparar os algoritmos AR:

- Critério de desempenho 1 (C1): Calcula o tamanho (número de passos) da trajetória partindo de um dado ponto inicial até a meta após cada treinamento.

- Critério de desempenho 2 (C2): Calcula o número de atualizações da função de avaliação após cada treinamento.

Para o levantamento dos dados, foram rodados 100 ensaios $^{31}$ para cada um dos algoritmos, em cada um dos quatro ambientes, e cada ensaio foi formado por 100 treinamentos aleatoriamente inicializados do algoritmo. Cada ambiente é uma grade (grid) de 40x40 estados dos quais apenas os estados livres podem ser ocupados pelo agente. O comportamento de cada algoritmo é descrito através das médias sobre os 100 ensaios de cada algoritmo e estes resultados são mostrados nas Subseções 6.1 .1 e 6.1 .2 onde eles são brevemente discutidos. Em ambas subseções, a política adotada pelos agentes AR é uma $\varepsilon$-greedy (Sutton e Barto, 1998) que seleciona uma ação entre as oito mostradas na Figura 2.2.b. A análise estatística dos resultados das subseções anteriores é feita com o auxílio de testes de hipóteses na Subseção 6.1.3.

\subsubsection{Resultados com Relação ao Critério 1}

Em um robô real, cada movimento rotacional e translacional usado para executar ações demanda um intervalo de tempo determinado pelos parâmetros do robô. Caso um grande número de passos de treinamentos seja necessário para gerar trajetórias viáveis então um agente AR não deve ser viável para a aplicação em problemas do mundo real. Portanto, o Critério 1 indica o desempenho da aprendizagem de cada agente AR simulado para diversos treinamentos mostrando o número de

\footnotetext{
${ }^{31}$ Todos os resultados apresentados neste capítulo foram obtidas a partir de rotinas desenvolvidas pelo autor e simuladas no aplicativo MATLAB®.
} 
passos de suas trajetórias geradas (Figura 6.1).
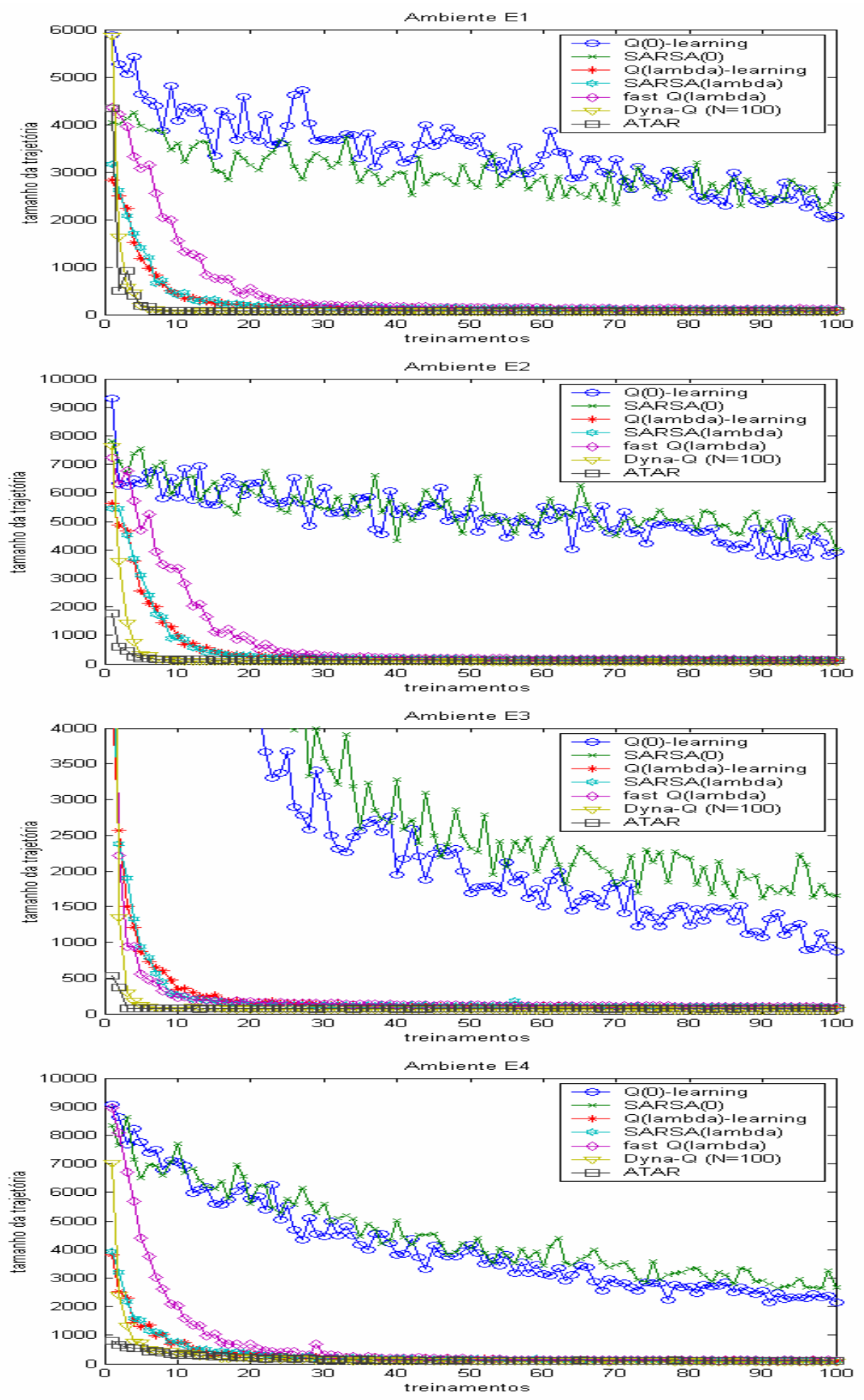

FIGURA 6.1 - Número de passos conectando as posições inicial e final para os sete algoritmos AR simulados, após cada treinamento, considerando os quatro ambientes da Figura 2.2: E1 - Ambiente simples com barreira, E2 Ambiente simples com obstáculo em U, E3 - Ambiente complexo, e E4 - Labirinto.

As curvas da Figura 6.1 sugerem um comportamento similar de cada agente AR em cada um dos quatro ambientes. Isto é, em todos os ambientes, pode-se perceber que o $A T A R$ e o Dyna- $Q$ geraram, na maioria dos treinamentos, as trajetórias mais curtas. No entanto, verifica-se que após o 
primeiro treinamento o ATAR levou em média 134.23 (E1), 166.93 (E2), 87.3 (E3) e 181.36 (E4) passos para alcançar a posição meta, enquanto o Dyna-Q levou 155.58 (E1), 227.14 (E2), 185.39 (E3) e 270.41 (E4) passos. Os algoritmos baseados em traços de elegibilidade alcançaram resultados próximos dos obtidos com o $A T A R$ e o Dyna-Q apenas após o qüinquagésimo treinamento. Os resultados numéricos para os 50 últimos treinamentos são melhor visualizados na Tabela 6.1.

TABELA 6.1 - Média e desvio padrão do número de passos calculados sobre os 50 últimos treinamentos.

\begin{tabular}{|c||c|c|c|c|}
\hline ALGORITMO & E1 & E2 & E3 & E4 \\
\hline \hline Aprendizagem-Q(0) & $2852,0 \pm 441,7$ & $4659,2 \pm 509,5$ & $1590,7 \pm 514,0$ & $3032,2 \pm 446,6$ \\
\hline \hline SARSA $(0)$ & $2704,3 \pm 253,5$ & $5018,2 \pm 455,6$ & $2014,5 \pm 562,1$ & $3439,0 \pm 464,7$ \\
\hline \hline Aprendizagem-Q $(\lambda)$ & $114,0 \pm 9,1$ & $149,6 \pm 9,2$ & $101,7 \pm 7,7$ & $148,0 \pm 22,7$ \\
\hline \hline SARSA $(\lambda)$ & $116,2 \pm 9,0$ & $156,5 \pm 11,6$ & $102,2 \pm 7,9$ & $200,6 \pm 54,2$ \\
\hline \hline Q $(\lambda)$ rápida & $123,9 \pm 12,8$ & $156,5 \pm 13,1$ & $104,2 \pm 7,6$ & $147,2 \pm 20,8$ \\
\hline \hline Dyna-Q & $64,7 \pm 2,6$ & $83,1 \pm 2,7$ & $61,8 \pm 1,7$ & $78,2 \pm 3,7$ \\
\hline \hline ATAR & $72,2 \pm 2,0$ & $138,2 \pm 3,6$ & $72,9 \pm 4,0$ & $91,7 \pm 6,1$ \\
\hline
\end{tabular}

Entre os algoritmos AR testados, os melhores resultados médios para os 50 últimos treinamentos de acordo com C1 foram obtidos pelo Dyna-Q. Na seqüência, o ATAR gerou trajetórias variando de $12 \%$ a $66 \%$ maiores que as do agente Dyna-Q (Tabela 6.1). Os três algoritmos baseados em traço de elegibilidade apresentaram trajetórias com tamanhos muito similares que variavam de $65 \%$ a $80 \%$ maiores que as do Dyna-Q. As trajetórias geradas pela Aprendizagem- $Q(0)$ e pelo $S A R S A(0)$ são as maiores, elas são 30 a 60 vezes maiores que as trajetórias do Dyna-Q.

\subsubsection{Resultados com Relação ao Critério 2}

Conforme mencionado no Capítulo 4, algumas abordagens para acelerar a aprendizagem por reforço são computacionalmente dispendiosas. Elas reduzem o número de treinamentos necessários para alcançar uma solução viável ao custo de um número maior de operações na atualização da função de avaliação. O Critério 2 adotado contabiliza o número de atualizações de cada agente AR simulado em cada treinamento (Figura 6.2).

$\mathrm{Na}$ Figura 6.2, pode-se facilmente observar que o número de atualizações do $A T A R$ nos quatro ambientes é freqüentemente bem menor que o número de atualizações dos demais algoritmos $\mathrm{AR}$ considerados. Isto ocorre porque as atualizações do $A T A R$ são realizadas apenas quando um retorno real é observado e então são mudados os atributos $V$ dos vértices do ITM. Assim, o número de atualizações por treinamento é igual ao número de vértices no mapa topológico.

É fácil observar que mesmo nos primeiros treinamentos o número de atualizações do $A T A R$ é abaixo de 1000, enquanto todos os demais algoritmos AR realizam mais que 4000 atualizações. Após o qüinquagésimo treinamento a Aprendiragem- $Q(\lambda)$ rápida, e em alguns ambientes a 
Aprendizagem-Q(0) e o $S A R S A(0)$, reduzem suas quantidades de atualizações para um número próximo ao do ATAR. Os resultados numéricos dos últimos 50 treinamentos podem ser observados na Tabela 6.2.
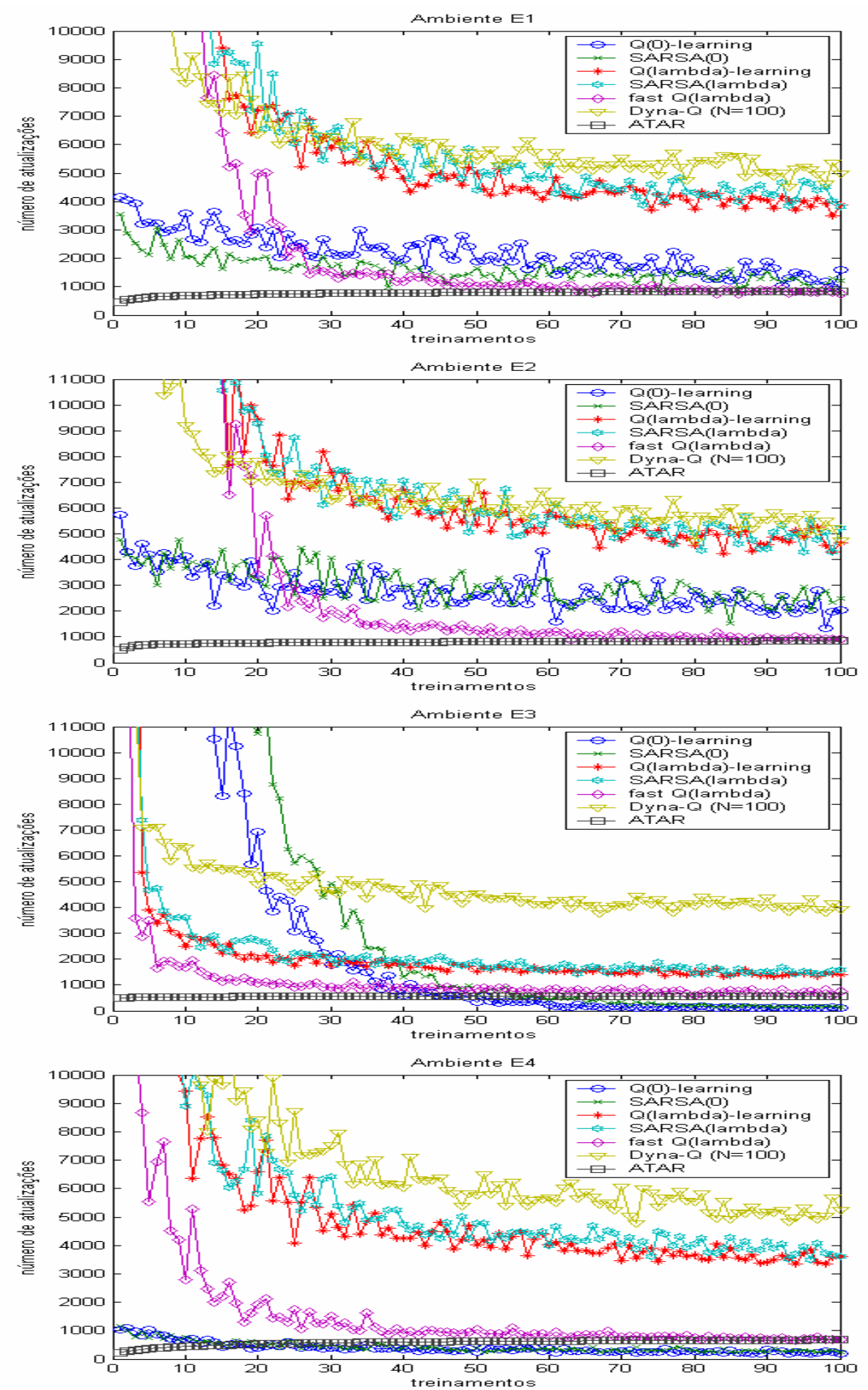

FIGURA 6.2 - Número de atualizações da função de avaliação para os sete algoritmos AR simulados, a cada treinamento, para os quatro ambientes da Figura 2.2: E1 - Ambiente simples com barreira, E2 - Ambiente simples com obstáculo em U, E3 - Ambiente complexo, e E4 - Labirinto. 
TABELA 6.2 - Média e desvio padrão do número de atualizações calculadas para os 50 últimos treinamentos.

\begin{tabular}{|c||c|c|c|c|}
\hline \hline ALGORITMO & E1 & E2 & E3 & E4 \\
\hline \hline Aprendizagem-Q(0) & $1671,8 \pm 352,6$ & $2408,9 \pm 493,0$ & $642,6 \pm 278,1$ & $1201,3 \pm 342,5$ \\
\hline \hline SARSA $(0)$ & $1354,5 \pm 211,7$ & $2608,5 \pm 376,6$ & $788,4 \pm 397,2$ & $1503,6 \pm 319,8$ \\
\hline \hline Aprendizagem-Q $(\lambda)$ & $4193,4 \pm 320,5$ & $5066,7 \pm 444,4$ & $1377,8 \pm 126,9$ & $3841,4 \pm 449,3$ \\
\hline \hline SARSA $(\lambda)$ & $4504,4 \pm 377,0$ & $5234,8 \pm 488,1$ & $1493,5 \pm 122,6$ & $1913,0 \pm 452,2$ \\
\hline \hline Q $(\lambda)$ rápida & $925,7 \pm 101,5$ & $1037,3 \pm 116,0$ & $686,7 \pm 57,4$ & $756,7 \pm 144,9$ \\
\hline \hline Dyna-Q & $5303,7 \pm 316,5$ & $5704,6 \pm 445,0$ & $4347,2 \pm 259,3$ & $5015,1 \pm 435,1$ \\
\hline \hline ATAR & $826,0 \pm 14,1$ & $826,5 \pm 10,2$ & $567,8 \pm 4,2$ & $722,4 \pm 5,5$ \\
\hline
\end{tabular}

Entre os algoritmos AR testados, os melhores resultados para os 50 últimos treinamentos de acordo com o Critério $\mathrm{C} 2$ foram alcançados pelo $A T A R$. Na seqüência, o número de atualizações da Aprendizagem-Q( $\lambda)$ rápida, variando por treinamento entre $4 \%$ e $25 \%$ acima do $A T A R$. O Dyna- $Q$ executa de 6 a 8 vezes mais atualizações que o $A T A R$ (Tabela 6.2). Os algoritmos $A$ prendizagem-Q(O) e $S A R S A(0)$ calculam aproximadamente o dobro de atualizações que o $A T A R$, enquanto suas versões baseadas em traços de elegibilidade executam ainda mais atualizações, algo em torno de 2 a 6 vezes mais que o $A T A R$.

\subsubsection{Consolidação dos Resultados Através de Testes de Hipóteses}

No caso aqui tratado, deseja-se consolidar as hipóteses do $A T A R$ ser melhor que alguns dos agentes AR simulados nos critérios já apresentados. Para tal, recorreu-se a Golden (1996) que sugere o uso de métodos de inferência estatística como os testes de hipóteses para analisar o procedimento mais eficiente dentre um conjunto de procedimentos. Os resultados das seções anteriores compararam as médias obtidas ao longo dos treinamentos realizados, porém testes de hipóteses permitem quantificar o nível de significância que as conclusões são consideradas corretas. Para cada treinamento de cada agente AR simulado, as 100 amostras geradas permitem aproximar uma distribuição do parâmetro medido em cada critério.

\section{Resultados Obtidos}

Para cada treinamento realizado, as 100 amostras obtidas com o ATAR são comparadas com as 100 amostras obtidas com cada um dos demais agentes AR objetivando verificar se as médias do ATAR são menores que as demais médias. Assim, foram realizados 2 (critérios considerados) x 6 (número de agentes AR com que o $A T A R$ foi comparado) $\times 100$ (número de treinamentos) $=1200$ testes de hipóteses cujos resultados estão nas Tabelas 6.3 e 6.4. A Tabela 6.3 indica para cada agente AR, em cada ambiente, o primeiro treinamento onde a hipótese $H_{0}$ : (a média do número de passos das trajetórias geradas pelo $A T A R$ é menor que ou igual à media do número de passos das trajetória de outro algoritmo AR) é rejeitada com nível de significância $0.01(\alpha=1 \%)$. A Tabela 6.4 indica para cada agente AR, em cada ambiente, o primeiro treinamento em que a hipótese $H_{0}$ : (a média do número de atualizações realizadas pelo $A T A R$ é menor que ou igual à média do número 
de atualizações de outro algoritmo AR) é rejeitada com nível de significância 0.01 .

TABELA 6.3 - Primeiro treinamento em que há rejeição da hipótese $\mathrm{H}_{0}$ : a média do número de passos das trajetórias geradas pelo $A T A R$ é menor que a média dos demais agentes AR com nível de significância de 0.01 .

\begin{tabular}{|c||c||c|c|c|}
\hline \hline ALGORITMO & E1 & E2 & E3 & E4 \\
\hline \hline Aprendizagem-Q(0) & Não há & Não há & Não há & Não há \\
\hline \hline SARSA $(0)$ & Não há & Não há & Não há & Não há \\
\hline \hline Aprendizagem-Q $(\lambda)$ & Não há & Não há & Não há & Não há \\
\hline \hline SARSA $(\lambda)$ & Não há & Não há & Não há & Não há \\
\hline \hline Q $(\lambda)$ rápida & Não há & Não há & Não há & Não há \\
\hline Dyna-Q & $53^{\circ}$ & $9^{\circ}$ & $39^{\circ}$ & $65^{\circ}$ \\
\hline
\end{tabular}

Observa-se da Tabela 6.3 que, à exceção do Dyna-Q, todos os agentes AR sempre apresentam, independente da quantidade de treinamentos, trajetórias com uma média de número de passos maior que a média de número de passos das trajetórias do $A T A R$ (na Tabela, Não há indica que, ao longo dos 100 treinamentos, todos os testes indicaram que as médias das trajetórias do ATAR são menores). Uma observação mais consistente nos quatro ambientes é o fato de que em todos o Dyna-Q continua a rejeitar a hipótese nula nos treinamentos seguintes ao primeiro em que há rejeição de $\mathrm{H}_{0}$. Entretanto, se o Dyna- $Q$ acaba por apresentar melhores trajetórias que o $A T A R$ com o aumento dos treinamentos (em alguns ambientes consegue esta melhoria mais rápido do que em outros), nos treinamentos iniciais o $A T A R$ consegue superar o Dyna- $Q$ - em uma situação real, uma solução subótima obtida rapidamente é mais relevante que a obtenção da solução ótima em um horizonte de tempo longo.

TABELA 6.4 - Primeiro treinamento em que há rejeição da hipótese $\mathrm{H}_{0}$ : a média do número de atualizações do ATAR é menor que a média dos demais agentes AR com nível de significância de 0.01 .

\begin{tabular}{|c||c||c|c|c|}
\hline ALGORITMO & E1 & E2 & E3 & E4 \\
\hline \hline Aprendizagem-Q(0) & Não há & Não há & $97^{\circ}$ & $84^{\circ}$ \\
\hline \hline SARSA $(0)$ & Não há & Não há & $96^{\circ}$ & Não há \\
\hline \hline Aprendizagem-Q $(\lambda)$ & Não há & Não há & Não há & Não há \\
\hline \hline SARSA $(\lambda)$ & Não há & Não há & Não há & Não há \\
\hline \hline Q $(\lambda)$ rápida & Não há & Não há & Não há & $59^{\circ}$ \\
\hline \hline Dyna-Q & Não há & Não há & Não há & Não há \\
\hline
\end{tabular}

A Tabela 6.4 mostra que três algoritmos, em alguns dos ambientes testados, realizam um número de atualizações da função de avaliação menor que o $A T A R$, sendo eles: a Aprendizagem-Q(0), o $S A R S A(0)$ e a $\mathrm{Q}(\lambda)$ rápida. Quanto aos dois primeiros, após o primeiro treinamento em que ocorre a rejeição de $\mathrm{H}_{0}$, os demais treinamentos continuam a rejeitar a hipótese nula. $\mathrm{O}$ baixo número de atualizações além de ocorrer apenas em um estágio já avançado dos treinamentos ainda é a principal causa do baixo desempenho deste algoritmo no critério C1. O caso da Aprendizagem-Q( $\lambda)$ rápida é mais interessante por este também gerar trajetórias pequenas rapidamente. Entretanto, só no qüinquagésimo nono treinamento (Tabela 6.4) a $Q(\lambda)$ rápida, pela primeira vez segundo o teste de 
hipóteses, executa menos atualizações que o $A T A R$. No sexagésimo treinamento o $A T A R$ já volta a realizar menos atualizações que a $Q(\lambda)$ rápida, permanecendo assim até o octagésimo nono treinamento, pois no nonagésimo treinamento a $Q(\lambda)$ rápida volta a apresentar um número de atualizações menor que o $A T A R$. Estas alternâncias entre o $A T A R$ e a $Q(\lambda)$ rápida ocorrem pela forma como são realizadas as atualizações da função de avaliação na Aprendizagem-Q( $\lambda$ ) rápida (ver Seção A.5 do Apêndice A): na maior parte do tempo, uma atualização local (que considera apenas as ações que podem ser tomadas a partir do estado atual) é realizada e um erro de truncamento é calculado; quando este erro atinge um patamar, a atualização de todos os pares estado-ação visitados acontece (o que aumenta a média de atualizações). Assim, a $\mathrm{Q}(\lambda)$ rápida alterna entre pequenas e grandes quantidades de atualizações ao longo dos treinamentos, enquanto o $A T A R$ não apresenta grandes variações no número de atualizações da função de avaliação.

\subsection{O ATAR em Ambientes Não-Estruturados}

A ausência total ou parcial de informação sobre o ambiente, tratada na seção anterior, representa um desafio significativo para a aplicação de técnicas de aprendizagem por reforço em ambientes reais. As condições anteriormente tratadas, entretanto, consideravam que os ambientes eram estruturados e não sofriam de outros aspectos observados em aplicações reais que tornam ainda maior o problema de navegação autônoma de um robô móvel.

No caso aqui tratado, para caracterizar um ambiente não-estruturado, estão sendo consideradas duas fontes de incertezas na interação robô-ambiente: (i) Imprecisão nos estados do robô (Nehmzow, 2000) e (ii) Alterações na configuração do ambiente (Gaussier et alli, 2000). Nas duas subseções que se seguem o comportamento do $A T A R$ será observado, em comparação aos mesmos algoritmos tratados na Seção 6.1, diante destas duas fontes de incerteza.

\subsubsection{Imprecisão sobre os Estados do Robô}

Muitos dos trabalhos que aplicam AR em robôs móveis assumem que estimadores de estado conseguem, a partir da informação ruidosa obtida dos sensores, fornecer uma aproximação adequada da localização do agente no ambiente. Entretanto, apesar dos avanços nos sistemas de localização (Fox, 1998; Fox, Burgard e Thrun, 1999; Thrun, 2002), ruídos na estimativa da localização permanecem, devido à natureza da informação utilizada por estes estimadores, e influenciam no desempenho do aprendizado da tarefa de navegação. Assim, os ensaios acompanharam o comportamento de diferentes algoritmos AR em ambientes não-estruturados cuja incerteza sobre os estados do ambiente é modelada por uma distribuição Gaussiana de média zero e variância unitária, e este sinal de ruído é multiplicado por um fator de ruído que permite variar a intensidade do ruído (Figura 6.3). 


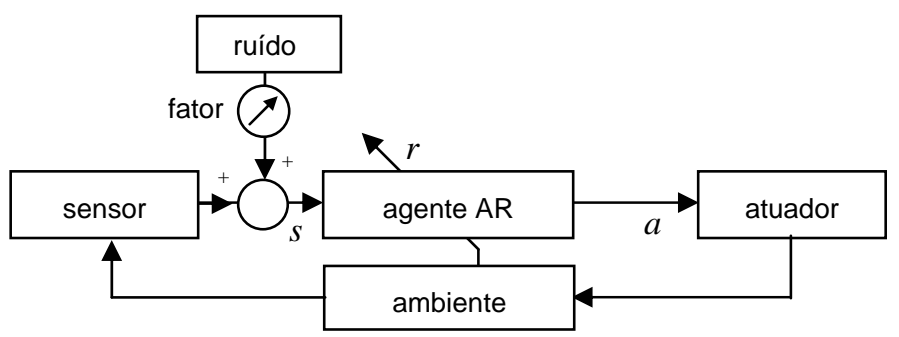

FIGURA 6.3 - Diagrama do ensaio inicial proposto para análise do agente em um ambiente não-estruturado.

Assim como na Seção 6.1, as simulações realizadas consideraram os quatro ambientes da Figura 2.5. Para levantar as curvas de aprendizagem, 20 ensaios de 100 treinamentos foram simulados para cada um dos algoritmos AR. As curvas apresentadas nas Figuras 6.4-6.10 são a média, tomada sobre estes 20 ensaios, do tamanho das trajetórias geradas entre um ponto de partida específico e o estado meta (Figura 2.5), a cada treinamento, variando o fator de ruído nos valores: 0.00, 0.25, 0.50, 0.75 e 1.00. Uma restrição tomada em todos os ensaios realizados foi estabelecer um limite máximo de 10.000 passos para cada treinamento, ou seja, caso o agente AR não consiga alcançar a meta em 10.000 passos um novo treinamento é iniciado e estes passos são contados como a trajetória gerada. A função de retorno dada na Expressão 6.1 é mantida nos experimentos desta Seção. Para facilitar a exposição dos resultados, estes serão apresentados em cinco blocos: (i) algoritmos de 1-passo, (ii) algoritmos com traços de elegibilidade, (iii) algoritmo Dyna-Q, (iv) algoritmo $A T A R$ e (v) degradação do desempenho do aprendizado.

\section{Algoritmos de 1-passo ${ }^{32}$}

A Aprendizagem- $Q$ e o $S A R S A$ são os algoritmos $\mathrm{AR}$ mais simples, mas também são muito utilizados na literatura. Pelas curvas das Figuras 6.4 e 6.5, há um fenômeno aparentemente contraditório no aprendizado destes algoritmos: com o aumento do fator de ruído, visualiza-se uma queda mais acentuada no tamanho das trajetórias - uma melhoria no aprendizado. No caso específico aqui tratado, em que a função de retorno (Eq. 6.1) premia um único estado e não apresenta penalizações, o aumento do ruído beneficia o agente porque este passa não só a atualizar a avaliação dos pares $(s, a)$ visitados, mas também aquela de pares próximos não visitados (devido ao erro no posicionamento), espalhando de forma mais rápida o reforço positivo. $\mathrm{Na}$ ocorrência de reforços negativos, haveria um grande prejuízo no desempenho da estimativa das avaliações pois estados livres e obstáculos seriam confundidos pelo agente com o aumento do fator de ruído.

A exemplo de como a presença de ruídos pode levar o agente a confundir obstáculos com estados livres, tem-se o ambiente E2 (Figura 2.5) em que, pela proximidade do estado inicial e da meta a obstáculos, posições, na tabela que armazena a função de avaliação, correspondentes a obstáculos recebem avaliações de estados livres - levando o agente a ficar preso (ver subida nas curvas referentes aos fatores de ruído 1,00 nas Figuras 6.4.b e 6.5.b) ao tentar alcançar estes obstáculos que possuem uma avaliação elevada na tabela.

32 Tradução da denominação usada em Suton e Barto (1998), 1-step backup, para os algoritmos que estimam a função de avaliação com base em apenas uma transição $\left(s_{t}, a_{t}, s_{t+1}, r_{t+1}\right)$ a Aprendizagem- $Q$ e o $S A R S A$. 
TABELA 6.5 - Acumulado do número de atualizações da função de avaliação para a Aprendizagem-Q ao longo de 100 treinamentos.

\begin{tabular}{|l||c|c|c|c|}
\hline \hline & E1 & E2 & E3 & E4 \\
\hline \hline Fator $=0,00$ & $327.300 \pm 23.336$ & $519.210 \pm 33.607$ & $521.680 \pm 37.017$ & $517.750 \pm 39.040$ \\
\hline \hline Fator $=0,25$ & $321.820 \pm 25.061$ & $515.420 \pm 31.106$ & $493.890 \pm 38.632$ & $496.120 \pm 49.161$ \\
\hline \hline Fator $=0,50$ & $313.530 \pm 20.012$ & $490.620 \pm 27.337$ & $417.320 \pm 37.684$ & $454.160 \pm 39.489$ \\
\hline \hline Fator $=0,75$ & $296.840 \pm 26.559$ & $514.200 \pm 99.098$ & $489.250 \pm 183.940$ & $385.110 \pm 44.551$ \\
\hline \hline Fator $=1,00$ & $356.710 \pm 130.270$ & $705.930 \pm 101.830$ & $606.020 \pm 197.510$ & $336.730 \pm 101.160$ \\
\hline
\end{tabular}

TABELA 6.6 - Acumulado do número de atualizações da função de avaliação para o SARSA ao longo de 100 treinamentos.

\begin{tabular}{||l||c|c|c||c|}
\hline & E1 & E2 & E3 & E4 \\
\hline \hline Fator $=0,00$ & $274.620 \pm 32.445$ & $466.890 \pm 28.409$ & $264.230 \pm 50.391$ & $341.650 \pm 46.770$ \\
\hline \hline Fator $=0,25$ & $261.510 \pm 25.803$ & $451.060 \pm 32.411$ & $220.970 \pm 48.069$ & $310.170 \pm 49.569$ \\
\hline \hline Fator $=0,50$ & $174.260 \pm 29.267$ & $336.950 \pm 53.083$ & $158.150 \pm 38.751$ & $217.870 \pm 58.010$ \\
\hline \hline Fator $=0,75$ & $135.877 \pm 31.376$ & $463.653 \pm 243.400$ & $174.970 \pm 73.474$ & $167.180 \pm 37.752$ \\
\hline \hline Fator $=1,00$ & $135.320 \pm 83.071$ & $855.190 \pm 109.820$ & $196.340 \pm 93.044$ & $170.530 \pm 107.770$ \\
\hline
\end{tabular}

As tabelas 6.5 e 6.6 mostram que o acumulado do número de atualizações da função de avaliação no $S A R S A$ foi, na maioria dos casos, menor que na Aprendizagem- $Q$. Os valores destas tabelas servirão como referência para o custo computacional dos demais algoritmos AR simulados seguindo o critério de desempenho C2 introduzido na Seção 6.1.

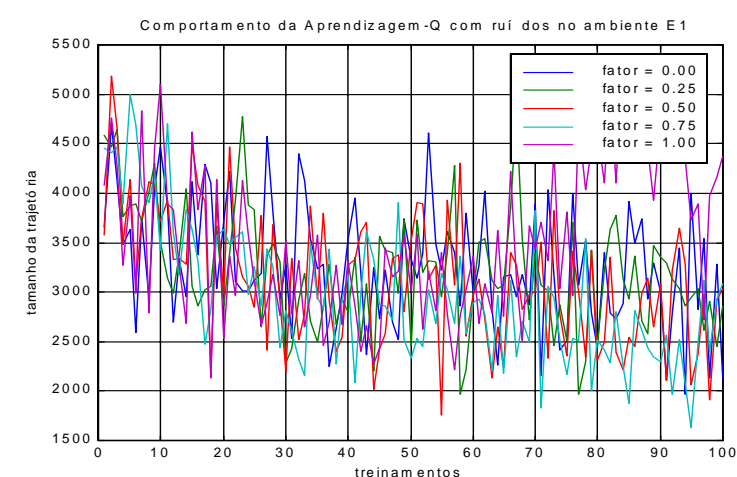

(a)

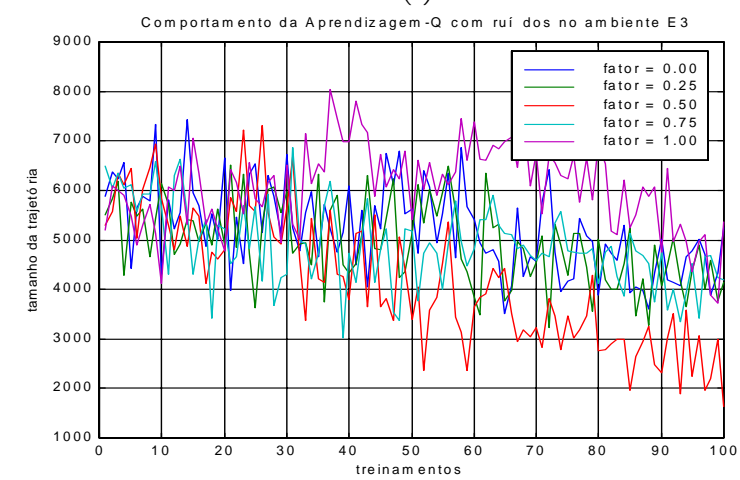

(c)

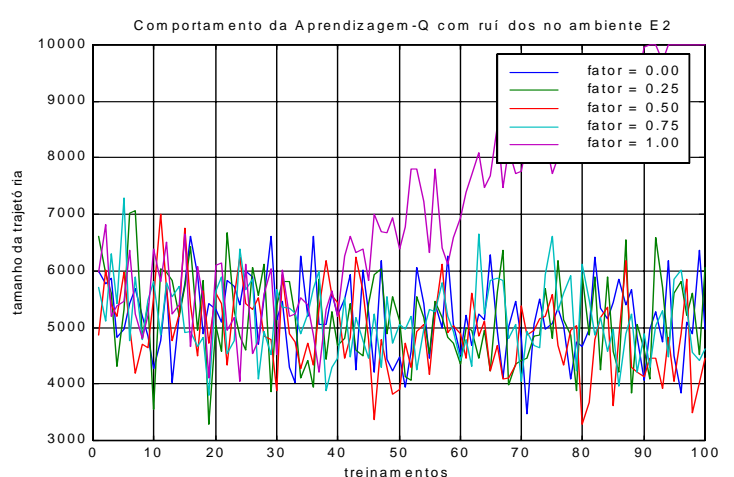

(b)

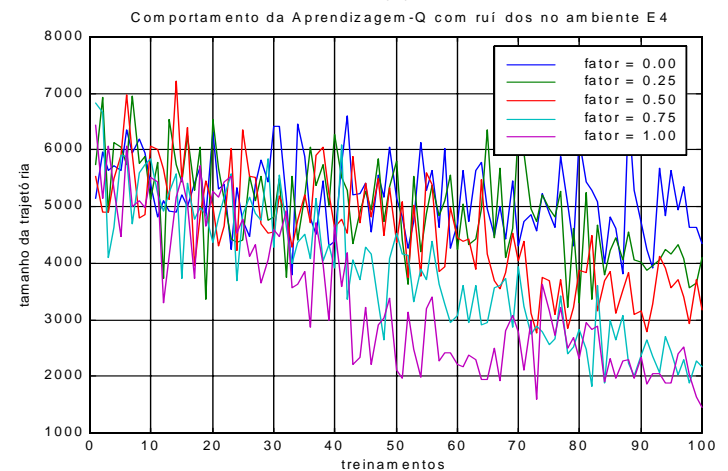

(d)

FIGURA 6.4 - Curvas dos tamanhos das trajetórias geradas pela Aprendizagem-Q, com a evolução dos treinamentos, para cinco diferentes fatores de ruídos nos ambientes: (a) E1, (b) E2, (c) E3 e (d) E4. 


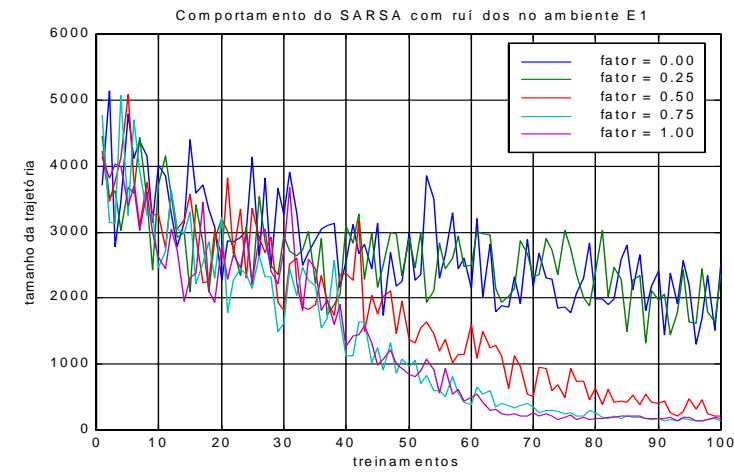

(a)

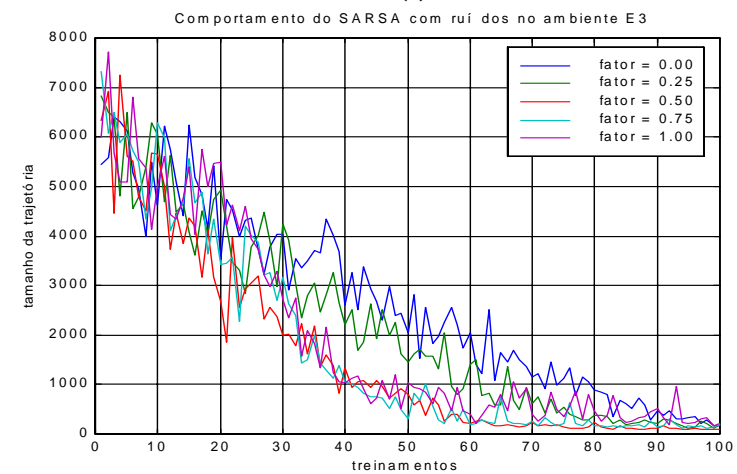

(c)

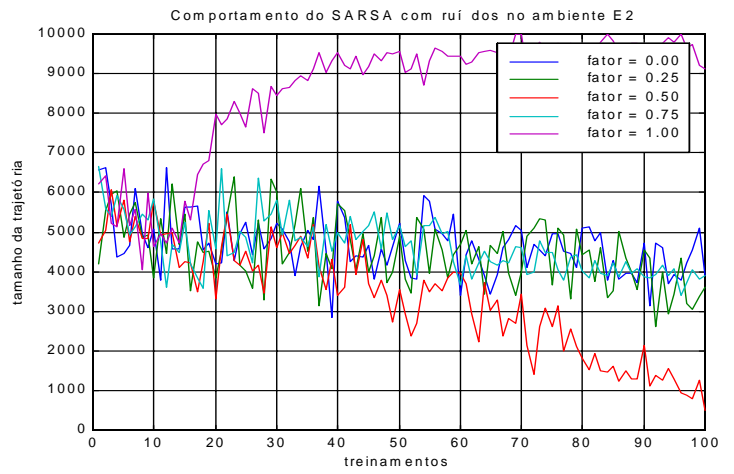

(b)

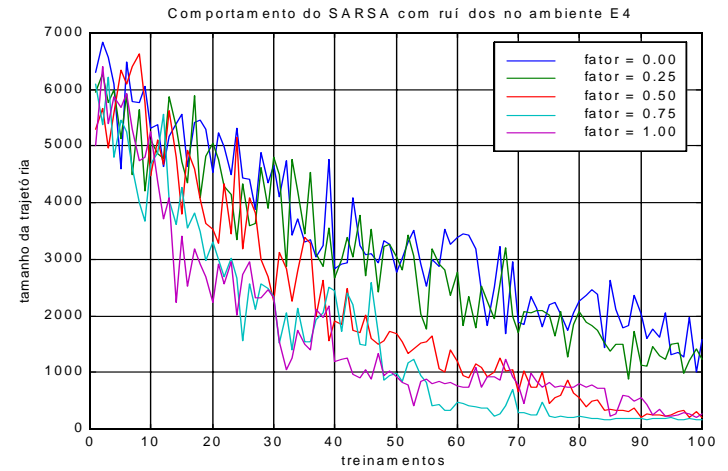

(d)

FIGURA 6.5 - Curvas dos tamanhos das trajetórias geradas pelo SARSA, com a evolução dos treinamentos, para cinco diferentes fatores de ruídos nos ambientes: (a) E1, (b) E2, (c) E3 e (d) E4.

Nos três blocos seguintes de resultados enfatiza-se os critérios C1 e C2 em comparação com os dados apresentados para os algoritmos de 1-passo.

\section{Algoritmos com Traços de Elegibilidade}

As curvas das Figuras 6.6, 6.7 e 6.8 voltam a mostrar (como na Seção 6.1) o ganho de velocidade que os traços de elegibilidade proporcionam, em comparação com os algoritmos de 1 passo, na redução do tamanho das trajetórias. Para os ambientes E1, E3 e E4, observa-se, principalmente nos ensaios com fator de ruído 0,75 e 1,00, que a introdução de ruído tende a ser mais sentida nos primeiros treinamentos, com um aumento no tamanho das trajetórias em comparação às trajetórias geradas com fator 0,00 , e com a evolução dos treinamentos a influência dos ruídos se enfraquece. No ambiente E2, como nos algoritmos de 1-passo, quando o fator de ruído é 1,00 , posições relacionadas a obstáculos na tabela que armazena a função de avaliação passam a ter avaliações elevadas - levando o agente a tomar ações que levem a estes obstáculos e que o mantém preso. Com os traços de elegibilidade, essa falha na estimativa da avaliação acaba sendo mais intensa que nos algoritmos de 1-passo - os traços acabam por propagar a influência do ruído no cálculo do erro TD.

$\mathrm{O}$ operador max dos algoritmos Aprendizagem- $Q(\lambda)$ e Aprendizagem-Q( $\lambda)$ rápida torna estes algoritmos mais susceptíveis à influência dos ruídos, como indicam a comparação dos gráficos do $S A R S A(\lambda)$ (Figura 6.7) com os das Figuras 6.6 e 6.8. 


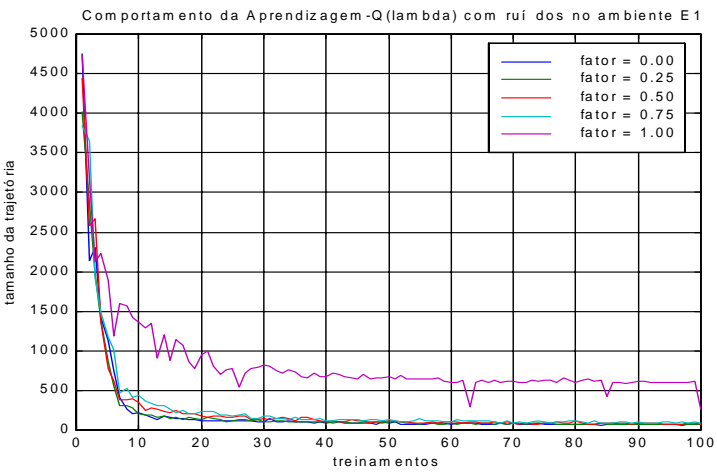

(a)

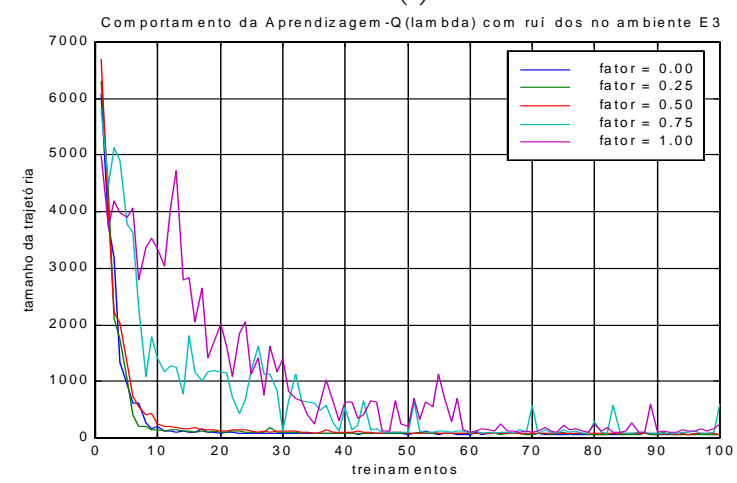

(c)

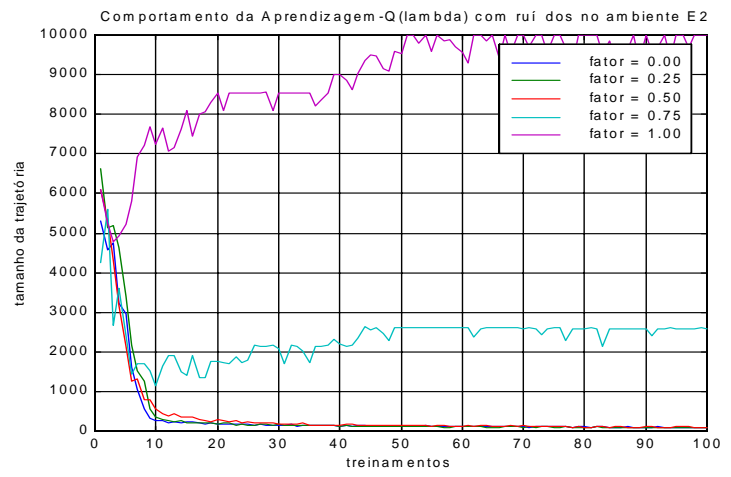

(b)

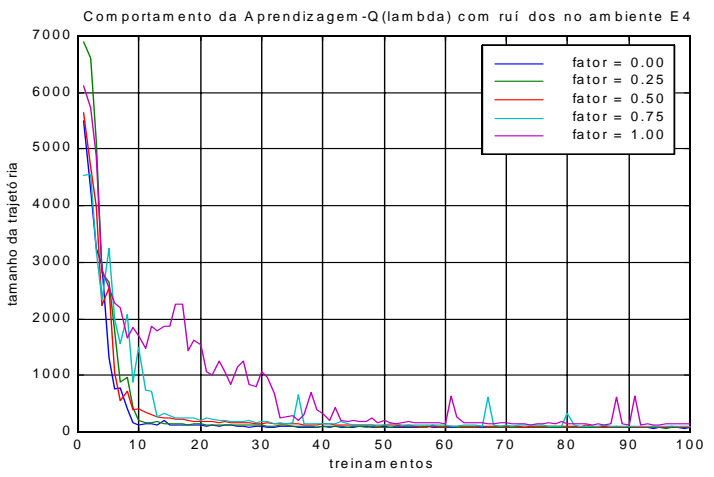

(d)

FIGURA 6.6 - Curvas dos tamanhos das trajetórias geradas pela Aprendizagem- $Q(\lambda)$, com a evolução dos treinamentos, para cinco diferentes fatores de ruídos nos ambientes: (a) E1, (b) E2, (c) E3 e (d) E4.

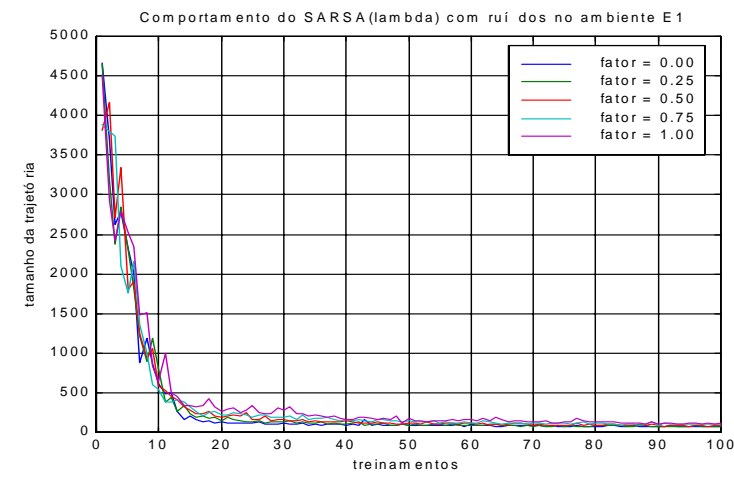

(a)

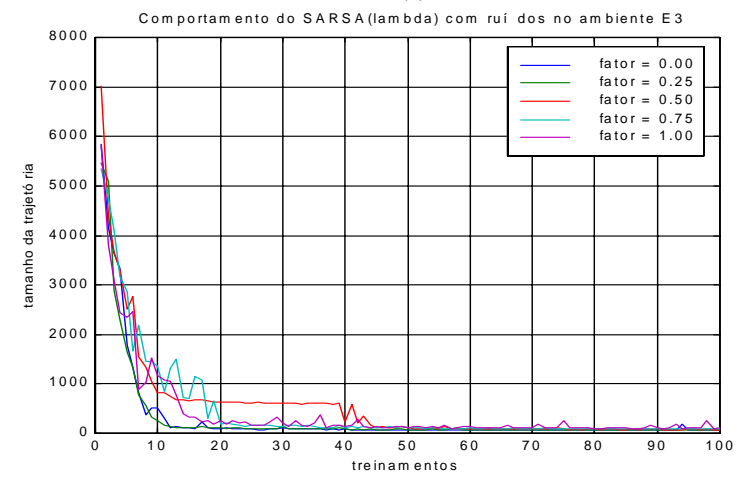

(c)

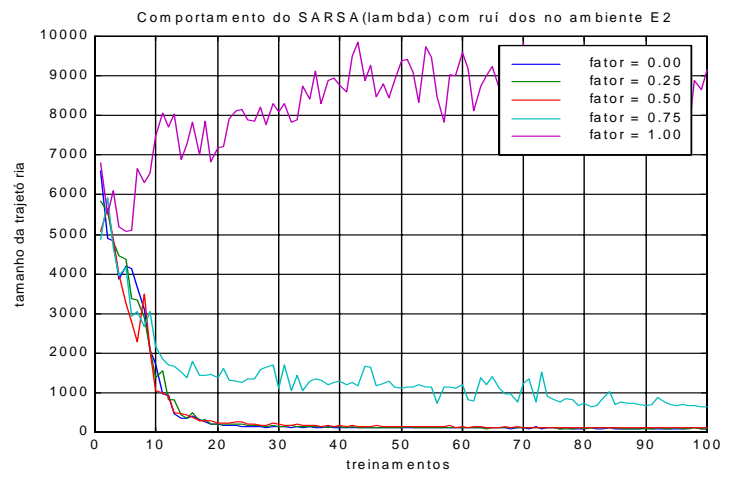

(b)

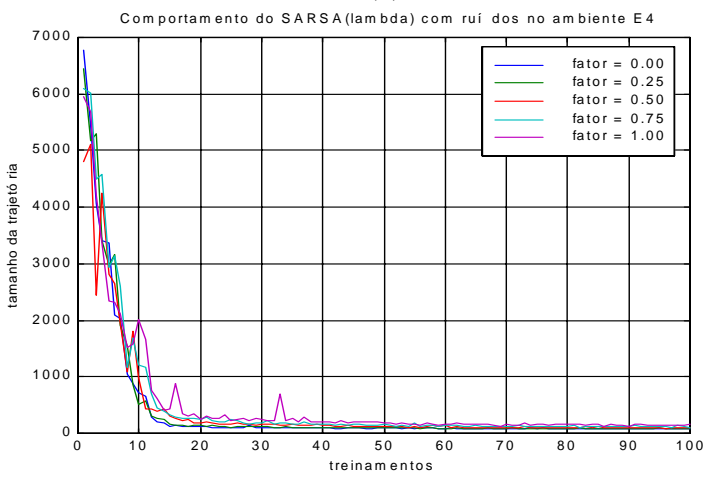

(d)

FIGURA 6.7 - Curvas dos tamanhos das trajetórias geradas pelo $\operatorname{SARSA}(\lambda)$, com a evolução dos treinamentos, para cinco diferentes fatores de ruídos nos ambientes: (a) E1, (b) E2, (c) E3 e (d) E4. 


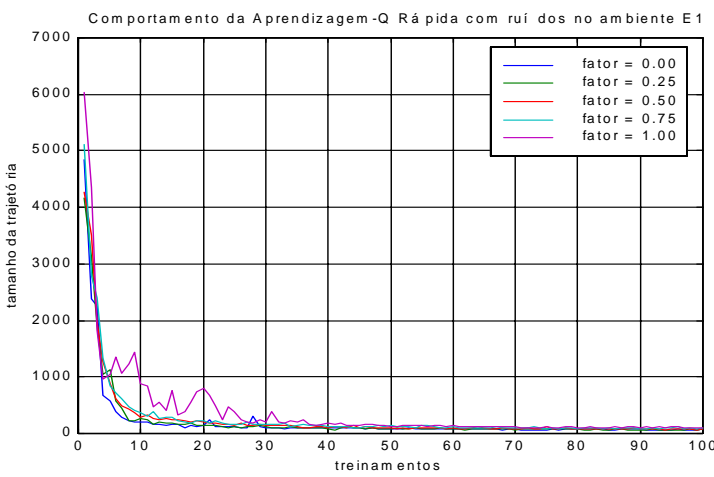

(a)

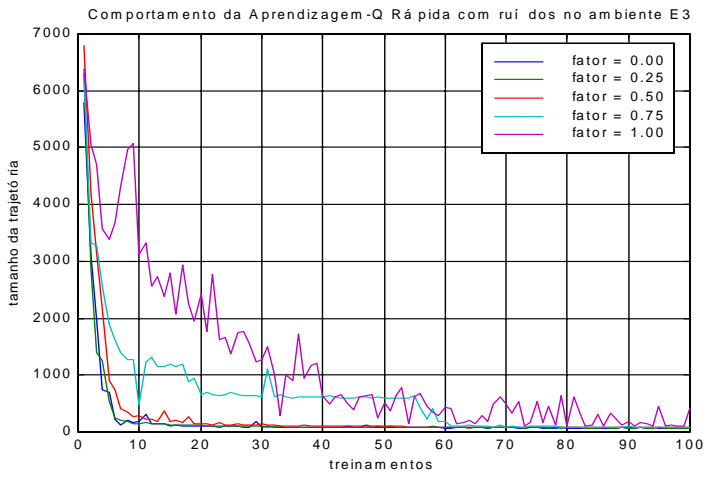

(c)

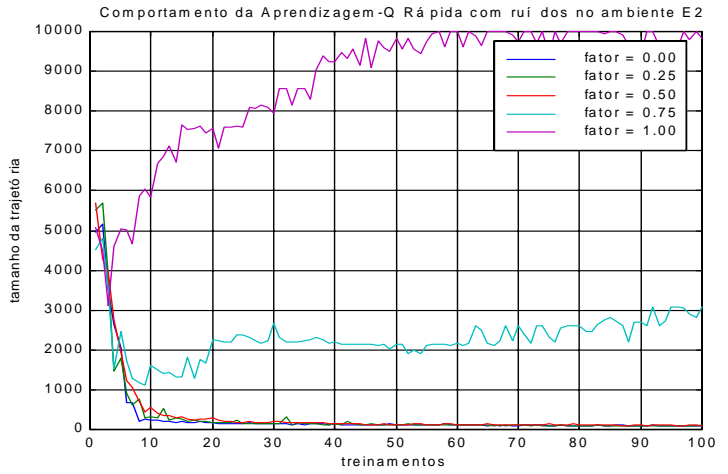

(b)

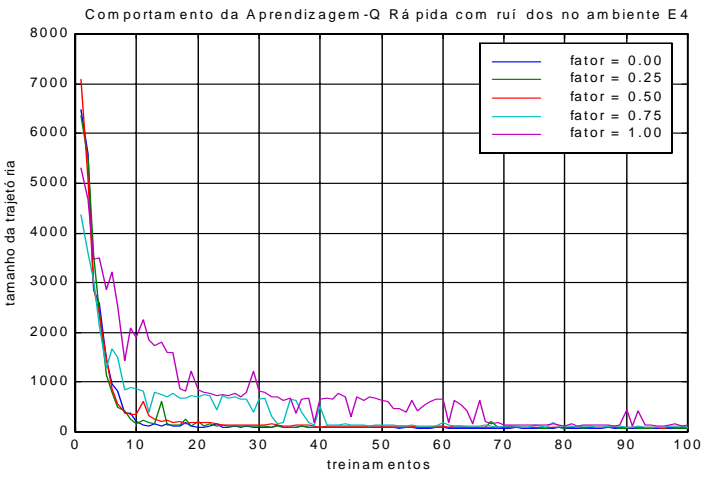

(d)

FIGURA 6.8 - Curvas dos tamanhos das trajetórias geradas pela Aprendizagem-Q( $\lambda)$ Rápida, com a evolução dos treinamentos, para cinco diferentes fatores de ruídos nos ambientes: (a) E1, (b) E2, (c) E3 e (d) E4.

As tabelas 6.7-6.8 mostram que a Aprendizagem- $Q(\lambda)$ e o $S A R S A(\lambda)$ demandam esforço computacional (mensurado no acumulado do número de atualizações) muito maior que seus equivalentes de 1-passo. Observa-se também que, conforme o fator de ruído aumenta, este esforço cresce de forma muito mais acentuada que os dados das tabelas 6.5-6.6.

TABELA 6.7 - Acumulado do número de atualizações da função de avaliação para a Aprendizagem-Q( $\lambda$ ) ao longo de 100 treinamentos.

\begin{tabular}{|l|c|c|c|c|}
\hline & E1 & E2 & E3 & E4 \\
\hline \hline Fator $=0,00$ & $1,3^{*} 10^{6} \pm 3,2^{*} 10^{5}$ & $2,15^{*} 10^{6} \pm 6,4 * 10^{5}$ & $1,4^{*} 10^{6} \pm 6,5^{*} 10^{5}$ & $1,6^{*} 10^{6} \pm 5,2^{*} 10^{5}$ \\
\hline \hline Fator $=0,25$ & $1,26^{*} 10^{6} \pm 2,9 * 10^{5}$ & $2,5^{*} 10^{6} \pm 9,4 * 10^{5}$ & $1,4^{*} 10^{6} \pm 5,9^{*} 10^{5}$ & $2,1^{*} 10^{6} \pm 5,6^{*} 10^{5}$ \\
\hline \hline Fator $=0,50$ & $1,4^{*} 10^{6} \pm 2,8^{*} 10^{5}$ & $2,3^{*} 10^{6} \pm 5,9^{*} 10^{5}$ & $1,6^{*} 10^{6} \pm 7,7 * 10^{5}$ & $1,9 * 10^{6} \pm 6 * 10^{5}$ \\
\hline \hline Fator $=0,75$ & $1,6^{*} 10^{6} \pm 3,5^{*} 10^{5}$ & $1,3^{*} 10^{7} \pm 2 * 10^{7}$ & $3,7 * 10^{6} \pm 4,1 * 10^{6}$ & $2,3 * 10^{6} \pm 1,03^{*} 10^{6}$ \\
\hline \hline Fator $=1,00$ & $4,81 * 10^{6} \pm 1.2^{*} 10^{7}$ & $5,1^{*} 10^{7} \pm 8,8^{*} 10^{6}$ & $5,5^{*} 10^{6} \pm 5,3^{*} 10^{6}$ & $4,14^{*} 10^{6} \pm 3,8^{*} 10^{6}$ \\
\hline
\end{tabular}

TABELA 6.8 - Acumulado do número de atualizações da função de avaliação para o $\operatorname{SARSA}(\lambda)$ ao longo de 100 treinamentos.

\begin{tabular}{|l|c|c|c|c|}
\hline & E1 & E2 & E3 & E4 \\
\hline \hline Fator $=0,00$ & $735.710 \pm 200.470$ & $1,24 * 10^{6} \pm 2,6^{*} 10^{5}$ & $699.286 \pm 211.300$ & $902.150 \pm 242.310$ \\
\hline \hline Fator $=0,25$ & $742.300 \pm 188.050$ & $1,25^{*} 10^{6} \pm 3,9 * 10^{5}$ & $658.230 \pm 166.690$ & $945.476 \pm 284.420$ \\
\hline \hline Fator $=0,50$ & $781.090 \pm 209.100$ & $1,18^{*} 10^{6} \pm 3 * 10^{5}$ & $1,2^{*} 10^{6} \pm 1,9 * 10^{6}$ & $935.770 \pm 261.930$ \\
\hline \hline Fator $=0,75$ & $805.461 \pm 176.440$ & $3,2^{*} 10^{6} \pm 5,3 * 10^{6}$ & $1,06^{*} 10^{6} \pm 8,7 * 10^{5}$ & $1,15^{*} 10^{6} \pm 3,8^{*} 10^{5}$ \\
\hline Fator $=1,00$ & $917.000 \pm 371.350$ & $1,9^{*} 10^{7} \pm 4 * 10^{6}$ & $954.760 \pm 598.450$ & $1,2^{*} 10^{6} \pm 3,6^{*} 10^{5}$ \\
\hline
\end{tabular}


TABELA 6.9 - Acumulado do número de atualizações da função de avaliação para a Aprendizagem-Q( $\lambda$ ) Rápida ao longo de 100 treinamentos.

\begin{tabular}{|l||c|c|c|c|}
\hline & E1 & E2 & E3 & E4 \\
\hline \hline Fator $=0,00$ & $239.970 \pm 49.801$ & $368.010 \pm 107.640$ & $238.920 \pm 85.388$ & $343.734 \pm 132.610$ \\
\hline \hline Fator $=0,25$ & $253.400 \pm 79.208$ & $389.610 \pm 160.110$ & $242.341 \pm 68.010$ & $355.110 \pm 131.060$ \\
\hline \hline Fator $=0,50$ & $288.210 \pm 49.260$ & $426.200 \pm 102.410$ & $332.930 \pm 128.810$ & $379.120 \pm 85.963$ \\
\hline \hline Fator $=0,75$ & $317.170 \pm 73.550$ & $2,7 * 10^{6} \pm 4,05 * 10^{6}$ & $7,07 * 10^{5} \pm 1,4^{*} 10^{6}$ & $513.450 \pm 688.790$ \\
\hline \hline Fator $=1,00$ & $450.490 \pm 381.580$ & $1,01 * 10^{7} \pm 1,7 * 10^{6}$ & $1,3 * 10^{6} \pm 1,6^{*} 10^{6}$ & $9,1^{*} 10^{5} \pm 1,4^{*} 10^{6}$ \\
\hline
\end{tabular}

A Aprendizagem-Q( $\lambda)$ rápida possui um acumulado do número de atualizações similar ao da Aprendizagem-Q e do $S A R S A$ para fatores de ruído entre 0,00 e 0,50. Entretanto, ao se elevar mais o fator de rú́do a escala das atualizações começa a se tornar mais próxima da verificada na Aprendiragem-Q( $(\lambda)$ e no $S A R S A(\lambda)$.

\section{Algoritmo Dyna-Q}

Verifica-se das curvas da Figura 6.9 que o Dyna-Q foi o algoritmo mais afetado pela presença de ruídos. Tal comportamento vem da estratégia adotada para a atualização da função de avaliação: ao armazenar uma lista das transições realizadas pelo agente, o Dyna- $Q$ consegue maior velocidade de aprendizagem em ambientes com transições de estados determinísticas. Porém, os erros na estimativa dos estados acabam por gerar transições erradas que serão guardadas no modelo do mundo utilizado pelo Dyna-Q para estimar a função de avaliação.

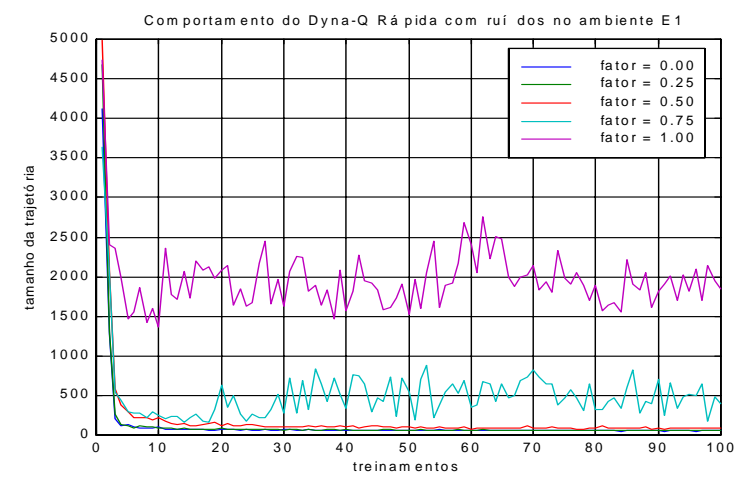

(a)

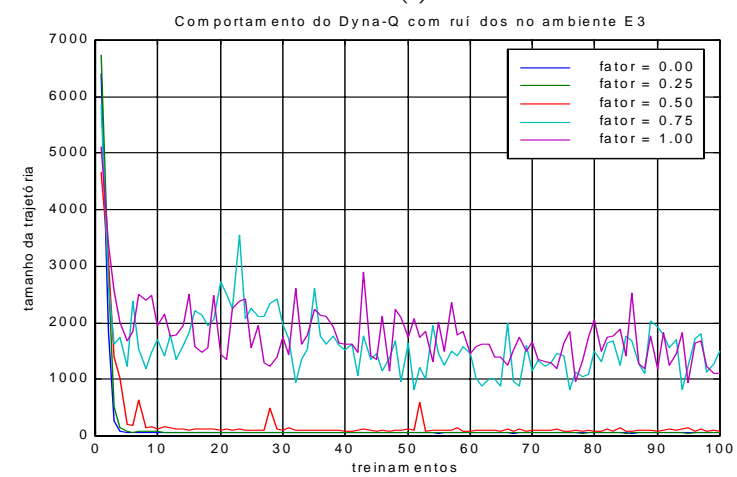

(c)

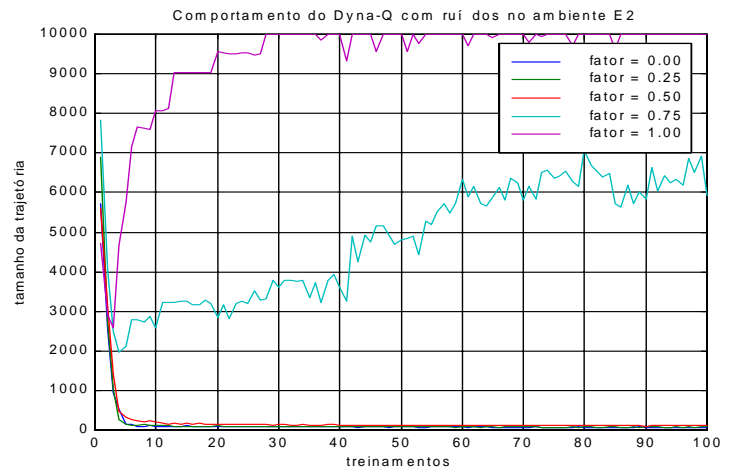

(b)

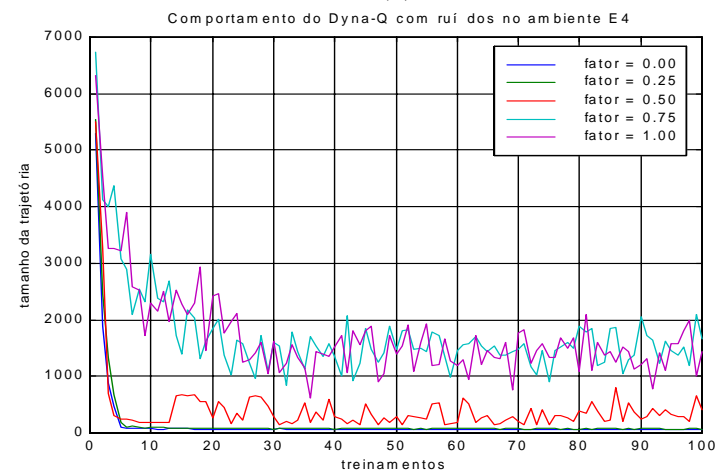

(d)

FIGURA 6.9 - Curvas dos tamanhos das trajetórias geradas pelo Dyna-Q, com a evolução dos treinamentos, para cinco diferentes fatores de ruídos nos ambientes: (a) E1, (b) E2, (c) E3 e (d) E4. 
TABELA 6.10 - Acumulado do número de atualizações da função de avaliação para o Dyna-Q ao longo de 100 treinamentos.

\begin{tabular}{|l||c|c|c|c||}
\hline \hline & $\mathrm{E} 1$ & $\mathrm{E} 2$ & $\mathrm{E} 3$ & $\mathrm{E} 4$ \\
\hline \hline Fator $=0,00$ & $1,18^{*} 10^{6} \pm 3,8 * 10^{5}$ & $1,7 * 10^{6} \pm 8,2^{*} 10^{5}$ & $1,4^{*} 10^{6} \pm 5,2^{*} 10^{5}$ & $1,5^{*} 10^{6} \pm 8,9 * 10^{5}$ \\
\hline \hline Fator $=0,25$ & $1,3 * 10^{6} \pm 3,5^{*} 10^{5}$ & $1,9 * 10^{6} \pm 6,5^{*} 10^{5}$ & $1,6^{*} 10^{6} \pm 6,3 * 10^{5}$ & $1,76^{*} 10^{6} \pm 9,9 * 10^{5}$ \\
\hline \hline Fator $=0,50$ & $1,87 * 10^{6} \pm 4 * 10^{5}$ & $2,3 * 10^{6} \pm 6,4 * 10^{5}$ & $2,2^{*} 10^{6} \pm 1,3 * 10^{6}$ & $4,2 * 10^{6} \pm 7,2 * 10^{6}$ \\
\hline \hline Fator $=0,75$ & $5,1 * 10^{6} \pm 8,8 * 10^{6}$ & $4,9 * 10^{7} \pm 3,8^{*} 10^{7}$ & $1,6^{*} 10^{7} \pm 2 * 10^{7}$ & $1,7 * 10^{7} \pm 2,4 * 10^{7}$ \\
\hline \hline Fator $=1,00$ & $1,97 * 10^{7} \pm 2,9 * 10^{7}$ & $9,5^{*} 10^{7} \pm 6,5^{*} 10^{6}$ & $1,8^{*} 10^{7} \pm 1,9 * 10^{7}$ & $1,7 * 10^{7} \pm 1,4^{*} 10^{7}$ \\
\hline
\end{tabular}

A tabela 6.10 mostra que o Dyna- $Q$ exige um esforço computacional que supera a Aprendizagem- $Q(\lambda)$ e o $S A R S A(\lambda)$ e, como estes últimos, o aumento do fator de ruído leva a um acentuado crescimento no acumulado do número de atualizações.

\section{Algoritmo $A T A R$}

As curvas da Figura 6.10 exibem os resultados dos ensaios ${ }^{33}$ realizados com o $A T A R$. Comparativamente com os resultados dos demais algoritmos (Figuras 6.4-6.9), verifica-se que a variação no fator de ruído não teve influência significativa na redução das trajetórias geradas mesmo no ambiente E2 com fator 1, que nos demais algoritmos levava o agente a ficar preso, o ATAR estima uma função de avaliação que gera trajetórias curtas.

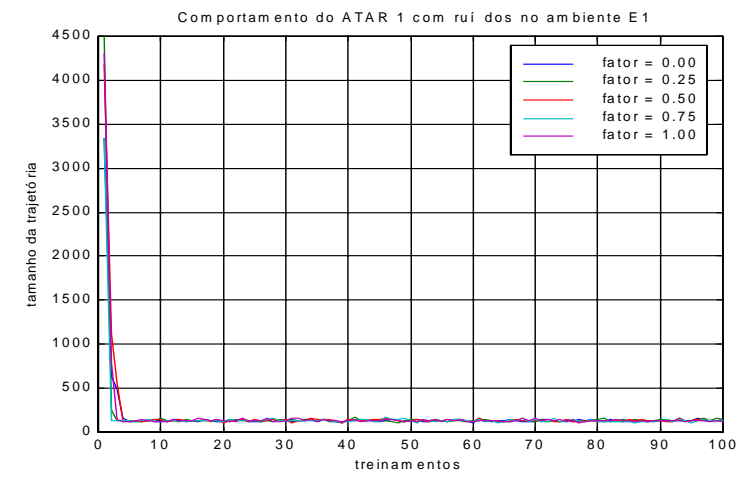

(a)

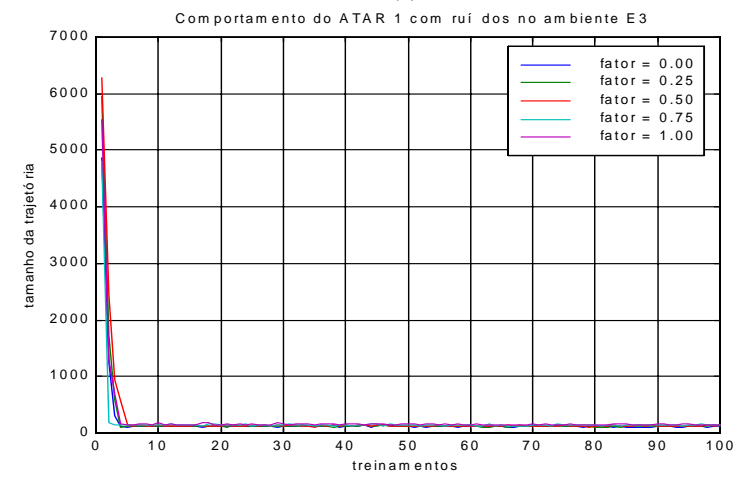

(c)

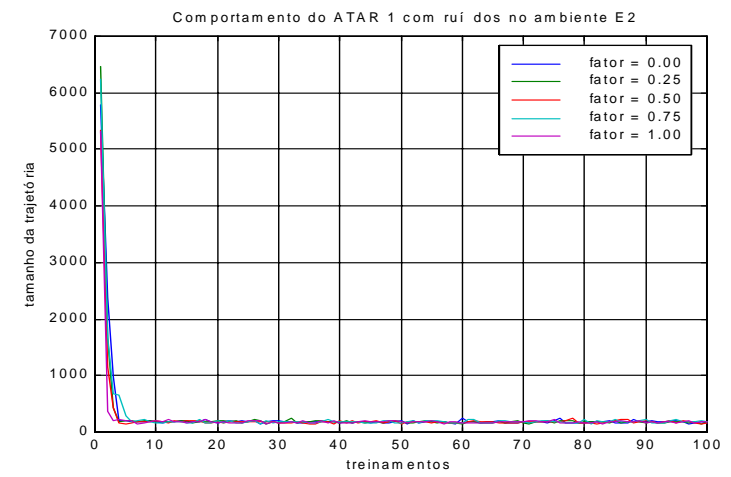

(b)

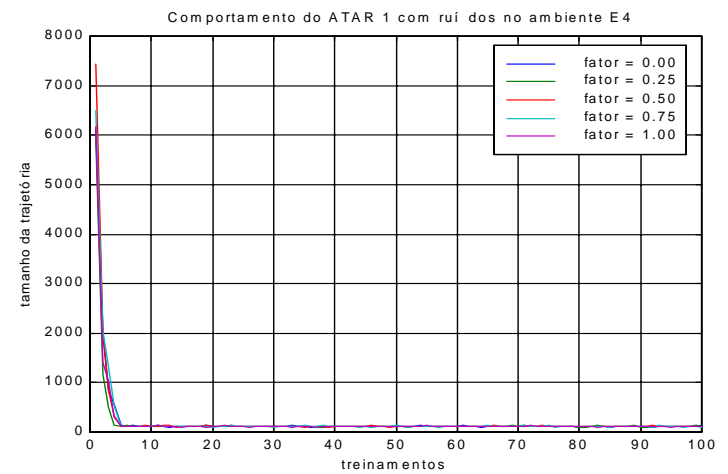

(d)

FIGURA 6.10 - Curvas dos tamanhos das trajetórias geradas pelo $A T A R$, com a evolução dos treinamentos, para cinco diferentes fatores de ruídos nos ambientes: (a) E1, (b) E2, (c) E3 e (d) E4.

${ }^{33}$ Para cada ambiente, um mesmo mapa topológico aprendido em uma fase pré-treinamentos foi utilizado nos ensaios com o ATAR. 
Podem ser citados dois principais motivos para esta maior "robustez" a ruídos no $A T A R$. O primeiro vem da estrutura adotada para armazenar a função de avaliação: o mapa topológico foi treinado para representar a topologia dos estados livres; assim, mesmo quando o ruído leva o agente a acreditar que está em um estado que na realidade seria um obstáculo, é o vértice do mapa topológico $M$ mais próximo à estimativa ruidosa do estado atual que receberá uma atualização de sua avaliação. O segundo vem da estratégia de atualização da avaliação utilizada pelo algoritmo (Subseção 5.3.2): o ruído pode levar a atualizações de vértices errados, entretanto diferentemente do que ocorre com os algoritmos com traço de elegibilidade, estes erros não vão sendo acumulados.

TABELA 6.11 - Acumulado do número de atualizações da função de avaliação para o ATAR ao longo de 100 treinamentos.

\begin{tabular}{|l||c|c|c|c|}
\hline & E1 & E2 & E3 & E4 \\
\hline \hline Fator $=0,00$ & $538.570 \pm 68.411$ & $1,08^{*} 10^{6} \pm 8 * 10^{4}$ & $258.480 \pm 26.348$ & $629.330 \pm 38.290$ \\
\hline \hline Fator $=0,25$ & $549.500 \pm 64.677$ & $1,07 * 10^{6} \pm 7,8 * 10^{4}$ & $222.060 \pm 21.715$ & $607.570 \pm 49.972$ \\
\hline \hline Fator $=0,50$ & $545.730 \pm 73.679$ & $1,07 * 10^{6} \pm 7,1 * 10^{4}$ & $196.470 \pm 16.921$ & $633.940 \pm 47.695$ \\
\hline \hline Fator $=0,75$ & $539.050 \pm 69.097$ & $1,09 * 10^{6} \pm 7,7 * 10^{4}$ & $221.230 \pm 15.481$ & $627.970 \pm 37.307$ \\
\hline \hline Fator $=1,00$ & $558.050 \pm 45.565$ & $1,08^{*} 10^{6} \pm 7,3 * 10^{4}$ & $267.720 \pm 18.568$ & $621.680 \pm 44.886$ \\
\hline
\end{tabular}

A tabela 6.11 mostra que o $A T A R$ (com valores dos acumulados do número de atualizações na ordem de $10^{5}$ a $10^{6}$ ) exige um esforço computacional intermediário entre os algoritmos de 1 passo (que realizam um número atualizações na ordem de $10^{5}$ ) e os algoritmos com traços de elegibilidade e o Dyna-Q (os quais realizam um número de atualizações na ordem de $10^{5}$ a $10^{7}$ ). O desvio padrão do número de atualizações do $A T A R$ sempre se apresentou na ordem de $10^{4}$, o que indica o algoritmo como o que tem a estimativa da função de avaliação menos influenciada pela presença de ruídos entre os algoritmos AR simulados.

\section{Degradação do Desempenho do Aprendizado}

Para melhor proceder com a análise do comportamento dos algoritmos AR simulados, e a comparação do $A T A R$ com seus pares, uma medida $D$ da degradação da curva de aprendizagem foi estabelecida para mensurar a influência dos ruídos na aprendizagem:

$$
D=\sum_{t=1}^{100} \frac{\left|m_{t}^{p r}-m_{t}^{a r}\right|}{m_{t}^{a r}}
$$

sendo:

$m_{t}^{p r}$ - média do tamanho das trajetórias no treinamento $t$ na presença de ruídos.

$m_{t}^{a r}$ - média do tamanho das trajetórias no treinamento $t$ na ausência de ruídos.

A medida $D$ de degradação busca avaliar quanto a presença de ruídos afasta o comportamento do agente daquele apresentado quando o fator de ruído é nulo. As Tabelas 6.12-6.18 trazem as medidas de $D$ para os ensaios realizados. 
TABELA 6.12 - Medidas $D$ das curvas de aprendizagem para a Aprendizagem-Q.

\begin{tabular}{|l|c|c|c|c|}
\hline & E1 & E2 & E3 & E4 \\
\hline \hline Fator $=0,25$ & 20,3634 & 15,7741 & 16,7664 & 14,6975 \\
\hline \hline Fator $=0,50$ & 19,0944 & 15,1408 & 25,9497 & 19,5958 \\
\hline Fator $=0,75$ & 20,1340 & 16,3408 & 17,2133 & 28,7783 \\
\hline \hline Fator $=1,00$ & 28,1929 & 43,7459 & 23,9597 & 36,9879 \\
\hline
\end{tabular}

TABELA 6.13 - Medidas $D$ das curvas de aprendizagem para o SARSA.

\begin{tabular}{|l||c|c|c|c|}
\hline & E1 & E2 & E3 & E4 \\
\hline \hline Fator $=0,25$ & 20,6103 & 17,5159 & 32,6271 & 17,8785 \\
\hline \hline Fator $=0,50$ & 44,7797 & 33,3173 & 57,5618 & 47,2104 \\
\hline \hline Fator $=0,75$ & 59,0534 & 13,5925 & 50,9039 & 61,5376 \\
\hline \hline Fator $=1,00$ & 58,1599 & 91,1477 & 44,3301 & 57,3161 \\
\hline
\end{tabular}

TABELA 6.14 - Medidas $D$ das curvas de aprendizagem para a Aprendizagem- $Q(\lambda)$.

\begin{tabular}{|l|c|c|c|c|}
\hline & E1 & E2 & E3 & E4 \\
\hline \hline Fator $=0,25$ & 10,7579 & 10,7757 & 13,2278 & 17,0837 \\
\hline \hline Fator $=0,50$ & 25,6290 & 23,1846 & 26,7435 & 41,6568 \\
\hline Fator $=0,75$ & 44,5170 & 1683,0 & 347,7329 & 95,3984 \\
\hline \hline Fator $=1,00$ & 604,3434 & 6873,0 & 648,6294 & 357,9859 \\
\hline
\end{tabular}

TABELA 6.15 - Medidas $D$ das curvas de aprendizagem para o $\operatorname{SARSA}(\lambda)$.

\begin{tabular}{|l|c|c|c|c|}
\hline & E1 & E2 & E3 & E4 \\
\hline \hline Fator $=0,25$ & 14,9267 & 11,1328 & 11,5812 & 10,5876 \\
\hline \hline Fator $=0,50$ & 30,4719 & 22,8101 & 192,8931 & 40,0202 \\
\hline Fator $=0,75$ & 49,9844 & 686,0518 & 104,9004 & 63,4299 \\
\hline \hline Fator $=1,00$ & 78,2961 & 6244,0 & 104,2848 & 109,0573 \\
\hline
\end{tabular}

TABELA 6.16- Medidas $D$ das curvas de aprendizagem para a Aprendizagem-Q( $\lambda)$ Rápida.

\begin{tabular}{|l|c|c|c|c|}
\hline & E1 & E2 & E3 & E4 \\
\hline \hline Fator $=0,25$ & 13,7448 & 16,0296 & 11,2331 & 18,9887 \\
\hline Fator $=0,50$ & 29,2745 & 26,9576 & 34,0862 & 33,9342 \\
\hline \hline Fator $=0,75$ & 46,0486 & 1692,5 & 359,2214 & 163,9075 \\
\hline \hline Fator $=1,00$ & 109,6555 & 7015,1 & 808,5747 & 421,6496 \\
\hline
\end{tabular}

TABELA 6.17 - Medidas $D$ das curvas de aprendizagem para o Dyna-Q.

\begin{tabular}{|l||c|c|c|c|}
\hline & E1 & E2 & E3 & E4 \\
\hline \hline Fator $=0,25$ & 10,4793 & 8,5151 & 7,0971 & 19,1201 \\
\hline \hline Fator $=0,50$ & 76,0483 & 63,9713 & 124,2441 & 395,1144 \\
\hline Fator $=0,75$ & 648,2584 & 6082,6 & 2555,9 & 2271,5 \\
\hline \hline Fator $=1,00$ & 2989,3 & 11925,0 & 2822,8 & 2251,8 \\
\hline
\end{tabular}

TABELA 6.18 - Medidas $D$ das curvas de aprendizagem para o ATAR.

\begin{tabular}{|l|c|c|c|c|}
\hline & E1 & E2 & E3 & E4 \\
\hline \hline Fator $=0,25$ & 10,7110 & 11,4870 & 8,3410 & 8,1499 \\
\hline \hline Fator $=0,50$ & 7,3532 & 12,6815 & 16,5446 & 7,5894 \\
\hline Fator $=0,75$ & 10,2262 & 13,8154 & 19,1209 & 8,9378 \\
\hline \hline Fator $=1,00$ & 10,6837 & 11,9928 & 28,6135 & 7,8874 \\
\hline
\end{tabular}

$\mathrm{Na}$ comparação das tabelas, o $A T A R$ apresentou a melhor rejeição a ruídos. Assim, pelos 
critérios C1 e C2 (Seção 6.1), o $A T A R$ apresentou a melhor combinação velocidade de aprendizagem x custo computacional.

\subsubsection{Alteração na Configuração do Ambiente}

A "capacidade de adaptação" é um dos argumentos mais utilizados na defesa da utilização de técnicas de aprendizagem de máquina em ambientes não-estruturados. Sem tal capacidade, uma simples atividade do cotidiano como decidir quais ações alternativas tomar diante da abertura e fechamento de portas (Gaussier et alli, 2000; Franz e Mallot, 2000) torna-se um problema de difícil solução. Para verificar como o $A T A R$, em comparação com outros agentes $\mathrm{AR}$, consegue se readaptar a uma mudança deste tipo, o cenário da Figura 2.6 (Capítulo 2) foi utilizado: durante os 99 primeiros treinamentos, os agentes AR interagem com o ambiente da Figura 2.6.a de modo a realizarem trajetórias entre o ponto inicial $(12,10)$ e a meta $(12,30)$; do centésimo treinamento até o ducentésimo a porta que liga o caminho mais curto entre o ponto inicial e a meta é fechada e observa-se como os agentes reagem a esta mudança no aprendizado de uma nova trajetória. Para cada algoritmo foram realizados 30 ensaios, tendo sido adotada a seguinte função de retorno:

$$
r_{t+1}=\left\{\begin{array}{l}
1, \text { caso seja } s_{t+1} \text { o estado meta } \\
0, \text { caso seja } s_{t+1} \text { um estado livre } \\
-1, \text { caso seja } s_{t+1} \text { um estado obstáculo }
\end{array}\right.
$$

A função de retorno considerada (Eq. 6.3) é mais informativa que a utilizada nos ensaios anteriores deste capítulo (Eq. 6.1). Isto torna o aprendizado mais rápido (Koenig e Simmons, 1996; Araújo e Braga, 1998c; Braga, 1998), mas no problema desta subseção tem principalmente o objetivo de, a partir do treinamento 100, punir ações que levem à porta fechada - informando os agentes AR que devem evitar os obstáculos que surjam à sua frente. Ainda mantendo os dois critérios de desempenho (C1 e C2) descritos na Seção 6.1, os gráficos das Figuras 6.11 e 6.12 indicam para cada agente AR simulado: (i) a evolução do tamanho (limitado a 10.000 passos) das trajetórias aprendidas (C1) e (ii) o número de atualizações da função de avaliação a cada treinamento (C2).

$\mathrm{Na}$ primeira etapa do ensaio (treinamentos 1-99), há um comportamento semelhante ao verificado nos ensaios anteriores (Figura 6.11): o Dyna-Q, a Aprendizagem-Q( $\lambda$ ) rápida, a Aprendizagem$Q(\lambda)$, o $S A R S A(\lambda)$ e o $A T A R$ geraram as menores trajetórias $(33,17 ; 39,04 ; 43,60 ; 41,73$ e 40,50, respectivamente, em média, no treinamento 99), e os algoritmos de 1-passo, Aprendizagem-Q e $S A R S A$, os piores resultados (89,71 e 83,78, respectivamente, em média, no treinamento 99). Mas é na segunda etapa do ensaio (treinamentos 100-200) que se encontra o foco de interesse desta subseção (Figura 6.11): à exceção do $A T A R$ e do Dyna-Q, os demais agentes AR, em maior ou menor intensidade, tiveram a tendência de não conseguir gerar uma trajetória alternativa para a meta, alcançando o limite máximo de 10.000 passos por treinamento, dentro do número de treinamentos do ensaio. Tal resultado justifica-se na Aprendizagem- $Q$ e no $S A R S A$ por realizarem uma única atualização da função de avaliação por passo, o que os leva a serem lentos para modificar 
suas políticas à nova configuração do ambiente - com o aumento dos treinamentos esta modificação vem a ocorrer. Os algoritmos com traço de elegibilidade apresentam uma maior inércia para o aprendizado da mudança ocorrida: os traços funcionam como uma memória da antiga configuração do ambiente.

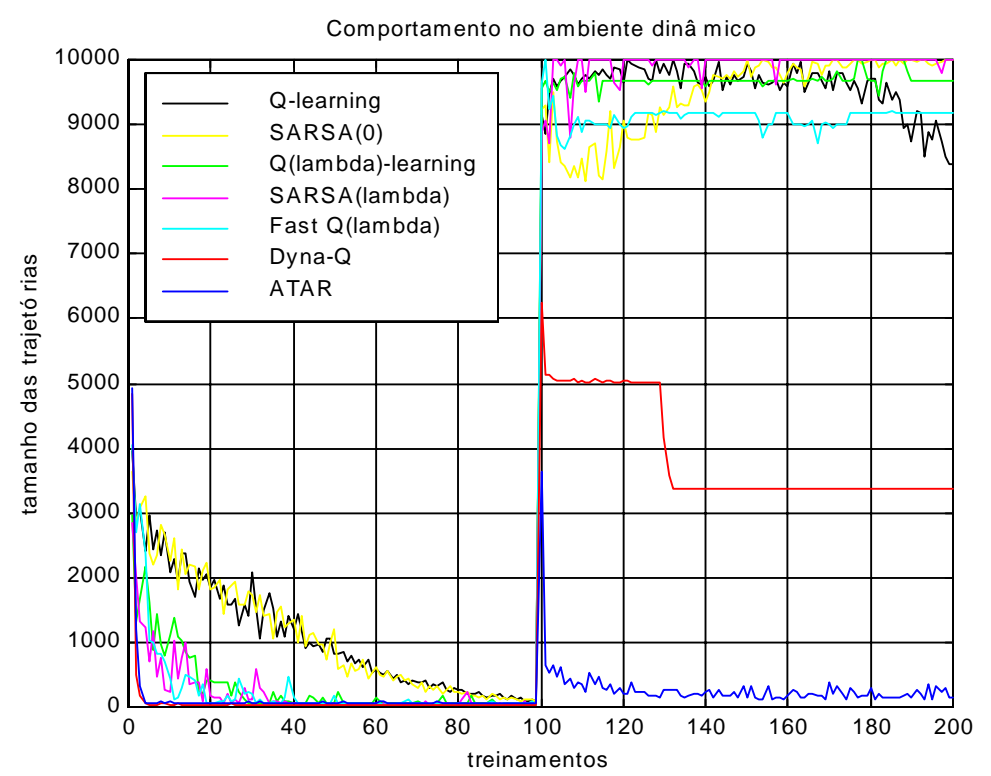

FIGURA 6.11 - Evolução no tamanho das trajetórias (média em 30 ensaios) aprendidas a cada treinamento para as configurações da Figura 2.6.

No Dyna-Q, a capacidade de adaptação à mudança do ambiente no intervalo de treinamentos considerado ocorre conforme o algoritmo acesse em seu modelo do mundo (ver Model(s,a) na Seção A.6) estados que permitam gerar a trajetória alternativa. Como no Dyna- $Q$ original o acesso aos pares $(s, a)$ do modelo do ambiente ocorre por sorteio aleatório, o aprendizado que levará à geração da nova trajetória é dependente da freqüência com que os estados da região por onde a nova trajetória passará são sorteados. Isto faz com que haja certa "latência", que varia de uma simulação para outra, no aprendizado da nova função de avaliação (comportamento semelhante é citado na pg. 236 de Sutton e Barto, 1998).

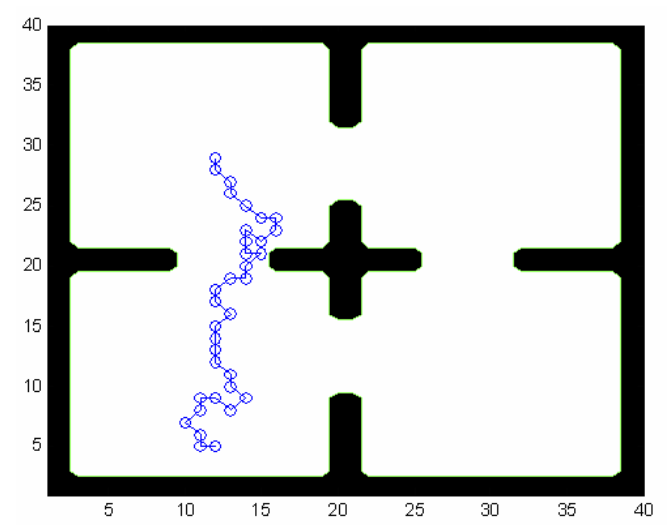

(a)

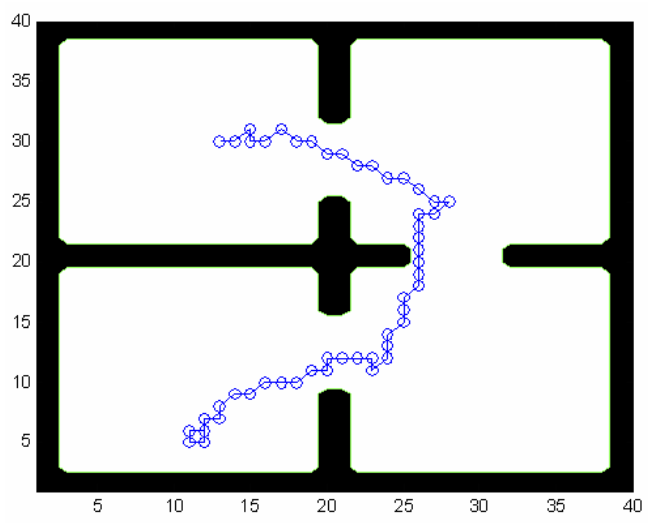

(b)

FIGURA 6.12 - Exemplos de trajetórias geradas pelo ATAR para o ambiente da Figura 2.6 na condição de: (a) porta aberta e (b) porta fechada. 
A estratégia de atualização das avaliações no ATAR mostrou-se a mais eficaz entre os algoritmos AR simulados (Figura 6.11). O mapa topológico utilizado pelo $A T A R$ nos ensaios realizados guarda a configuração original do ambiente com a porta aberta (Figura 2.6.a), o que, a exemplo dos resultados da Seção 6.1 e Subseção 6.2.1, mantém as justificativas anteriormente apresentadas para o bom desempenho do algoritmo na primeira fase do ensaio. Entretanto, com o fechamento da porta (Figura 2.6.b) na segunda fase do ensaio, o mapa topológico utilizado pelo $A T A R$ já não representa tão fielmente a nova configuração, e novas considerações podem ser feitas sobre o funcionamento do agente proposto: o conceito de região de influência (Subseção 5.1.1) permanece, mesmo com a diferença entre a topologia do mapa utilizado e do ambiente, pois ao encontrar o novo obstáculo o Passo 1 do $A T A R$ (Subseção 5.3.2) reduz a avaliação dos pares $(s, a)$ que levam à porta que se fechou. Com esta redução, a região de influência destes estados também é reduzida, pois os estados vizinhos (mesmo que sejam vizinhos topológicos no mapa) passam a ter uma maior avaliação. Com o decorrer das iterações, os estados próximos da porta fechada passam a fazer parte da região de influência de outros estados que levam a áreas livres na configuração da Figura 2.6.b, até que a estimativa da função de avaliação seja atualizada e permita a geração de trajetórias nesta nova configuração (Figura 6.12).

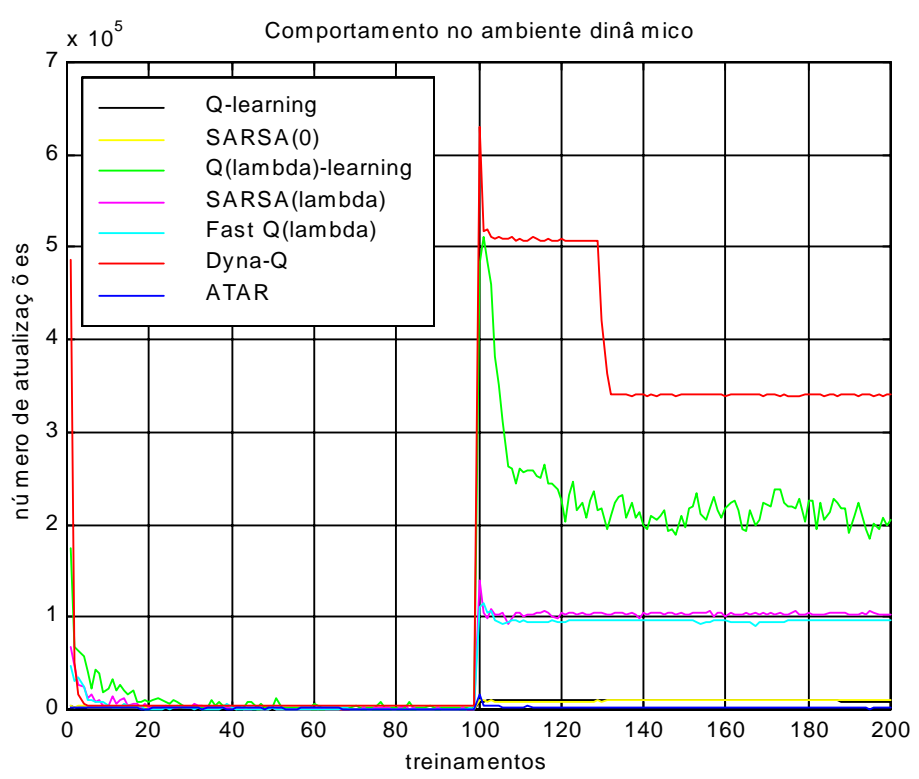

FIGURA 6.13 - Número das atualizações da função de avaliação (média para 30 ensaios) para as configurações da Figura 2.6.

A Figura 6.13 mostra que o aumento no número de atualizações da função de atualização exigido pelo $A T A R$ para se adaptar à mudança no ambiente (1.757,2 atualizações, em média, nos 50 últimos treinamentos) ainda é significativamente inferior ao verificado em algoritmos como a Aprendizagem-Q( $\lambda$ ) (213.690 atualizações, em média, nos 50 últimos treinamentos), o $S A R S A(\lambda)$ (103.710 atualizações, em média, nos 50 últimos treinamentos), a Aprendizagem-Q( $\lambda$ ) rápida (95.291 atualizações, em média, nos 50 últimos treinamentos) e o Dyna-Q (339.860 atualizações, em média, nos 50 últimos treinamentos). Mesmo os algoritmos Aprendizagem- $Q$ e $S A R S A$ realizam maior 
número de atualizações (9.430,5 e 9.919,0 atualizações, respectivamente, em média, nos 50 últimos treinamentos), com resultados muito inferiores, que o $A T A R$. Como estes algoritmos realizam uma atualização por passo, tendem a atingir 10.000 atualizações por não conseguirem atingir a meta antes do limite máximo de passos estipulado no ensaio.

Cabe ressaltar que, assim como nos resultados da Seção 6.1 e da Subseção 6.2.1, o tempo de simulação $^{34}$ do $A T A R$ foi próximo dos algoritmos Dyna-Q, Aprendizagem-Q( $\left.\lambda\right)$ e $S A R S A(\lambda)$, e superior que o tempo dos algoritmos Aprendizagem-Q, $S A R S A$ e Aprendizagem- $Q(\lambda)$ rápida. Dado que implementações reais com o Dyna-Q e a Aprendizagem- $Q(\lambda)$ já foram realizadas em robôs móveis (Bhanu et alli, 2001), o ATAR potencialmente pode ser utilizado nas mesmas aplicações. Entretanto, formas de melhorar o desempenho do agente AR proposto foram estudadas para torná-lo mais viável em aplicações práticas, e são apresentadas nas seções seguintes.

\subsection{Melhoria das Trajetórias}

Devido à utilização de um mapa topológico, o ATAR pode gerar trajetórias sub-ótimas (Thrun, 1998) e, para contornar esta limitação, na subseção 5.4.2 foi apresentada uma metodologia baseada em geometria computacional que permite a melhoria de trajetórias geradas a partir de grafos. Como forma de demostrar esta melhoria no $A T A R$ foram realizados ensaios nos quatro ambientes da Figura 2.5: para cada ambiente, 500 estados iniciais foram aleatoriamente selecionados e trajetórias ligando-os a um estado meta único foram geradas (i) usando a política do $A T A R$ descrita na subseção 5.3 .3 e (ii) usando a melhoria de trajetórias por detecção de ponto interno.

TABELA 6.19 - Classes de trajetórias consideradas para analisar as melhorias nas trajetórias - as trajetórias de cada ambiente foram dividas em 10 classes conforme o seu tamanho.

\begin{tabular}{|c|c|c|c|c|c|c|c|c|c|c|}
\hline & \multicolumn{10}{|c|}{ בCLASSES DE TRAJETÓRIAS } \\
\hline & 1 & 2 & 3 & 4 & 5 & 6 & 7 & 8 & 9 & 10 \\
\hline E1 & 5,35 & 10,05 & 14,75 & 19,45 & 24,15 & 28,85 & 33,55 & 38,25 & 42,95 & 47,65 \\
\hline E2 & 4,60 & 9,80 & 15,00 & 20,20 & 25,40 & 30,60 & 35,80 & 41,00 & 46,20 & 51,40 \\
\hline E3 & 4,05 & 8,15 & 12,25 & 16,35 & 20,45 & 24,55 & 28,65 & 32,75 & 36,85 & 40,95 \\
\hline E4 & 5,35 & 10,05 & 14,75 & 19,45 & 24,15 & 28,85 & 33,55 & 38,25 & 42,95 & 47,65 \\
\hline
\end{tabular}

Para avaliar as reduções obtidas, as trajetórias de cada ambiente geradas pela política original do $A T A R$ foram dividas em 10 classes conforme o seu tamanho: entre a maior e a menor das 500 trajetórias foram tomadas 10 divisões (as classes), igualmente espaçadas e cujos centros são dados na Tabela 6.19. Os gráficos da Figura 6.14 exibem os valores médios das trajetórias de cada classe obtidas com o $A T A R$ original e o valor médio das trajetórias equivalentes obtidas com a melhoria por detecção de ponto interno.

À exceção da classe 4 do ambiente E3, observa-se na Figura 6.13 que houve redução das

\footnotetext{
${ }^{34}$ Não são explicitadas medidas comparativas de tempo de simulação entre os algoritmos por terem sido utilizados diferentes computadores, com configurações variadas, para o levantamento dos resultados apresentados.
} 
trajetórias em todas as classes dos quatro ambientes considerados:

Ambiente E1: redução de 10,82 \% a 26,86 \%.

Ambiente E2: redução de 4,01 \% a 14,75 \%.

Ambiente E3: redução de 5,18 \% a 16,70\%.

Ambiente E4: redução de 4,92 \% a 12,03 \%.

As maiores reduções ocorreram justamente nas classes de trajetórias com maior tamanho (Figura 6.14). Isto ocorrer porque quanto maior o percurso a ser planejado, maiores as chances de se gerar um caminho sub-ótimo - pois maior será o número de vértices do mapa a serem percorridos.
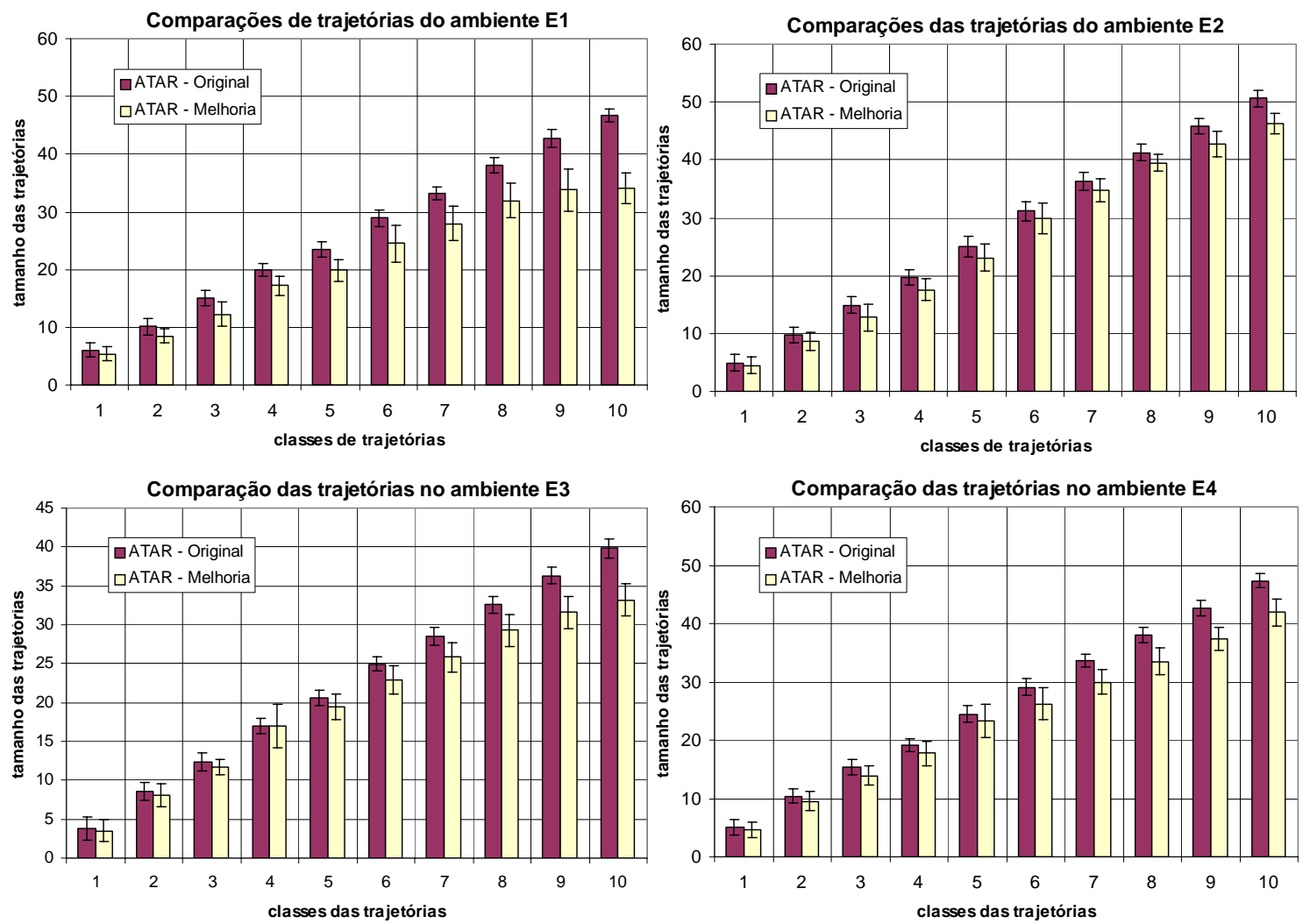

FIGURA 6.14 - Gráficos comparativos entre as trajetórias originalmente geradas pelo ATAR e as trajetórias equivalentes geradas ao aplicar o método de melhoria por detecção do ponto interno, segundo as classes de trajetórias definidas na Tabela 6.1 para os quatro ambiente: E1, E2, E3 e E4.

Para facilitar a vizualização dos caminhos sub-ótimos que podem ser gerados pelo $A T A R$, e de como são as novas trajetórias obtidas a partir destes caminhos com a detecção de ponto interno, a Figura 6.15 traz exemplos de trajetórias originais ( $A T A R$ ) e melhoradas para os quatro ambientes considerados nos ensaios. Verifica-se nos exemplos que as trajetórias originais tendem a seguir a forma com que os vértices do mapa topológico utilizado estão interconectados, motivo da tendência à sub-otimalidade, e a melhoria ocorre ao identificar trechos desta trajetória original que podem ser substituídos por segmentos de retas sem cruzar com obstáculos. Assim, não há garantia de que as trajetórias melhoradas sejam ótimas, mas a redução é conseguida ao se otimizar partes dela. 

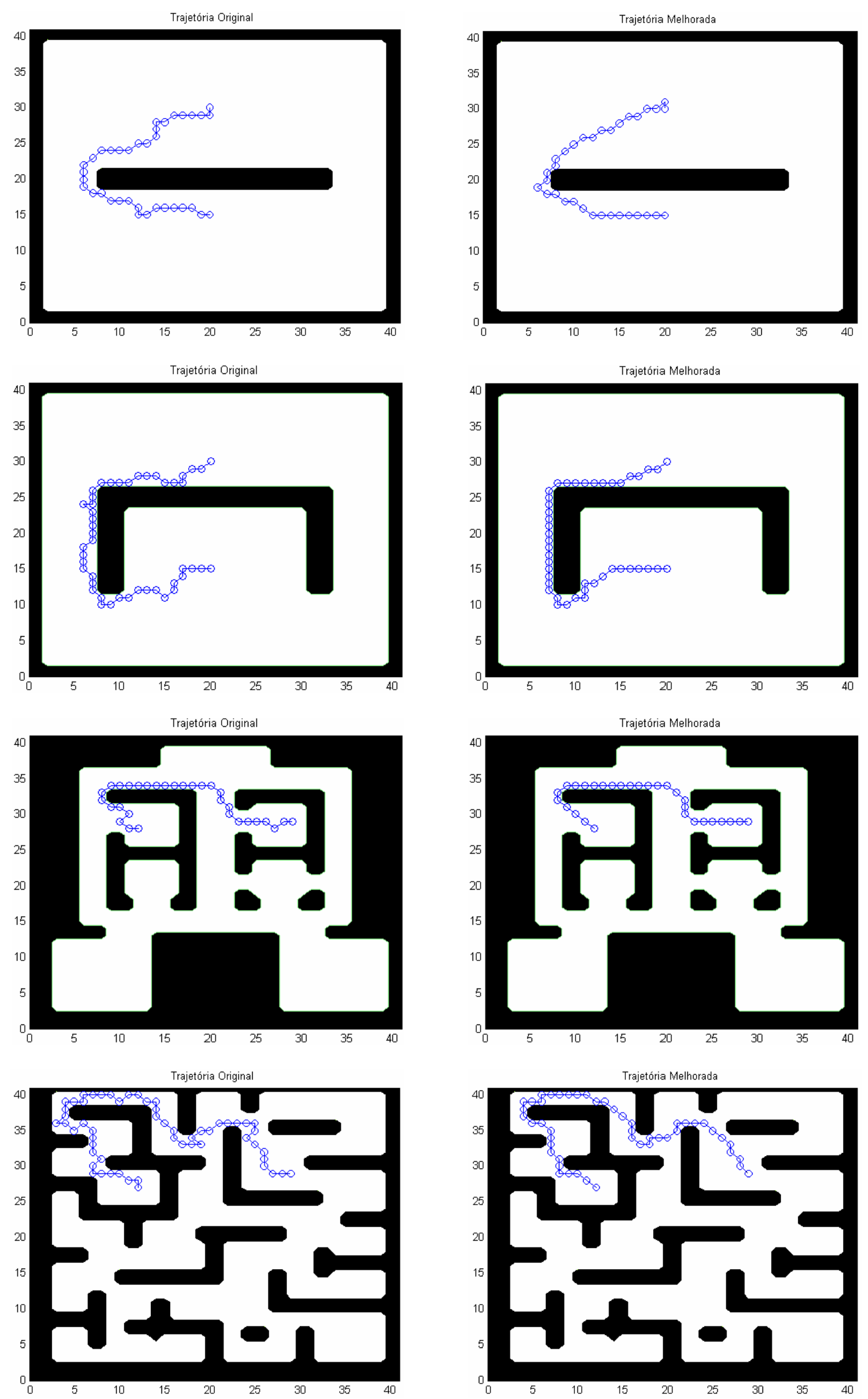

FIGURA 6.15 - Exemplos das trajetórias originalmente geradas pelo ATAR e as trajetórias equivalentes geradas ao aplicar o método de melhoria por detecção do ponto interno para os quatro ambiente: E1, E2, E3 e E4. 


\subsection{Testes com os Mapas Topológicos}

Conforme comentado no Capítulo 5, o MTI (utilizado nos ensaios das Seções 6.1 e 6.2) é dependente de parâmetros que devem ser ajustados conforme o ambiente com que o agente irá interagir. Para contornar esta limitação, e conseguir uma representação mais compacta do ambiente, que exija menos memória, foi proposto um mapa topológico derivado da triangularização incremental de Watson (1981), Subseção 5.2.2, denominado Mapa Topológico Incremental Classificador MTIC. Os gráficos da Figura 6.16 mostram a diferença no aprendizado destes mapas.

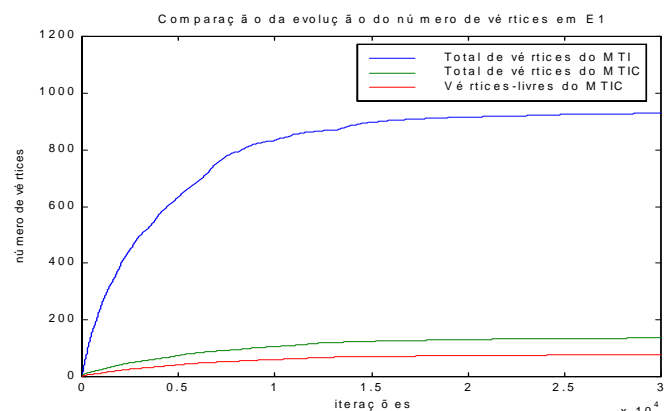

(a)

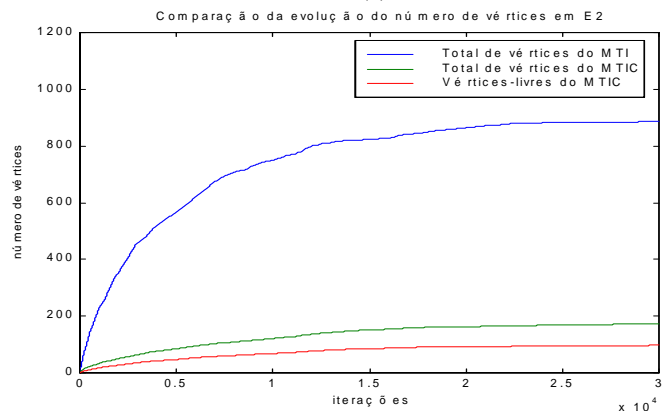

(c)

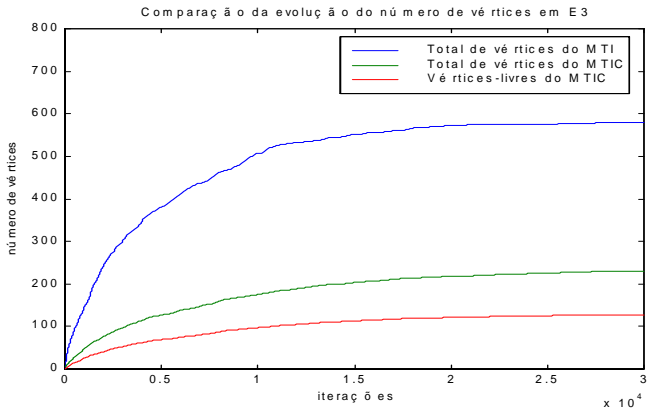

(e)

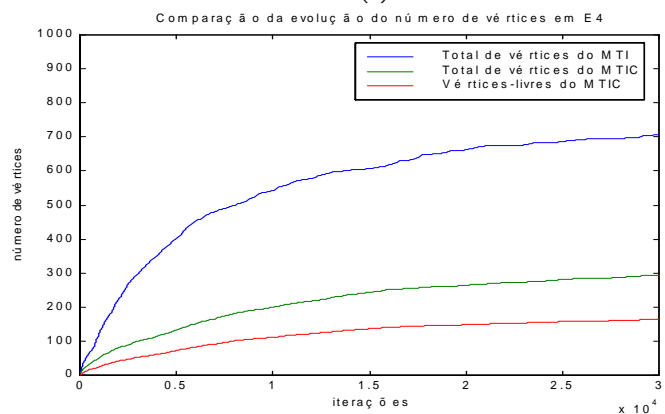

(g)

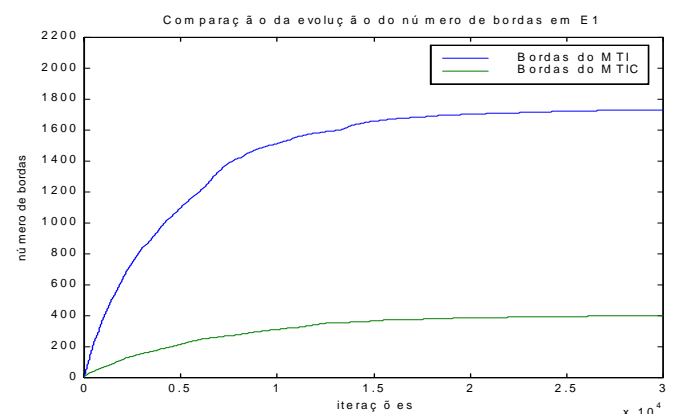

(b)

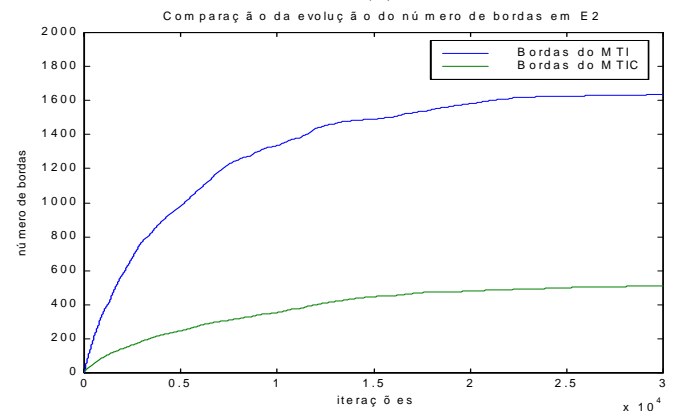

(d)

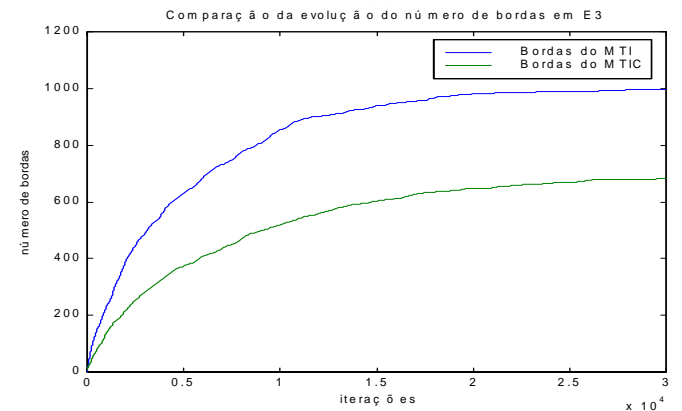

(f)

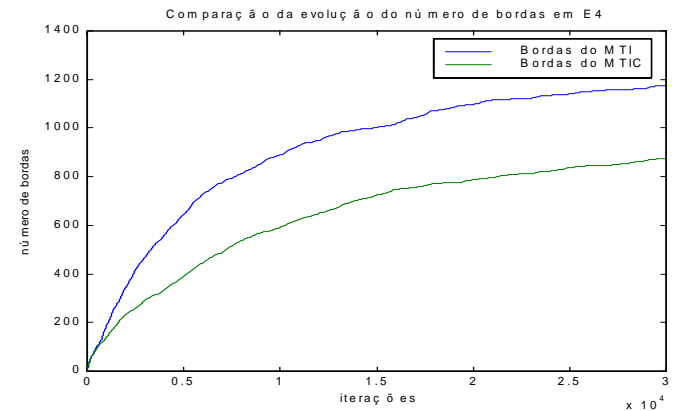

(h)

FIGURA 6.16 - Gráficos comparativos entre os mapas topológicos MTI e MTIC sob os aspecto da geração de vértices - (a),(c),(e) e (g) - e a geração de bordas - (b),(d), (f) e (h). 
O MTIC não realiza uma triangularização uniforme do ambiente como o MTI (Figura 6.17), tendo a distribuição de seus vértices dependência com a complexidade de cada região do ambiente. Com isto, ocorre uma considerável redução na quantidade de vértices e bordas do MTIC em comparação ao MTI (gráficos da Figura 6.16), permitindo que o tempo de simulação do ATAR também tenha uma grande decréscimo - as atualizações da função de avaliação são realizadas sobre um espaço menor.

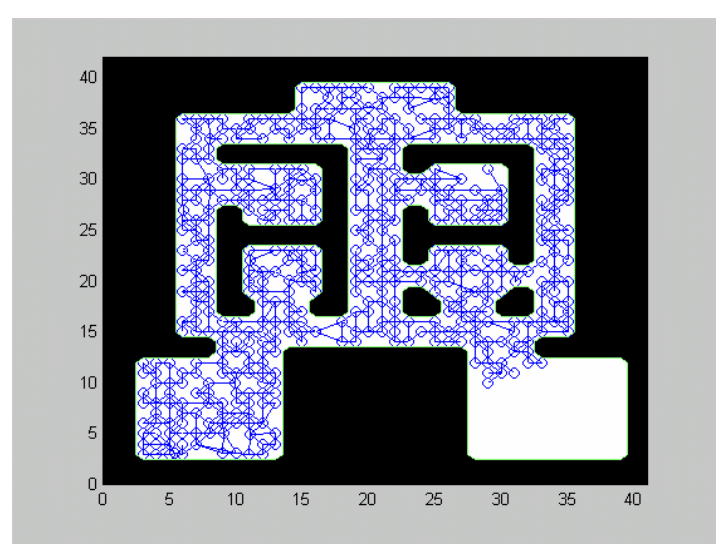

(a)

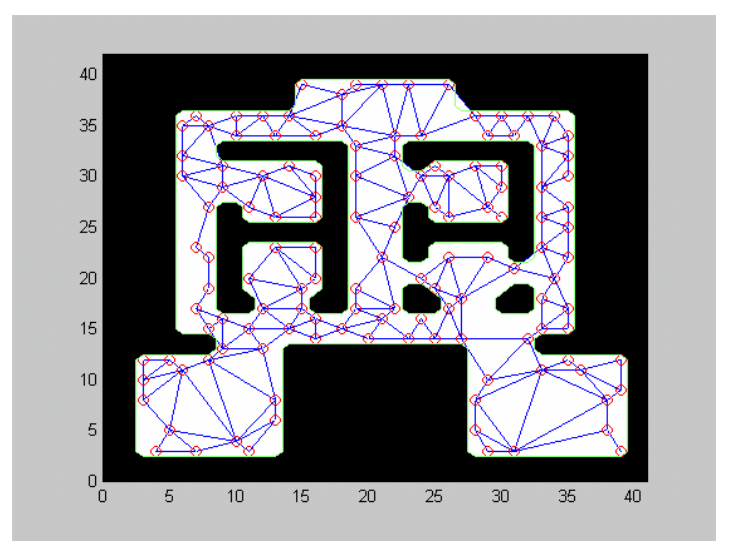

(b)

FIGURA 6.17 - Exemplo de mapas topológicos gerados para um mesmo ambiente pelo: (a) MTI - 505 vértices. (b) MTIC - 131 vértices.

Para avaliar como a mudança de mapa topológico afeta o desempenho da curva de aprendizagem do $A T A R$, ensaios com o novo mapa foram realizados (Figura 6.18).

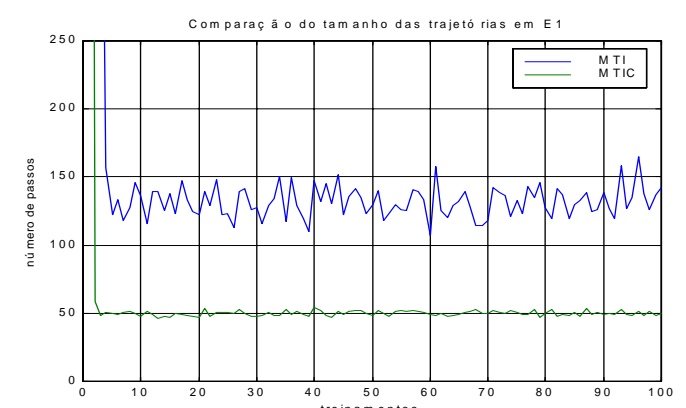

(a)

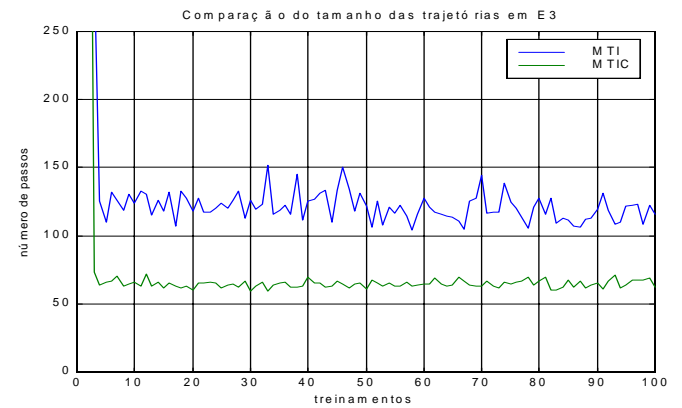

(c)

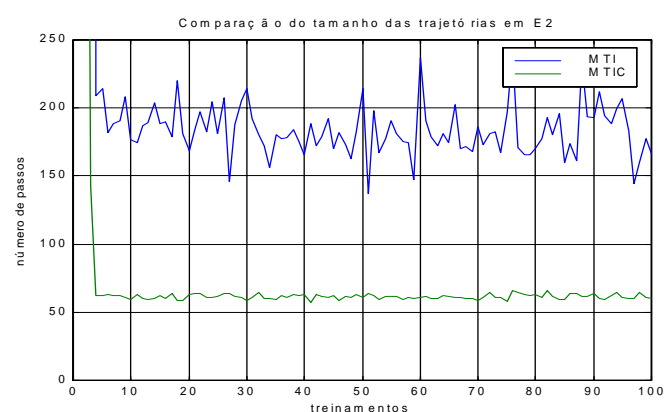

(b)

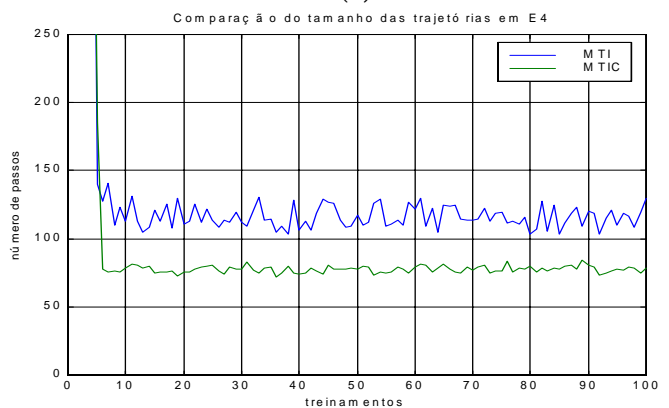

(d)

FIGURA 6.18 - Comparação das curvas de aprendizagem do ATAR usando o MTI ou o MTIC para os ambientes da Figura 2.2: (a) E1 - Ambiente simples com barreira, (b) E2 - Ambiente simples com obstáculo em U, (c) E3 Ambiente complexo, e (d) E4 - Labirinto. 
Os resultados obtidos apontam para a obtenção de trajetórias com um número menor de transições de estados quando se implementa o $A T A R$ com o MTIC. Muito desta redução se deve à forma mais eficiente com que o MTIC constrói as bordas: no MTI, a cada inclusão de um novo vértice uma única nova borda é criada (outras podem ser criadas ao longo da iteração com o ambiente, mas há garantia de que serão); no MTIC, a cada novo vértice são criadas todas as bordas de Delaunay do novo vértice com seus vizinhos. Esta diferença torna o MTIC capaz de representar melhor as vizinhanças topológicas de cada vértice, vizinhanças estas fundamentais no funcionamento do $A T A R$.

\subsection{A Estratégia de Exploração}

Para testar a influência da componente de exploração da política no desempenho do aprendizado do $A T A R$, exemplos dos três tipos de estratégias comentadas na Seção 4.3 foram implementadas. Dois critérios foram adotados para avaliar a contribuição da exploração no desempenho do $A T A R$ : (i) o número de transições de estados até o estado meta ser alcançado no primeiro treinamento, e (ii) o tamanho das trajetórias geradas.

Nas simulações realizadas nas seções anteriores, o $A T A R$ adotava uma política do tipo $\varepsilon$-greedy (estratégia de exploração não-direcionada). Assim, os resultados com esta estratégia servirão de referencial comparativo para as estratégias de exploração direcionada: local (baseada em contadores

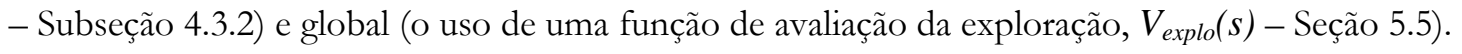

TABELA 6.20 - Medidas obtidas a partir da variação da estratégia de exploração.

\begin{tabular}{|r||r|r|r|r|r|r|r||}
\hline \hline & \multicolumn{4}{|c||}{ Primeira ocorrência da meta } & \multicolumn{3}{c||}{ Trajetórias médias nos 50 últimos } \\
treinamentos
\end{tabular}

A estratégia baseada puramente em contadores é a que leva o agente mais rapidamente à meta quando o ambiente ainda é desconhecido (Tabela 6.20). Porém, dependendo da complexidade do ambiente, observou-se comportamentos distintos no tamanho das trajetórias geradas (Figura 6.19). Nos ambientes mais simples, E1 e E2, o uso de contadores levou à redução nas trajetórias em comparação com os resultados do E-greedy. Entretanto, nos ambientes E3 e E4 ocorreu o comportamento contrário - certo aumento das trajetórias em relação ao $\varepsilon$-greedy.

Os resultados obtidos com a exploração baseada na estratégia direcionada global, denominada Vexplo, apontam que ao aproximar medidas globais de incerteza do ambiente a partir de medidas locais (no caso, a contagem das visitas a um par estado-ação) consegue-se aprender uma política para o $A T A R$ que nos primeiros treinamentos é inferior à obtida com o $\varepsilon$-greedy, mas que em poucos treinamentos supera as trajetórias geradas com a estratégia não-direcionada (Figura 6.19). 

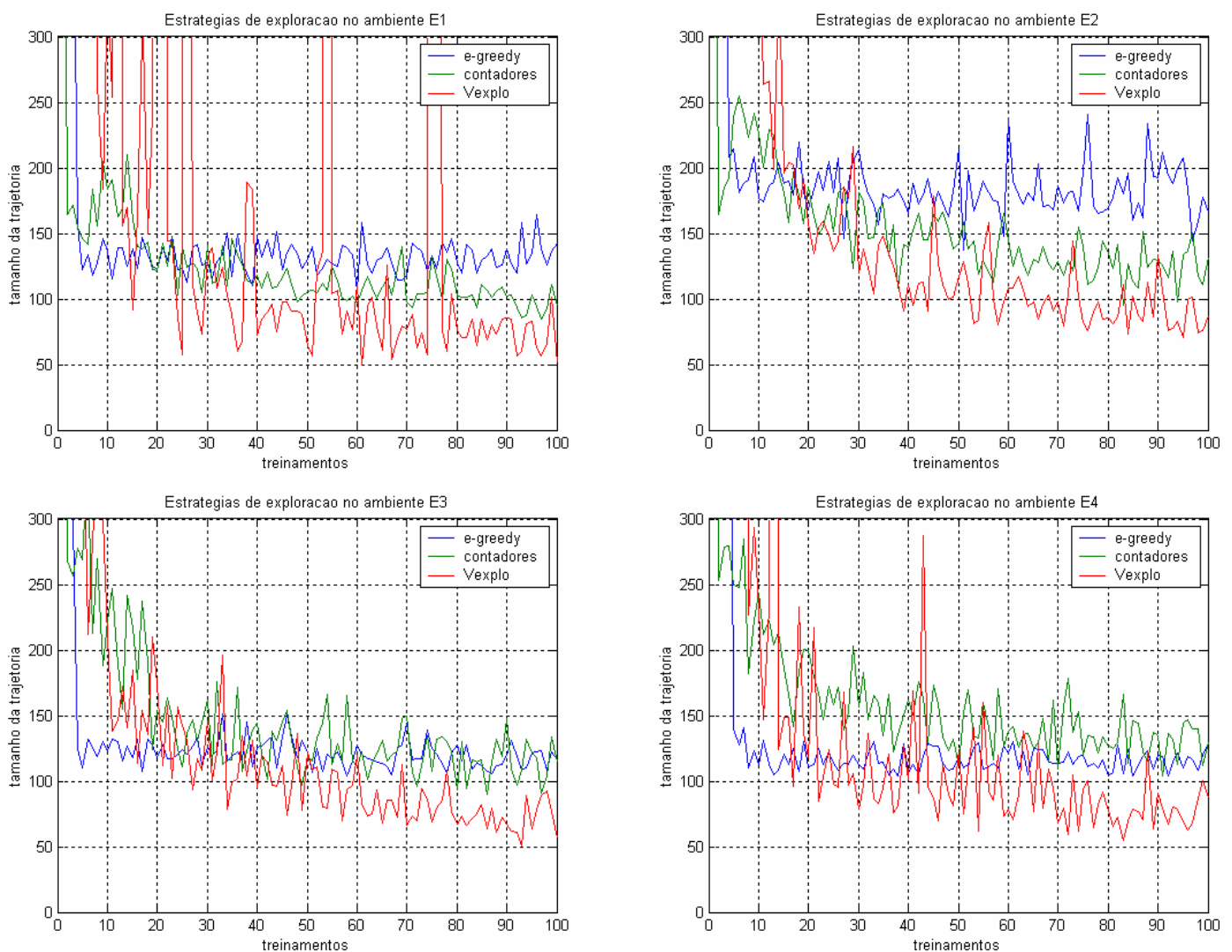

FIGURA 6.19 - Curvas de aprendizagem do ATAR para diferentes técnicas de exploração (não-direcionada, direcionada local, direcionada global) nos ambientes da Figura 2.5 .

Dos ensaios, depreende-se o dilema exploração-explotação sendo tratado nas estratégias direcionadas simuladas, diferente do que ocorre com o $\varepsilon$-greedy, mesmo que de forma rudimentar: os valores iniciais dos contadores de visitas dos pares estado-ação, usados nas duas estratégias direcionadas, permitem que a política do $A T A R$ passe de proeminentemente exploratória, nos treinamentos iniciais, para uma maior explotação com a evolução dos treinamentos (devido ao aumento dos valores dos contadores - ver Subseções 4.3.2 e 4.3.3). Esta mudança na tendência de comportamento é que contribui para que o $A T A R$ reduza, com relação aos ensaios com $\varepsilon$-greedy, suas trajetórias na maioria dos ensaios com política de componente exploratória direcionada.

\subsection{Discussão e Conclusões}

Ao longo dos resultados apresentados neste capítulo, dois critérios principais foram utilizados para analisar o desempenho do agente proposto: (i) o tamanho das trajetórias geradas e (ii) o número de atualizações da função de avaliação. Entre os algoritmos AR utilizados para comparação, estes critérios se mostraram conflitantes, sendo o $A T A R$ o algoritmo que mostrou o melhor compromisso entre estes dois pontos.

Nos ambientes estruturados, o número de atualizações do $A T A R$ se aproxima do número exigido por algoritmos mais simples de 1-passo, porém com um aprendizado muito mais rápido - 
equiparado com algoritmos como o Dyna- $Q$ e a Aprendizagem- $Q(\lambda)$ rápida. Em ambientes nãoestruturados, sujeitos a ruídos e a mudanças em sua estrutura, o desempenho do $A T A R$ mostrou-se comparativamente pouco influenciado pela presença de ruídos, e de rápida adaptação ao tipo de mudança estrutural simulada (Subseção 6.2.2).

A despeito dos promissores resultados, o ATAR apresenta limitações como um tempo de simulação comparável ao de algoritmos pesados como Dyna- $Q$ e os baseados em traços de elegibilidade, e uma tendência a gerar trajetórias sub-ótimas. Para acontornar estas limitações, três mudanças no algoritmo foram testadas: (i) a mudança na heurística usada na seleção das ações do agente; (ii) a mudança do mapa topológico e (iii) a adoção de estratégias direcionadas de exploração na política do $A T A R$.

Em uma situação real, uma solução subótima obtida rapidamente é mais relevante que a obtenção da solução ótima em um horizonte de tempo longo. Entretanto, a metodologia de melhoria das trajetórias por detecção de ponto interno pode otimiza trechos desta solução subótima obtida e melhorá-la, proporcionando uma redução razóavel de passos sem mais treinamentos, da ordem de até $26 \%$ nos melhores casos.

A utilização de um mapa topológico mais compacto, com uma quantidade menor de vértices, proporcionou um grande aumento na velocidade de simulação do algoritmo proposto, bem como significativas melhorias nas curvas de aprendizagem (Figura 6.18). O maior espaçamento entre os vértices dá menor margem à oscilações nas trajetórias, levando-as a serem menores.

As estratégias direcionadas de exploração permitem uma transição do comportamento predominantemente exploratório, para uma seleção de ações que priorize as avaliações aprendidas. Nos experimentos realizados, essa transição leva o $A T A R$ com o aumento dos treinamentos a um desepenho consideravelmente melhor que o obtido com uma política $\varepsilon$-greedy.

Os resultados apresentados neste capítulo indicam o potencial do agente descrito no Capítulo 5 para a aceleração da aprendizagem por reforço, em ambientes estruturados e não-estruturados. Satisfazendo os objetivos principal e secundário colocados no Capítulo 2. Um resumo do trabalho tratado nesta tese é feito no próximo capítulo, bem como são tratadas algumas perspectivas de futuros trabalhos que os dados obtidos nas simulações permitem vislumbrar. 


\section{Capítulo 7}

\section{Conclusões e Trabalhos Futuros}

A aprendizagem latente (Tolman e Honzik, 1930), e o conceito de mapa cognitivo (Tolman, 1948), foram tomados como inspiração para a proposição do algoritmo de aprendizagem por reforço (AR) denominado Agente Topológico de Aprendizagem por Reforço - ATAR tratado nesta pesquisa. Este algoritmo foi desenvolvido com o objetivo de acelerar a estimativa da função de avaliação (Suton e Barto, 1998), almejando conseguir rapidamente uma aproximação da política ótima ${ }^{35}$, ao custo de um quantidade de atualizações desta função inferior a outros algoritmos AR tratados na literatura, porém com um desempenho comparável ou superior ao de algoritmos como: (i) a Aprendizagem$Q(0)$ (Watkins, 1989); (ii) o $S A R S A(0)$ (Rummery, 1995); (iii) a Aprendizagem-Q( $\lambda$ ) (Peng e Williams, 1996); (iv) o $S A R S A(\lambda)$ (Rummery, 1995); (v) o Dyna-Q (Sutton, 1991) e (vi) a Aprendizagem-Q( $\lambda$ ) rápida (Wiering e Schimidhuber, 1998a).

Um mapa topológico derivado do SOM de Kohonen (Kohonen, 1984) é utilizado para armazenar a estimativa calculada da função de avaliação. Normalmente, abordagens AR+SOM (Touzet, 1997; Großmann, 2001; Smith, 2001; Milán et alli, 2002; Smith, 2002) utilizam o mapa topológico para aumentar a velocidade no aprendizado ao reduzir o espaço de trabalho de $S_{\mathrm{x}} A$, sendo $S$ e $A$ os espaços dos estados e das ações, para $N$, sendo $N$ o espaço dos vértices do mapa topológico, pois $|N| \leq|S|$. No $A T A R$, o uso do mapa topológico para aumentar a velocidade no aprendizado é motivado pela informação de vizinhança contida no mapa e que guia a seleção dos pares $(s, a)$ que terão as estimativas de suas avaliações atualizadas a cada passo de treinamento. Esta seleção mantém semelhanças com trabalhos como McCallum (1992), Touzet (1997), Ribeiro (1998) e Pegoraro (2001) ao se valer de relações espaciais para propagar a atualização das avaliações, entretanto inova basicamente ao utilizar uma heurística diferenciada baseada no conceito colocado no Capítulo 5 de área de influência (Subseção 5.1.1).

Simulações do $A T A R$ em ambientes estruturados (Seção 6.1) apontam resultados compatíveis com o Dyna-Q e a Aprendizagem-Q( $\lambda)$ rápida, algoritmos que pela sua velocidade em estimar a função de avaliação já se mostraram viáveis em aplicações de robótica (Bhanu et alli, 2001). Simulações em ambientes não-estruturados (Seção 6.2.1) mostraram que, uma vez definido o mapa topológico do

${ }^{35}$ Explica-se que não necessariamente uma política ótima é alcançada, mas rapidamente uma sub-ótima próxima da ótima. 
ambiente, o ATAR é pouco influênciado pela presença de ruídos nos estados comparativamento com os outros algoritmos AR testados. Na ocorrência de um mudança simples no ambiente, simulações mostraram que a re-estimativa da função de avaliação para a nova configuração do ambiente pode ocorrer de forma lenta em alguns algoritmos AR (Subseção 6.2.1), mas o mecanismo de atualização adotado permite uma adaptação mais rápida no $A T A R$.

Três abordagens para a melhoria do desempenho do ATAR foram estudadas buscando tornálo mais viável em aplicações práticas: (i) mudanças no mapa topológico para reduzir o número de vértices, (ii) mudança na heurística usada na seleção das ações do agente e (iii) variações na estratégia de exploração do $A T A R$. Da primeira abordagem, gerou-se a proposição de um novo mapa topológico, o Mapa Topológico Incremental Classificador - MTIC, que a partir da classificação dos estados do ambiente gera os vértices de uma triangularização de Watson (1981). A segunda abordagem criou um método aplicável a outros problemas de planejamento de trajetória em grafos denominado de Melhoria das trajetórias por deteç̧ão de ponto interior. A terceira abordagem apontou a exploração direcionada (Thrun, 1992; Wyatt, 1997; Meleau e Bourgine, 1999) como uma opção para acelerar o aprendizado.

A Seção 7.1 faz um apanhado das contribuições deste projeto de doutorado, enfatizando os resultados positivos obtidos com os modelos do ATAR. A Seção 7.2 encerra este capítulo com uma discussão sobre as perspectivas para futuras pesquisas com o ATAR, a partir das limitações observadas nos resultados em simulação do Capítulo 6 e de pontos do modelo não desenvolvidos neste trabalho, bem como novas potenciais aplicações.

\subsection{Resumo das Contribuições Científicas da Tese}

As principais contribuições deste trabalho de doutorado estão relacionadas abaixo:

(i) Proposição de um novo mecanismo que combina aprendizagem por reforço e não supervisionada. Outros algoritmos já realizaram a combinação SOM+AR, como Prescott, 1994; Touzet, 1997; Murao e Kitamura, 1998; Großmann, 2001; Smith, 2001; Quoy et alli, 2000; Milán et alli, 2002; Smith, 2002, para citar alguns. Entretanto, na grande maioria destes trabalhos o mapa topológico é visto apenas como uma estrutura que armazena a função de avaliação. Na proposta deste trabalho, as relações entre os vértices do mapa influenciam na forma com que são realizadas as atualizações da função de avaliação, servindo como um mecanismo alternativo - designação estrutural de crédito ao traço de elegibilidade (Kaelbling et alli, 1996).

(ii) Proposição de uma representação compacta para a topologia de um ambiente. $O$ MTIC (Subseção 5.2.2) é oriundo diretamente da triangularização de Watson (1981), mas inova na proposta de associar o crescimento do mapa não intervalos fixos e erros na proximidade dos estados amostrados, mas à correção ou não das classificações de regiões 
do ambiente - conseguindo uma representação topológica do ambiente com um número reduzido de vértices e bordas (Seção 6.4).

(iii) Solução (parcial e/ou limitada aos casos simulados) de problemas em ambientes dinâmicos e não estruturados. Ensaios preliminares, simulando situações presentes em implementações reais como a incerteza no estado presente e a ocorrência de mudança no formato do ambiente (Seção 6.2), indicam o potencial do ATAR para aplicação em ambientes deste tipo.

(iv) Proposta de heurística de melhoria de soluções iniciais no planejamento de trajetórias com grafos. Em robótica, mapas topológicos são muito utilizados no planejamento de trajetórias. Entretanto, as trajetórias geradas costumam ser sub-ótimas (Thrun, 1998). A proposta de melhoria de trajetórias por detecção de ponto interior da Subseção 5.4.2 é um forma de reduzir este problema da sub-otimalidade.

(v) Estimativa parcial da influência de técnicas de exploração diferentes para melhoria do desempenho do modelo.

(vi) Resolução de versão generalizada do PARDM.

A consolidação destas contribuições a longo prazo depende de estudos teóricos e um elenco maior de testes comparativos, em adição aos apresentados neste documento. A seção seguinte relaciona algumas destas próximas etapas planejadas para a um maior embasamento do $A T A R$, bem como caminhos para o seu aprimoramento e diversificação de suas aplicações.

\subsection{Perspectivas de Trabalhos Futuros}

As principais extensões deste trabalho visualizados pelo autor são:

(i) Estudo de técnicas para restringir na área de influência do estado os pares $(s, a)$ a serem atualizados, sem comprometer o desempenho do algoritmo. Apesar da redução no número de treinamentos necessários para a geração de trajetórias curtas nos ensaios das Seções 6.1 e 6.2, o tempo de simulação do $A$ TAR com o MTI foi próximo ao dos algoritmos Dyna-Q, Aprendizagem-Q( $\lambda)$ e $S A R S A(\lambda)$, e superior ao tempo dos algoritmos Aprendizagem- $Q, S A R S A$ e Aprendizagem- $Q(\lambda)$ rápida. Uma grande queda no tempo de simulação do $A T A R$ foi conseguida ao se substituir o mapa topológico pelo MTIC, mas estratégias que realizem as atualizações da avaliação aos pares $(s, a)$ apenas em subconjuntos da área de influência, a exemplo do que ocorre na Aprendizagem- $Q(\lambda)$ de Peng e Williams (1996) ao usar uma lista $H$ para restringir os pares com maior traço de elegibilidade, podem também conseguir reduções no tempo de simulação. 
(ii) Implementação do $\boldsymbol{A} \boldsymbol{T A R}$ no planejamento de trajetórias de um robô real. Dados os resultados em simulação das Subseções 6.1 e 6.2 e que implementações reais com o Dyna$Q$ e a Aprendizagem- $Q(\lambda)$ já foram realizadas em robôs móveis (Bhanu et alli, 2001), o ATAR potencialmente pode ser utilizado nas mesmas aplicações. Entretanto, apenas a implementação real do algoritmo proposto pode consolidar sua aplicabilidade.

(iii) Espaço de estados multidimensional. Expandir o estudo do $A T A R$ para problemas em que o espaço de estados seja multidimensional, o que permitiria a consolidação do conceito de área de influência de um estado $s_{t}$ ao espaço $\mathfrak{R}^{n}$.

(iv) Função de retorno multiobjetivo. Expandir o estudo do $A T A R$ a problemas em que a função de avaliação envolve a maximização dos custos de múltiplos objetivos, como em times de robôs cooperativos.

(v) Desenvolvimento teórico. A apresentação do modelo realizada no Capítulo 5 teve um enfoque algorítmico, um estudo teórico do $A T A R$ viabilizaria uma prova analítica da convergência do algoritmo.

(vi) Construção do mapa em alternância com o aprendizado em ambientes não estruturados. Nos ensaios em ambientes não-estruturados ${ }^{36}$ foi adotada uma fase de prétreinamento (sem-ruído no caso da Subseção 6.2.1, e no ambiente com porta aberta na Subseção 6.2.2) como forma de ter uma estrutura que, como as tabelas adotadas nos demais algoritmos, não se modificasse ao longo dos treinamentos. Em algumas aplicações, entretanto, pode se tornar inviável esta fase de pré-treinamento do mapa topológico para o funcionamento do $A T A R$ em ambientes ruidosos.

(vii) Expandir o campo de aplicação do $\boldsymbol{A} \boldsymbol{T A R}$. Estudar a aplicação do agente proposto a outros problemas que utilizam Aprendizagem por Reforço e Programação Dinâmica como o planejamento do tráfego de linhas telefônicas (Littman e Boyan, 1993; Carlstrom e Norstrom, 1997; Nie e Haykin, 1999; Tong e Brown, 2002), planejamento de descarga em navios (Scárdua et alli, 2003), a determinação de estratégias em jogos (Littman, 1994; Thrun, 1995; Tesauro, 1995) ou em bioinformática (Baldi e Brunak, 1998).

\footnotetext{
${ }^{36}$ Nos ambientes estruturados, ensaios foram realizados com êxito em que o mapa topológico é alterado durante os treinamentos que atualizam a função de avaliação.
} 


\section{Referências Bibliográficas}

Agre, P. E. e Chapman, D. (1987). Pengi: an implementation of a theory of activity. In Proceedings of Sixth National Conference on Artificial Intelligence. Morgan Kaufmann. Los Altos, CA. pp: 268-272. Agre, P. E. (1988). The dynamic structure of the everyday life. PhD thesis, MIT Artificial Intelligence Laboratory, Cambridge, MA.

Althoefer, K.; Krekelberg, B.; Husmeier e Seneviratne, L. (2001). Reinforcement learning in a rulebased navigator for robotic manipulators. Neurocomputing, 37, pp: 51-70.

Araújo, A. F. R. e Braga, A. P. S. (1998a). Goal-directed reinforcement learning using variable learning rate. Lecture Notes in Computer Science. v.1515, p.131 - 140.

Araújo, A. F. R. e Braga, A. P. S. (1998b). Navegação em ambiente fechado e inicialmente desconhecido utilizando aprendizagem por reforço. Anais do XII Congresso Brasileiro de Automática (CBA).v.1. p.587 - 592.

Araújo, A. F. R. e Braga, A. P. S. (1998c). A reward-penalty reinforcement learning scheme for planning and reactive behavior. Proceedings of the IEEE International Conference on Systems, Man, and Cybernetics. v.1. p.1485 - 1490.

Araújo, A. F. R. e Braga, A. P. S. (1998d). A reinforcement learning based on potential field methods to navigate in initially unknown environments. Proceedings of the 1998 LASTED International Conference on Artificial Intelligence and Soft Computing. v.1. p.435 - 438.

Arbib, M. A.; Érdi, P. e Szentágothai, J. (1998). Neural Organization - Structure, Function and Dynamics. A Bradford Book/The MIT Press. Cambridge, Massachusetts.

Arkin, R. C. (1998). Behavior-Based Robotics. The MIT Press.

Atkeson, C. G. e Schaal, S. (1995). Memory-based neural networks for robot learning. Neurocomputing, V.9, N. 13 , pp: 243-269.

Baird, L.C. (1995). Residual algorithms: reinforcement learning with function approximation. In Proceedings of the twelfth International Conference on Machine Learning, pp. 30-37. Morgan Kaufmann, San francisco.

Baldi, P. e Brunak, S. (1998). Bioinformatics : the machine learning approach. MIT Press.

Baird, L.C. (1999). Reinforcement learning through gradient descent. PhD thesis CMU-CS-99-132. School of Computer Science. Carnegie Mellon University. Pittsburgh, PA 
Barto, A. G.; Sutton, R. S. e Anderson, C. W. (1983). Neuronlike adaptative elements that can solve difficult learning control problems. IEEE Transactions on Systems, Man, and Cybernetics, V. 3, N. 5, pp: 834-846.

Barto, A. G. e Singh, S. P. (1990). On computational economics of reinforcement learning. In D. S. Touretzky, J. L. Elman, T. J. Sejnowski, and G. E. Hinton, editors, Connectionist Models, Proceedings of the 1990 Summer School, pp: 35-44, San Mateo, CA. Morgan Kaufmann.

Baxter, J. e Bartlett, P. (1999). Direct gradient-based reinforcement learning: 1. Gradient estimation algorithms (Technical Report). Computer Sciences Laboratory, Australian National University.

Beer, R. D.; Chiel, H. J. e Sterling, L. S. (1990). A biological perspective on autonomous agent design. Robotics and Autonomous Systems. V.6. N. 1-2. pp: 169-186.

Bellman, R. (1957). Dynamic Programming. Princeton University Press, Princeton, New Jersey.

Bertsekas, D. P. e Tsitsiklis. J. N. (1996). Neuro-Dynamic Programming. Athena Scientific, Belmont, Massachusetts.

Bhanu, B.; Leang, P.; Cowden, C.; Li, Y. e Patterson, M. (2001). Real-time robot learning. In Proceedings of the 2001 IEEE International Conference on Robotics \& Automation, pp.: 491-498.

Blodgett, C. (1929). The effect of the introduction of reward upon the maze performance of rats. University of California Publications in Psychology, V. 4, N. 8, p. 120.

Boyan, J.A. e Moore, A.W. (1995). Generalization in reinforcement learning: safely approximating the value function. In Advances in Neural Information Processing Systems, V.7. MIT Press.

Braga, A. P. S. (1998). Um Agente Autônomo Baseado em Aprendizagem por Reforço Direcionado à Meta. Dissertação de Mestrado.

Braga, A. P. S. e Araújo, A. F. R. (1999). Robot navigation in complex and initially unknown environments. Proceedings of the 14th International Federation of Automatic Control (IFAC) World Congress. v.1. p.179 - 184.

Braga, A. P. S. e Araújo, A. F. R. (2003). A topological reinforcement learning agent for navigation. Neural Computing \& Applications. 12 (3-4): 220-236.

Brooks, R. A. (1986). A robust layered control system for a mobile robot, IEEE Journal of Robotics and Automation, V. RA-2, N.1, pp: 14-23.

Brooks, R. A. (1990). Elephants don't play chess. Robotics and Autonomous Systems, V. 6, pp: 3-15.

Brown, M.A. e Sharp, P.E. (1995). Simulation of spatial learning in the Morris water maze by a neural network model of the hippocampal formation and nucleus accumbens. Hippocampus, V. 3, N. 5, pp. 171-188.

Burgess, N.; Reece, M. e O’Keefe, J. (1994). A model of hippocampal function. Neural Networks, V. 7 N. 6/7, pp: 1065-1081.

Bussab, W. O. e Morettin, P. A. (1987). Estatística básica. Atual Editora.

Carlstrom, J. e Norstrom, E. (1997). Control of self-similar ATM call trafic by reinforcement larning. In J. Alspector et al. (Eds), Applications of neural networks to telecomunications 3. LEA Publishers. 
Chance, M.R.A. e Mead, A.P. (1955). Competition between feeding and investigation in the rat. Behavior, V.8, pp:174-181.

Chapman, D. (1987). Planning for conjunctive goals. Artificial Intelligence. V. 32. pp: 333-377.

Cichosz, P. (1995). Truncating temporal differences: On the efficient implementation of $\operatorname{TD}(\lambda)$ for reinforcement learning. Journal of Artificial Intelligence Research, V. 2, pp:287-318.

Cichosz, P. (1997). Reinforcement learning by truncating temporal differences. PhD thesis. Department of Eletronics and Information Technology. Warsaw University of Tecnology.

Cohn, D. A. (1996). Neural network exploration using optimal experiment design. Neural Networks, V. 9, N. 6, pp: 1071-1083.

Crabe, F. L. e Dyer, M. G. (2000). Goal directed adaptive behavior in second-order neural networks: The MAXSON family of architectures. Adaptive Behavior, V. 8, N. 2, pp: 149-172.

Crites, R.H. e Barto, A. G. (1996). Improving elevator performance using reinforcement learning. In Advances in Neural Information Processing Systems: Proceedings of the 1995 Conference, pp: 1017-1023. MIT Press, Cambridge, MA.

Dean, T.; Kaelbling, L. P.; Kirman, J. e Nicholson, A. (1995). Planning under time constraints in stochastic domains. Artificial Intelligence, V. 76, pp: 35-74.

Dearden, R.; Friedman, N. e Andre, D. (1999). Model based Bayesian exploration. In Proceedings of the Fifteenth Annual Conference on Uncertainty in Artificial Intelligence (UAI-99), pp: 150-159, San Francisco, CA.

Feldbaum, A. (1965). Optimal Control Systems. Academic Press.

Fikes, R. E.; Hart, P. E. e Nilsson, N. J. (1972). Learning and executing generalized robot plans. Artificial Intelligence, V. 3, pp: 251-288.

Foley, J. D.; Van Dam, A.; Feiner, S. K. and Hughes, J. F. (1990). Computer Graphics: Principles and Pratice. Addison-Wesley, $2^{\text {nd }}$ edition.

Foster, D.J.; Morris, R.G.M. e Dayan, P. (2000). A model of hippocampally dependent navigation, using temporal difference learning rule. Hippocampus, V. 10, pp: 1-16.

Fox, D. (1998). Markov localization: a probabilistic framework for mobile robot localization and navigation. Tese de doutorado. Universidade de Bonn, Alemanha.

Fox, D.; Burgard, W. e Thrun, S. (1999). Markov localization for mobile robots in dynamic environments. Journal of Artificial Intelligence Research, V. 11, pp: 391-427.

Franz, M. O. e Mallot, H. A. (2000). Biomimetic robot navigation. Robotics and Autonomous Systems, V. 30, pp: 133-153.

Fritzke, B. (1994). Growing cell structures - a self-organizing network for unsupervised and supervised learning. Neural Networks, V. 7, N.9, pp:1441-1460.

Fritzke, B. (1993). Growing cell structures - a self-organizing network for unsupervised and supervised learning. Technical Report TR-93-026, International Computer Science Institute, Berkeley, CA, USA. 
Fritzke, B. (1995). A growing neural gas network learns topologies. Advances in Neural Information Processing Systems, 7, pp: 625-632.

Gallistel, C. R. (1990). The Organization of Learning. The MIT Press.

Gaussier, P.; Leprêtre, S.; Quoy, M.; Revel, A.; Joulain, C. e Banquet, J.P. (2000). Experiments and models about cognitive map learning for motivated navigation. Interdisciplinary Approaches to Robot Learning (Ed. J. Demeris \& A. Birk). World Scientific Publishing Co. Pte. Ltd.

George, P. L. (1991). Automatic Mesh Generation - Application to Finite Element Methods. John Wiley \& Sons.

Georgeff, M. P. e Lansky, A. L. (1987). Reactive reasoning and planning. In Proceedings of Sixth National Conference on Artificial Intelligence. Morgan Kaufmann. Los Altos, CA. pp: 677-682.

Golani, I.; Benjamin, Y. e Eilan, D. (1993) Stopping behavior: Constraints on exploration in rats (rattus norvegicus). Behavioral Brains research, V.53, N.1-2, pp:21-33.

Golden, R. M. (1996). Mathematical methods for neural network analysis and design. The MIT Press.

Gordon, G.J. (1995). Stable function approximation in dynamic programming. Carnegie Mellon University. Technical Report CMU-CS-95-103.

Gothard, K.M.; Skaggs, W.E. e McNaughton, B.L. (1996). Dynamics of mismatch correction in the hippocampal ensemble code for space: Interactions between path integration and environmental cues. Journal of Neuroscience, V. 16, N.24, pp:8027-8040.

Gray, J. O. e Caldwell, D. G. (1996). Advanced robotics e intelligent machines. IEE Control Engineering Series 51. London, United Kingdom.

Großmann, A. (2001). Continual learning for mobile robots. PhD thesis. School of Computer Science. The University of Birmingham, Birmingham, UK.

Gulyás, A. I.; Miles, R.; Sik, A.; Tóh, K.; Tamamaki, M. e Freund, T. F. (1993). Hippocampal pyramidal cells excite inhibitory neurons through a single release site. Nature. V.366, pp: 683687.

Haykin, S. (1999). Neural Networks - A Comprehensive Foundation. Prentice Hall, Inc.

Hendler, J.; Tate, A. e Drummond, M. (1990). AI Planning: Systems and Techniques. AI Magazine, V. 11, N.2, pp: 61-77.

Hill, A.J. e Best, P.J. (1981). Effects of deafness and blindness on the spatial correlates of hippocampal unit activity in the rat. Experimental neurology, V.74, pp. 204-217.

Humphrys, M. (1995). W-learning: competition among selfish Q-learners. Technical report 362. University of Cambridge, Computer Laboratory.

Humphrys, M. (1996). Action selection methods using reinforcement learning. PhD thesis, University of Cambridge.

Jacobs, R.A.; Jordan, M.I.; Nowlan, S.J.; Hinton, G.E. (1991). Adaptive mixtures of local experts. Neural Computation, V. 3, pp: 79-87. 
Jockusch, J. e Ritter, H. (1999). An instantaneous topological mapping model for correlated stimuli. Proceedings of the IJCNN'99, pp: 445.

Jockusch, J. (2000). Exploration based on neural networks with applications in manipulator control. PhD thesis, University of Bielefeld, Germany.

Johannet, A. e Sarda, I. (1999). Goal-directed behaviours by reinforcement learning. Neurocomputing, 28, pp: 107-125.

Kaelbling, L. P. (1993). Learning in Embedded Systems. MIT Press. Cambridge, Massachusetts.

Kaelbling, L. P., Littman, M. L. e Moore, A. W. (1996). Reinforcement learning: A survey, Journal of Artificial Intelligence Research, V. 4, pp: 237-285.

Kalmár, Z.; Szepesvári, C. e Lörincz, A. (1998). Module-based reinforcement learning: experiments with a real robot. Macbine Learning. V.31, pp: 55-85.

Khalil, H. K. (1996). Nonlinear Systems. Prentice Hall, NJ.

Khatib, O. (1986). Real-time obstacle avoidance for manipulators and mobile robots. The International Journal of Robotics Research, V. 5, N. 1, pp: 90-98.

Koenig, S. e Simmons, R. G. (1996). The effect of representation and knowledge on goal-directed exploration with reinforcement learning algorithms. Machine Learning, V. 22, pp: 227-250.

Kohonen, T. (1984). Self-Organization and Associative Memory. Springer. Heidelberg

Kohonen, T. (2001). Self-Organizing Maps. Springer. Heidelberg.

Korf, R. E. (1985). Learning to solve problems by searcbing for macro-operators. Pitman Publisher, Massachussetts.

Kortenkamp, D.; Bonasso, R. P. e Murphy, R. (1998). Artificial intelligence and mobile robots. AAAI Press / The MIT Press.

Kubie, J.L. e Rank, Jr, J.B. (1983). Sensory-behavioral correlates in individual hippocampus neurons in the three situations: Space and context. In Seifert, W., editor, Neurobiology of the Hippocampus, chapter 22, pp: 433-447. Academic Press Inc., New York.

Laird, J. E.; Rosenbloom, P. S. e Newell, A. (1986). Chunking in soar: The anatomy of a general learning mechanism. Machine Learning, V. 1, pp: 11-46.

Latombe, J. C. (1996). Robot Motion Planning. Kluwer Academic Publishers. London.

Lent, R. (2001). Cem Bilhões de Neurônios. Editora Ateneu.

Lin, L. -J. (1992). Self-improving reactive agents based on reinforcement learning, planning, and teaching. Machine Learning, V. 8, pp: 293-321.

Lin, L.-J. (1993). Reinforcement learning for robots using neural networks. PhD thesis, Carnegie Mellon University, School of Computer Science.

Littman, M. L. e Boyan, J. A. (1993). A distributed reinforcement learning scheme for networks routing. In Joshua Alspector, Rodney Goodman, and Timotby X. Brown, editors, Proceedings of the 1993 International Workshop on Applications of Neural Networks to Telecommunications, pp: 45-51. Lawrence Erlbaum Associates, Hillsdale NJ. 
Littman, M. L. (1994). Markov games as a framework for multi-agent reinforcement learning. In Proceedings of the Eleventh International Conference on Machine Learning, pp: 157-163 San Francisco, Ca. Morgan Kaufmann.

Lorente de Nó, R. (1934). Studies on the structure of cerebral cortex: II. Continuation of the study of the ammonic system. J. Physiol. Neurol. V.46, pp: 113-177.

Lorenz, K. (1995). Os Fundamentos da Etologia. Editora da UNESP.

Mahadevan, S. e Connell, J. (1992). Automatic programming of behavior-based robots using reinforcement learning. Artificial Intelligence, V.55, pp:311-365.

Marsland, S.; Shapiro, J. e Nehmzow, U. (2002). A self-organizing network that grows when required. Neural Networks. N. 15. pp: 1041-1058.

Martinetz, T. e Schulten, K. (1994). Topology representing networks. Neural Networks, V. 7, N. 3 , pp: 507-522.

Mason, R. L.; Gunst, R. F. e Hess, J. L. (1989). Statistical Design and Analysis of Experiments - with Applications to Engineering and Science. John Wiley \& Sons.

Mataric, M. (1994). Interaction and intelligent behavior. PhD thesis. Department of Electrical Engineering and computer Science. Massachusetts Institute of Tecnology.

Mataric, M. J. (1997). Learning social behavior. Robotics and Autonomous Systems. V. 20. pp: 191-204.

Martin, J. J. (1967). Bayesian Decision Problems and Markov Chains. John Wiley and Sons.

McCallum, R. A. (1992). Using transitional proximity for faster reinforcement learning. Proceedings of the Ninth International Conference on Machine Learning, pp: 316-321.

McCallum, A. K. (1995). Reinforcement learning with selective perception and hidden state. PhD thesis. Department of Computer Science, University of Rochester, Rochester, NY, USA.

Meuleau, N. e Bourgine, P. (1999). Exploration of multi-state environments: local measures and back-propagation of uncertainty. Macbine Learning, V. 35, pp: 117-154.

Milán, J. del R. (1996). Rapid, safe, and incremental learning of navigation strategies. IEEE Transactions on Systems, Man, and Cybernetics, V. 26, pp: 408-420.

Millán, J. del R. (1997). Incremental acquisition of local networks for the control of autonomous robots. In Proceedings of the $7^{\text {th }}$ International Conference on Artificial Neural Networks, pp.: 739-744.

Millán, J. del R.; Posenato, D. e Dedieu, E. (2002). Continuous-action Q-learning. Macbine Learning, V. 49, pp: 247-265.

Minsky, M. L. (1961). Steps towards artificial intelligence. In Proceedings of the Institute of Radio Engineers. V. 49. pp: 8-30.

Miyazaki, K.; Yamamura, M. e Kobayashi, S. (1997). K-certainty exploration method: an action selector to identify the environment in reinforcement learning. Artificial Intelligence, V. 91, pp: $155-171$.

Montgomery, D. C. (1984). Design and analysis of experiments. John Wiley \& Sons.

Moore, A. W. (1990). Efficient memory-based learning for robot control. Ph.D. thesis, Trinity Hall, University of Cambridge, England. 
Moore, A. W. e Atkeson, C. G. (1993). Prioritized sweeping: reinforcement learning with less data and less time. Machine Learning, V. 13, pp: 103-130.

Muller, J. e Kubie, J.L. (1987). The effects of changes in the environment on the spatial firing of hippocampal complex-spike cells. Journal of Neuroscience, V.7, pp:1951-1968.

Muller, R.U.; Kubie, J.L.; e Ranck, Jr.,J.B. (1987). Spatial firing patterns of hippocampal complexspike cells in a fixed environment. Journal of Neuroscience, V.7, pp:1935-1950.

Muller, R.U.; Kubie, J.L.; Bostock, E.M.; Taube, J.S.; and Quirk, G.J. (1991). Spatial firing correlates of neurons in the hippocampal foramation of freely moving rats. In Paillard, J., editor, Brain and Space, chapter 17, pp: 296-333. Oxford University Press, New York.

Muller, R.U.; Bostock, E.; Taube, J.S.; e Kubie, J.L. (1994). On the directional firing properties of hippocampal firing properties of hippocampal place cells. Journal of neuroscience, V.14, N.2, pp:7235-7251.

Muller, R. U.; Stead, M. e Pach, J. (1996). The hippocampus as a cognitive graph. Journal of General Physiology., V. 7, pp: 663-694.

Munos, R. e Moore, A. (2002). Variable resolution discretization in optimal control. Machine Learning, V. 49, pp: 291-323.

Murao, H. e Kitamura, S. (1998). Q-learning with adaptive state space construction. Lecture Notes in Artificial Intelligence 1545 - Learning Robots (ed. Andreas Birk e Jobn Demiris) - Proceedings of The $6^{\text {th }}$ European Workshop, EWLR - 6, Brighton, UK, pp: 13-28.

Nehmzow, U. (2000). Mobile Robotics: A Practical Introduction. Springer-Verlag London Limited.

Newell, A. e Simon, H. A. (1972). Human problem solving. Prentice-Hall, Englewood Cliffs, NJ.

Nie, J. e Haykin, S. (1999). A Q-learning based dynamic channel assignment technique for mobile communication systems. IEEE Transactions on Vebicular Technology, V. 48, N. 5, pp: 1676-1687.

Nolfi, S. (2002). Power and limits of reactive agents. Neurocomputing, 42, pp: 119-145.

O'Keefe, J. (1979). A review of the hippocampal place cells. Progress in Neurobiology, V.13, pp: 419439.

O'Keefe, J. e Burgess, N. (1996). Geometric determinants of the place fields of hippocampal neurons. Nature, V. 381, pp. 425-428.

O'Keefe, J. e Conway, D.H. (1978). Hippocampal place units in the freely moving rat: Why they fire where they fire. Experimental Brain Research, V.31, pp:573-590.

O'Keefe, J. e Dostrovsky, J. (1971). The hippocampus as a spatial map. Preliminary evidence from unit activity in the freely moving rat. Experimental Brain research, V.34, pp:171-175.

O'Keefe, J. e Nadel, L. (1978). The Hippocampus as a Cognitive Map. Claredon Press, Oxford.

O'Keefe, J. e Speakman, A. (1987). Single unit activity in the rat hippocampus during a spatial memory task. Experimental Brain Research, 68:-27.

Olson, C. F. (2000). Probabilistic self-localization for mobile robots. IEEE Transactions on Robotics and Automation, V. 16, N. 1, pp.: 55-66.

O’Rourke, J. (1998). Computational Geometry in C. Cambridge University Press, 2nd edition. 
Pacher, M. and Chandler, P.R. (1998). Challenges of Autonomous Control. IEEE Control Systems Magazine, V. 18, N. 4, pp: 92-97.

Payton, D. W.; Rosnblatt, J. K. e Keirsey, D. M. (1990). Plan guided reaction. IEEE Transactions on Systems, Man and Cybernetics, V. 20, N.6, pp: 1370-1382.

Pegoraro, R. (2001). Agilizando aprendizagem por reforço em robótica móvel através do uso de conhecimento sobre o domínio. Tese de Doutorado. Escola Politécnica. Universidade de São Paulo.

Pendrith, M. (1994). On reinforcement learning of control actions in noisy and non-markovian domains. Technical Report UNSW-CSE-TR-9410, University of New South Wales,School of Computer Science and Engineering, Sydney, Australia.

Peng, J. e Williams, R. J. (1993). Efficient learning and planning within the Dyna framework. Adaptive Behavior, V. 1, N. 4, pp: 437-454.

Peng, J. e Williams, R. J. (1996). Incremental multi-step Q-learning. Machine Learning. V.22, pp: 283290.

Poucet, B. e Herrmann, T. (2001). Exploratory patterns of rats on a complex maze provide evidence for topological coding. Behavioural Processes, V. 53, pp.: 155-162.

Prescott, A.J. (1994). Explorations in reinforcement and model-based learning. PhD thesis, University of Sheffield. UK.

Pico, R.M.; Gerbrandt, L.K.; Pondel, M.; e Ivy, G. (1985). During stepwise cue deletion, rat place behaviors correlate with place unit responses. Brain Research, V.330, pp: 369-372.

Pipe, A. G. (2000). An architecture for learning "Potential Field" cognitive maps with an application to mobile robotics. Adaptive Behavior, V.8, N.2, pp: 173-204.

Poncela, A.; Perez, E. J.; Bandera, A.; Urdiales, C. e Sandoval, F. (2002). Efficient integration of metric and topological maps for directed exploration of unknown environments. Robotics and Autonomous Systems, V. 41, pp: 21-39.

Prescott, A.J. (1994). Explorations in reinforcement and model-based learning. PhD thesis, University of Sheffield, Inglaterra

Puterman, D. A. (1994). Markov Decision Processes - Discrete Stochastic Dynamic Programming. John Wiley $\&$ Sons, Inc.

Quoy, M.; Gaussier, P.; Leprêt, S.; Revel, A. e Banquet, J. P. (2000). A planning map for mobile robots: speed control and path finding in a changing environment. Lecture Notes in Artificial Intelligence 1812 (Ed. Jeremy Wyatt and John Demiris - Proceedings of the 8th European Workshop on Learning Robots, EWLR-8, Lausanne, Switzerland), pp:103-119.

Redish, A.D. (1997). Beyond the Cognitive Map: contributions to a computational neuroscience theory of rodent navigation. Tese de Doutorado. CMU.

Ribeiro, C. H. C. (1998). Aspects of the behaviour of a learning agent in control tasks. Tese de Doutorado. Imperial College of Science, Tecnology and Medicine. University of London. 
Ribeiro, C. H. C. R.; Costa, A. H. R. e Romero, R. A. F. (2001). Robôs móveis inteligentes: Princípios e Técnicas. Anais do XXI Congresso da Sociedade Brasileira de Computação, V. 3, pp.: 257306.

Ribeiro, C. H. C. R. (2002). Reinforcement learning agents. Artificial Intelligence Review, V. 17, pp.: 223-250.

Rummery, G. A. (1995). Problem solving with reinforcement learning. Ph.D. thesis. Cambridge University.

Russel, S. J. e Norvig, P. (1995). Artificial intelligence: a modern approach, Englewood Cliffs, NJ: Prentice Hall.

Rylatt, M.; Czarnecki, C. e Routen, T. (1998). Connectionist learning in behaviour-based mobile robots: A survey. Artificial Intelligence Review, V. 12, pp: 445-468.

Salichs, M. A. e Moreno, L. (2000). Navigation of mobile robots: Open questions. Robotica, V. 18, pp.: 227-234.

Samejima, K. e Omori, T. (1999). Adaptive internal state space construction method for reinforcement learning of a real-world agent. Neural Networks. V.12, pp: 1143-1155.

Santos, J. M. e Touzet, C. (1999). Exploration tuned reinforcement function. Neurocomputing, V. 28, pp: 93-105.

Save, E.; Cressant, A.; Thinus-Blanc, C. e Poucet, B. (1996). Early visual deprivation does not prevent hippocampal place cell firing in the rat. Society for Neuroscience Abstracts, 22:912.

Santamaría, J. C.; Sutton, R. S. e Ram, A. (1997). Experiments with Reinforcement Learning in problems with Continuous State and action Spaces. Adaptive Behavior, V. 6, N. 2, pp: 163-217.

Scárdua, L.A.; Cruz, J.J. e Costa, A. H. R. (2003). Controle ótimo de descarregadores de navios utilizando aprendizado por reforço. Controle \& Automação, V. 14, N.4, pp: 368-376.

Schultz, W.; Dayan, P. e Montague, P.R. (1997). A neural substrate of prediction and reward. Science, 275, pp. 1593-1599.

Schmidhuber, J. (1991). Curious model-building control systems. Proceedinds of International Joint Conference on Neural Networks, pp: 1458-1463.

Schmitt, P. R. (1996). Reactive path shaping: local path planning for autonomous mobile robots in aisles. Master thesis. Mechanical Engineering. Georgia Institute of Tecnology.

Shatkay, H. e Kaelbling, L. P. (2002). Learning geometrically-constrained hidden markov models for robot navigation: brindging the topological-geometrical gap. Journal of Artificial Intelligence Research, V. 16, pp.: 167-207.

Singh, S. P. (1992). Transfer of learning by composing solutions of elemental sequential tasks. Macbine Learning, V. 8, pp: 323-339.

Smith, A.J. (2001). Dynamic generalisation of continuous action spaces in reinforcement learning: A neurally inspired approach. PhD thesis. University of Edinburgh. UK.

Smith, A. J. (2002). Applications of the self-organising map to reinforcement learning. Neural Networks, V. 15, N. 8-9, pp: 1107-1124. 
Sutton, R. S. (1988). Learning to predict by methods of temporal differences. Macbine Learning, V. 8, pp: $9-44$.

Sutton, R. (1990). Integrated architectures for learning, planning and reacting based on approximating dynamic programming. In Proceedings of the Seventh International Conference on Macbine Learning, San Mateo, CA, pp: 216-224.

Sutton, R. S. (1991). Dyna, an integrated architecture for learning, planning, and reacting. SIGART Bulletin, 2: 160-163. ACM Press.

Sutton, R.S. e Barto, A. (1998). Introduction to Reinforcement Learning. MIT Press / Bradford Books, Cambridge, MA.

Sutton, R.S. (1999) Open theoretical questions in reinforcement learning. In Proceedings of 4th European Conference on Computational Learning Theory, EuroCOLT'99, Nordkirchen, Germany. Paul Fischer, Hans-Ulrich Simon (Eds.). Lecture Notes in Computer Science, Vol. 1572, Springer.

Tchernichovski, O; Benjamini, Y. e Golani, I. (1998). The dynamics of long-term exploration in rat. Part I - A phase-plane analysis of the relationship between location and velocity. Biological Cybernetics, V. 78, pp. 423-432.

Tchernichovski, O e Benjamini, Y. (1998). The dynamics of long-term exploration in rat. Part II An analytical model of the kinematic structure of rat exploratory behavior. Biological Cybernetics, V. 78, pp. 433-440.

Tesauro, G. (1995). Temporal differences learning and TD-Gammon. Communications of the ACM, V. 38, pp: 58-68.

Thompson, L.T. e Best, P.J. (1989). Place cells and silent cells in the hippocampus of freelybehaving rats. Journal of Neuroscience, V. 9, N. 7, pp: 2382-2390.

Thompson, L.T. e Best, P.J. (1990). Long-term stability of the place-field activity of single units recorded from the dorsal hippocampus of freely behaving rats. Brain Research, V. 509, N. 2, pp: 299-308.

Thrun, S.; Moeller, K. e Linden, A. (1991). Planning with an adaptive world model. In Advances in Neural Information Processing Systems (NIPS) 3, D. Touretrky, R. Lippmann (eds.), Morgan Kaufmann, San Mateo, CA.

Thrun, S. (1992). Efficient exploration in reinforcement learning. Technical Report CMU-CS-92-102, Carnegie Mellon University.

Thrun, S. (1995). Learning to play the game of chess. In Tesauro, G.; Touretzky, D. S. \& Leen, T. K. (Eds.), Advances in Neural Information Processing Systems 7. The MIT Press.

Thrun, S. (1998). Learning metric-topological maps for indoor mobile robot navigation. Artificial Intelligence, N. 99, pp: 21-71.

Tolman, E.C. e Honzik, C.H. (1930). Insight in rats. University of California Publications in Psychology. V. 4, pp: 215-232.

Tolman, E. C. (1948). Cognitive maps in rats and men. Psychological Review, 55, pp: 189-208. 
Tong, H. e Brown, T. X. (2002). Reinforcement learning for call admission control and routing under quality of service constraints in multimedia networks. Machine Learning, V. 49, pp: 111139.

Touzet, C. (1997). Neural reinforcement learning for behaviour synthesis. Robotics and Autonomous Systems. V.22, N. 3-4, pp: 251-281.

Touzet, C. F. (2000). Robot awareness in cooperative mobile robot learning. Autonomous Robots. V. 8, N. 1, pp: 87-97.

Trullier, O.; Wiener, S.; Berthoz, A. e Meyer, J.A. (1997). Biologically-based artificial navigation systems: Review and Prospects. Progress in Neurobiology. V. 51, N.5, pp: 483-544.

Trullier, O. and Meyer, J.-A. (2000). Animat navigation using a cognitive graph. Biological Cybernetics, 83, pp: 271-285.

Tsitsiklis, J.N. e Van Roy, B. (1996). Feature-based methods for large scale dynamic programming. Machine Learning, V. 22, pp. 59-94.

Tsitsiklis, J.N. e Van Roy, B. (1997). An analysis of temporal-difference learning with function approximation. IEEE Transactions on Automatic Control, V.42, pp: 674-690.

Voicu, H. and Schmajuk, N. (2002). Latent learning, shortcuts and detours: a computational model. Behavioural Processes, 59, pp: 67-86.

Waterman, T.H. (1989). Animal Navigation. Scientific American Library.

Watkins, C.J.C.H. (1989). Learning from delayed rewards. PhD thesis, King's College, Cambridge.

Watson, D. F. (1981). Computing the n-dimensional Delaunay tessellation with application to Voronoi polytopes. The Computer Journal, V. 24, N.2, pp: 167-172.

Whitehead, S. D. (1991). A complexity analysis of cooperative mechanisms in reinforcement learning. In Proceedings of AAAI. pp: 607-613.

Whitehead, S. D. e Ballard, D. H. (1991). Learning to perceive and act by trial and error. Machine Learning, V. 7, pp: 45-83.

Wiering, M. e Schimidhuber, J. (1998a). Fast online Q( $\lambda$ ). Macbine Learning, V. 33, pp: 105-115.

Wiering, M. e Schmidhuber, J. (1998b). Efficient model-based exploration. In proceedings of the Fifth International Conference on Simulation of Adaptive Behavior (SAB'98): From Animals to Animats 5, pp: 223-228.

Witter, M. P.; Ostendorf, R. H. e Groenwegen, H. J. (1990). Heterogeneity in the dorsal subiculum of the rat. Distinct neuronal Zones project to different cortical and subcortical targets. European Journal of Neuroscience, V. 2, pp: 718-725.

Wyatt, J. (1997). Exploration and inference in learning from reinforcement, Ph.D. thesis, Department of Artificial Intelligence, University of Edinburgh.

Wyatt, J.; Hoar, J. e Hayes, G. (1998). Design, analysis and comparison of robot learners. Robotics and Autonomous Systems, V. 24, pp.: 17-32. 
Wyatt, J. (2001). Exploration control in reinforcement learning using optimistic model selection, In Proceedings of the Eighteenth International Conference on Machine Learning, ICML-2001 A. Danyluk and C. Brodley (Eds).

Zalama, E.; Gaudiano, P. e Coronado, J.L. (1995). A real-time, unsupervised neural network for the low-level control of a mobile robot in a nonstationary environment, Neural Networks, V. 8, N. 1, pp: 103-123.

Zeller, M.; Sharma, R. e Schulten, K. (1997). Motion planning of a pneumatic robot using a neural network. IEEE Control Systems Magazine, V. 17, pp: 89-98.

Zhang, N. L. e Zhang, W. (2001). Speeding up the convergence of value iteration in partially observable markov decision processes. Journal of Artificial Intelligence Research, V. 14, pp.: 29-51. 


\section{Apêndice A - Algoritmos de Aprendizagem por Reforço Simulados}

Neste Apêndice estão descritos os seis algoritmos de Aprendizagem por Reforço utilizados para realizar comparações com o agente AR proposto. Cada um está descrito na forma de procedimento.

\section{A.1. Aprendizagem-Q}

Inicialize $Q(s, a)$ arbitrariamente.

Repita (para cada episódio):

Inicialize $s$.

Repita (para cada passo do episódio):

Escolha $a$ para $s$ usando uma política derivada de $Q$ (exemplo: $\varepsilon$-greedy).

Execute a ação $a$, observe $r$ e $s$ '.

$$
\begin{aligned}
& Q(s, a) \leftarrow Q(s, a)+\alpha\left[r+\gamma \cdot \max _{a^{\prime}} Q\left(s^{\prime}, a^{\prime}\right)-Q(s, a)\right] . \\
& s \leftarrow s^{\prime} ;
\end{aligned}
$$

até que $s$ seja o estado meta.

\section{A.2. SARSA}

Inicialize $Q(s, a)$ arbitrariamente.

Repita (para cada episódio):

Inicialize $s$.

Escolha a ação $a$ para o estado $s$ usando uma política derivada de $Q$ (exemplo: $\varepsilon$-greedy).

Repita (para cada passo do episódio):

Execute a ação $a$, observe $r$ e $s$ '.

Escolha $a$ ' para s' usando uma política derivada de $Q$ (exemplo: $\varepsilon$-greedy).

$Q(s, a) \leftarrow Q(s, a)+\alpha\left[r+\gamma \cdot Q\left(s^{\prime}, a^{\prime}\right)-Q(s, a)\right]$.

$s \leftarrow s^{\prime} ; a \leftarrow a^{\prime} ;$

até que $s$ seja o estado meta. 


\section{A.3. Aprendizagem- $Q(\lambda)$}

Inicialize $Q(s, a)=0, \operatorname{Tr} a c ̧ o(s, a)=0$ e $\operatorname{Visitas}(s, a)=0$ para todo $s \in \mathrm{S}$ e $a \in \mathrm{A}(\mathrm{s})$ e $H=\varnothing$. Repita (para cada episódio):

(a) $s \leftarrow$ estado atual (não-terminal).

(b) $a \leftarrow \varepsilon$-greedy(s,Q).

(c) Execute a ação $a$, observe $r$ e $s$ '.

(d) $e_{t}^{\prime}=r+\gamma \cdot V\left(s^{\prime}\right)-Q(s, a)$.

(e) $e_{t}=r+\gamma \cdot V\left(s^{\prime}\right)-V(s)$.

(f) Para cada par estado-ação $(s, a)$ pertencente à lista $H$, faça:

$$
\begin{aligned}
& \operatorname{Tr} a c ̧ o(s, a)=\gamma \cdot \lambda \cdot \operatorname{Tr} a c ̧ o(s, a) \text {. } \\
& Q(s, a) \leftarrow Q(s, a)+\alpha \cdot \operatorname{Traço}(s, a) \cdot e_{t} . \\
& \text { Caso }(\operatorname{Traço}(s, a)<\xi) \text {, } \\
& H \leftarrow H \backslash(s, a) . \\
& \operatorname{Visitas}(s, a) \leftarrow 0
\end{aligned}
$$

(g) $Q(s, a) \leftarrow Q(s, a)+\alpha \cdot e_{t}^{\prime}$.

(h) $\operatorname{Tr} a c ̧ o(s, a)=\operatorname{Tr} a c ̧ o(s, a)+1$.

(i) Caso (Visitas $(s, a)=0$ ),

$\operatorname{Visitas}(s, a) \leftarrow 1$

$H \leftarrow H \cup(s, a)$ 


\section{A.4. $\operatorname{SARSA}(\lambda)$}

Inicialize $Q(s, a)=0, \operatorname{Tr} a c ̧ o(s, a)=0$ e $\operatorname{Visitas}(s, a)=0$ para todo $s \in \mathrm{S}$ e $a \in \mathrm{A}(\mathrm{s})$ e $H=\varnothing$. Repita (para cada episódio):

(a) $s \leftarrow$ estado atual (não-terminal).

(b) $a \leftarrow \varepsilon$-greedy(s,Q).

(c) Execute a ação $a$, observe $r$ e $s$ '.

(d) $a^{\prime} \leftarrow \varepsilon$-greedy $(s, Q)$.

(e) $e_{t}=r+\gamma \cdot Q\left(s^{\prime}, a^{\prime}\right)-Q(s, a)$.

(f) $\operatorname{Tr} a c ̧ o(s, a)=\operatorname{Tr} a c ̧ o(s, a)+1$.

(g) Para cada par estado-ação $(s, a)$ pertencente à lista $H$, faça:

$\operatorname{Tr} a c ̧ o(s, a)=\gamma \cdot \lambda \cdot \operatorname{Tr} a c ̧ o(s, a)$.

$Q(s, a) \leftarrow Q(s, a)+\alpha \cdot \operatorname{Tr} a c ̧ o(s, a) \cdot e_{t}$.

Caso $(\operatorname{Tr} a c ̧ o(s, a)<\xi)$,

$$
\begin{aligned}
& H \leftarrow H \backslash(s, a) . \\
& \operatorname{Visitas}(s, a) \leftarrow 0
\end{aligned}
$$

(h) Caso (Visitas $(s, a)=0)$,

$\operatorname{Visitas}(s, a) \leftarrow 1$

$H \leftarrow H \cup(s, a)$ 


\section{A.5. Aprendizagem-Q( $\lambda)$ Rápida}

Inicialize $Q(s, a)=0$, Traço_local $(s, a)=0$, Visitas $(s, a)=0$ e $\delta(s, a)=0$, para todo $s \in \mathrm{S}$ e $a \in \mathrm{A}(\mathrm{s}), \phi^{0}=$ $1, \Delta=0 \mathrm{e}$

$H=\varnothing$.

Repita (para cada episódio):

(a) $s \leftarrow$ estado atual (não-terminal).

(b) $a \leftarrow \varepsilon$-greedy $(s, Q)$.

(c) Execute a ação $a$, observe $r$ e $s$ '.

(d) Para todo $a^{\prime} \in \mathrm{A}$ (s) faça

(d.1) Atualização_local(s', a')

(e) $e_{t}^{\prime}=r+\gamma \cdot V\left(s^{\prime}\right)-Q(s, a)$.

(f) $e_{t}=r+\gamma \cdot V\left(s^{\prime}\right)-V(s)$.

(g) $\phi^{t}=\gamma \cdot \lambda \cdot \phi^{t-1}$.

(i) $\Delta \leftarrow \Delta+e_{t \cdot} \phi^{t}$.

(j) Atualização_local(s,a)

(k) $Q(s, a) \leftarrow Q(s, a)+\alpha \cdot e_{t}^{\prime}$

(l) Traço_local $(s, a)=$ Traço_local $(s, a)+1 / \phi^{t}$.

(m) Caso (Visitas $(s, a)=0)$,

(m.1) $H \leftarrow H \cup(s, a)$

(m.2) Visitas $(s, a) \leftarrow 1$

(n) Caso $\left(\phi^{t}<\xi\right)$,

(n.1) Faça para $\forall(s, a) \in H$,

(n.1.1) Atualização_local(s,a)

(n.1.2) Traço_local(s,a) = Traço_local $(s, a) . \phi^{t}$.

(n.1.3) Caso (Traço_local(s,a) < $)$ ),

$$
\begin{aligned}
& \text { (n.1.3.1) } H \leftarrow H \backslash(s, a) . \\
& \text { (n.1.3.2) Visitas }(s, a) \leftarrow 0
\end{aligned}
$$

(n.1.4) $\delta(s, a)=0$

(n.2) $\Delta=0$

(n.3) $\phi^{t}=1$.

Atualização_local(s,a)

(1) $M \leftarrow \operatorname{Visitas}(s, a)$.

(2) $Q(s, a) \leftarrow Q(s, a)+\alpha \cdot\left(\Delta^{M}-\delta(s, a)\right) \cdot$ Traço_local $(s, a)$

(3) $\delta(s, a)=\Delta^{N}$

(4) Caso $(M<N)$,

(4.1) Traço_local $(s, a)=0$

(4.2) $\operatorname{Visitas}(s, a)=N$ 


\section{A.6. Dyna-Q}

Inicialize $Q(s, a)$ e Modelo(s,a) para todo $s \in \mathrm{S}$ e $a \in \mathrm{A}(\mathrm{s})$

Repita (para cada episódio):

(a) $s \leftarrow$ estado atual (não-terminal).

(b) $a \leftarrow \varepsilon$-greedy $(s, Q)$

(c) Execute a ação $a$, observe $r$ e $s$,

(d) $Q(s, a) \leftarrow Q(s, a)+\alpha\left[r+\gamma \cdot Q\left(s^{\prime}, a^{\prime}\right)-Q(s, a)\right]$

(e) $\operatorname{Model}(s, a) \leftarrow s^{\prime}, r$ (assumindo que o ambiente seja determinístico)

(f) Repita $N$ vezes:

$s \leftarrow$ selecione aleatoriamente um estado anteriormente visitado.

$a \leftarrow$ uma ação aleatória anteriormente selecionada em $s$.

$s^{\prime}, r \leftarrow \operatorname{Modelo}(s, a)$.

$$
Q(s, a) \leftarrow Q(s, a)+\alpha\left[r+\gamma \cdot \max _{a^{\prime} \in A\left(s^{\prime}\right)} Q\left(s^{\prime}, a^{\prime}\right)-Q(s, a)\right]
$$




\section{Apêndice B - Parâmetros utilizados nos algoritmos simulados}

\begin{tabular}{|c|c|}
\hline Algoritmo & Parâmetros \\
\hline Aprendizagem-Q(0) & $\alpha=0.5 ; \gamma=0.8 ; \varepsilon=0.3$ \\
\hline SARSA $(0)$ & $\alpha=0.5 ; \gamma=0.8 ; \varepsilon=0.3$ \\
\hline Aprendizagem-Q( $\lambda)$ & $\alpha=0.5 ; \gamma=0.8 ; \varepsilon=0.3 ; \lambda=0.7 ; \varepsilon_{\mathrm{H}}=10^{-16}$ \\
\hline SARSA $(\lambda)$ & $\alpha=0.5 ; \gamma=0.8 ; \varepsilon=0.3 ; \lambda=0.7 ; \varepsilon_{\mathrm{H}}=10^{-16}$ \\
\hline $\mathrm{Q}(\lambda)$ rápida & $\alpha=0.5 ; \gamma=0.8 ; \varepsilon=0.3 ; \lambda=0.7 ; \varepsilon_{\mathrm{m}}=10^{-16}$ \\
\hline Dyna-Q & $\alpha=0.5 ; \gamma=0.8 ; \varepsilon=0.3 ; \mathrm{N}=100$ \\
\hline ATAR & $\gamma=0.8 ; \varepsilon=0.3 ; \mathrm{e}_{\max }=0.5 ; \in=0.001$ \\
\hline
\end{tabular}

$\alpha=$ taxa de aprendizagem no AR; $\gamma=$ fator de desconto ; $\varepsilon=$ parâmetro da política $\varepsilon$-greedy; $\lambda=$ lambda; $\varepsilon_{\mathrm{H}}=$ parâmetro de controle da inclusão na lista $\mathrm{H} ; \varepsilon_{\mathrm{m}}=$ parâmetro para controlar as atualizações na Aprendizagem- $Q(\lambda)$ rápida; $\mathrm{e}_{\max }=$ raio máximo no $\mathrm{ITM} ; \epsilon=$ taxa de aprendizagem no mapa autoorganizável; $\mathrm{N}$ = número de repetições. 